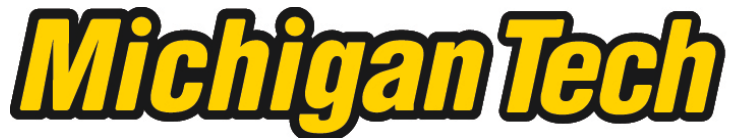 \\ Michigan Technological University Create the Future Digital Commons @ Michigan Tech
}

2013

Sustainable Energy Production in the United States: Life Cycle Assessment of Biofuels and Bioenergy

Jiqing Fan

Michigan Technological University

Follow this and additional works at: https://digitalcommons.mtu.edu/etds

Part of the Chemical Engineering Commons

Copyright 2013 Jiqing Fan

\section{Recommended Citation}

Fan, Jiqing, "Sustainable Energy Production in the United States: Life Cycle Assessment of Biofuels and Bioenergy", Dissertation, Michigan Technological University, 2013.

https://doi.org/10.37099/mtu.dc.etds/615

Follow this and additional works at: https://digitalcommons.mtu.edu/etds

Part of the Chemical Engineering Commons 


\title{
SUSTAINABLE ENERGY PRODUCTION IN THE UNITED STATES: LIFE CYCLE ASSESSMENT OF BIOFUELS AND BIOENERGY
}

\author{
By \\ Jiqing Fan \\ A DISSERTATION \\ Submitted in partial fulfillment of the requirements for the degree of \\ DOCTOR OF PHILOSOPHY \\ In Chemical Engineering \\ MICHIGAN TECHNOLOGICAL UNIVERSITY \\ 2013 \\ (C) 2013 Jiqing Fan
}


This dissertation has been approved in partial fulfillment of the requirements for the Degree of DOCTOR OF PHILOSOPHY in Chemical Engineering

\section{Department of Chemical Engineering}

\section{Dissertation Advisor: $\quad$ David R Shonnard}

Committee Member: Robert Froese

Committee Member: Ching-An Peng

Committee Member: Wen Zhou

Department Chair: S. Komar Kawatra 


\section{Table of Contents}

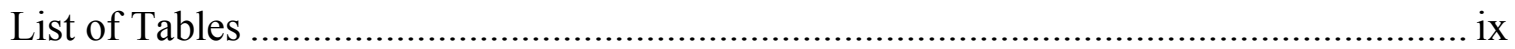

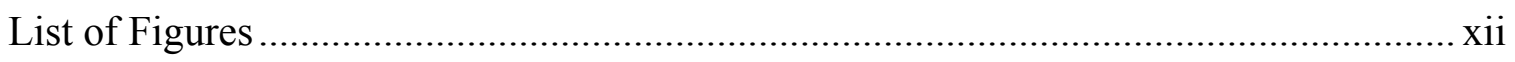

Preface

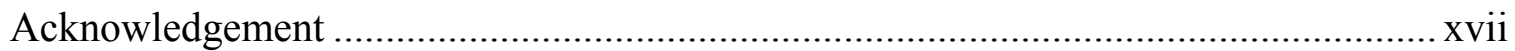

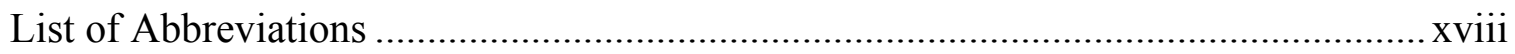

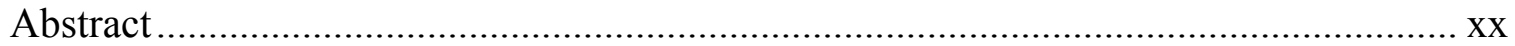

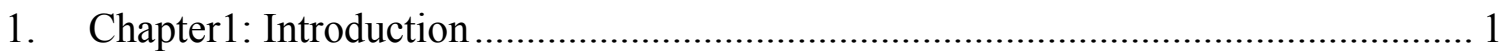

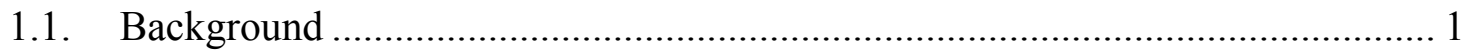

1.2. $\mathrm{PhD}$ research objective ............................................................................. 1

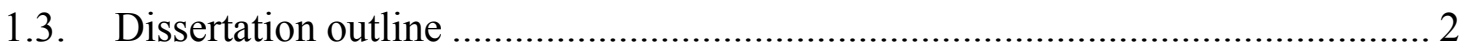

2. Chapter 2: A Life Cycle Assessment of Pennycress (Thlaspi arvense L.) Derived Jet

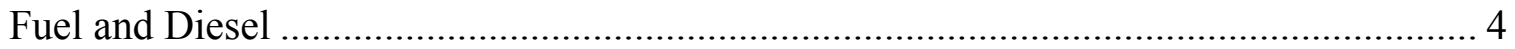

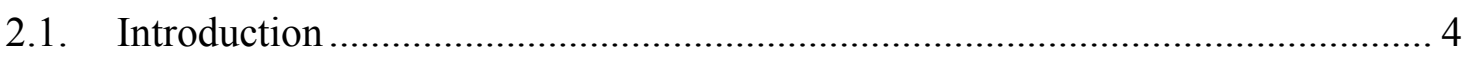

2.1.1. Sustainable Energy and transportation biofuels.......................................... 4

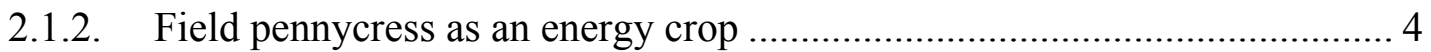

2.1.3. Process Technology Overview for Drop-In Hydrocarbon Biofuels ............. 8

2.1.4. Research objective ............................................................................. 13

2.2. LCA methods: Scope, Functional Unit, Inventory, and Impact Assessment..... 13

2.2.1. Pennycress cultivation and seed transport ................................................. 14

2.2.2. Oil extraction and upgrading ................................................................. 18

2.2.3. Co-products credits ............................................................................. 20

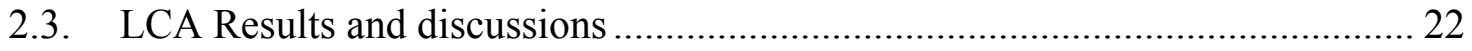

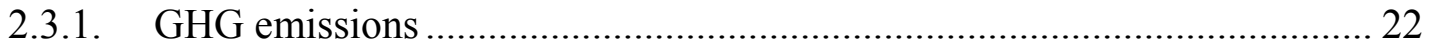

2.3.2. Energy demand results (CED; FED)....................................................... 24

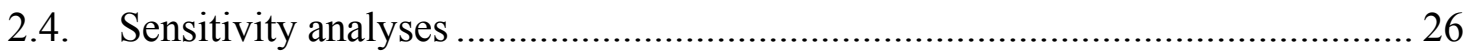

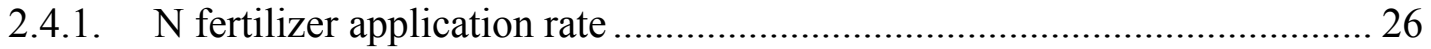

2.4.2. $\quad \mathrm{N}$ content in crop residues......................................................................... 27

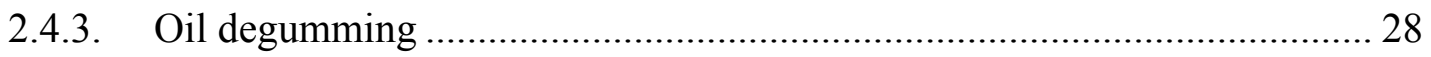


2.4.4. $\mathrm{H}_{2}$ source (natural gas fed $\mathrm{SMR}$ vs. integrated $\mathrm{H}_{2}$ production) ................. 29

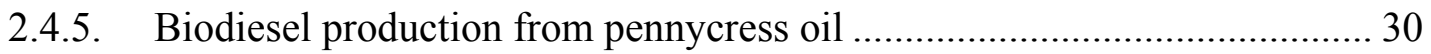

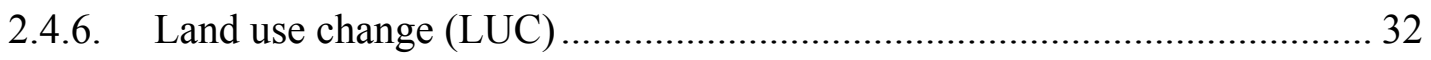

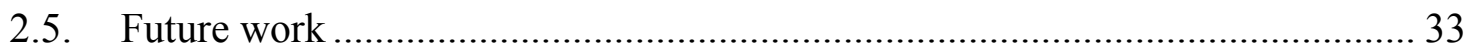

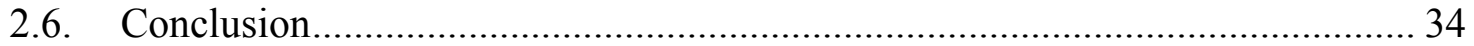

3. Chapter 3: A Life Cycle Assessment of Jatropha Oil Derived Jet Fuel and Diesel.. 35

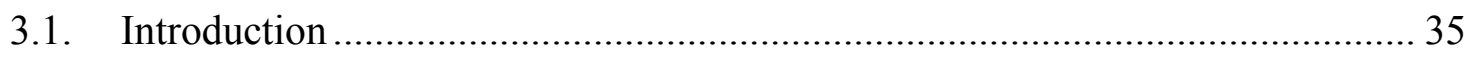

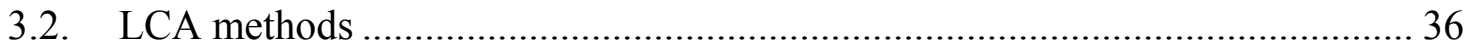

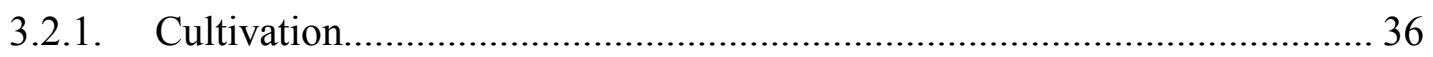

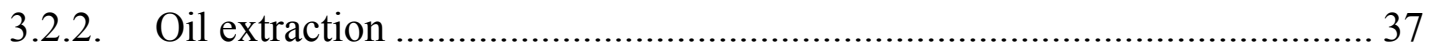

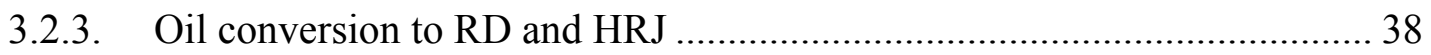

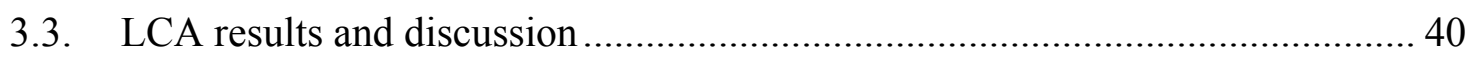

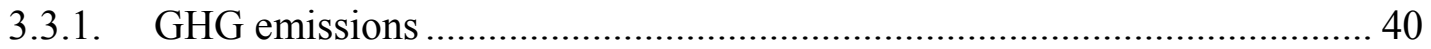

3.3.2. Energy demand results (CED; FED) .................................................. 41

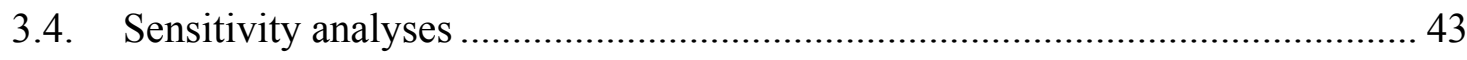

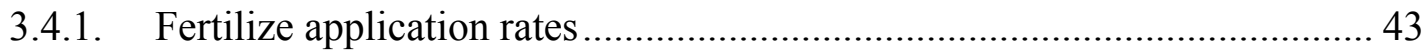

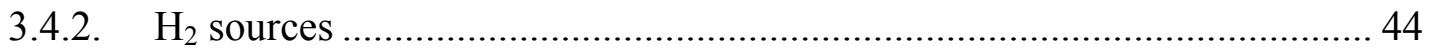

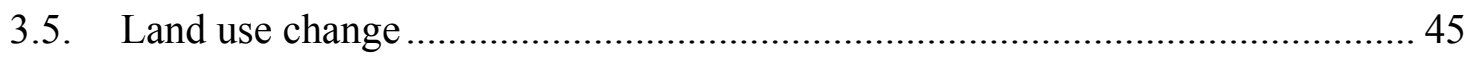

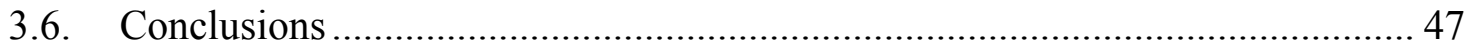

4. Chapter 4: A Review of Life Cycle GHG Emissions of HRJ from Renewable Oils

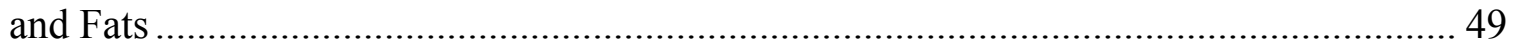

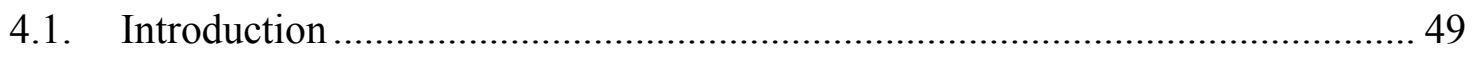

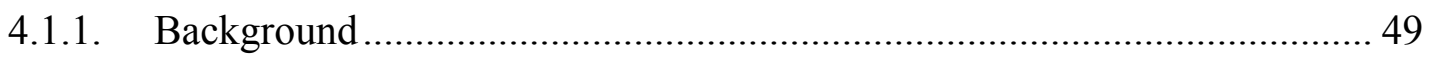

4.1.2. Hydroprocessed renewable jet (HRJ) ................................................... 50

4.1.3. Life cycle assessment (LCA) of biofuels .............................................. 52

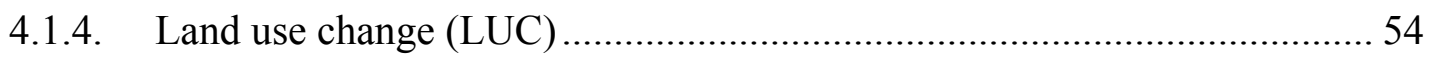

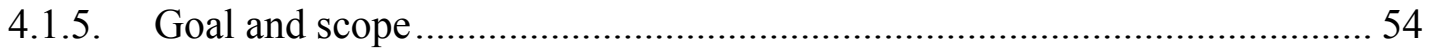

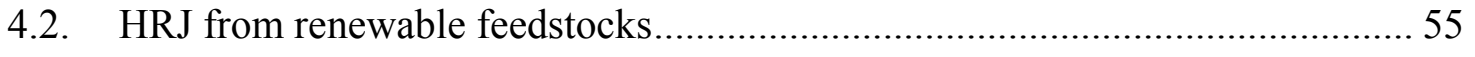

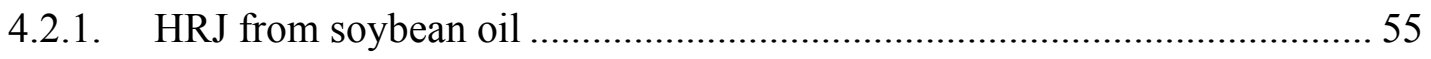

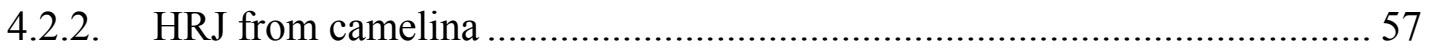




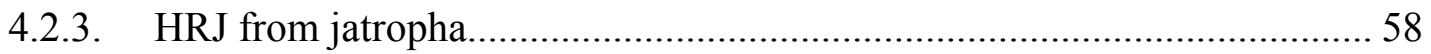

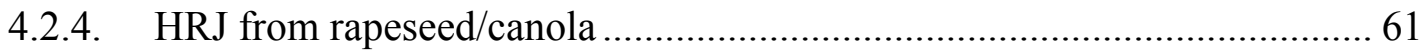

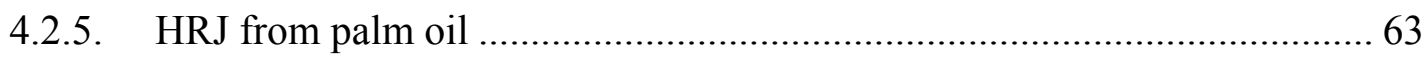

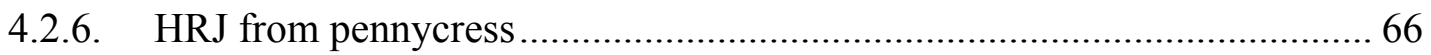

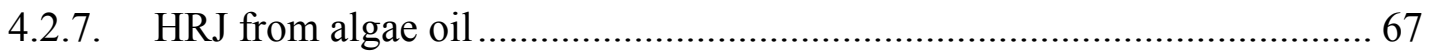

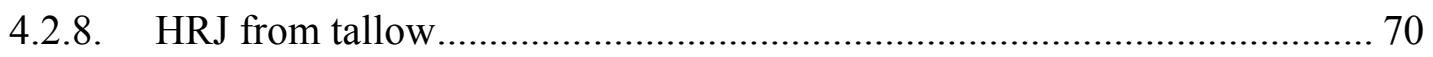

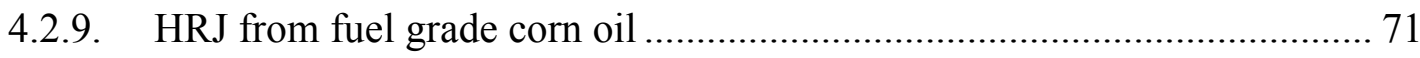

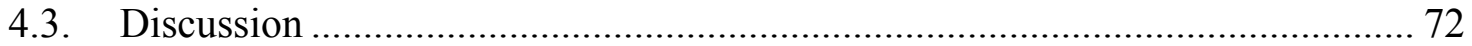

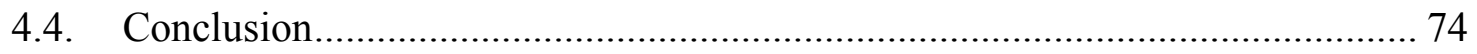

5. Chapter 5: Emission Reduction using RTP Green Fuel in Industry Facilities ........ 76

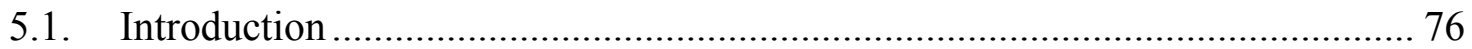

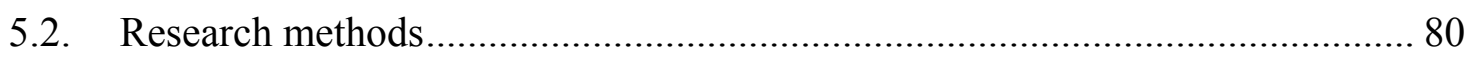

5.2.1. System scope, methods, and impact assessment.................................... 80

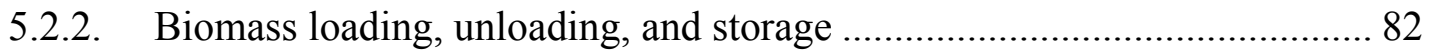

5.2.3. RTP green fuel production and distribution.......................................... 82

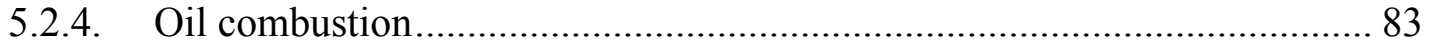

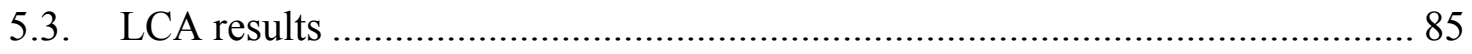

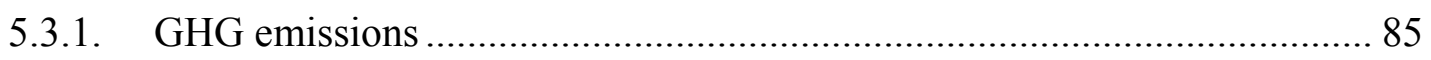

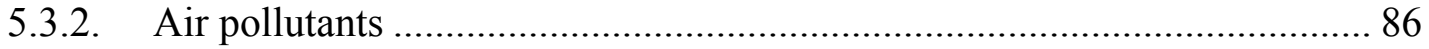

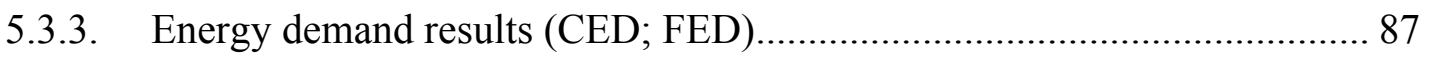

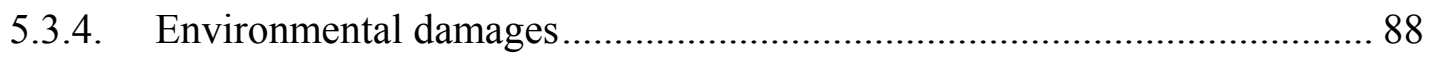

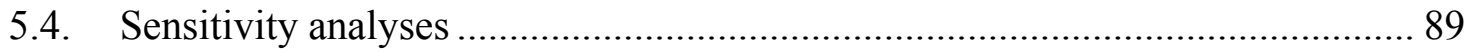

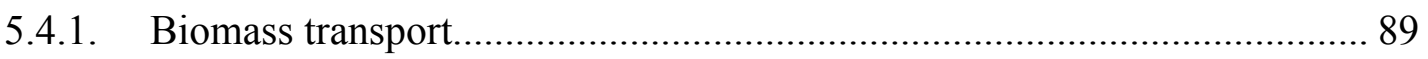

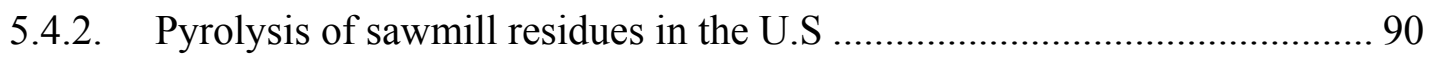

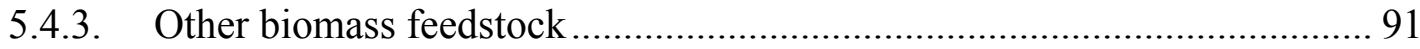

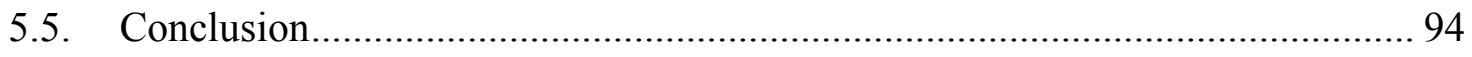

6. Chapter 6: LCA of Electricity Generation using Fast Pyrolysis Bio-Oil................. 95

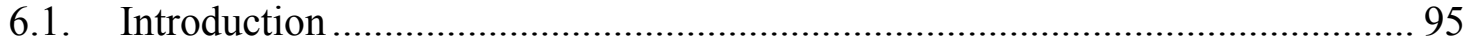

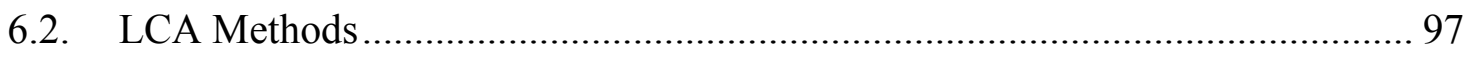


6.2.1. System Scope, Functional Unit, Inventory, and Impact Assessment ......... 97

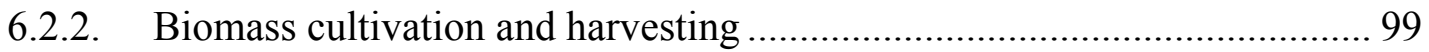

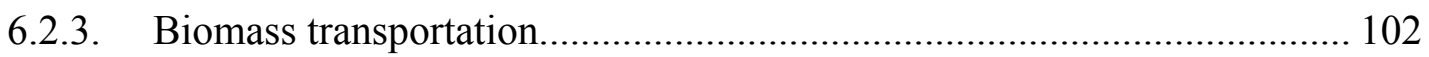

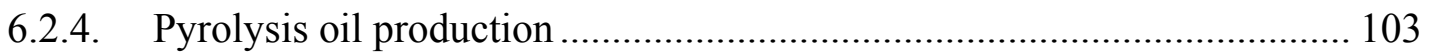

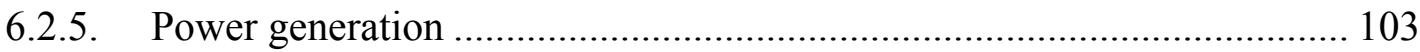

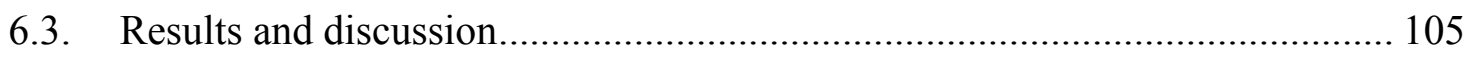

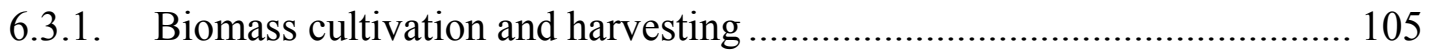

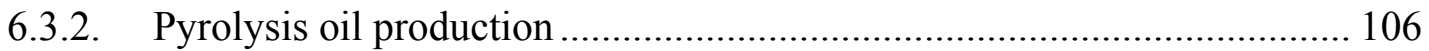

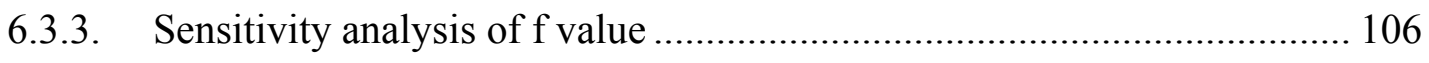

6.3.4. Pyrolysis oil production in a parasitic plant.......................................... 108

6.3.5. Power generation from pyrolysis oil combustion ................................. 108

6.3.6. Sensitivity analysis of pyrolysis oil transportation distance .................... 113

6.3.7. Biomass direct combustion ................................................................ 114

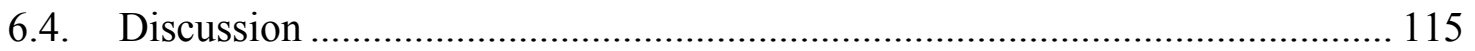

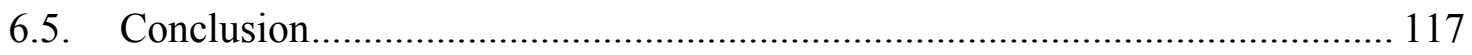

7. Chapter 7: LCA of transportation fuels produced from pyrolysis oil................... 118

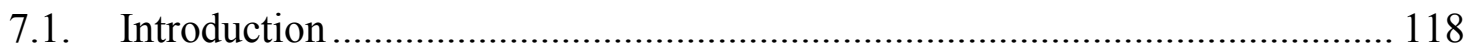

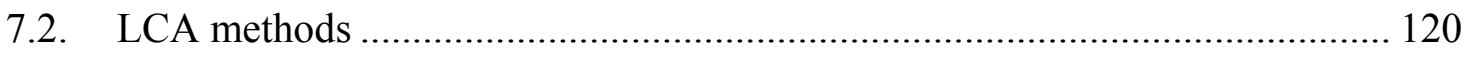

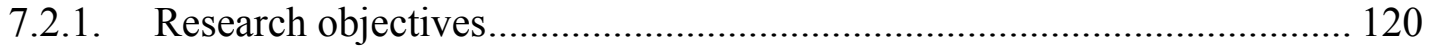

7.2.2. System Scope, Functional Unit, Inventory, and Impact Assessment ....... 120

7.2.3. Pyrolysis gasoline and diesel production .............................................. 122

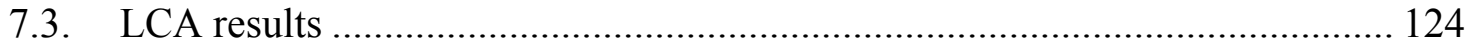

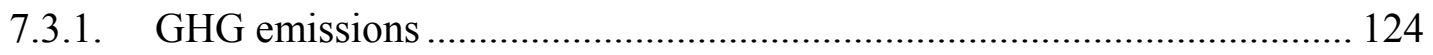

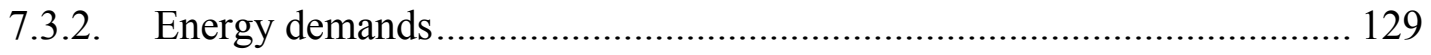

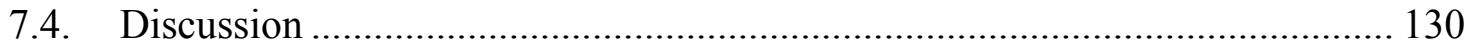

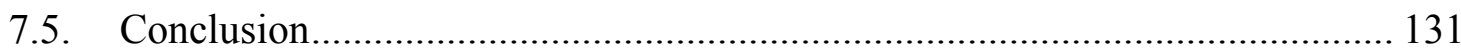

8. Chapter 8: Direct land use change emissions associated with forest-based biofuels

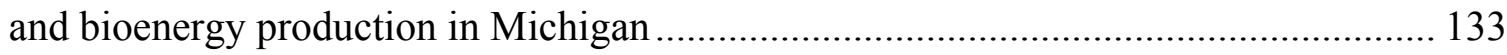

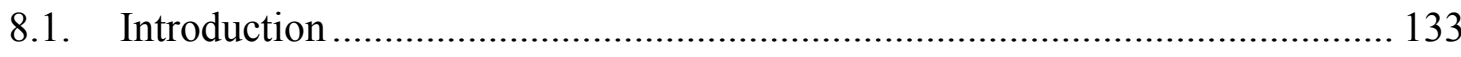

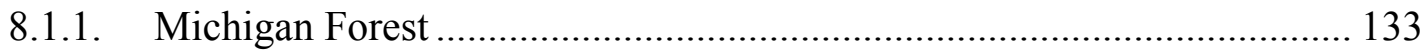




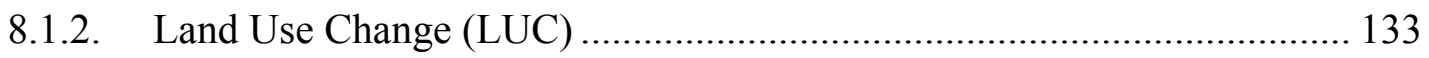

8.1.3. Carbon Budget Model for the Canadian Forest Sector (CBM-CFS3)...... 138

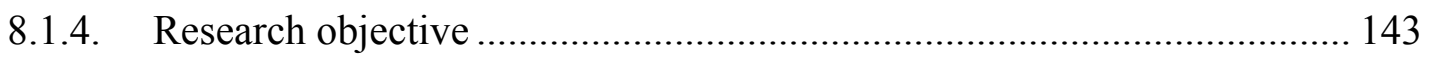

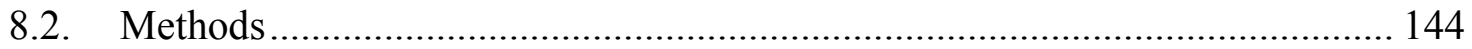

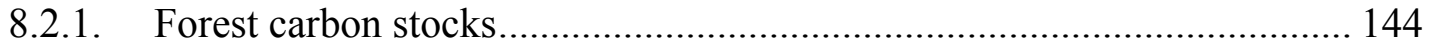

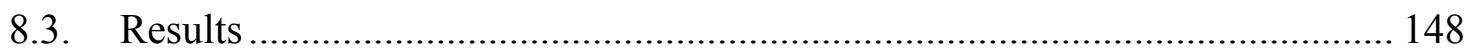

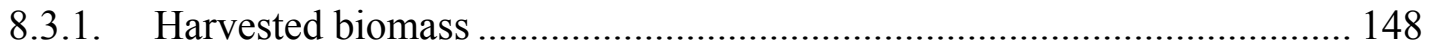

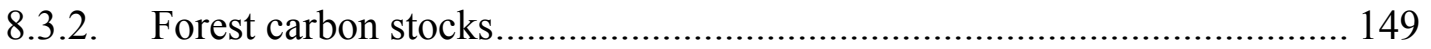

8.3.3. dLUC of biofuels and bioenergy .......................................................... 150

8.3.4. Life cycle results, including dLUC ..................................................... 152

8.3.5. Bioenergy system total emissions ........................................................ 153

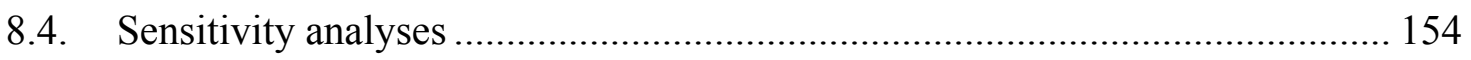

8.4.1. Post-disturbance growth curve uncertainty............................................. 154

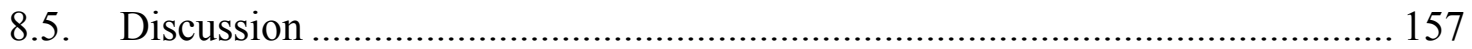

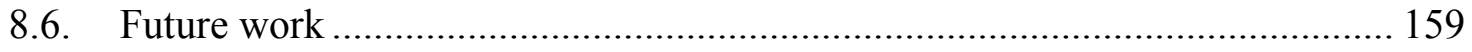

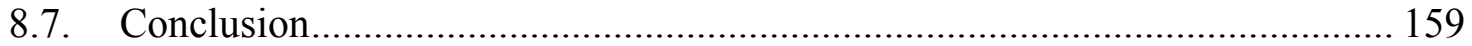

9. Chapter 9: Depolymerization Kinetic Model for Dilute Acid Hydrolysis of Aspen 160

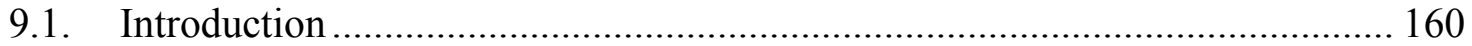

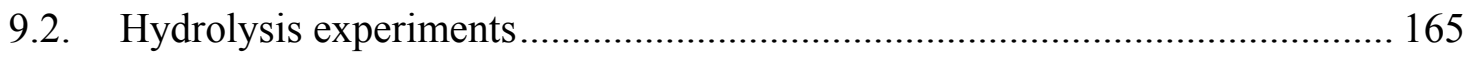

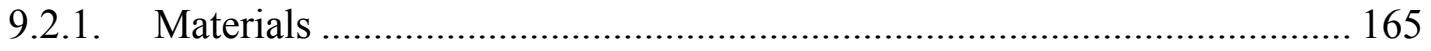

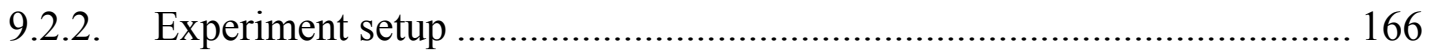

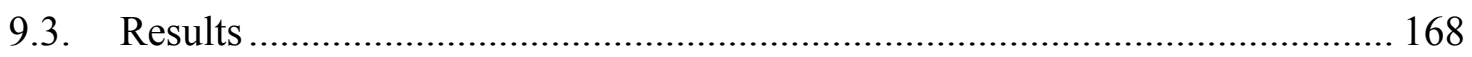

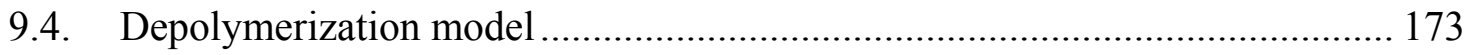

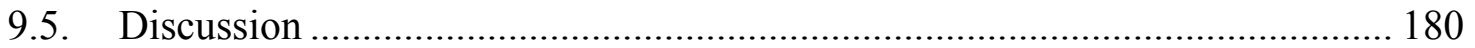

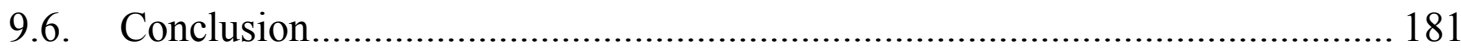

10. Chapter 10: Future work ……………………............................................... 182

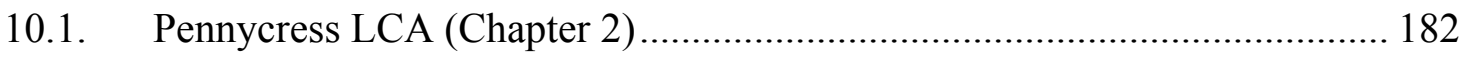

10.2. dLUC of forest-based biofuel and bioenergy (Chapter 8) ........................... 182

10.3. Depolymerization model (Chapter 9) …………......................................... 183 


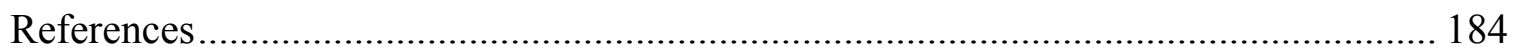

A. Appendix A: Supporting Information for Chapter 3............................................... 201

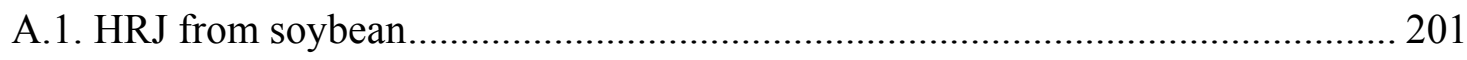

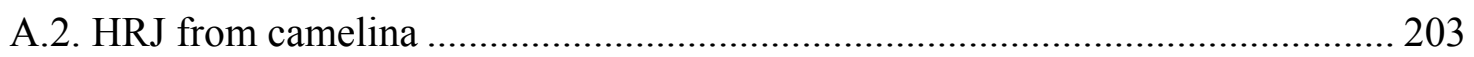

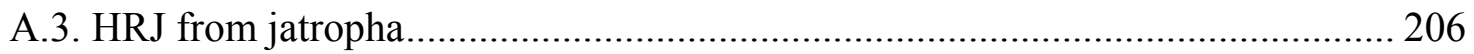

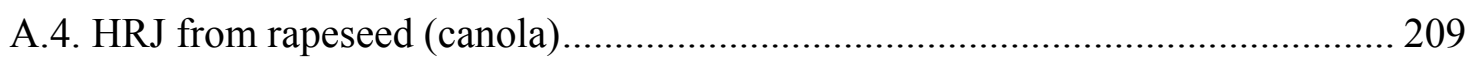

A.5. HRJ from palm oil.................................................................................... 212

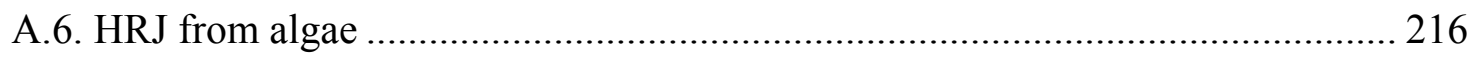

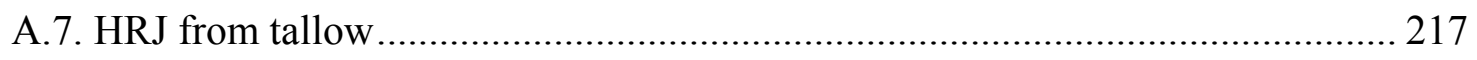

A.8. HRJ from fuel grade corn oil ................................................................ 218

B. Appendix B: Supporting information for Chapter 8 ………………………...... 220

C. Appendix C: Supporting information for chapter 9............................................ 233

C.1. Procedures of solving differential equations of N N.............................................. 233

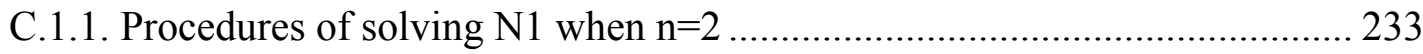

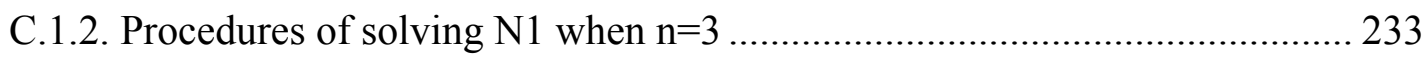

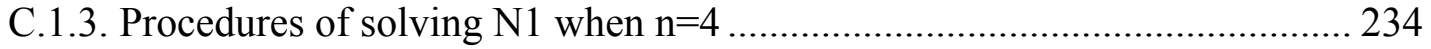

C.2. Depolymerization model with different hydrolysis reaction rates ...................... 235

C.3. Depolymerization model with updated kinetic reactions ..................................... 237

C.4. Reaction kinetics of xylooligomers developed by Kumar and Wyman.............. 239

D. Appendix D: Copyright clearance …………………......................................... 241 


\section{List of Tables}

Table 2.1: Fatty acid profile of field pennycress oil, camelina oil and jatropha oil ........... 6

Table 2.2: Properties of Ecofining RD compared to ASTM D975-08 specs.................... 10

Table 2.3: Properties of HRJ at 50 Percent Blend with Petroleum Jet Fuel ...................... 11

Table 2.4: Commercial Aviation Test Flights............................................................... 12

Table 2.5: Energy and Fertilizer Inputs per kg Seeds for Cultivation and Harvesting..... 16

Table 2.6: Elemental composition data of harvested seed............................................... 17

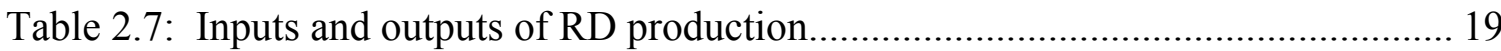

Table 2.8: Inputs and outputs of HRJ production ............................................................ 20

Table 2.9: LHV, market values, and allocation factors (as \%) of products and co-products

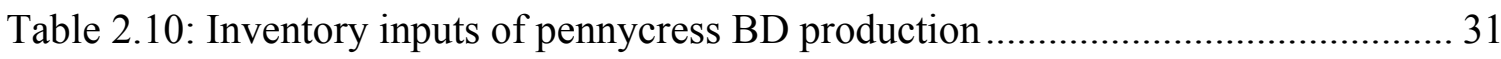

Table 2.11: Soil data of pennycress/soybean rotation for the last two years..................... 33

Table 3.1: Inputs and outputs of jatropha oil extraction ................................................ 38

Table 3.2: The energy content and market value, along with the allocation factors of the products and co-products of jatropha RD and HRJ 39

Table 3.3: Land category classes of native vegetation of the green bordered area, as well

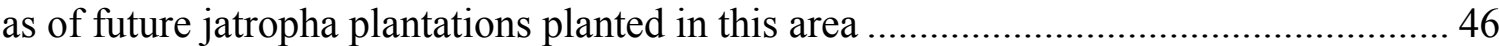

Table 3.4: GHG emissions ( $\mathrm{g} \mathrm{CO}_{2}$ eq/MJ) due to dLUC of jatropha plantation ............... 46

Table 4.1: Inputs and outputs of HRJ production from renewable oils ............................5 52

Table 4.2: Life cycle GHG emissions of soybean-derived HRJ ……………………........56

Table 4.3: Life cycle GHG emissions of camelina derived HRJ from various sources ... 58

Table 4.4: Life cycle GHG emissions of jatropha derived HRJ from various sources..... 60

Table 4.5: Life cycle GHG emissions of rapeseed derived HRJ from various sources.... 62

Table 4.6: Life cycle GHG emissions of palm oil derived HRJ from various sources..... 65

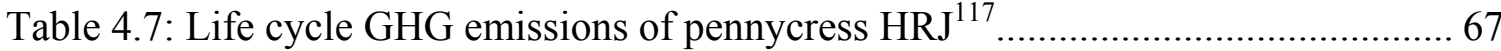

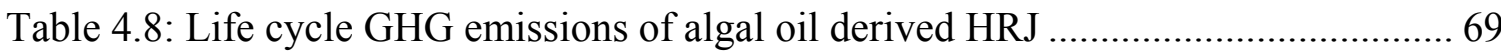

Table 4.9: Life cycle GHG emissions of tallow derived HRJ ........................................... 71

Table 4.10: Life cycle GHG emissions of HRJ from fuel grade corn oil (EA) ................ 72

Table 5.1: Typical properties and compositions of pyrolysis oil...................................... 78

Table 5.2: Inventory inputs of biomass loading, unloading and storage .......................... 82

Table 5.3: Measured emission data (mg/MJ) of RTP green fuel and No. 6 fuel oil......... 84

Table 5.4: Life cycle GHG emissions of RTP green fuel, comparing to heavy fuel oil... 86

Table 5.5: Inputs of wood residues pyrolysis (per L of pyrolysis oil) .............................. 86

Table 5.6: Combustion emissions of pyrolysis oil (g/GJ pyrolysis oil)............................. 86

Table 5.7: Life cycle air pollutants (mg/MJ) of RTP green fuel and heavy fuel oil......... 87

Table 5.8: Human health, ecosystem quality and resources impacts of RTP green fuel, compared to heavy fuel oil 
Table 5.9: Transport mode and distance $(\mathrm{km})$ of mill residues .................................... 90

Table 5.10: Inputs of 1 dry metric ton low ash corn stover ....................................... 92

Table 5.11: Inputs of 1 dry metric ton of logging residues.......................................... 93

Table 6.1: Forest residues supply in the Michigan Upper Peninsula.............................. 96

Table 6.2: Net volume of live trees (at least 5 inches d.b.h./d.r.c.), in cubic feet............ 97

Table 6.3: Inventory inputs of willow cultivation and harvesting ............................... 100

Table 6.4: Inventory inputs of poplar cultivation and harvesting ................................. 101

Table 6.5: Biomass transportation distances for power conversion systems ................. 102

Table 6.6: Plant size and efficiency of each power generation system ......................... 104

Table 6.7: GHG emissions results of PyOil production from 4 biomass feedstocks...... 106

Table 6.8: Transportation distances of biomass feedstock under different f values ....... 107

Table 6.9: GHG emissions results of pyrolysis oil production in parasitic plant ........... 108

Table 6.10: Life cycle GHG emissions of electricity from pyrolysis oil in GTCC ........ 109

Table 6.11: Life cycle GHG emissions of electricity from pyrolysis oil in diesel generator

Table 6.12: Life cycle GHG emissions of pyrolysis oil combustion in coal-fired plant 111 Table 6.13: Life cycle GHG emissions of pyrolysis oil combustion in natural gas plant

Table 6.14: Life cycle GHG emissions of pyrolysis oil combustion in fuel oil-fired plant 113

Table 6.15: Life cycle GHG emissions of electricity from biomass direct combustion. 115 Table 7.1: Inputs of pyrolysis gasoline and diesel production from logging residues .. 123 Table 7.2: Inputs of pyrolysis gasoline and diesel production from corn stover ........... 124 Table 7.3: GHG emissions of pyrolysis gasoline/diesel from logging residues ............ 126

Table 7.4: GHG emissions of pyrolysis gasoline/diesel from corn stover .................... 127

Table 7.5: Corn stover collection and additional nutrients added to soil....................... 128

Table 8.1: The life cycle year 2022 GHG emissions results for the RFS2 final rule .... 135

Table 8.2: Carbon intensity values of gasoline, diesel and fuels that substitute for them

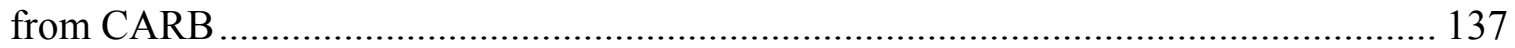

Table 8.3: Carbon pools in the CBM-CFS3 and pools recommended by IPCC GPG... 139

Table 8.4: The parameters used to simulate DOM dynamics in CBM-CFS3 ............... 142

Table 8.5: Current age distribution of aspen in Michigan ........................................ 144

Table 9.1: Pretreatment severities for acid concentration and temperature................... 168

Table A.1: Fertilizers and energy inputs of soybean farming .................................... 201

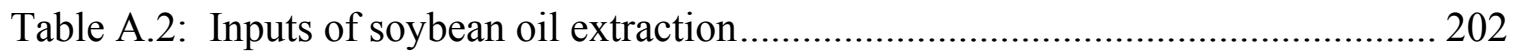

Table A.3: Product and co-products of soybean HRJ ................................................ 203

Table A.4: Chemicals and energy inputs of camelina farming ................................... 204

Table A.5: Inputs and co-product of camelina oil extraction (and refining) ................. 205

Table A.6: Chemical and energy inputs of jatropha cultivation ................................ 206 
Table A.7: Process inputs of jatropha oil extraction (and refining).............................. 208

Table A.8: Chemical and energy inputs of rapeseed cultivation ................................ 210

Table A.9: Chemical and energy inputs of rapeseed oil extraction .............................. 211

Table A.10: Transport mode and distance of rapeseed and oil ................................... 212

Table A.11: Chemicals and energy inputs of palm fruit farming and harvest ................ 213

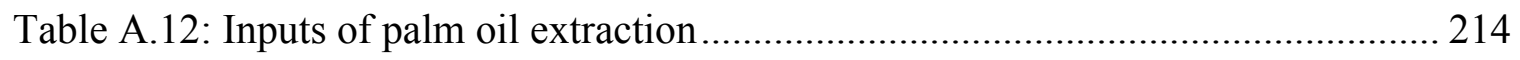

Table A.13: Feedstock and fuel transport of palm oil derived HRJ .............................. 215

Table A.14: Inputs for algae cultivation and dewatering ......................................... 216

Table A.15: Inputs for algae oil extraction and refining to HRJ ................................. 217

Table A.16: Tallow rendering process from CARB and GHGenius ............................. 218

Table A.17: Energy inputs of corn oil extraction ......................................................... 219

Table A.18:Material and energy inputs of corn oil refining ......................................... 219

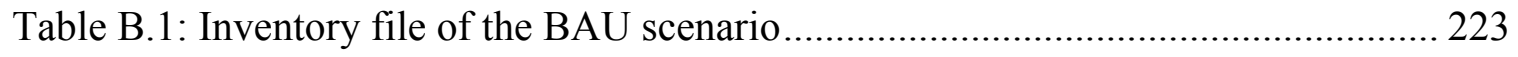

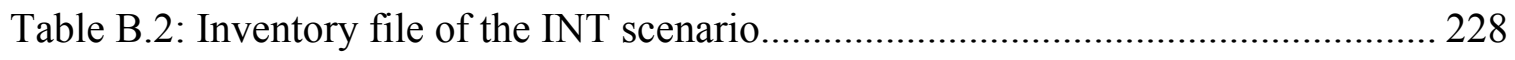

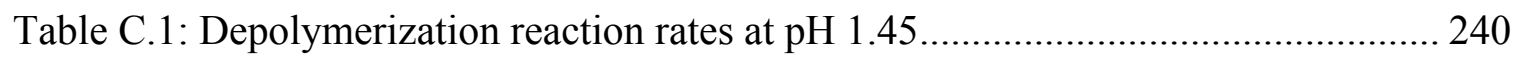




\section{List of Figures}

Figure 2.1: Pennycress production area across Midwest (Zone 5A, 5B and 6A) ..... 7

Figure 2.2: Cultivation scheme of field pennycress implemented by the farmers across

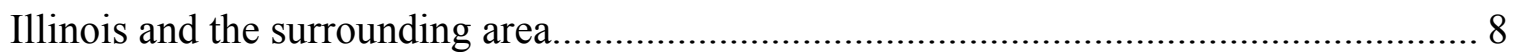

Figure 2.3: Ecofining ${ }^{\mathrm{TM}}$ process flow diagram......................................................... 9

Figure 2.4: Pathway diagram of pennycress RD and HRJ LCA study .......................... 14

Figure 2.5: Life cycle GHG emissions of pennycress RD and HRJ, comparing to petroleum fuels........................................................................................................ 24

Figure 2.6: The CED results of pennycress RD and HRJ, compared to petroleum fuels. 25 Figure 2.7: The FED results of pennycress RD and HRJ, compared to petroleum fuels. 26 Figure 2.8: Life cycle GHG emissions of pennycress RD and HRJ, various $\mathrm{N}$ application

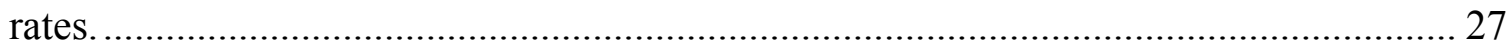

Figure 2.9: Life cycle GHG emissions of RD and HRJ with different $\mathrm{N}$ content in seed

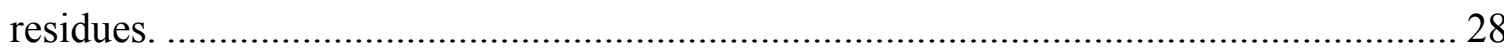

Figure 2.10: Life cycle GHG emissions of RD and HRJ with different $\mathrm{H}_{2}$ sources......... 30 Figure 2.11: Life cycle GHG emission of pennycress oil derived biodiesel, comparing to pennycress RD.

Figure 3.1: The life cycle GHG emissions of jatropha RD and HRJ (base case), using imported $\mathrm{H}_{2}$ from $\mathrm{SMR}$, compared to petroleum fuels.

Figure 3.2: CED results (base case) of jatropha derived RD and HRJ, compared to petroleum fuels

Figure 3.3: FED results (base case) of jatropha derived RD and HRJ, compared to petroleum fuels. 43

Figure 3.4: Life cycle GHG emissions of jatropha RD and HRJ, with different fertilizer application rates

Figure 3.5: Life cycle GHG emissions of jatropha RD and HRJ, with different $\mathrm{H}_{2}$ sources

Figure 3.6: Life cycle GHG emissions of jatropha RD and HRJ, including dLUC impact

Figure 4.1: Overview of the UOP Renewable Jet Fuel Process .................................... 50

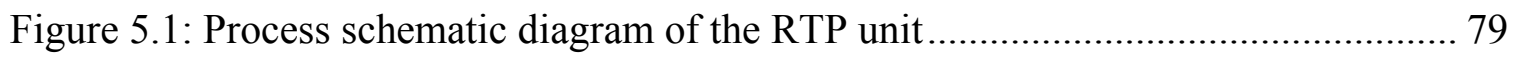

Figure 5.2: Pathway diagram of the pyrolysis oil LCA. ............................................... 82

Figure 5.3: CED and FED results of RTP green fuel. ................................................. 88

Figure 5.4: Impact of biomass transport on the total GHG emissions of RTP green fuel.90 Figure 5.5: Life cycle GHG emissions of RTP green fuel from sawmill residue produced in the U.S. 91

Figure 5.6: GHG emissions of RTP green fuel from various feedstocks, comparing to heavy fuel oil. 94 
Figure 6.1: Pathway diagram of pyrolysis oil to power LCA study............................. 99

Figure 6.2: GHG emission of biomass cultivation and harvesting (no transport)......... 105

Figure 6.3: Cradle to gate GHG emission of pyrolysis oil production with different $\mathrm{f}$

values.

Figure 6.4: Life cycle GHG emissions of pyrolysis oil combusted in power plant with different pyrolysis oil transportation distances.

Figure 6.5: Life cycle GHG emissions of power generation. ...................................... 116

Figure 7.1: Flow diagram of liquid fuels production via fast pyrolysis of biomass. ...... 119

Figure 7.2: Pathway diagram of pyrolysis oil to liquid fuels LCA study ..................... 122

Figure 7.3: GHG emissions of pyrolysis gasoline and diesel, comparing to the petroleum

fuels

Figure 7.4: CED results of pyrolysis gasoline/diesel, comparing to petroleum gasoline and diesel

Figure 7.5: FED results of pyrolysis gasoline/diesel (Fuel transport includes transport of

hydrotreated pyrolysis oil and final gasoline/diesel product) ................................... 130

Figure 8.1: LUC impacts estimation process by CARB ............................................. 136

Figure 8.2: C flow between biomass and DOM pools in the CBM-CFS3 .................... 140

Figure 8.3: Growth curves of aspen in Michigan ....................................................... 145

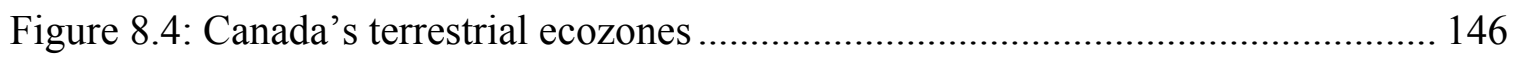

Figure 8.5: Conceptual design of trembling aspen forest in the CBM-CFS3 ................ 147

Figure 8.6: Total biomass harvested in the BAU and INT scenarios over 250 years.... 149

Figure 8.7: Ecosystem $\mathrm{C}$ stored in the BAU and INT scenarios ................................ 150

Figure 8.8: The GHG emissions due to dLUC of biofuel and bioenergy over 250 years

Figure 8.9: GHG emissions (w/dLUC) of EtOH, pyrolysis oil and electricity over 250 years, comparing to their petroleum counterparts.

Figure 8.10: Total GHG emissions of EtOH and pyrolysis oil.................................. 154

Figure 8.11: Total ecosystem $\mathrm{C}$ storage of the 4 scenarios........................................... 155

Figure 8.12: GHG emissions due to dLUC of ethanol, comparing 3 growth curve scenarios.

Figure 8.13: GHG emissions due to dLUC of pyrolysis oil, comparing 3 growth curve scenarios.

Figure 8.14: Total GHG emissions of EtOH and pyrolysis oil, comparing 3 growth curve scenarios.

Figure 9.1: Components of lignocellulosic biomass 161

Figure 9.2: Experiment setup of aspen hydrolysis................................................... 168

Figure 9.3: Concentrations of xylose monomers during dilute acid hydrolysis ............ 169

Figure 9.4: Furfural and HMF concentrations during dilute acid hydrolysis ................ 170

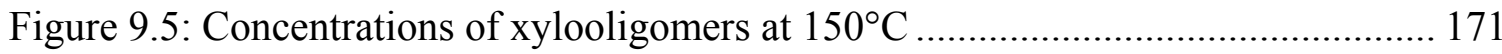




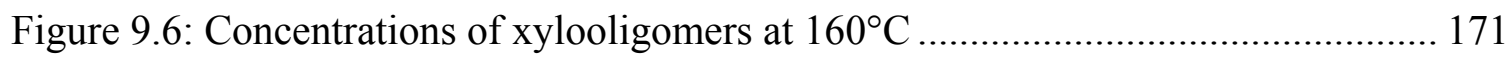

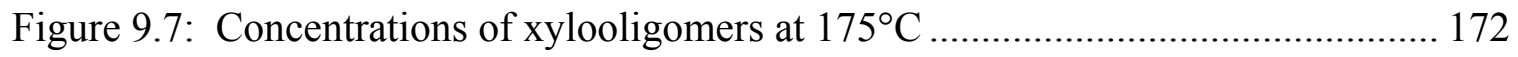

Figure 9.8: Total oligomers concentrations in the hydrolyzate using the NREL procedure.

Figure 9.9: Xylose experiment data at $150^{\circ} \mathrm{C}$ and model prediction............................ 174

Figure 9.10: Xylose experiment data at $160^{\circ} \mathrm{C}$ and model prediction............................ 175

Figure 9.11: Xylose experiment data at $175^{\circ} \mathrm{C}$ and model prediction .......................... 175

Figure 9.12: Xylobiose, xylotriose and xylotetrose concentrations at $150^{\circ} \mathrm{C}$, comparing to

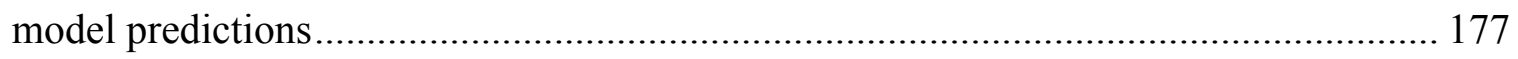

Figure 9.13: Xylobiose, xylotriose and xylotetrose concentrations at $160^{\circ} \mathrm{C}$, comparing to

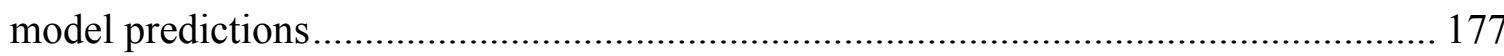

Figure 9.14: Xylobiose, xylotriose and xylotetrose concentrations at $175^{\circ} \mathrm{C}$, comparing to

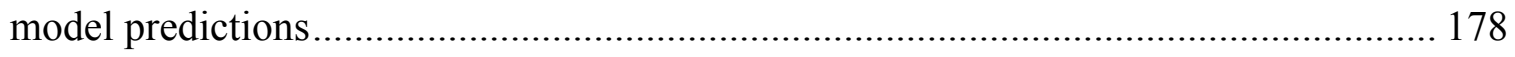

Figure 9.15: Total xylooligomers concentrations at $150^{\circ} \mathrm{C}$, comparing to model

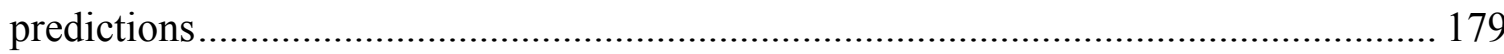

Figure 9.16: Total xylooligomers concentrations at $160^{\circ} \mathrm{C}$, comparing to model predictions. 179

Figure 9.17: Total xylooligomers concentrations at $175^{\circ} \mathrm{C}$, comparing to model

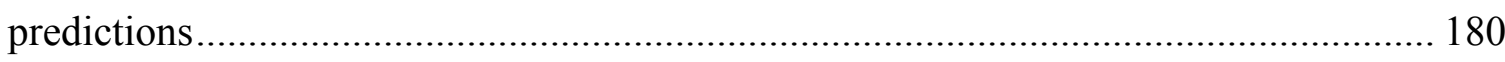

Figure A.1: Flow diagram of GREET jatropha oil extraction .................................... 207

Figure B.1: Age class import file of the BAU and INT scenarios .............................. 220

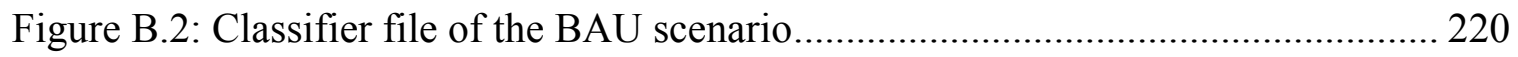

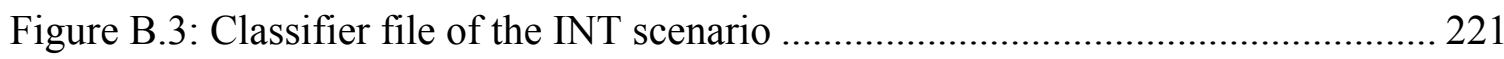

Figure B.4: Disturbance type import file of the BAU and INT scenarios .................... 221

Figure B.5: Yield import file of the BAU scenario ................................................ 221

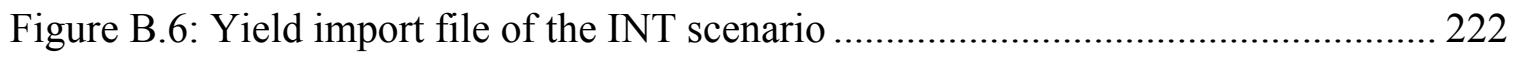

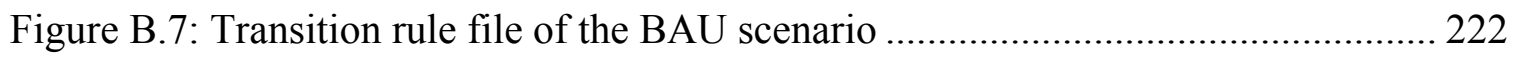

Figure B.8: Transition rule file of the INT scenario .................................................. 222

Figure C.1: Xylotriose hydrolysis profiles predicted by the depolymerization model... 237

Figure C.2: Xylotetrose hydrolysis predicted by the depolymerization model ............. 239

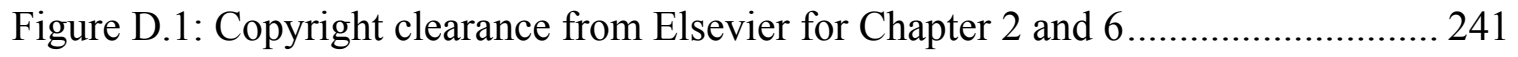

Figure D.2: Copyright clearance from USDA ................................................... 242

Figure D.3: Copyright clearance from UOP Honeywell .......................................... 242

Figure D.4: Permission by the IJESER editor Thomas White ..................................... 243

Figure D.5: Permission by Tom Kalnes to use Figure 4.1 and 5.1 in this dissertation... 243

Figure D.6: Copyright clearance from Natural Resources Canada for Figure 8.4 ........ 243 


\section{Preface}

This dissertation "Sustainable Energy Production in the United States: Life Cycle Assessment of Biofuels and Bioenergy" centers on the environmental life cycle analysis of biofuels derived from renewable feedstocks. This Ph.D. research is unique in that within one body of work is contained analyses of multiple pathways for biofuel and bioenergy (electricity generation) production from diverse biomass feedstocks. These liquid biofuel products include pyrolysis oil, renewable diesel, hydroprocessed renewable jet, and electricity generation from feedstocks such as lignocellulosic biomass as well as renewable fats and oils. In addition to these pathways, this dissertation research investigated direct land use change emissions of greenhouse gases associated with forest based biofuel and bioenergy using a forest carbon budget model. Finally, this dissertation research studied depolymerization of hemicellulose using a modeling framework for hydrolysis under dilute acid conditions.

Life cycle assessment (LCA) of renewable diesel (RD) and hydroprocessed jet fuels (HRJ) are from a collaboration between Michigan Technological University and researchers at UOP LLC. All the studies were conducted in consultation with my Ph.D. advisor Professor David Shonnard from MTU and Mr. Tom Kalnes from UOP LLC. Chapter 2 researches the LCA of pennycress derived RD and HRJ, which was published in the journal Biomass and Bioenergy (Elsevier) in 2013. Chapter 3 is the LCA of jatropha derived RD and HRJ, which is based on the study conducted to support UOP and Global Clean Energy Holdings (GCEH) combined efforts for the EPA Petition for Evaluation of New Renewable Fuels and Pathways. Chapter 4 is a review of the greenhouse gas emissions of hydroprocessed jet fuels from renewable oils and fats. This work was published in the International Journal of Environmental Science and Engineering Research (IJESER) in 2012.

LCAs of pyrolysis oil and pyrolysis oil derived biofuels and bioenergy are results from a collaboration between Michigan Technological University, UOP and Envergent 
Technologies (a joint venture between UOP and Ensyn). Pyrolysis oil produced from sawmill residues and used in a heating application was studied and documented in Chapter 5, which is being prepared for submission to Energy \& Fuels journal. Chapter 6 is the LCA of pyrolysis oil derived electricity, which was published in Renewable Energy (Elsevier) in 2011. Chapter 7 is the LCA of pyrolysis gasoline and diesel produced from lignocellulosic biomass.

Direct land use change impacts associated with forest based biofuel and bioenergy production and use is presented in Chapter 8. This project was studied in consultation with Professor David Shonnard and Dr. Robert Froese (PhD committee member, SFRES). Stephen Kull of Natural Resources Canada and Robert Handler also provide valuable assistance for me to understand the Carbon Budget Model of the Canadian Forest System (CBM-CFS 3) model. This work will be submitted to a peer-reviewed journal for publication.

Chapter 9 represents the work of using depolymerization model to describe the kinetic reaction of hemicellulose hydrolysis under dilute acid conditions. The experiment method was adjusted from the work performed by two former students Jill Jensen and Juan Morinelly. Sheri Kopka (Mercer School, Mercer.WI), Susan Stoll (Pine River Middle School, LeRoy, MI), and Lloyd Hilger (Hanover-Horton Middle School, Horton, MI); all teachers participating in the NSF-funded Research Experience for Teachers (RET) program at MTU, helped with the experiments in the laboratory.

Finally, all the future work proposed in this dissertation are summarized in Chapter 10.

With the kind permission of both IJESER and Elsevier (Appendix D), previously published materials have been reproduced for use in this dissertation. 


\section{Acknowledgement}

I would first like to thank my advisor, Dr. David Shonnard, for sharing his knowledge, experience and insights with me over the course of my $\mathrm{PhD}$ program. I sincerely appreciate his guidance and help, both academic and non-academic. My gratitude also goes to my PhD supervisory committee: Dr. Robert Froese, Dr. Ching-An Peng, and Dr. Wen Zhou. Their expertise in their own areas greatly broadened my horizons and expanded understanding of my research.

I would also like to gratefully acknowledge the funding source that made my Ph.D. work possible. UOP LLC provided financial support to my research projects and Mr. Tom Kalnes, program manager at UOP LLC, also provided insights on process technology, helpful feedback on my LCA projects, and professional experiences. He also shares UOP process technology and confidential data with me, which significantly improved the quality and breadth of my $\mathrm{PhD}$ research.

I am appreciative of my colleagues and fellow graduate students, namely Dr. Robert Handler, Dr. Michael Brodeur-Campbell, Dr. Felix Adom, Jordan Klinger and Jifei Liu. Other people provide help to my work, including Matthew Alward, Adam Sadehvandi (both undergraduate students), Sheri Kopka, Susan Stoll, and Lloyd Hilger (all high school teachers from the Research Experience for Teachers (RET) program).

Finally, I must thank my family for their love and support throughout my stay at Michigan Technological University. Their unwavering love, encouragement and belief in me have brought me this far. 


\section{List of Abbreviations}

AITC: 2-propenyl allyl isothiocyanate ATC: Allyl thiocyanate

BAU: business as usual

CARB: California Air Resources Board

CBM-CFS: Carbon Budget Model for the Canadian Forest Sector

CED: cumulative energy demand

DALY: disability-adjusted life years

dLUC: direct land use change

DOM: dead organic matter

EA: energy allocation

EAF: energy allocation factor

EFB: empty fruit bunches

EISA: Energy Independence and Security Act EPA: Environmental Protection Agency

FAA: Federal Aviation Administration

FAPRI: Food and Agricultural Policy Research Institute

FASOM: Forestry and Agricultural Sector Optimization Model

FAME: fatty acid methyl esters

FED: fossil energy demand

GCEH: Global Clean Energy Holdings

GWP: global warming potentials

GTCC: gas turbine combined cycle

HEFA: hydroprocessed esters and fatty acids

HPLC: high performance liquid chromatography HMF: hydroxymethyl furfural

HRJ: hydroprocessed renewable jet

IPCC: Intergovernmental Panel on Climate Change

LCA: life cycle assessment

LEA: lipid extracted algae

LPG: liquefied petroleum gas

iLUC: indirect land use change

OZT: Oxazolidene-2-thione

PM: particular matter
iLUC: indirect land use change

FDA: Food and Drug Administration

FIA: Forest Inventory and Analysis

GHG: greenhouse gas

GTAP: Global Trade Analysis Project

LCFS: Low Carbon Fuels Standard

LHV: lower heating value

LUC: land use change

MVA: market value allocation

PDF: potentially disappeared fraction 
PNNL: Pacific Northwest National Laboratory

PTW: pump-to-wake

RFS: Renewable Fuels Standard

RSB: Roundtable on Sustainable Biofuels

SCR: selective catalytic reduction

SMR: steam methane reforming

SRF: short rotation forestry

TSP: triple super phosphate
POME: palm oil mill effluent

$\mathrm{RD}$ : renewable diesel

RMA: raw material acquisition

RTP: rapid thermal processing

SE: system expansion

SPK: synthetic paraffinic kerosene

SSP: single super phosphate 


\begin{abstract}
The United States of America is making great efforts to transform the renewable and abundant biomass resources into cost-competitive, high-performance biofuels, bioproducts, and biopower. This is the key to increase domestic production of transportation fuels and renewable energy, and reduce greenhouse gas and other pollutant emissions.
\end{abstract}

This dissertation focuses specifically on assessing the life cycle environmental impacts of biofuels and bioenergy produced from renewable feedstocks, such as lignocellulosic biomass, renewable oils and fats. The first part of the dissertation presents the life cycle greenhouse gas (GHG) emissions and energy demands of renewable diesel (RD) and hydroprocessed jet fuels (HRJ). The feedstocks include soybean, camelina, field pennycress, jatropha, algae, tallow and etc. Results show that RD and HRJ produced from these feedstocks reduce GHG emissions by over $50 \%$ compared to comparably performing petroleum fuels. Fossil energy requirements are also significantly reduced.

The second part of this dissertation discusses the life cycle GHG emissions, energy demands and other environmental aspects of pyrolysis oil as well as pyrolysis oil derived biofuels and bioenergy. The feedstocks include waste materials such as sawmill residues, logging residues, sugarcane bagasse and corn stover, and short rotation forestry feedstocks such as hybrid poplar and willow. These LCA results show that as much as 98\% GHG emission savings is possible relative to a petroleum heavy fuel oil. Life cycle GHG savings of 77 to $99 \%$ were estimated for power generation from pyrolysis oil combustion relative to fossil fuels combustion for electricity, depending on the biomass feedstock and combustion technologies used. Transportation fuels hydroprocessed from pyrolysis oil show over $60 \%$ of GHG reductions compared to petroleum gasoline and diesel. The energy required to produce pyrolysis oil and pyrolysis oil derived biofuels and bioelectricity are mainly from renewable biomass, as opposed to fossil energy. Other environmental benefits include human health, ecosystem quality and fossil resources. 
The third part of the dissertation addresses the direct land use change (dLUC) impact of forest based biofuels and bioenergy. An intensive harvest of aspen in Michigan is investigated to understand the GHG mitigation with biofuels and bioenergy production. The study shows that the intensive harvest of aspen in MI compared to business as usual (BAU) harvesting can produce 18.5 billion gallons of ethanol to blend with gasoline for the transport sector over the next 250 years, or 32.2 billion gallons of bio-oil by the fast pyrolysis process, which can be combusted to generate electricity or upgraded to gasoline and diesel. Intensive harvesting of these forests can result in carbon loss initially in the aspen forest, but eventually accumulates more carbon in the ecosystem, which translates to a $\mathrm{CO}_{2}$ credit from the dLUC impact. Time required for the forest-based biofuels to reach carbon neutrality is approximately 60 years.

The last part of the dissertation describes the use of depolymerization model as a tool to understand the kinetic behavior of hemicellulose hydrolysis under dilute acid conditions. Experiments are carried out to measure the concentrations of xylose and xylooligomers during dilute acid hydrolysis of aspen. The experiment data are used to fine tune the parameters of the depolymerization model. The results show that the depolymerization model successfully predicts the xylose monomer profile in the reaction, however, it overestimates the concentrations of xylooligomers. 


\section{Chapter1: Introduction}

\subsection{Background}

The United States consumed 97.3 Quads of energy in 2011, of which almost forty percent was provided by petroleum import ${ }^{1}$. Petroleum also serves as the dominant energy source for transportation sector, which was responsible for approximately 30 percent of total energy demand ${ }^{1}$. Also, the heavy dependence on foreign sources of petroleum poses a threat to national energy security. The current reliance almost exclusively on resources that will eventually be depleted is also another motivation to develop renewable forms of energy. The use of renewable sources of fuels has great potential to help solve this problem $^{2}$. In addition, domestic renewable energy can lower the trade deficit, help generate jobs and revenues ${ }^{2}$, and most importantly, reduce greenhouse gas (GHG) emissions $^{3}$. Because of the strategic, economic, social and environmental benefits of biofuels compared to petroleum, the United States government has been promoting research leading to the increased use of biofuels. The Energy Independence and Security Act of 2007 (EISA) ${ }^{4}$ mandates annual use of 36 billion gallons of renewable transportation fuel by 2022, which includes corn ethanol, cellulosic ethanol and biodiesel of 15, 16 and 5 billion gallons respectively. Forest land and agricultural land in the U.S can provide 368 and 998 million dry tons of biomass annually, sufficient to provide $30 \%$ or more of the country's petroleum consumption with modest changes in land use and current forest and agricultural practices ${ }^{5}$.

\subsection{PhD research objective}

This $\mathrm{PhD}$ research contains four major components. The first component is the life cycle assessment (LCA) of renewable diesel (RD) and hydroprocessed jet fuels (HRJ) produced from renewable oils and fats. LCAs of RD and HRJ from various feedstocks such as camelina, jatropha, rapeseed, palm, tallow, and others are conducted and compared to literature and publicly available models, such as the GREET and GHGenius. The second component of this research is LCA of biofuels and bioenergy from fast pyrolysis of lignocellulosic biomass. Environmental impacts of pyrolysis oil produced 
from forest and agricultural byproducts are evaluated. Electricity and transportation fuels produced from pyrolysis oil are also studied. Land use change (LUC) impact associated with forest-based bioenergy was evaluated in the third component. In the last component, a kinetic model is proposed to describe the reaction kinetics of hemicellulose hydrolysis in dilute acid condition.

Specific objectives of this $\mathrm{PhD}$ research are listed as follows:

1. Evaluate the greenhouse gas (GHG) emission and energy demands of RD and HRJ produced from renewable oils and fats.

2. Present a review of current LCAs of HRJ available in literature and LCA models; identify the key drivers of GHG emissions in order to propose recommendations for improving the carbon footprint of future renewable jet fuel production.

3. Evaluate the GHG emission, energy demands and other environmental impacts of biooils and bioenergy from fast pyrolysis of lignocellulosic biomass, including pyrolysis oil, electricity and transportation fuels from logging residues, sawmill residues, and short rotation forestry.

4. Estimate the current harvest of Michigan forest for conventional timber industry, propose an intensive harvest scenario to produce extra feedstock for biofuel and bioenergy production; estimate the carbon stock change in the Michigan forest due to intensive harvest

5. Design and conduct experiment to obtain data of xylose and xylooligomers concentrations during dilute acid hydrolysis; develop a kinetic model to describe the hemicellulose hydrolysis reaction

\subsection{Dissertation outline}

This dissertation comprises of 10 chapters. The first chapter identifies the motivation of the research and development of biofuels and bioenergy industry. Chapter 2-3 present the life cycle GHG emissions and energy demands of RD and HRJ produced from field pennycress and jatropha respectively. Chapter 4 is a review of the life cycle GHG emissions of HRJ from renewable oils and fats, including soybean, camelina, rapeseed, 
algae, corn oil, tallow, etc. Chapter 5-7 discuss the life cycle GHG emissions, energy demands and other environmental aspects of pyrolysis oil, pyrolysis oil derived electricity and pyrolysis oil derived transportation fuels. Chapter 8 estimates the land use change (LUC) impact of forest based biofuels and bioenergy. Intensive harvest of aspen forest in Michigan is investigated as an example for potential biofuel and bioenergy production. Chapter 9 reports the experiments of hemicellulose hydrolysis under dilute acid conditions. It also describes the use of depolymerization model as a tool to understand the kinetic behavior of hemicellulose hydrolysis under dilute acid conditions. Chapter 10 summarizes the future work proposed in this dissertation. 


\section{Chapter 2: A Life Cycle Assessment of Pennycress (Thlaspi arvense L.) Derived Jet Fuel and Diesel ${ }^{1}$}

\subsection{Introduction}

\subsubsection{Sustainable Energy and transportation biofuels}

The Energy Independence and Security Act of 2007 (EISA) mandates the use of 136 million cubic meter of renewable transportation fuel by $2022^{4}$. The European Emissions Trading Scheme (ETS) is also encouraging the international production of renewable jet fuel $^{6}$. ASTM D7566 was approved on July 1st 2011, which allows blending of hydroprocessed renewable jet fuel (HRJ) (also referred to as SPK (synthetic paraffinic kerosene) from Hydroprocessed Esters and Fatty Acids, HEFA) up to 50 \% (volume fraction) with D1655 jet fuels ${ }^{7}$, thus facilitating a commercial pathway to sustainable aviation fuels.

\subsubsection{Field pennycress as an energy crop}

Field Pennycress (Thalaspi arvense L.) is a winter annual native to Eurasia and now widely distributed throughout temperate North America ${ }^{8}$. It germinates in the fall and forms its early vegetative stage characterized by a low-growing rosette that protects it from low temperatures and drying winds as it over-winters. The plant flowers in the spring, sets seeds and is harvested before typical summer crops (soybean) are planted. Thus, it has the potential to be grown as a winter crop between traditional summer crops to produce renewable biomass for fuel production ${ }^{9}$. Pennycress is a prolific seed producer, with seed yields of $1.5 \mathrm{Mg} /$ ha from test plots in North Dakota having been reported $^{10}$. In Illinois, Isbell reported that wild type strains planted in prepared ground resulted in seed yields of $900 \mathrm{~kg} /$ ha to over $2,352 \mathrm{~kg} / \mathrm{ha}^{11}$. Current commercial strains with genetically improved research lines are now exceeding $2,463 \mathrm{~kg} / \mathrm{ha}^{12}$ indicating that higher yields are possible. The harvested pennycress seeds contain oil up to a mass

\footnotetext{
${ }^{1}$ This chapter has been published in Biomass \& Bioenergy. Figure D-1 shows copyright clearance allowing for use in dissertation. Citation: Fan J, Shonnard DR, Kalnes TN, Johnsen PB, Rao S. A life cycle assessment of pennycress (Thlaspi arvense L.) -derived jet fuel and diesel. Biomass and Bioenergy, Available online 26 February 2013 http://dx.doi.org/10.1016/j.biombioe.2012.12.040
} 
fraction of $36 \%$ of the seed, nearly twice the amount as soybeans ${ }^{13}$ and comparable to other high yield oil producing plants such as camelina ${ }^{14}$. This high oil content (similar to other commercial renewable oils) and fatty acid profile (high contents of unsaturated fatty acids as shown in Table 2.1) make pennycress oil acceptable for biodiesel production ${ }^{14}$ and a potentially attractive feedstock for conversion to drop-in hydrocarbon fuels. As useful applications for pennycress meal develop, the oil is a candidate to become a sustainable alternative for advanced biofuels production. The remaining de-oiled presscake has an inherently high energy content of 9,554 Btu/lb dry basis ${ }^{13}(22.2 \mathrm{MJ} / \mathrm{kg})$, suitable for direct combustion or gasification for energy production. The presscake has also been demonstrated to produce a uniquely stable bio-oil when subjected to thermochemical conversion using fast pyrolysis ${ }^{13}$. While traditionally considered unsuitable for animal feed due to the presence of glucosinolates ${ }^{14,15}$, pennycress presscake contains only sinigrin which is present in several other food plants such as horseradish and brown mustard ${ }^{16}$. Sinigrin has little or no biological activity ${ }^{17}$, but there is concern that enzymatic hydrolysis by myrosinase could produce the toxic compound 2propenyl allyl isothiocyanate (AITC). However, temperatures produced in seed crushing denature myrosinase preventing AITC formation and by extension oxazolidene-2-thione (OZTs) known to cause nutritional problems in animals (Vaughn SF, USDA, personal comunication July 20, 2011). Majak et a $1^{18}$ considered the potential that glucosinolate hydrolysis by microorganisms of the rumen could produce AITC or allyl thiocyanate (ATC) in the absence of plant derived myrosinase. Sinigrin incubated for 2-6 hours in bovine rumen fluid did not release detectable amounts of AITC or ATC. The authors conclude that the sinigrin aglycone can only be generated by specific thioglucosidases of plant origin ${ }^{18}$. In animal feeding studies, Shires ${ }^{19}$ concludes that pennycress seeds cooked and extracted can be feed at relatively high levels without appreciable risk associated with glucosinolates. In fact, pennycress seed meal with its beneficial crude protein content of $31 \%^{20}$ has been fed successfully to sheep ${ }^{21}$. The meal is also considered as animal feed by one group of Canadian researchers in their pennycress biorefinery strategy ${ }^{22}$. 
Table 2.1: Fatty acid profile of field pennycress oil, camelina oil and jatropha oil

\begin{tabular}{|c|c|c|c|}
\hline fatty acid composition ${ }^{a}$ & field pennycress oil $^{14}$ & Camelina oil $^{23}$ & jatropha oil $^{24}$ \\
\hline C14:0 & 0.1 & 0.1 & $0-0.1$ \\
\hline C16:0 & 3.1 & 6.8 & $14.1-15.3$ \\
\hline C16:1 9c & 0.2 & trace & $0-1.3$ \\
\hline C18:0 & 0.5 & 2.7 & $3.7-9.8$ \\
\hline C18:1 9c & 11.1 & 18.6 & $34.3-45.8$ \\
\hline C18:1 11c & 1.5 & 1.1 & \\
\hline C18:2 9c 12c & 22.4 & 19.6 & $29-44.2$ \\
\hline $\mathrm{C} 18: 3$ 9c $12 \mathrm{c} 15 \mathrm{c}$ & 11.8 & 32.6 & \\
\hline C20:0 & 0.3 & 1.5 & $0-0.3$ \\
\hline C20:1 11c & 8.6 & 12.4 & \\
\hline $\mathrm{C} 20: 2$ 11c $14 \mathrm{c}$ & 1.6 & 1.3 & \\
\hline C22:0 & 0.6 & 0.2 & $0-0.2$ \\
\hline $\mathrm{C} 22: 113 \mathrm{c}$ & 32.8 & 2.3 & \\
\hline $\mathrm{C} 22: 2$ 13c 16c & 0.7 & & \\
\hline $\mathrm{C} 22: 3$ 13c 16c 19c & 0.3 & & \\
\hline $\mathrm{C} 24: 115 \mathrm{c}$ & 2.9 & trace & \\
\hline
\end{tabular}

${ }^{a}$ for example, C18:1 9c means an 18 carbon fatty acid chain with one double bond located at carbon 9

Field pennycress has a relatively early harvest date compared to other winter annual oil seed crops, which makes a two-crop rotation with soybean possible ${ }^{25}$. It is currently proposed to be grown as a winter annual in the Midwest (Zone 5A, 5B and 6A in Figure 2.1) on unused land following the corn harvest and prior to the spring planting of soybeans. This means that farmers can continue to grow corn and soybeans in the traditional way but add this new crop in the winter allowing them to earn additional income with underutilized land and equipment assets. Approximately 16.2 million ha of land are available each year for the winter production of pennycress ${ }^{26}$ under this strategy 
with no impact to the food supply or critical wildlife habitats. As an energy crop, pennycress has the potential to produce approximately 15 million cubic meter of liquid transportation fuels per year ${ }^{27}$ while providing farmers with 4 billion US dollars $\left(\$ 4 * 10^{9}\right)$ in extra revenue and creating 23,000 new jobs ${ }^{26}$. The pennycress cultivation strategy being implemented by the farmers across Illinois and the surrounding area is shown in the Figure 2.2.

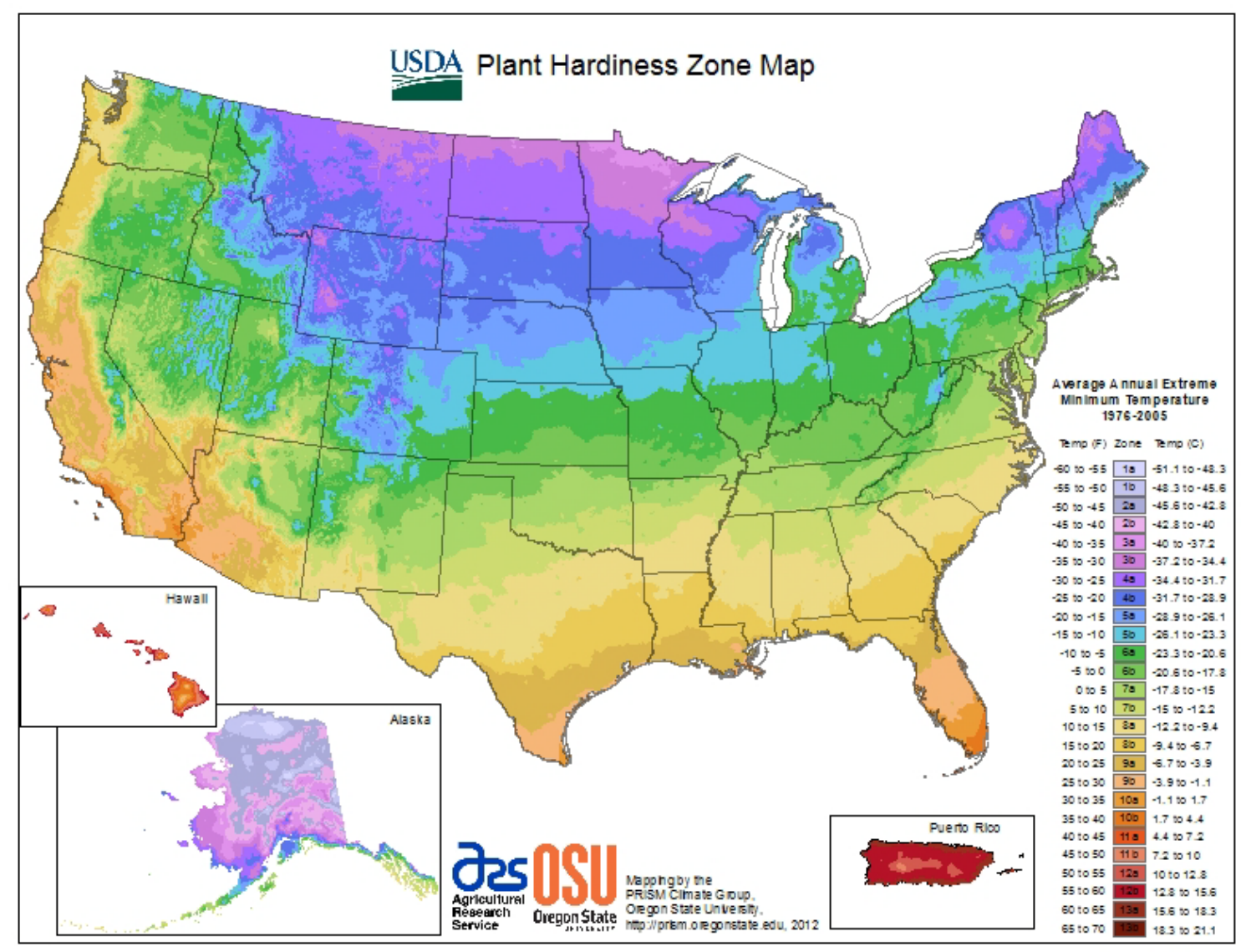

Figure $2.1^{2}$ : Pennycress production area across Midwest (Zone 5A, 5B and 6A) ${ }^{28}$

\footnotetext{
22 This figure was downloaded from United States Department of Agriculture (USDA) website http://planthardiness.ars.usda.gov/PHZMWeb/. Information presented on the USDA Web site is considered public domain information and may be freely distributed or copied. Clearance is available from USDA Policies and Links and shown in Figure D.2.

http://www.usda.gov/wps/portal/usda/usdahome?navtype=FT\&navid=POLICY_LINK
} 


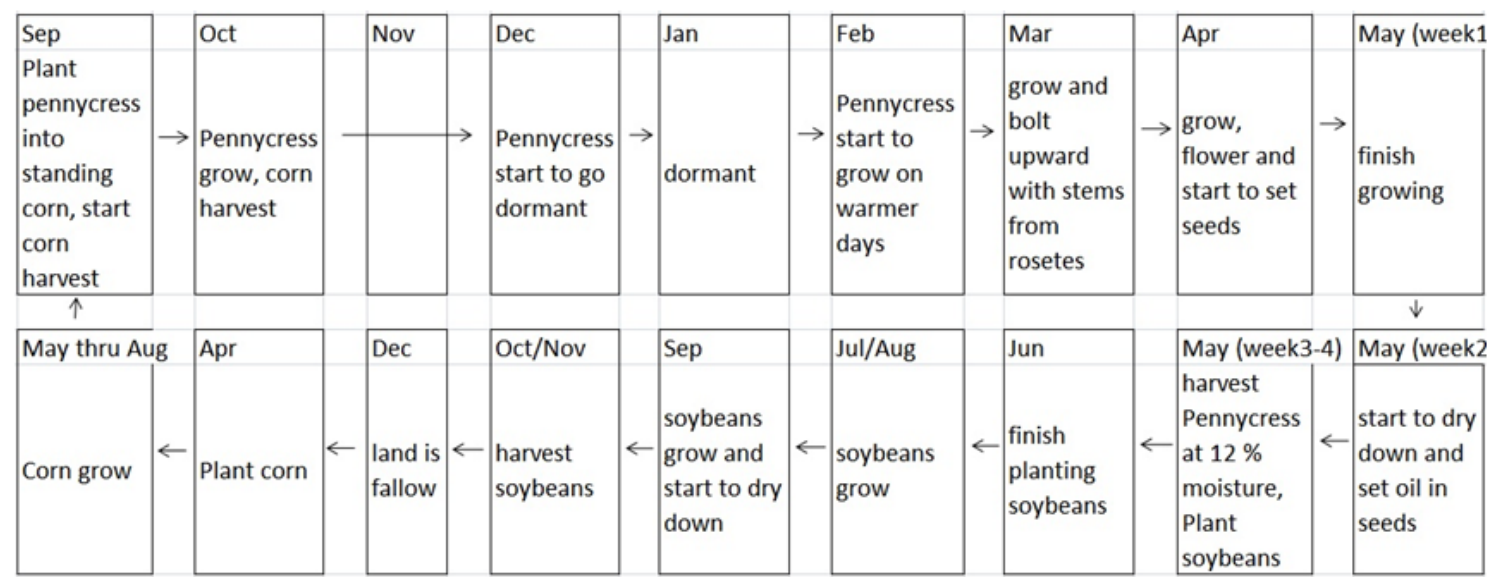

Figure 2.2: Cultivation scheme of field pennycress implemented by the farmers across Illinois and the surrounding area.

Western Illinois University ${ }^{29}$ has conducted preliminary field trials examining the impact of the presence or absence of pennycress as a previous crop on soybean yields. Soybeans were drilled into pennycress stubble for five consecutive weeks from mid-May to late June. Soybean following pennycress and soybean following fallow ground (control) were triplicated on the same Ipava soil type. Observations of soybean plant growth, flowering and pod formation in fields planted after the spring pennycress harvest all appear to be normal. Soybean yields were slightly higher following pennycress production for all planting dates possibly due to increased soil moisture thought to be caused by soil cover. No significant changes have been found in oil constituents or protein profiles between soybean following pennycress and the control. Therefore from these preliminary results, we assume that pennycress will not raise any concerns over food security or negative indirect land use change (iLUC) impact due to food (soybean) productivity decrease.

\subsubsection{Process Technology Overview for Drop-In Hydrocarbon Biofuels}

The UOP/Eni Ecofining ${ }^{\mathrm{TM}}$ process and the UOP Renewable Jet Fuel process hydrogenate and deoxygenate triglyceride and/or free fatty acid containing feedstocks such as vegetable oils and animal fats. The resulting normal paraffins are then isomerized and/or hydrocracked to yield drop-in hydrocarbon biofuels. A block flow diagram of the 
Ecofining ${ }^{\mathrm{TM}}$ process $^{30}$ is shown in Figure 2.3 . The feedstock is catalytically converted to high quality transportation fuels by a series of optimized hydrodeoxygenation, decarboxylation, hydroisomerization and hydrocracking reactions. The biofuel products are then recovered from the reactor effluent using commercially proven separation and fractionation technology. The excess hydrogen provided to the reactor system is recovered and recycled back to the reactor to minimize net hydrogen consumption and maintain a minimum required hydrogen partial pressure. Make-up hydrogen is added to the process to balance both chemical consumption and solution losses ${ }^{31}$.

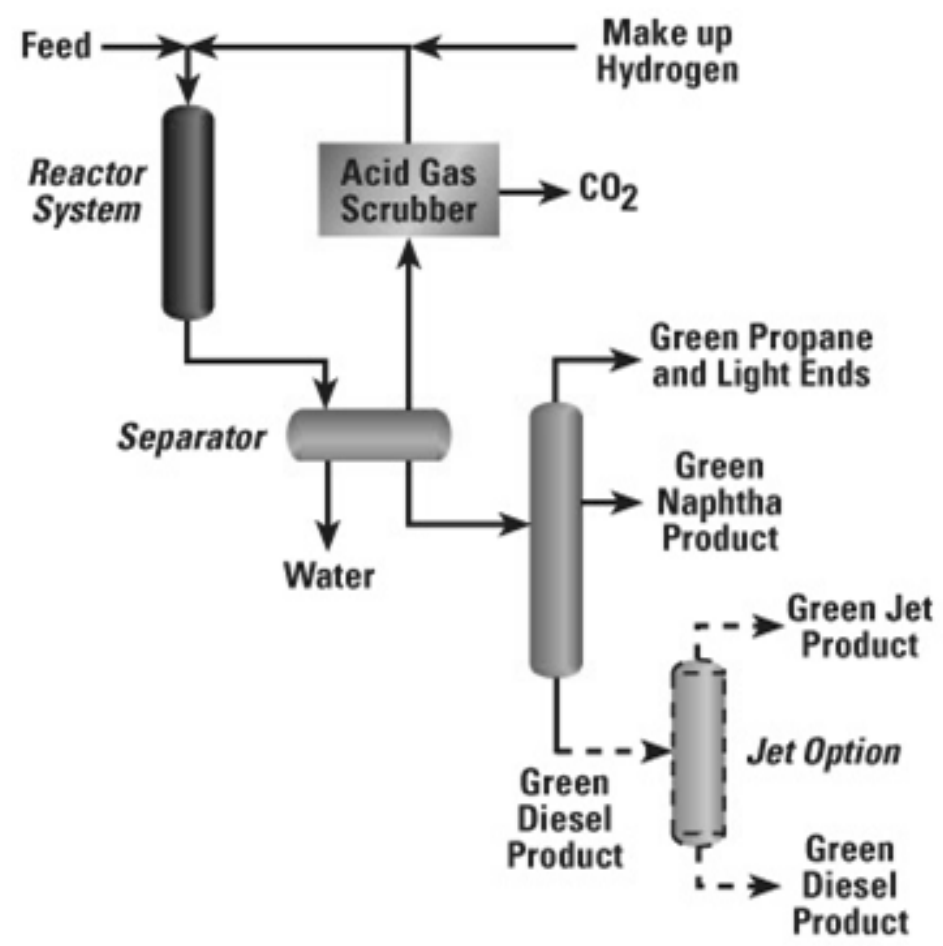

Figure $2.3^{3}$ : Ecofining ${ }^{\mathrm{TM}}$ process flow diagram ${ }^{30}$

The renewable diesel (RD) and HRJ produced by these processes show comparable compositions and combustion properties to Fischer Tropsch (FT) syndiesel and SPK. The $\mathrm{RD}$ exhibits superior properties of low density, substantially higher cetane number and

\footnotetext{
${ }^{33}$ This figure was downloaded from UOP Honeywell website http://www.uop.com/hydroprocessingecofining/. Honeywell International Inc. authorizes documents published online for personal or noncommercial use. The clearance is available from $\mathrm{http}: / /$ honeywell.com/Pages/TermsConditions.aspx and shown in Figure D.3.
} 
excellent storage stability compared to biodiesel and petroleum diesel ${ }^{32}$. Based on engineering correlations (Ellig YE, UOP internal correspondence November 11, 2011), the RD from pennycress oil will meet the ASTM D975 specification (Table 2.2).

Table 2.2: Properties of Ecofining RD compared to ASTM D975-08 specs $^{33}$

\begin{tabular}{|l|l|l|l|}
\hline & RD & ASTM Spec & Test Method \\
\hline Flash Point $\left({ }^{\circ} \mathrm{C}\right)$ & 71 & $52 \mathrm{~min}$ & ASTM 93 \\
\hline Distillation $\left({ }^{\circ} \mathrm{C}\right)$ & 292.6 & $282 \mathrm{~min} ; 338 \mathrm{max}$ & ASTM D86 \\
\hline Kinetic Viscosity, $40^{\circ} \mathrm{C}(\mathrm{cst})$ & 2.835 & $1.9 \mathrm{~min} ; 4.1 \mathrm{max}$ & ASTM D445 \\
\hline Ash (mass fraction, \%) & $<0.0001$ & $0.01 \mathrm{max}$ & ASTM D5453 \\
\hline Sulfur $\left(\mathrm{mg} \mathrm{kg}^{-1}\right)$ & $<3.0$ & $15 \mathrm{max}$ & ASTM D483 \\
\hline Cetane Number & $>66$ & $40 \mathrm{~min}$ & ASTM D613 \\
\hline Cloud Point $\left({ }^{\circ} \mathrm{C}\right)$ & -8 & & ASTM D2500 \\
\hline
\end{tabular}

Likewise, the HRJ derived from pennycress oil is expected to meet all the stringent specifications required for use as a jet fuel at blends up to $50 \%$ (volume fraction) $^{34}$ (Table 2.3). Significant quantities of HRJ have been produced by UOP to support the rigorous testing and protocols required for aviation fuel certification when introducing a new fuel to the aviation fuel supply chain (lab testing, fit for purpose testing, component/rig testing and finally flight testing). An updated list of successfully completed commercial test flights is provided in Table 2.4. In addition to these commercial test flights, HRJ derived from camelina and jatropha, blended with $50 \%$ (volume fraction) petroleum-based jet fuel, have been flight-tested by the United States Air Force and Navy including the United States Air Force Thunderbirds ${ }^{35}$. Several other military test flights have been completed and the aircraft certified for operation on HRJ blends. The tests and flight demonstrations confirm that the HRJ meets stringent engine fuel composition and performance specifications such as ASTM D $7566^{36}$ and Annex $\mathrm{A} 2^{37}$. 
Table 2.3: Properties of HRJ at 50 Percent Blend with Petroleum Jet Fuel ${ }^{34}$

\begin{tabular}{|l|l|l|l|l|}
\hline & $\begin{array}{l}\text { Jet A/Jet } \\
\text { A-1 }\end{array}$ & ANZ & CAL & JAL $^{\mathrm{d}}$ \\
\hline Acidity (KOH), mg/g & 0.1 & 0.002 & 0.001 & 0.002 \\
\hline Sulfur (mass fraction, \%) & 0.3 & $<0.015$ & $<0.0001$ & 0.0403 \\
\hline Flash point, ${ }^{\circ} \mathrm{C}$ & 38 & 45 & 45 & 44.5 \\
\hline Density at $15^{\circ} \mathrm{C}, \mathrm{kg} \mathrm{m}^{-3}$ & 775 to 840 & 779 & 780 & 789 \\
\hline Freezing point, ${ }^{\circ} \mathrm{C}$ & $-40 /-47$ & -62.5 & -61 & -55.5 \\
\hline Viscosity $-20^{\circ} \mathrm{C}, \mathrm{mm}^{2} / \mathrm{s}$ & 8 & 3.606 & 3.817 & 4.305 \\
\hline $\begin{array}{l}\text { Net heat of combustion, } \\
\mathrm{MJ} / \mathrm{kg}\end{array}$ & 42.8 & 43.6 & 43.7 & 43.5 \\
\hline $\mathrm{JFTOT}^{\mathrm{e}}, \mathrm{Temperature}{ }^{\circ} \mathrm{C}$ & 260 & 300 & 300 & 300 \\
\hline Existent gum, $\mathrm{mg} / \mathrm{ml}$ & 0.07 & 0.01 & $<0.01$ & $<0.01$ \\
\hline
\end{tabular}

${ }^{\mathrm{a}}$ Jet A: US specification for jet fuel; Jet A-1: international specification for jet fuel outside of North America

${ }^{\mathrm{b}}$ ANZ: Air New Zealand

${ }^{\mathrm{c}} \mathrm{CAL}$ : Continental Airlines

dJAL: Japan Airlines

${ }^{\mathrm{e} J F T O T: ~ J e t ~ F u e l ~ T h e r m a l ~ O x i d a t i o n ~ T e s t e r ~}$ 
Table 2.4: Commercial Aviation Test Flights

\begin{tabular}{|c|c|c|c|}
\hline Airline & Partner & Date & Feed \\
\hline $\begin{array}{c}\text { Air New Zealand } \\
\text { (ANZ) }\end{array}$ & $\begin{array}{c}\text { Honeywell/UOP, Boeing, } \\
\text { Rolls Royce, Terasol }\end{array}$ & Dec 30, 2008 & Jatropha \\
\hline $\begin{array}{c}\text { Continental } \\
\text { Airlines (CAL) }\end{array}$ & $\begin{array}{c}\text { Honeywell/UOP, Boeing, } \\
\text { CFM, Sapphire }\end{array}$ & Jan 7, 2009 & $\begin{array}{c}\text { Jatropha/ } \\
\text { Algal }\end{array}$ \\
\hline $\begin{array}{c}\text { Japan Airlines } \\
\text { (JAL) }\end{array}$ & $\begin{array}{c}\text { Honeywell/UOP, Boeing, } \\
\text { Pratt \& Whitney, Sustainable } \\
\text { Oils }\end{array}$ & Jan 30, 2009 & $\begin{array}{c}\text { Jatropha/ } \\
\text { Algal }\end{array}$ \\
\hline KLM & Honeywell/UOP, Boeing, GE & Nov 23, 2009 & Camelina \\
\hline TAM, Brazil & $\begin{array}{l}\text { Honeywell/UOP, Airbus, } \\
\text { CFM }\end{array}$ & Nov 23, 2010 & Jatropha \\
\hline Interjet, Mexico & $\begin{array}{l}\text { Honeywell/UOP, Airbus, } \\
\text { CFM }\end{array}$ & Apr 01, 2011 & Jatropha \\
\hline $\begin{array}{c}\text { Honeywell, USA } \\
\text { (Corporate Jet) }\end{array}$ & $\begin{array}{c}\text { Honeywel1/UOP, Gulfstream, } \\
\text { Sustainable Oils }\end{array}$ & Jun 17, 2011 & Camelina \\
\hline Boeing, USA & $\begin{array}{c}\text { Honeywell/UOP, Boeing, } \\
\text { Sustainable Oils }\end{array}$ & Jun 19, 2011 & Camelina \\
\hline Interjet, Mexico & Honeywell/UOP, Airbus, & Jul 21, 2011 & Jatropha \\
\hline Aeroméxico & Honeywell/UOP, Boeing, GE & Aug 2, 2011 & Jatropha \\
\hline
\end{tabular}

The yield of RD (and HRJ) has been shown to be relatively insensitive to feedstock source. Close to $100 \%$ (volume fraction) yield of deoxygenated diesel range product was observed in UOP pilot data of various feedstocks, including soybean, jatropha, canola and tallow ${ }^{33}$. Based on similarities in oil properties such as oxygenate content and current engineering correlations, conversion of pennycress oil is expected to achieve similar yields when the same technology is applied (Ellig YE, UOP internal correspondence November 11, 2011). 


\subsubsection{Research objective}

Life cycle assessment (LCA) studies have been conducted to estimate the life cycle GHG emissions from renewable diesel and aviation fuels ${ }^{38-40}$, but pennycress is a relatively new biomass feedstock which has not been thoroughly investigated yet. One goal of this study is to determine the life cycle GHG emissions, cumulative energy demand (CED), and fossil energy demand (FED) of pennycress-derived RD and HRJ fuel as produced by the Ecofining ${ }^{\mathrm{TM}}$ and Renewable Jet Fuel processes, and compute the GHG savings per MJ of fuel compared to petroleum-based jet fuels and diesel. Another goal is to explore the impacts of model assumptions and parameter uncertainty in the calculation of GHG emissions. A variety of methodology approaches will be investigated, such as system expansion, energy allocation, and market value allocation because different international biofuels organizations recommend different approaches for the co-products within the system. A series of scenario analyses will probe the effects of various LCA inputs: $\mathrm{N}$ fertilizer application rate, $\mathrm{N}$ content in crop residues, source of hydrogen for oil upgrading, and direct land use change (dLUC).

\subsection{LCA methods: Scope, Functional Unit, Inventory, and Impact Assessment} The baseline pathway diagram of this LCA study is illustrated in Figure 2.4. The scope of this study encompasses the entire life cycle from pennycress cultivation and raw materials acquisition through the production and use of the fuels in vehicles and aircraft operations. The pennycress is grown in the Midwestern United States as a winter annual. After harvesting, the pennycress seeds are transported by truck to a centralized processing facility where the oil is recovered and a de-oiled meal co-product is generated for use as a secondary energy source or animal feed. The oil is then transported $322 \mathrm{~km}$ by rail to a hydroprocessing plant as a source of renewable feedstock for HRJ and RD production. Transport of the final fuel product to market was included over a distance of $120 \mathrm{~km}$ by truck. Inventory data for pennycress cultivation, transportation, and oil recovery were provided by Arvens Technology Inc. Data for conversion of the pennycress oil to HRJ and RD were obtained from engineering design data supplied by 
UOP. All the inventory data were assembled based on energy content of $1 \mathrm{MJ}$ of final fuel product, which was the functional unit of this LCA.

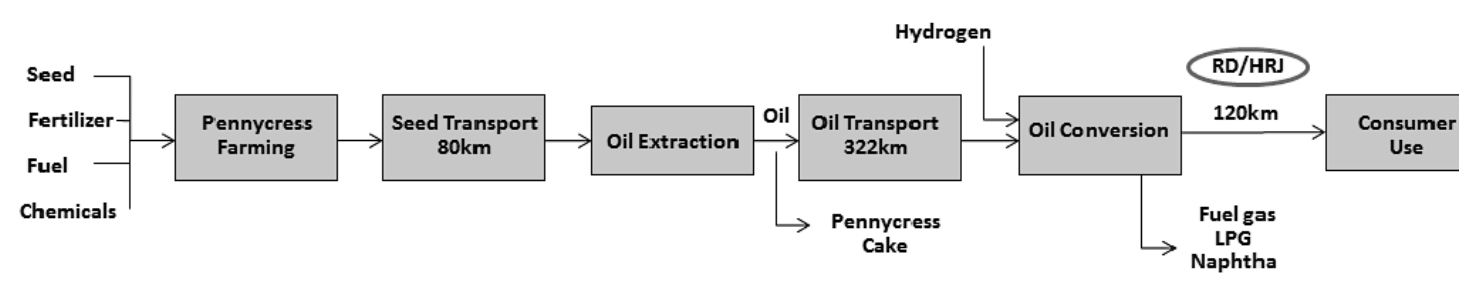

Figure 2.4: Pathway diagram of pennycress RD and HRJ LCA study

The software used for this LCA was SimaPro $7.2^{41}$, which contains a large database of inventory data for material, chemical, and energy inputs. Inventory data is from the Ecoinvent database ${ }^{42}$, which is comprised of mostly European data that has close technology relevance to U.S. production, but whenever possible, these ecoprofiles were adjusted for U.S. conditions; for example electricity generation was modeled using a combination of current U.S. grid electricity primary energy sources ${ }^{43}$. The GHG impact assessment method used was the IPCC 2007 GWP 100a V1.01 method ${ }^{44}$ whose output is in $\mathrm{g} \mathrm{CO}_{2}$ equivalents for all of the GHG emissions using global warming potentials (GWP) of 1 for $\mathrm{CO}_{2}, 25$ for $\mathrm{CH}_{4}, 298$ for $\mathrm{N}_{2} \mathrm{O}$. GWPs for refrigerants, solvents, and other compounds were included in the analysis. The cumulative and fossil energy demand are calculated by using Cumulative Energy Demand 1.07 method in the SimaPro, the results include non-renewable fossil (coal, oil, natural gas) and nuclear energy use, renewable biomass energy use, and other renewable energy sources, which include solar, geothermal, and hydroelectric power, which are given as the amount of process energy inputs (MJ) along the life cycle per unit of energy in the fuel products.

\subsubsection{Pennycress cultivation and seed transport}

The data inputs for chemicals and fuels consumed during pennycress cultivation and harvest stages provided by Arvens Inc. are tabulated in Table 2.5. Pennycress seeds are broadcasted using an airplane into standing corn field prior to corn harvesting. The aviation fuel profile was created in SimaPro using GHG burdens of petroleum jet fuels 
obtained from a recent U.S. Department of Energy (DOE) study ${ }^{45}$. The nutrients removed by pennycress harvesting are assumed to be compensated by applying fertilizers to the field as part of a general nutrient management strategy by the farmers. The elemental composition of harvested seed was provided by the A\&L Great Lakes Laboratories and shown in Table 2.6. Pennycress requires limited chemical inputs for productive cultivation. Insect pressure is insignificant due to its natural chemistry as a member of the mustard family and the temperatures of the growing season thus limiting an insecticide requirement. A pennycress seed yield of $2242 \mathrm{~kg} / \mathrm{ha}$ was assumed in this study, which is within the range of seed yields reported in the cited literature ${ }^{10-12}$. Pennycress seeds are harvested by traditional combines with grain heads when mass fraction of seed moisture reaches $12 \%$ in June. After harvesting, the pennycress seeds are transported by truck to the oil processing facility, distance of $80 \mathrm{~km}$ has been chosen to maximize logistics while providing sufficient production acreage. 
Table 2.5: Energy and Fertilizer Inputs per kg Seeds for Cultivation and Harvesting (Arvens)

\begin{tabular}{|c|c|c|c|}
\hline $\begin{array}{l}\text { Diesel, low-sulfur, at } \\
\text { regional storage }\end{array}$ & 0.00382 & $\mathrm{~kg}$ & harvest machine \\
\hline $\begin{array}{l}\text { Ammonium sulfate, as } \mathrm{N} \text {, } \\
\text { at regional storehouse }\end{array}$ & 0.038 & $\mathrm{~kg}$ & \\
\hline Fertilizer $\left(\mathrm{P}_{2} \mathrm{O}_{5}\right)$ & 0.019 & $\mathrm{~kg}$ & \\
\hline $\begin{array}{l}\text { Potassium chloride, as } \\
\mathrm{K}_{2} \mathrm{O} \text {, at regional storehouse }\end{array}$ & 0.014 & $\mathrm{~kg}$ & \\
\hline $\begin{array}{l}\mathrm{N}_{2} \mathrm{O} \text { emission from } \mathrm{N} \\
\text { fertilizer }\end{array}$ & $0.038 * 0.01325 * 44 / 28$ & $\mathrm{~kg}$ & $\begin{array}{c}1.325 \% \text { of } \mathrm{N} \text { in } \\
\text { fertilizer emitted } \\
\text { as } \mathrm{N} \text { in } \mathrm{N}_{2} \mathrm{O}\end{array}$ \\
\hline $\begin{array}{l}\mathrm{N}_{2} \mathrm{O} \text { emission from crop } \\
\text { residues }\end{array}$ & $0.0076 * 0.01225 * 44 / 28$ & $\mathrm{~kg}$ & $\begin{array}{c}1.225 \% \text { of } \mathrm{N} \text { in } \\
\text { crop residues } \\
\text { emitted as } \mathrm{N} \text { in } \\
\mathrm{N}_{2} \mathrm{O}\end{array}$ \\
\hline $\begin{array}{l}\mathrm{CO}_{2} \text { emission from diesel } \\
\text { combustion }\end{array}$ & $0.00382 * 3.172$ & $\mathrm{~kg}$ & $\begin{array}{c}\text { Diesel } \\
\text { combustion } \\
\text { emission } 3.172 \mathrm{~kg} \\
\mathrm{CO}_{2} \mathrm{eq} / \mathrm{kg}\end{array}$ \\
\hline $\begin{array}{l}\text { GHG emissions from } \\
\text { petroleum aviation fuel }\end{array}$ & $0.001 * 88.01 * 44$ & $\mathrm{~g} \mathrm{CO}_{2} \mathrm{eq}$ & $\begin{array}{c}\text { Airplane fuel } \\
\text { requirement } 0.001 \\
\mathrm{~kg} \mathrm{~kg}^{-1} \text {, jet fuel } \\
\text { emission } 88.01 \mathrm{~g} \\
\mathrm{CO}_{2} \text { eq/MJ }\end{array}$ \\
\hline
\end{tabular}


Table 2.6: Elemental composition data of harvested seed (A\&L Great Lakes Laboratories)

\begin{tabular}{|l|l|l|}
\hline & $\begin{array}{l}\text { Analysis result } \\
(\text { dry basis })\end{array}$ & $\begin{array}{l}\text { Crop nutrient removal } \\
(\mathrm{kg} / \mathrm{kg} \text { seeds })\end{array}$ \\
\hline Nitrogen, $\mathrm{N}$ & $3.810 \%$ & 0.038 \\
\hline Sulfur, S & $0.895 \%$ & 0.009 \\
\hline Phosphorus, $\mathrm{P}$ & $0.839 \%$ & $0.019\left(\mathrm{P}_{2} \mathrm{O}_{5}\right)$ \\
\hline Potassium, K & $1.140 \%$ & $0.014\left(\mathrm{~K}_{2} \mathrm{O}\right)$ \\
\hline
\end{tabular}

$\mathrm{N}_{2} \mathrm{O}$ emission (both direct and indirect) from pennycress farming was estimated using emission factors from the Intergovernmental Panel on Climate Change (IPCC). IPCC ${ }^{46}$ estimates conversion rate of $1 \%$ (mass fraction of $\mathrm{N}$ in the various nitrogen-containing compounds) for direct $\mathrm{N}_{2} \mathrm{O}$ emissions from soil, indirect $\mathrm{N}_{2} \mathrm{O}$ emission include volatilization of $\mathrm{NH}_{3}$ and $\mathrm{NOx}$ from the soil to the air and leaching and runoff of nitrate into water streams. Volatilization amount for soil nitrogen is $10 \%$, with $1 \%$ of volatilized nitrogen converted from $\mathrm{N}$ in volatilized nitrogen compounds to $\mathrm{N}$ in $\mathrm{N}_{2} \mathrm{O}$ emissions. The leaching and runoff rate of soil nitrogen is estimated to be $30 \%$, with $0.75 \%$ of $\mathrm{N}$ converted to $\mathrm{N}$ in $\mathrm{N}_{2} \mathrm{O}$ emission. Therefore, $1.325 \%(1 \%+10 \% \times 1 \%+30$ $\% \times 0.75 \%)$ of $\mathrm{N}$ in fertilizer and $1.225 \%(1 \%+30 \% \times 0.75 \%)$ of $\mathrm{N}$ in crop residues are emitted to atmosphere as $\mathrm{N}$ in $\mathrm{N}_{2} \mathrm{O}$. The total amount of $\mathrm{N}$ in crop residues (aboveground and belowground) per kg of pennycress seed harvested can be calculated by the IPCC Tier 1 approach $^{46}$, as shown in Equation 2.1. We used the default factors of "grains" (one crop type listed in the IPCC document) to represent pennycress because crops in this major crop type have the most similar properties (plant size and growth habits) compared to pennycress. The ratio of aboveground residues to harvested yield is 1.09 , and aboveground biomass has a nitrogen mass content of $0.6 \%$. The mass of belowground biomass is approximately $22 \%$ of that of aboveground biomass, with a nitrogen mass content of $0.9 \%$. A range of $\mathrm{N}$ content in crop residues were also applied to investigate their impact on the life cycle GHG emissions, the results are given in the sensitivity analyses section below. 
$0.88($ dry matter fraction $) *(1.09 * 0.006+0.22 * 1.09 * 0.009)=0.0076 \mathrm{~kg} \mathrm{~kg}^{-1}$

Eq.2.1

\subsubsection{Oil extraction and upgrading}

The pennycress oil accounts for $34 \%$ of total seed mass, of which $29 \%$ is extracted by mechanical crushing using the Dox/Hivex TM System with a seed capacity of $100 \mathrm{t} \mathrm{d}^{-1}$ to $250 \mathrm{t} \mathrm{d}^{-1}$; the remainder residue oil (5\%) is left in the presscake. $59.62 \mathrm{kWh}$ (including presses, conveyor, cake grinder, air compressor, etc) of electricity (assuming Illinois grid $\operatorname{mix}^{47}$ ) is consumed to crush one $\mathrm{t}$ of pennycress seed. Temperature of $82.2^{\circ} \mathrm{C}$ is achieved by friction and compression, which is high enough to denature the enzyme myrosinase. Solvent extraction operation is not considered as it must operate on very large volumes (beyond the supply of pennycress) to be economically feasible. If solvent extraction is applied, there is a first crush to fracture the seed hull and break oil bodies and release some oil. During this first crush temperatures do reach the critical deactivation temperature. The oil is transported $322 \mathrm{~km}$ by rail to a centralized biofuels production plant to produce HRJ and RD.

Pennycress oil is catalytically converted to renewable fuels by combination of hydrogenation, deoxygenation, isomerization and hydrocracking reactions. The $\mathrm{H}_{2}$ required in these reactions is assumed to be produced from natural gas in a steam methane reforming (SMR) plant since it is the most common method ${ }^{48}$. Electricity (U.S grid mix $^{47}$ assumed for production in the U.S) and natural gas are also consumed in the process to power pumps and compressors and provide the process heat requirement. Small amounts of other renewable fuels are also produced as co-products, including fuel gas, naphtha and liquefied "petroleum" gas (LPG). Conversion inputs for our study were obtained from confidential UOP design data. Similar inputs have been reported by others in published studies ${ }^{38,39}$, which are summarized in Tables 2.7 and 2.8 to provide a reasonable degree of tranparency without comprising confidential data. The final fuel products (RD and HRJ) are assumed to be distributed to consumers within a radius of 120 $\mathrm{km}$, which was estimated by the average distance between the fuel terminals ${ }^{49}$ in the Midwest states (Iowa, Illinois and Indiana). 
Table 2.7: Inputs and outputs of RD production (per kg of $\mathrm{RD}$ )

\begin{tabular}{|l|l|l|l|l|}
\hline & \multicolumn{3}{l|}{ renewable oils $^{38}$ a } & soybean oil $^{39}$ \\
\hline & low & baseline & high & \\
\hline Inputs & & & & \\
\hline Oil (kg) & 1.21 & 1.19 & 1.16 & 1.17 \\
\hline $\mathrm{H}_{2}(\mathrm{~kg})$ & 0.018 & 0.0323 & 0.044 & 0.032 \\
\hline electricity (kWh) & 0.045 & 0.053 & 0.061 & 0.061 \\
\hline natural gas (kJ) & 250.8 & 247.2 & 242 & 244.1 \\
\hline Co-products & & & & \\
\hline HRJ (kJ) & & & & \\
\hline propane mix (kJ) & 1115.3 & 2611.4 & 2690.9 & 2548.6 \\
\hline LPG (kJ) & & & & \\
\hline naphtha (kJ) & & & & \\
\hline
\end{tabular}

a: renewable oils include pure vegetable oils, recycles products, animal fats and pyrolysis oil b: confidential data not shown 
Table 2.8: Inputs and outputs of HRJ production (per kg of HRJ)

\begin{tabular}{|l|l|l|l|}
\hline & \multicolumn{3}{l|}{ renewable oils ${ }^{38}$ a } \\
\hline & low & baseline & high \\
\hline Inputs & & & \\
\hline Oil (kg) & 1.73 & 1.71 & 1.67 \\
\hline $\mathrm{H}_{2}(\mathrm{~kg})$ & 0.037 & 0.058 & 0.075 \\
\hline electricity (kWh) & 0.032 & 0.042 & 0.052 \\
\hline natural gas (kJ) & 179.7 & 193.1 & 204.9 \\
\hline Co-products & & & \\
\hline RD (kJ) & & & \\
\hline propane mix (kJ) & 1601.5 & 3784.7 & 3863.4 \\
\hline LPG (kJ) & & & \\
\hline naphtha (kJ) & 19944.3 & 19942.9 & 19991 \\
\hline
\end{tabular}

a renewable oils include pure vegetable oils, recycles products, animal fats and pyrolysis oil b: confidential data not shown

\subsubsection{Co-products credits}

Various co-products are produced during the life cycle of pennycress RD and HRJ, including protein products such as presscake, and energy products such as renewable fuel gas, renewable LPG and steam. Both system expansion and allocation approaches were applied to account for these co-products. Due to the multiple applications of the various co-products, inventory can be allocated on the basis of both energy content and market value, and therefore a sensitivity analysis was included to investigate the impacts of various allocation methods, which is a required allocation principle stated in the ISO $14041^{50}$.

\subsubsection{System expansion (displacement) approach}

The ISO $14041^{50}$ recommends using system expansion approach to deal with coproducts. The U.S.EPA ${ }^{51}$ also states that this is the preferred method for life-cycle energy and GHG analyses in its analysis of the Renewable Fuel Standard Program. This method was applied to assign the energy and GHG credits to the co-products. Based on promising 
study with sheep ${ }^{21}$, the pennycress cake is envisioned by Arvens as animal feed, displacing soybean meal. The soybean meal credit of $-0.405 \mathrm{~kg} \mathrm{CO}_{2} \mathrm{eq} / \mathrm{kg}$ was calculated based on a USDA report ${ }^{52}$ for soybean cultivation, and NREL biodiesel study $^{53}$ for soybean transport, milling/crushing impacts. Renewable fuel gas, LPG and naphtha produced along with the diesel/jet products were assumed to displace natural gas, propane and petroleum naphtha, respectively. Renewable diesel is produced as a co-

product in the HRJ production process, and it is assumed to displace petroleum diesel. The credits were estimated using ecoprofiles in SimaPro7.2 and avoided combustion emissions.

\subsubsection{Energy and Market Value Allocation}

In the energy allocation (EA) scenario, all the co-products along the life cycle, including the presscake produced after oil extraction, and renewable fuels produced in the biofuels production process, were considered as energy sources. The energy allocation method was used in accordance with the European Renewable Energy Directive ${ }^{54}$ to distribute the environmental burden among various products and co-products along the life cycle. At the pennycress oil extraction stage, inventory data from pennycress cultivation up to and including oil extraction were allocated to pennycress oil and co-product presscake. Allocation to oil $=\left(\mathrm{A} * \mathrm{LHV}_{\mathrm{A}}\right) /\left(\mathrm{A} * \mathrm{LHV}_{\mathrm{A}}+\mathrm{B} * \mathrm{LHV}_{\mathrm{B}}\right)$, where $\mathrm{A}$ is the mass flow rate of output oil from the seed extraction step, B is mass flow rate of cake, LHV is lower heating value, and subscripts A and B are pennycress oil and cake, respectively. A similar calculation was performed at the RD and HRJ production stages considering the coproducts produced at that stage. The allocation factors of all the products and co-products are shown in Table 2.9.

In the market value allocation (MVA) scenario, the energy and emission burdens of products and co-products along the pennycress RD and HRJ life cycle were allocated based on their market values. A value of $200 \$ / t$ for the pennycress presscake is assumed based on the $30 \%$ crude protein content ${ }^{21}$ which is equivalent to the corn dried distillers grains currently selling for the same price. The market value of pennycress oil was 
assumed to be the same as soybean oil (we have been told by biodiesel producers that they will offer prices equal to soybean oil due to pennycress's perceived benefit in cold flow properties). The market prices of soybean oil, RD, HRJ, fuel gas, LPG were obtained from the GREET model ${ }^{55}$. Price of naphtha was set as $1 \$ \mathrm{~kg}^{-1}$ based on ICIS Pricing $^{56}$. Table 2.9 summarizes the energy content and market value of all the products and co-products in the life cycle of RD and HRJ production. The LHV and prices of pennycress oil and presscake were provided by Arvens, Inc. The LHV of fuel products were provided by UOP.

Table 2.9: LHV, market values, and allocation factors (as \%) of products and co-products

\begin{tabular}{|c|c|c|c|c|}
\hline & LHV (MJ/kg) & $\begin{array}{l}\text { Market value } \\
(\$ / \mathrm{kg})\end{array}$ & $\begin{array}{l}\text { Energy } \\
\text { allocation } \\
\text { factor }(\%)\end{array}$ & $\begin{array}{l}\text { Market value } \\
\text { allocation } \\
\text { factor }(\%)\end{array}$ \\
\hline \multicolumn{5}{|l|}{ Oil extraction } \\
\hline Pennycress oil & 36.6 & 0.846 & 44.6 & 63.3 \\
\hline Pennycress cake & 18.6 & 0.22 & 55.4 & 36.7 \\
\hline \multicolumn{5}{|l|}{ Fuel production } \\
\hline $\mathrm{RD}$ & 44 & 1.21 & 79.1 & 85.6 \\
\hline HRJ & 44 & 1.21 & 51.8 & 57.8 \\
\hline Fuel gas & 46.9 & 0.383 & & \\
\hline LPG & 46.6 & 0.663 & & \\
\hline Naphtha & 44.9 & 1 & & \\
\hline
\end{tabular}

\subsection{LCA Results and discussions}

\subsubsection{GHG emissions}

The life cycle GHG emission results of pennycress RD and HRJ are benchmarked to the petroleum fuels baseline obtained from the DOE study ${ }^{45}$ in Figure 2.5. The total GHG emissions are labeled above each bar. In accordance with the EPA Renewable Fuel Standard (RFS2) ${ }^{51}$ and the Low Carbon Fuels Standard (LCFS) of California ${ }^{57}$, the net 
$\mathrm{CO}_{2}$ emissions of renewable fuels at the combustion stage are considered carbon neutral because $\mathrm{CO}_{2}$ is sequestered by photosynthesis during the growth of biomass. The GHG reductions of RD compared to petroleum diesel range from $56 \%$ to $85 \%$, depending on how the co-products are credited. The displacement method yields the most favorable results because of two reasons: the soy meal displaced by presscake represents a significant GHG credit, and the co-products of the conversion process have much lower carbon intensity than the fossil fuels they displace. Pennycress cultivation is the leading GHG contributor. $\mathrm{N}$ fertilizer and $\mathrm{N}_{2} \mathrm{O}$ emissions from fertilizer and crop residues account for the majority ( $>85 \%)$ of cultivation emissions. Fuel production is second largest GHG contributor, the emissions are mainly from $\mathrm{H}_{2}$ production, and other utilities such as electricity and steam are responsible for approximately $10 \%$ of fuel production emissions. Oil extraction is the third largest component, which accounts for 1.4 to $2.3 \mathrm{~g}$ $\mathrm{CO}_{2}$ eq/MJ when allocation methods were applied, but the emission could increase if solvent extraction is employed in the future. The impact of electricity for oil crushing on total GHG emissions is very low, therefore, electricity grid profiles from other Midwest states were not included in the sensitivity analyses. For the MVA method, because of the high market value of pennycress oil, the majority of emission burdens from cultivation and oil extraction are allocated to the oil, thus the life cycle GHG emissions of RD calculated by this method is the highest among the three methods. The results of pennycress HRJ show a similar trend. The HRJ results show slightly less GHG reductions compared to RD for the allocation approach, mainly because more pennycress oil, and other materials such as hydrogen and water, are required to produce the same amount of HRJ. However, a larger amount of oil requirement also means more presscake produced per MJ of HRJ. In addition, the HRJ production process yields more co-products (fuel gas, propane and naphtha), offering more $\mathrm{CO}_{2}$ credits when displacement approach was applied. 


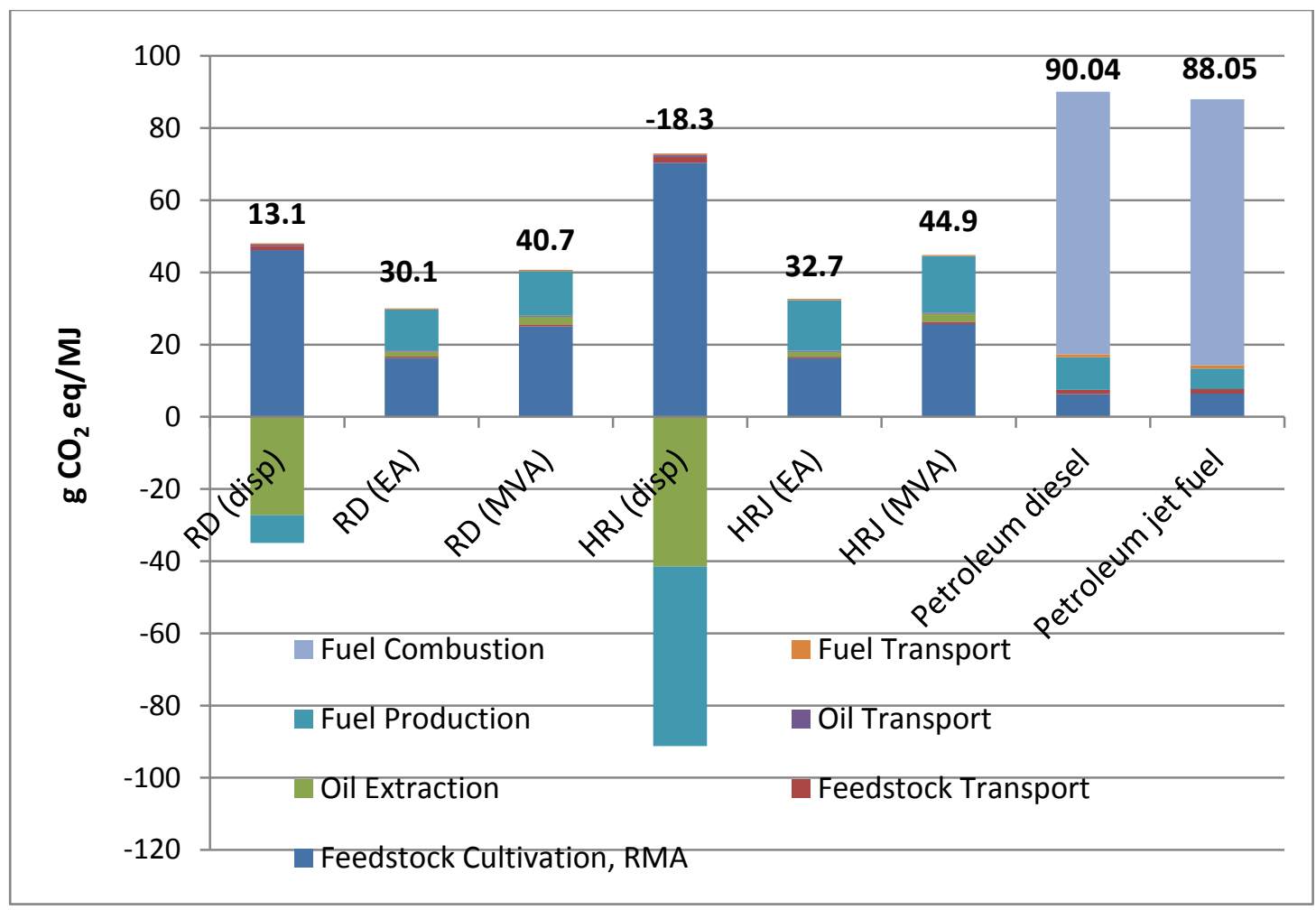

Figure 2.5: Life cycle GHG emissions of pennycress RD and HRJ, comparing to petroleum fuels.

\subsubsection{Energy demand results (CED; FED)}

Figure 2.6 shows the CED results of pennycress-derived RD and HRJ, comparing to the petroleum baseline. The net energy demand results are labeled above each bar. The CED consists of four parts; non-renewable fossil and nuclear energy use, renewable biomass energy use, and other renewable energy sources, which include solar, geothermal, and hydroelectric power. The total energy demand of RD and HRJ calculated by energy allocation method are comparable to their petroleum counterparts, while the other two methods generate higher CED results. For the market allocation method, more energy flow is assigned to the pennycress oil because of its higher price than the co-product presscake. Thus the final fuel products have higher CED than the results generated by the energy allocation method. But the majority of the energy demands are from renewable biomass, the renewable fuels require substantially less fossil energy than petroleum fuels through the life cycle, as shown in Figure 2.7. 


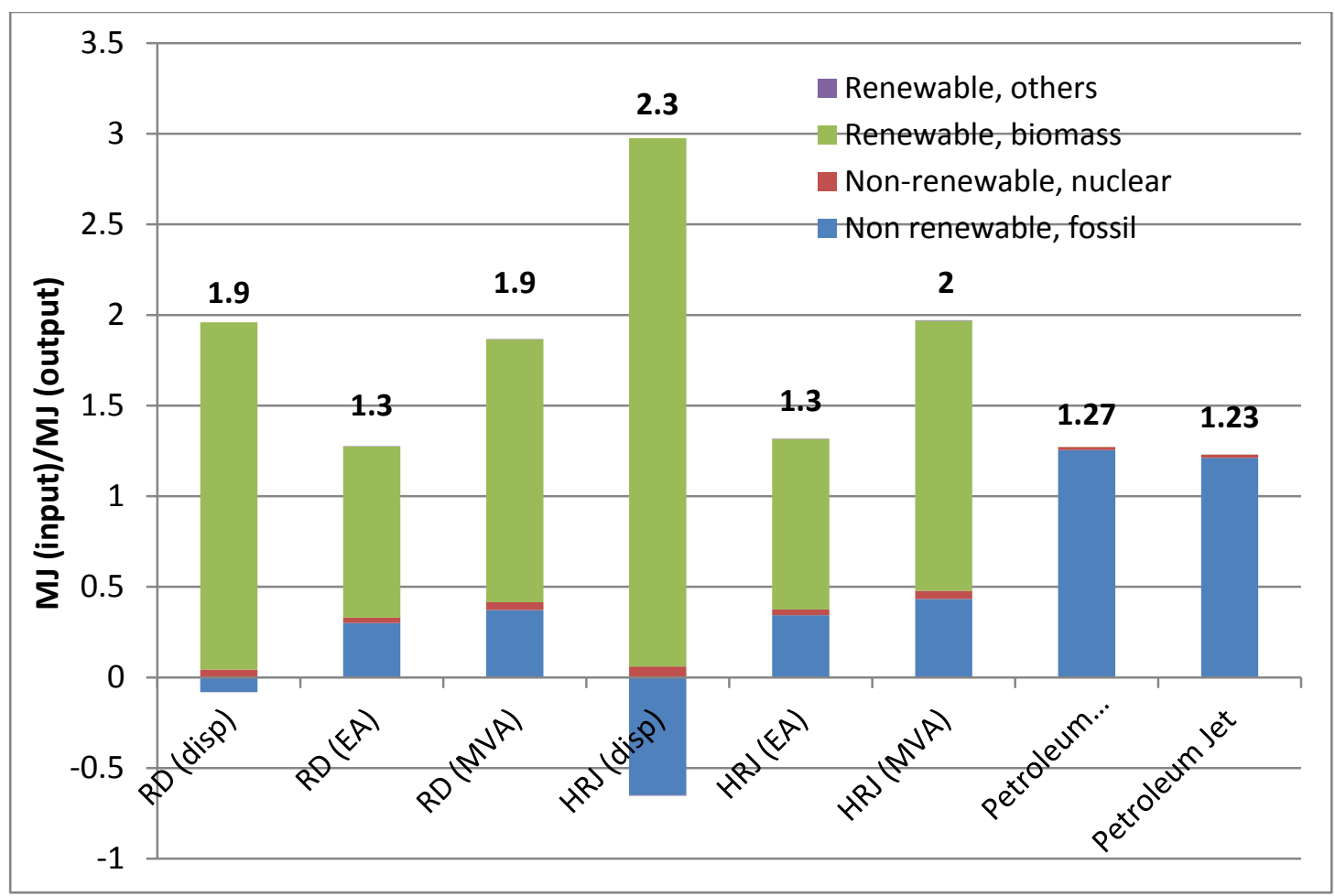

Figure 2.6: The CED results of pennycress RD and HRJ, compared to petroleum fuels.

When analyzing the FED impacts, it is worthwhile to note at which point in the processes that the energy is actually consumed. Therefore the FED has been broken into seven process stages; cultivation/RMA (raw material acquisition), feedstock transportation, oil extraction and transportation, fuel production, distribution, and use. For petroleum diesel and jet, most of the fossil energy is embodied in the fuel itself, as shown by the large fuel use segment in their bars on Figure 2.7. For the renewable fuels, fuel production stage is responsible for most of the fossil energy use, because of the electricity and natural gas used to power the oil-to-biofuel conversion process. Cultivation is the second largest contributor due to the use of petroleum diesel and aviation fuel. 


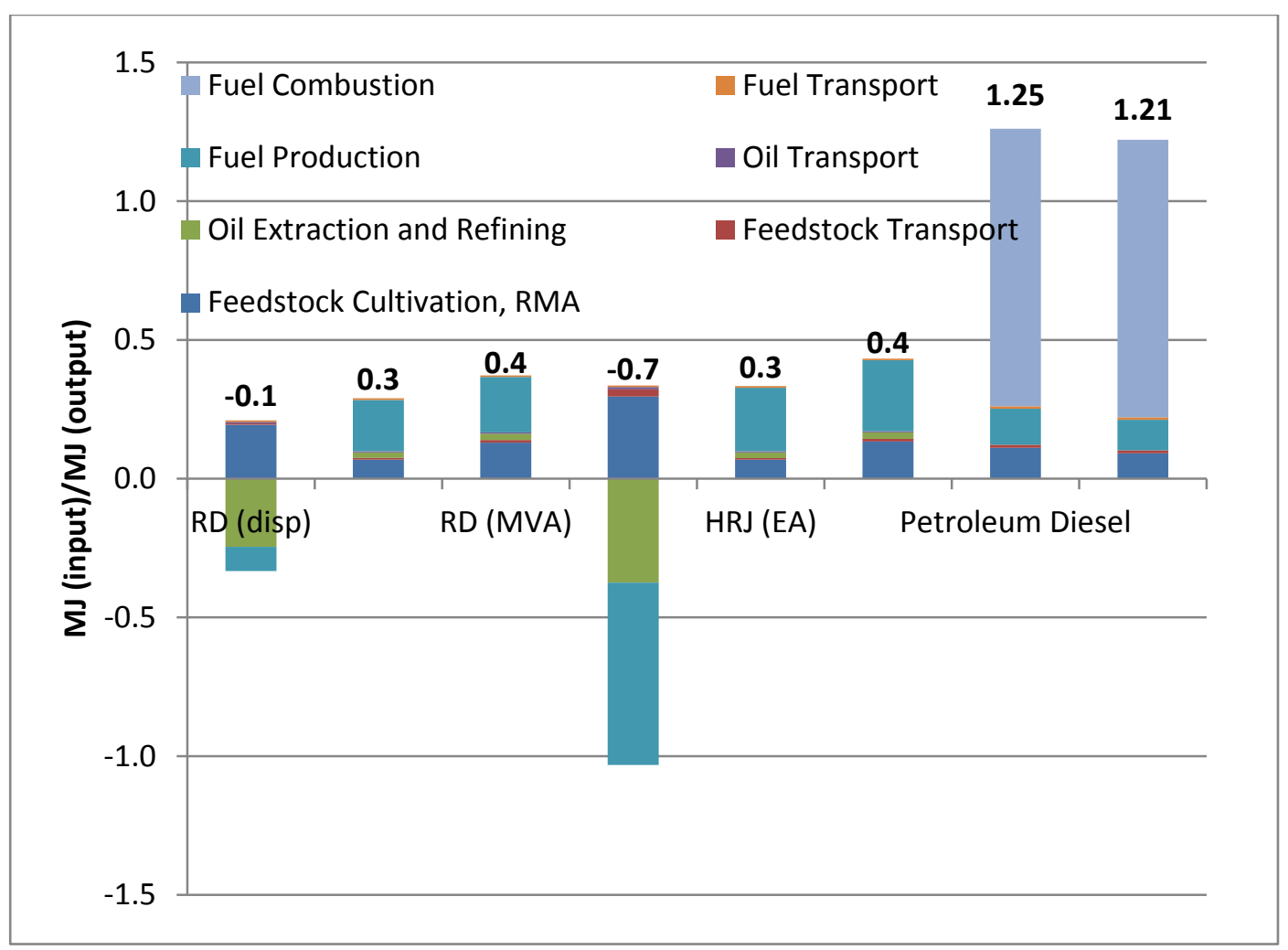

Figure 2.7: The FED results of pennycress RD and HRJ, compared to petroleum fuels.

\subsection{Sensitivity analyses}

\subsection{1. $\mathrm{N}$ fertilizer application rate}

In the base case study, ammonium sulfate fertilizer is used to meet both nitrogen and sulfur requirement. The amount of fertilizer was calculated by the elemental composition of pennycress seeds. Because $\mathrm{N}_{2} \mathrm{O}$ from $\mathrm{N}$ fertilizer and crop residues is a potent $\mathrm{GHG}$ pollutant which has a significant impact on the total GHG emission results, a sensitivity analysis on the $\mathrm{N}$ fertilizer application rate is included. The amount of $\mathrm{N}$ fertilizer applied to soil was increased and decreased by $50 \%$, respectively $(0.019 \mathrm{~kg} / \mathrm{kg}$ and $0.057 \mathrm{~kg} / \mathrm{kg})$, and then entered into the SimaPro. The life cycle GHG emissions of this sensitivity analysis are shown in the Figure 2.8. The $\mathrm{N}$ fertilizer application rate has a significant impact $(>20 \%)$ on the life cycle GHG emissions, especially when system expansion approach was applied. 


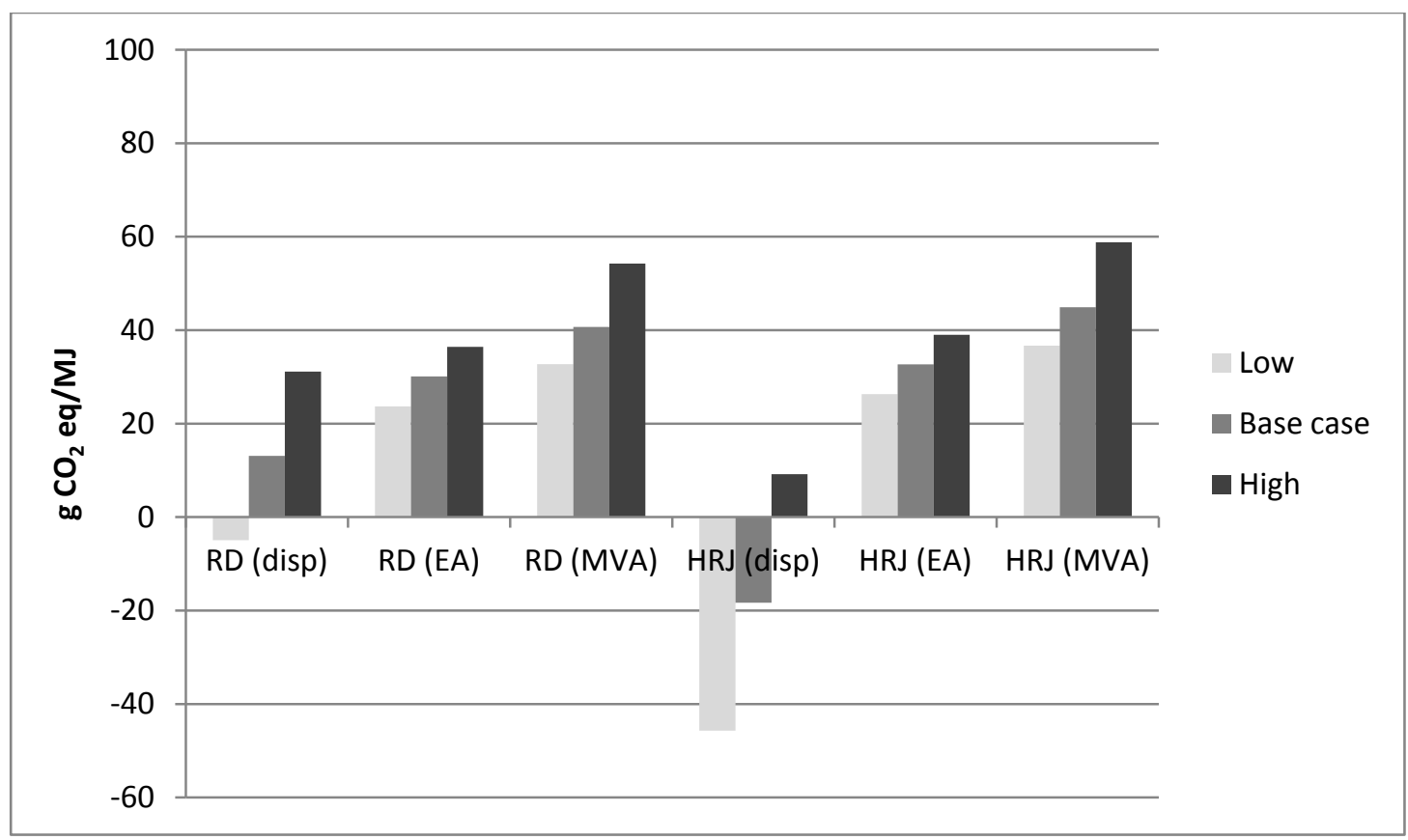

Figure 2.8: Life cycle GHG emissions of pennycress RD and HRJ, various N application rates.

\subsection{2. $\mathrm{N}$ content in crop residues}

The IPCC presents default factors to calculate crop residue nitrogen $(\mathrm{N})$ content of eight major crop types. In this scenario, $\mathrm{N}$ content in crop residues were calculated by substituting those default factors in Equation 2.1. The $\mathrm{N}$ content in seeds calculated (excluding root crops and perennial as they are very different from pennycress in crop properties) range from 0.005 to $0.01 \mathrm{~kg} / \mathrm{kg}$, and were used for this sensitivity analysis. The GHG emissions results of this sensitivity analysis are illustrated in Figure 2.9. No significant impact $(<2 \%)$ on the life cycle environmental burdens of renewable fuels were observed when allocation approaches were applied. System expansion approach yields larger variations, but the $\mathrm{GHG}$ emission reductions $\left(\mathrm{CO}_{2} \mathrm{eq}\right)$ of renewable fuels are still above the $50 \%$ threshold mandated by the $\mathrm{EPA}^{4}$. 


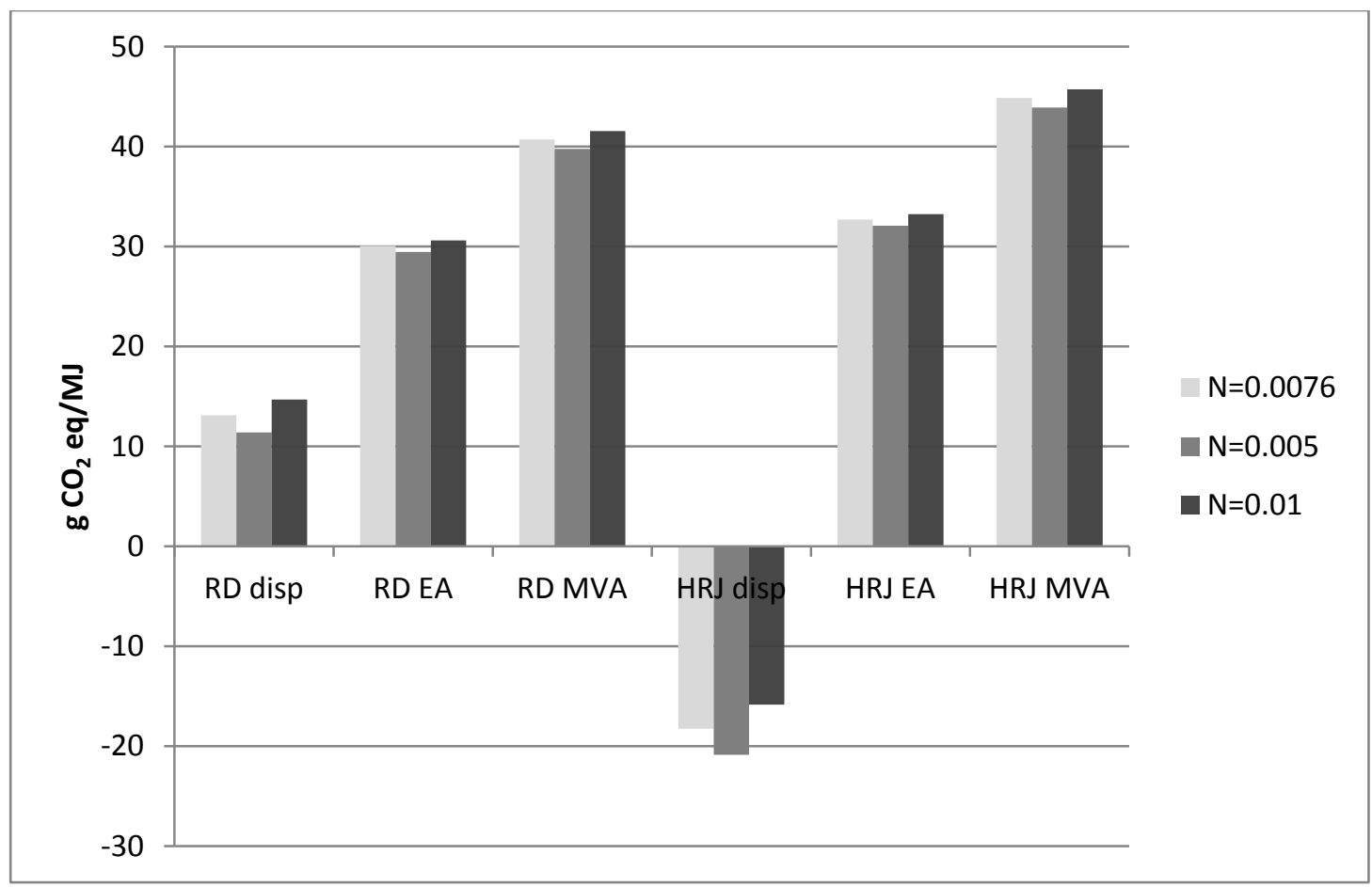

Figure 2.9: Life cycle GHG emissions of RD and HRJ with different $\mathrm{N}$ content in seed residues.

\subsubsection{Oil degumming}

The crude pennycress oil, if crushed carefully, can meet the requirements for fuel production, which has been confirmed by the fuel production companies who purchase the crude oil (sources are not disclosed due to confidential business relationships). However, gums consist mainly of phosphatides may be present in the crude vegetable oils obtained by screw pressing and solvent extraction, which can increase refining loss due to their strong emulsifying action ${ }^{58}$. In this scenario, a water degumming step was included, $0.5 \mathrm{MJ}$ of natural gas is used to heat $1 \mathrm{~kg}$ of crude pennycress oil, which was estimated by the degumming energy requirement reported in literature ${ }^{60}$. The additional energy requirement results in GHG increase of 0.22 to $0.97 \mathrm{~g} \mathrm{CO}_{2}$ eq / $\mathrm{MJ}$, depending on how the co-products are credited, which are insignificant compared to the overall GHG emissions. 


\subsection{4. $\mathrm{H}_{2}$ source (natural gas fed $S M R$ vs. integrated $\mathrm{H}_{2}$ production)}

In the baseline analysis, $\mathrm{H}_{2}$ is produced from natural gas using SMR. Data for steam reforming of methane was derived from an ecoprofile in SimaPro and augmented with $\mathrm{CO}_{2}$ released upon steam reforming. The carbon intensity $\left(\mathrm{CO}_{2}\right.$ eq $)$ of $\mathrm{H}_{2}$ was calculated as $11.4 \mathrm{~kg} / \mathrm{kg}$, similar to what was reported by Spath and Mann ${ }^{48}$. In the integrated scenario $\mathrm{H}_{2}$ is produced using co-products from the biofuel conversion process such as fuel gas, propane and butane (renewable LPG) and naphtha instead of natural gas as the steam reforming feedstock. The $\mathrm{CO}_{2}$ released in the integrated reformer is not climate active because the carbon is from a renewable biomass source. A small amount of electricity and cooling water is also used in the integrated $\mathrm{H}_{2}$ plant. The remainders of the co-products after integrated $\mathrm{H}_{2}$ production are assumed to displace their corresponding petroleum fuels. For the allocation methods, the results of this sensitivity analysis (Figure 2.10) show reduced GHG emissions ( -4 to $-6.3 \mathrm{~g} \mathrm{CO}_{2}$ eq./MJ) of pennycress $\mathrm{RD}$ and HRJ. It is because the SMR plant uses co-products of the biofuel production process as feedstocks, and these co-products have much lower GHG intensity than natural gas. However, displacement approach yields the opposite trend, the GHG emissions increase by 3.9 and $6.1 \mathrm{~g} \mathrm{CO}_{2}$ eq./MJ for $\mathrm{RD}$ and $\mathrm{HRJ}$, respectively, as it is because less GHG emissions are credited to the life cycle, due to the consumption of co-products in the integrated $\mathrm{H}_{2}$ plant. 


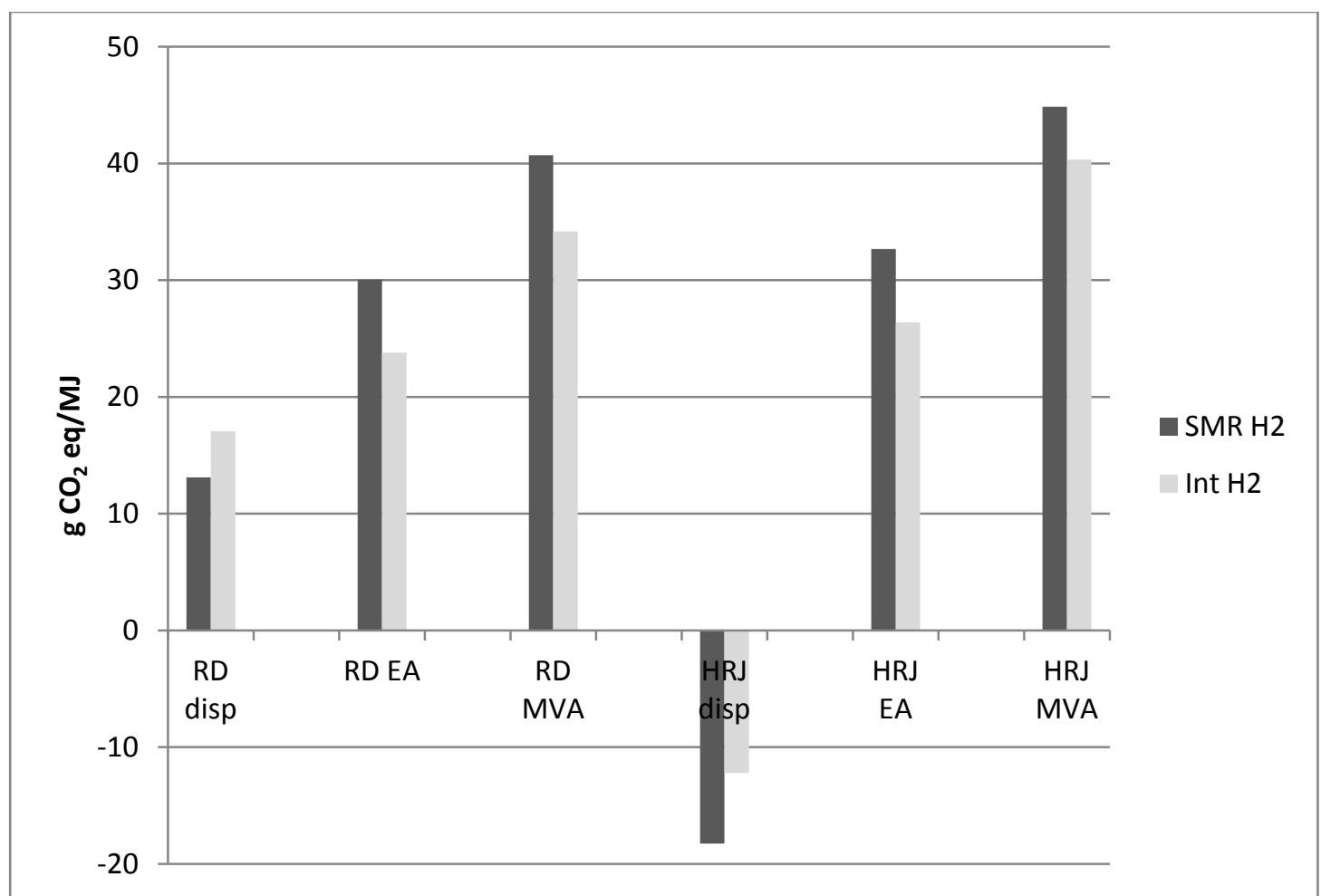

Figure 2.10: Life cycle GHG emissions of $\mathrm{RD}$ and $\mathrm{HRJ}$ with different $\mathrm{H}_{2}$ sources.

\subsubsection{Biodiesel production from pennycress oil}

Vegetable oils have been used to produce biodiesel by transesterification of these feedstocks, where in the oils react with methanol (or ethanol) in the presence of sodium hydroxide, and produce fatty acid methyl esters (FAME) and glycerin ${ }^{61}$. Pennycress has shown promise to replace edible vegetable oils as biodiesel feedstock, while the biodiesel product exhibits a high cetane number of 59.8 and excellent low temperature properties (cloud point of $-10^{\circ} \mathrm{C}$ ), meeting the United States biodiesel standard ASTM D6751 ${ }^{14}$.

A separate LCA case was developed to investigate the relative impact of biodiesel production using pennycress oil as feedstock. The inventory inputs of biodiesel production (Table 2.10) were obtained from Arvens and literatures ${ }^{52,53}$. In this case, only the energy allocation method was applied to calculate the GHG credits of co-products along the life cycle, which include presscake after oil extraction. In accordance with the European Renewable Energy Directive ${ }^{54}$, zero GHG emission was assigned to the crude 
glycerin produced by transesterification reaction. All the environmental burdens at the biodiesel production stage were allocated to biodiesel itself. Because methanol from natural gas is used to produce biodiesel, biodiesel contains fossil carbon atoms, and 0.15 $\mathrm{kg}$ of fossil $\mathrm{CO}_{2}$ is emitted when $1 \mathrm{~kg}$ of biodiesel is combusted (assuming all carbon in methanol converts to $\mathrm{CO}_{2}$ ), which converts to biodiesel combustion emission of $4.02 \mathrm{~g}$ $\mathrm{CO}_{2}$ eq./MJ. As illustrated in Figure 2.11, the pennycress oil derived biodiesel has a GHG intensity (28.4 $\mathrm{g} \mathrm{MJ}^{-1} \mathrm{CO}_{2}$ eq.) similar to pennycress $\mathrm{RD}$ produced using natural gas derived hydrogen but a higher intensity when compared to RD using integrated $\mathrm{H}_{2}$ production and energy allocation.

Table 2.10: Inventory inputs of pennycress BD production (per kg of BD)

\begin{tabular}{|c|c|c|c|}
\hline \multicolumn{3}{|l|}{ Materials/Assemblies } & \\
\hline Pennycress oil & 1.0374 & $\mathrm{~kg}$ & \\
\hline Methanol, at regional storage & 0.11 & $\mathrm{~kg}$ & \\
\hline Sodium hydroxide, at plant & 0.02 & $\mathrm{~kg}$ & \\
\hline Hydrochloric acid, at plant & 0.021 & $\mathrm{~kg}$ & \\
\hline Water, completely softened, at plant & 19.773 & $\mathrm{~kg}$ & cooling water \\
\hline Water, completely softened, at plant & 4.8 & $\mathrm{~kg}$ & chilled water \\
\hline Water, completely softened, at plant & 0.025 & $\mathrm{~kg}$ & process water \\
\hline \multicolumn{2}{|l|}{ Processes } & & \\
\hline U.S electricity mix & $7.1 / 1000 * 2.204$ & $\mathrm{kWh}$ & \\
\hline $\begin{array}{l}\mathrm{CO}_{2} \text { emission from biodiesel } \\
\text { combustion }\end{array}$ & $0.11 / 32 * 44$ & $\mathrm{~kg}$ & $\begin{array}{l}\text { Fossil C in } \\
\text { methanol }\end{array}$ \\
\hline Steam, for chemical processes, at plant & 0.258 & $\mathrm{~kg}$ & \\
\hline
\end{tabular}




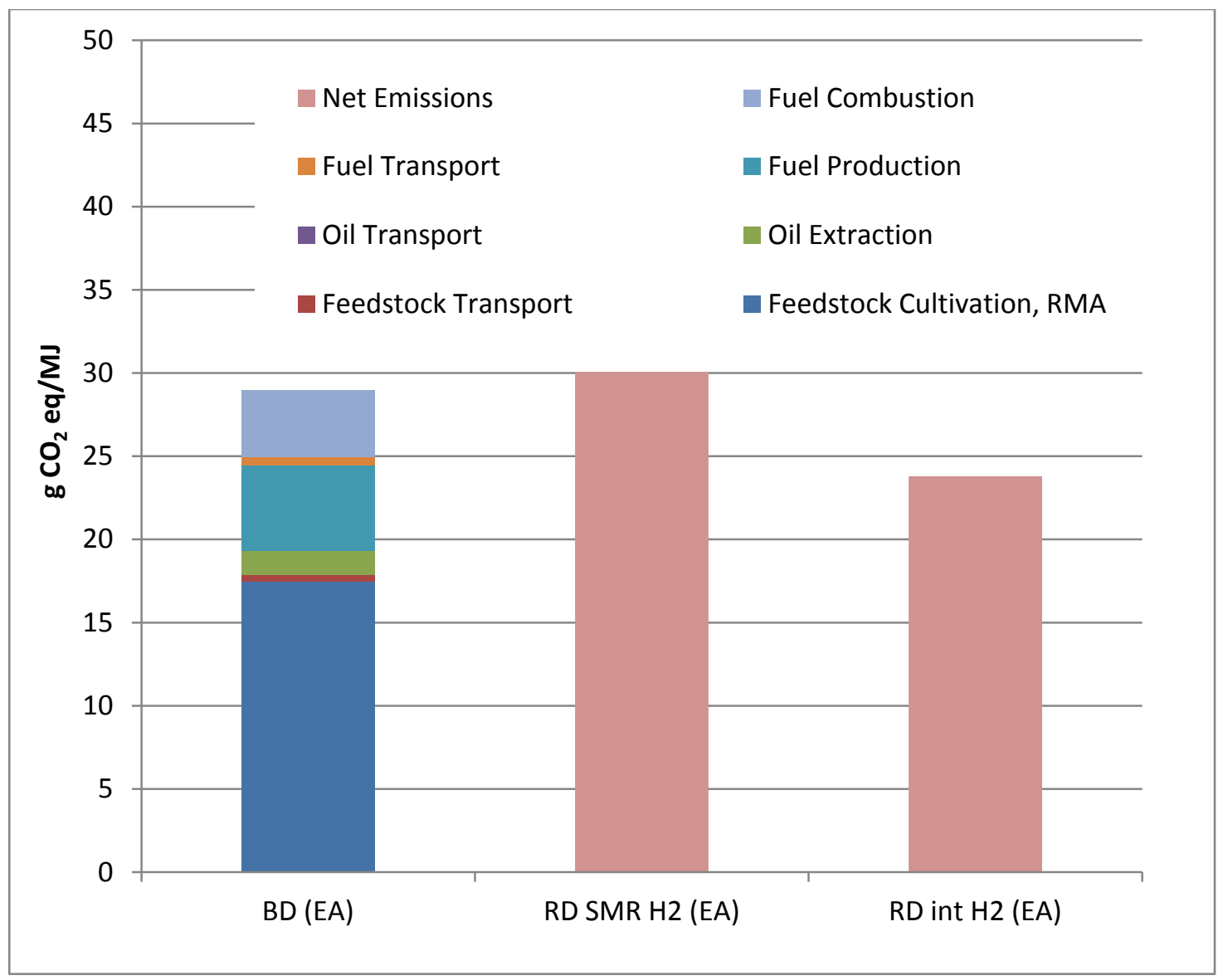

Figure 2.11: Life cycle GHG emission of pennycress oil derived biodiesel, comparing to pennycress RD.

\subsubsection{Land use change (LUC)}

In this study we cite evidence that the winter annual and double cropping strategy for the production of pennycress does not compete with food crops for land, does not decrease subsequent soybean crop yields, and thus is not expected to result in indirect land use change (iLUC) impacts. However, the GHG results from our study should be reconsidered when multi-year and large-scale field cultivation of pennycress occurs in rotation with corn and soybeans. Should yields post pennycress cultivation indicate yield differences from control trials, then the iLUC impacts must be incorporated. The direct LUC impact due to pennycress cultivation is under investigation. The carbon stock change is expected to be small or negative because of the envisioned farming strategy: 
broadcast planting of pennycress without soil disturbance in the fall, followed by no-till soybeans in the spring, and in the second spring, minimal-till corn. The soil data for the last two years (given in Table 2.11) confirm that very little change occurs in soil properties, especially the organic matter values. Therefore, we did not include the dLUC impact in this study as it is expected to be negligible, although ongoing studies are in place to confirm this assumption.

Table 2.11: Soil data of pennycress/soybean rotation for the last two years

\begin{tabular}{|l|l|l|l|l|l|l|l|}
\hline & $\begin{array}{l}\text { Soil } \\
\mathrm{pH}\end{array}$ & $\begin{array}{l}\text { Organic } \\
\text { matter } \\
(\%)\end{array}$ & $\mathrm{P}(\mathrm{kg} / \mathrm{ha})$ & $\mathrm{K}(\mathrm{kg} / \mathrm{ha})$ & $\begin{array}{l}\mathrm{Mg} \\
(\mathrm{kg} / \mathrm{ha})\end{array}$ & $\begin{array}{l}\mathrm{Ca} \\
(\mathrm{kg} / \mathrm{ha})\end{array}$ & $\begin{array}{l}\text { CEC } \\
\mathrm{meq} / 100 \mathrm{~g}\end{array}$ \\
\hline $\begin{array}{l}\text { Fallow- } \\
\text { soybean }\end{array}$ & 6.3 & 2.2 & 89.7 & 361.0 & 928.3 & 7234.7 & 22 \\
\hline $\begin{array}{l}\text { pennycress- } \\
\text { soybean }\end{array}$ & 6.3 & 2 & 53.8 & 316.2 & 1180.6 & 6508.2 & 21.2 \\
\hline $\begin{array}{l}\text { Fallow- } \\
\text { soybean }\end{array}$ & 6.5 & 2.5 & 60.5 & 423.8 & 837.5 & 7648.4 & 21.9 \\
\hline $\begin{array}{l}\text { pennycress- } \\
\text { soybean }\end{array}$ & 7.1 & 2.3 & 56.1 & 338.6 & 797.1 & 6881.6 & 18.7 \\
\hline $\begin{array}{l}10 y r-a v g \text { for } \\
\text { plot } 10\end{array}$ & 6.55 & 2.5 & 93.7 & & & & 19.9 \\
\hline
\end{tabular}

\subsection{Future work}

For future work, multi-year and large-scale field cultivation of pennycress in rotation with corn and soybeans is needed to be studied to understand the sustainability of soil properties and confirm the iLUC assumptions. Field measurements of soil carbon stocks prior and after pennycress cultivation can be used to calculate the GHG emissions due to dLUC (if any occurs). Pennycress residues need to be examined to measure the above and belowground $\mathrm{N}$ content, so the amount of $\mathrm{N}$ left in soil after harvesting can be determined. The crop residues $\mathrm{N}$ left in soil may reduce the $\mathrm{N}$ fertilizer use for the next 
crop (soybean), and this credit should be examined and included in future LCA analyses. The use of pennycress meal as an animal feed is not yet practiced commercially and this assumption requires future market validation. Energy use of the presscake via direct combustion or fast pyrolysis can also be studied to understand the environmental impact of its use for bio-power.

\subsection{Conclusion}

Pennycress, a non-food member of the mustard family Brassicacae, has the potential to be grown between soybean/corn rotations as a winter annual crop yielding feedstock for drop-in hydrocarbon biofuel production. Because the planting of pennycress does not compete with food production nor reduce post-pennycress soybean yields, it is not expected to raise any concerns over iLUC. The life cycle GHG results $\left(\mathrm{CO}_{2} \mathrm{eq}\right)$ of pennycress oil derived RD and HRJ show over $50 \%$ of reductions compared to their petroleum counterparts, which could qualify them as advanced biofuel and as biomassbased diesel by the RFS standard. Most of the energy required for each pennycress biofuel product is derived from renewable biomass as opposed to non renewable fossil. The fossil energy consumptions are considerably lower than the petroleum fuels. With the potential of 15 million cubic meter of annual liquid renewable fuels yield, pennycress can be a significant contributor to meet the 79.5 million cubic meter advanced biofuel target by 2022 . 


\section{Chapter 3: A Life Cycle Assessment of Jatropha Oil Derived Jet Fuel and Diesel}

\subsection{Introduction}

Jatropha is a perennial plant native to Central America which belongs to the Euphorbiaceae family ${ }^{62,63}$, it is now commonly seen across tropical and sub-tropical regions and presents promising properties as oil feedstock for biofuel production ${ }^{64}$. Jatropha can survive in adverse conditions and grown on marginal land, thus is less likely to compete with food production and cause any negative land use change impact. In addition, it requires very little fertilizer inputs or irrigation ${ }^{65}$. Moreover, jatropha is claimed to have lower pesticides requirement as it has fewer pests and diseases ${ }^{66}$. Jatropha is not currently produced for food or animal feed because of the toxicity of its seeds. However, the whole plant and parts can be used in many other ways. The entire plant has been used for soil erosion control, pest repellent, medicinal use, and fire $\operatorname{wood}^{67}$. The fruit and seed cake of the plant can be used as fertilizer or energy source through gasification and combustion ${ }^{68}$. Jatropha seeds contain relatively high oil content compared to conventional oil seeds such as soybean, ranging from 27 to $40 \%{ }^{65,69}$. Jatropha oil is not edible due to certain antinutrient compounds such as phosphatides, which makes it ideal as energy source ${ }^{65}$.

However, jatropha faces many environmental and socio-economic issues ${ }^{64,69}$. Although jatropha can be grown on marginal land, active management and some level of inputs such as fertilization and irrigation are required to achieve high yields to be profitable. Marginal lands only yield very poor productivity (2-3 t/ha-yr) and the highest yields come from fertile land and intensive production practice ${ }^{70,71}$. Studies have shown that the environmental impact of jatropha derived energy is highly dependent on the type of land use which is converted to jatropha plantation, land use change can significantly change the GHG balance ${ }^{64,69}$. Decisions have to be made based on local environmental, economic, cultural and social characteristics ${ }^{69}$. 
This study was conducted to understand the environmental impact of jatropha derived biofuel and bioenergy. A jatropha plantation in Yucatan Mexico by the Global Clean Energy Holdings (GCEH) was studied in this research. The jatropha fruits are crushed to produce oil at the oil facilities near the jatropha farm. The oil is then transported from Mexico to U.S to produce RD and HRJ at a fuel facility using UOP's Ecofining ${ }^{\text {TM }}$ process and Green Jet Fuel ${ }^{\mathrm{TM}}$ process. GHG emission and energy demands of the RD and HRJ were estimated using the LCA software SimaPro. Sensitivity analyses were also conducted to evaluate the impact of fertilizer application rates, $\mathrm{H}_{2}$ source and land use change.

\subsection{LCA methods}

\subsubsection{Cultivation}

The land for jatropha plantation was originally developed for henequen around 1900, but very little of which are being produced in Mexico currently, and therefore, most of these land have been fallow for decades. iLUC is assumed to be minimal for these lands because they are not suitable for food production. The inputs of jatropha cultivation were obtained from GCEH (personal communication, GCEH), the detailed inventory data are not tabulated due to the confidential agreement with the company. Some nitrogen (urea), phosphorus (single superphosphate and triple superphosphate) and potassium (potassium chloride) fertilizers are used during jatropha cultivation, but the jatropha husks and other organic waste are also applied to soil to offset the mineral fertilizer use. $1.325 \%$ (direct and indirect) of $\mathrm{N}$ applied to soil is converted to $\mathrm{N}_{2} \mathrm{O}$ emission, as per the IPCC guidelines described in section 2.2.1. Although jatropha has been reported as pest resistant $^{67}$, there are some pests that can infest jatropha monocultures ${ }^{63,72}$, therefore, pesticides are used to control insect and unfavorable microorganisms. Diesel is used to establish, maintain and operate jatropha plantation, but the energy requirement is relatively low compare to other oil plant such as soybean, mostly because the soil doesn't need to be plowed and seeded every year (personal communication, GCEH). 


\subsubsection{Oil extraction}

The oil can be extracted by both mechanical extraction and chemical-based processes such as solvent extraction. Although solvent extraction could reach higher extraction rate $(90-99 \%)$, it is more expensive and energy intensive $e^{69,73}$. Therefore, the oil is assumed to be extracted by mechanical press. The presscake after oil extraction are toxic due to the phorbol esters ${ }^{74}$ and other heat-sensitive antinutrients such as lectins, trypsin inhibitors etc ${ }^{67}$. Therefore, the cake will be used as energy source.

The inputs of jatropha oil extraction were provided by GCEH and literature review. The husk which comprises about $30 \%$ of the dry weight of the fruit is removed by mechanical means after harvesting. The majority of husks $(98.3 \mathrm{wt} \%)$ are used as a green fertilizer to reduce the use of mineral fertilizers, with the remainder is expected to enter the fuel market as a bio-energy source. After the husks are removed, the inner seeds are crushed to extract about $90 \%$ of the total oil present. For every $1000 \mathrm{~kg}$ of fruit, $300 \mathrm{~kg}$ husk are removed before oil extraction, $214 \mathrm{~kg}$ of oil is extracted from the seeds, leaving $486 \mathrm{~kg}$ of de-oiled cake. The remaining cake $(19.2 \mathrm{MJ} / \mathrm{kg}$ ) can be used as bio-energy or animal feed if the antinutrient components are removed by either physical or chemical treatment. The crude jatropha oil contains a low concentration of phosphatides, which are poison to fuel production catalyst. To remove the remaining phosphatides, a chemical treatment step generates a mixture of precipitated gums and soapstock that separate from the oil using a centrifuge. Following chemical precipitation and centrifuging, absorptive solids such as Trisyl ${ }^{\circledR}$ will be used to absorb trace contaminants. About $0.3 \mathrm{wt} \%$ (of crude oil) of solid sorbent will be used, which will then be removed by filtration. This material (filtered cake) is considered a waste, with no market value. The detailed mass flow and energy flow are listed in Table 3.1. 
Table 3.1: Inputs and outputs of jatropha oil extraction

\begin{tabular}{|l|l|l|}
\hline Inputs & & \\
\hline Jatropha seed & 3.271 & $\mathrm{~kg} / \mathrm{kg}$ crude oil \\
\hline Chemicals & 0.007 & $\mathrm{~kg} / \mathrm{kg}$ crude oil \\
\hline Electricity & 0.001 & $\mathrm{kWh} / \mathrm{kg}$ crude oil \\
\hline & & \\
\hline Outputs & & \\
\hline Jatropha husks & 1.402 & $\mathrm{~kg} / \mathrm{kg}$ crude oil \\
\hline Jatropha cake & 2.271 & $\mathrm{~kg} / \mathrm{kg}$ crude oil \\
\hline Refined jatropha oil & 0.986 & $\mathrm{~kg} / \mathrm{kg}$ crude oil \\
\hline Filter Cake (waste) & 0.004 & $\mathrm{~kg} / \mathrm{kg}$ crude oil \\
\hline Soapstock & 0.018 & $\mathrm{~kg} / \mathrm{kg}$ crude oil \\
\hline
\end{tabular}

The oil is transported $50 \mathrm{~km}$ by truck to a port, and then loaded to transoceanic tank and ship to Virginia, U.S. The shipping distance is estimated to be $2400 \mathrm{~km}$. Finally the oil is transported $650 \mathrm{~km}$ by rail from Virginia to Institute, WV for fuel production.

\subsubsection{Oil conversion to RD and HRJ}

The jatropha oil is converted to RD and HRJ via UOP's Ecofining ${ }^{\mathrm{TM}}$ process and Green Jet Fuel ${ }^{\mathrm{TM}}$ Process. Conversion inputs were obtained from confidential UOP design data.Simalar data reported in the literatures are presented in Table 2.7 and 2.8. The $\mathrm{H}_{2}$ required is assumed to be produced using steam methane reforming (SMR) in the base case analysis. The final fuel products are distributed by truck to consumers within a radius of $150 \mathrm{~km}$.

System expansion and allocation approaches (energy and market value) were applied in the jatropha study. For the system expansion method, jatropha husks are displacing mineral fertilizers, with the amount of fertilizers calculated by the nutrient $(\mathrm{N}, \mathrm{P}, \mathrm{K})$ content in the husks, obtained from literature: the percent of $\mathrm{N}, \mathrm{P}_{2} \mathrm{O}_{5}$ and $\mathrm{K}_{2} \mathrm{O}$ in 
harvested jatropha seeds are $2.1 \%, 0.84 \%$ and $2.3 \%$, respectively ${ }^{64}$. The seed cake and soapstock produced in oil refining step are assumed to be used as energy source, displacing coal. Renewable fuel gas, LPG and naphtha produced along with the diesel/jet products were assumed to displace fossil natural gas, propane and petroleum naphtha, respectively. The avoided emissions were calculated by the emission burdens of these fossil fuels included in the Ecoinvent database, including their combustion emissions. For the energy allocation method, the allocation factors of jatropha oil and fuel products were calculated by their energy contents. For the market value allocation, the pricing of husks was indexed to a market energy price of coal, the current market value would be about $\$ 60$ per dry t (personal communication with GCEH). Seed cake was valued as energy source, which would have a current market value of about $\$ 60$ per dry t. Because of the higher market value of crude jatropha oil compared to husks and cakes, the majority of the burdens up to oil extraction step were allocated to the oil itself. The allocation factors of the jatropha oil and final fuel products were calculated by the same equations described in section 2.2.3.2, and are tabulated in Table 3.2.

Table 3.2: The energy content and market value, along with the allocation factors of the products and co-products of jatropha RD and HRJ

\begin{tabular}{|l|l|l|l|l|}
\hline & $\begin{array}{l}\text { LHV } \\
(\mathrm{MJ} / \mathrm{kg})\end{array}$ & $\begin{array}{l}\text { Market value } \\
(\$ / \mathrm{kg})\end{array}$ & EA factor & MVA factor \\
\hline Crude oil & 40.7 & 0.85 & 0.358 & 0.794 \\
\hline Husk & 19.5 & 0.06 & & \\
\hline Seed cake & 19.5 & 0.06 & & \\
\hline Soapstock & 20.4 & & & \\
\hline Filtered cake & 10.625 & & & 0.892 \\
\hline RD & 44 & 1.21 & 0.531 & 0.568 \\
\hline HRJ & 44 & 1.21 & & \\
\hline
\end{tabular}




\subsection{LCA results and discussion}

\subsubsection{GHG emissions}

The life cycle GHG emissions of jatropha RD and HRJ are shown by life cycle stage in Figure 3.1. Renewable fuels derived from jatropha contain no fossil carbons in the fuel molecules, only carbon atoms sequestered from the atmosphere as $\mathrm{CO}_{2}$ during plant growth. Therefore, these fuels do not contribute to climate warming when combustion occurs. Fuel production stage is the leading GHG contributor, mainly because of the $\mathrm{H}_{2}$ and fossil fuels (natural gas and electricity) used in the fuel production process. Cultivation is the second largest GHG contributor mainly because of the nitrogen fertilizer used. Life cycle GHG emissions of jatropha RD and HRJ are most favorable compared to petroleum fuels when displacement method is used to account for the coproducts. It is because the co-products of the process, which include fertilizers and renewable fuels (fuel gas, LPG, naphtha) have much lower carbon intensity than the fossil based products they displaced. Market value allocation method yields the highest emission, because of the high economic values of the jatropha oil compared to the husks and cake, where most of the energy and emission burdens of the cultivation and oil extraction process are allocated to the oil, and subsequently to the final fuel products. Savings of GHG emissions compared to fossil fuel are greater than $60 \%$ in for all jatropha biofuels shown in Figure 3.1. 


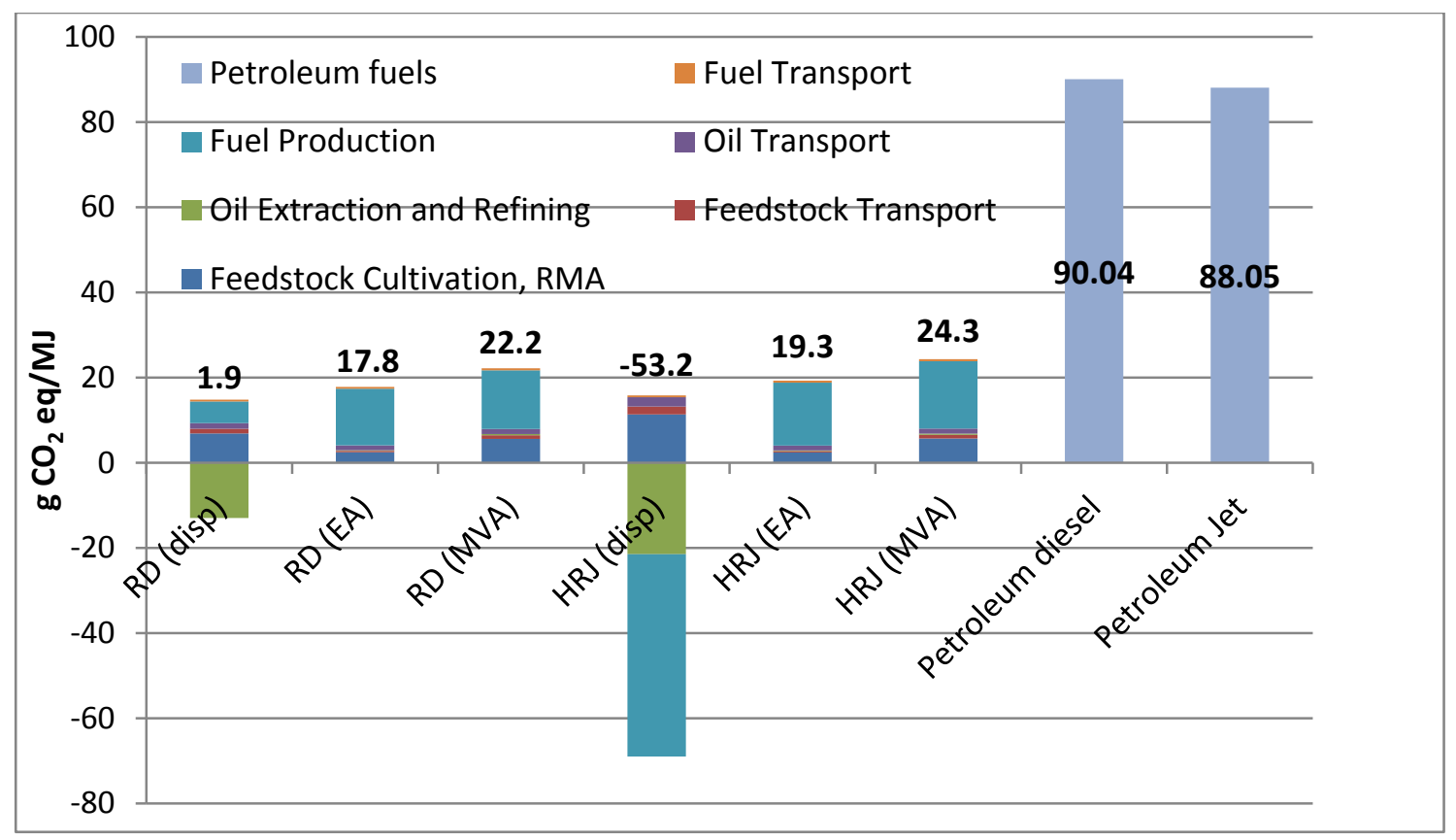

Figure 3.1: The life cycle GHG emissions of jatropha RD and HRJ (base case), using imported $\mathrm{H}_{2}$ from $\mathrm{SMR}$, compared to petroleum fuels

\subsubsection{Energy demand results (CED; FED)}

Figure 3.2 shows the CED results of jatropha RD and HRJ, and with comparison to the petroleum baseline. The net energy demand results are labeled above each bar. The CED consists of four parts; non-renewable fossil and nuclear energy use, renewable biomass energy use, and other renewable energy sources, which include solar, geothermal, and hydroelectric power. The total energy demand of RD and HRJ calculated by energy allocation method are comparable to their petroleum counterparts, while the other two methods generate higher CED results. For the market allocation method, more energy flow is assigned to the jatropha oil because of its higher price than the co-product presscake. Thus the final fuel products have higher CED than the results generated by the energy allocation method. But the majority of the energy demands are from renewable biomass, the renewable fuels require substantially less fossil energy than petroleum fuels through the life cycle, as shown in Figure 3.3. 


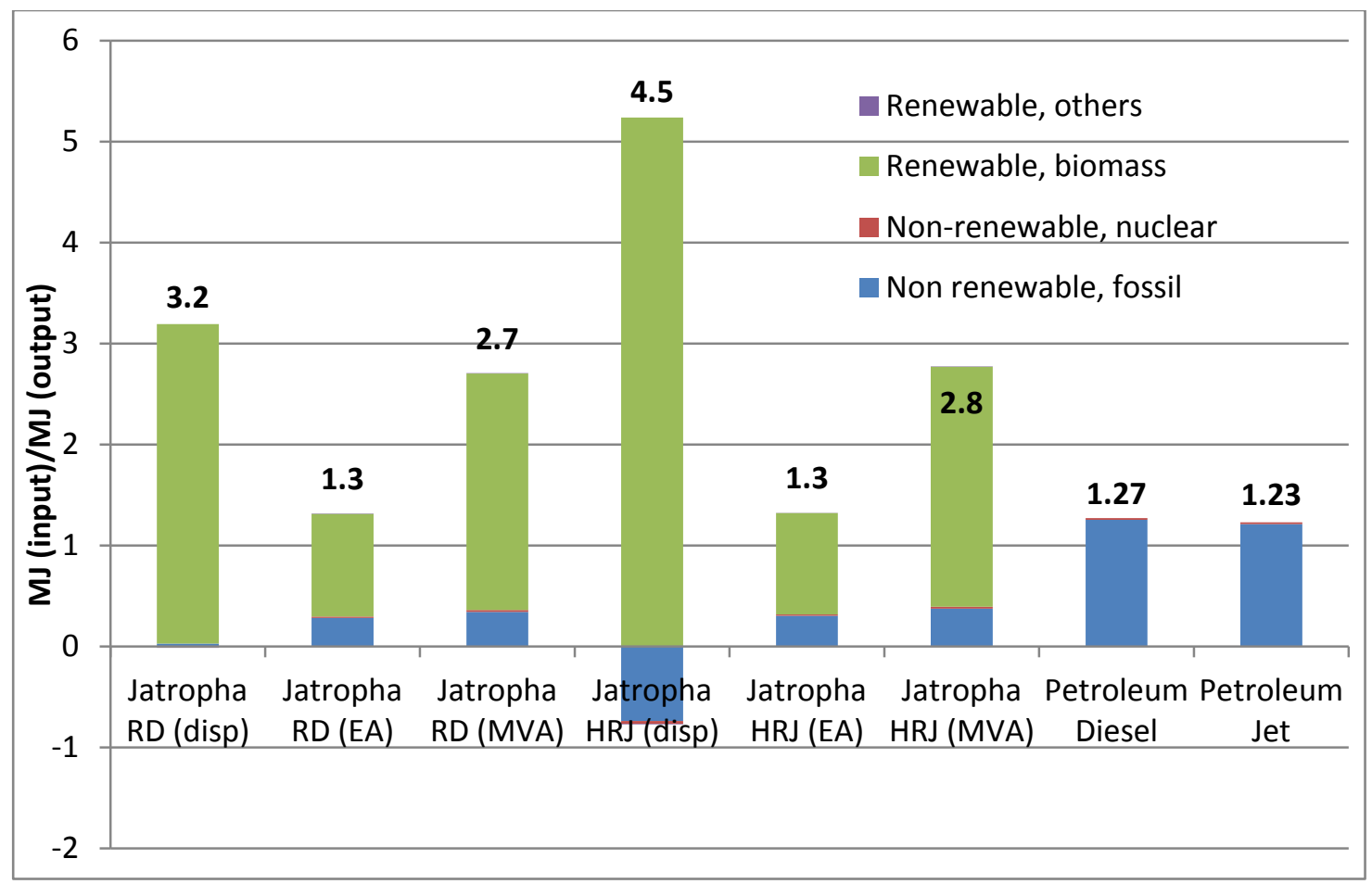

Figure 3.2: CED results (base case) of jatropha derived RD and HRJ, compared to petroleum fuels

When analyzing the FED impacts, it is worthwhile to note at which point in the processes that the energy is actually consumed. Therefore the FED has been broken into seven process stages; cultivation/RMA (raw material acquisition), feedstock transportation, oil extraction and transportation, fuel production, distribution, and use. For petroleum diesel and jet, most of the fossil energy is embodied in the fuel itself, as shown by the large fuel use segment in their bars on Figure 3.3. For the renewable fuels, fuel production stage is responsible for most of the fossil energy use, because of the electricity and natural gas used to power the oil-to-biofuel conversion process. Cultivation is the second largest contributor due to the use of petroleum diesel and fertilizers. 


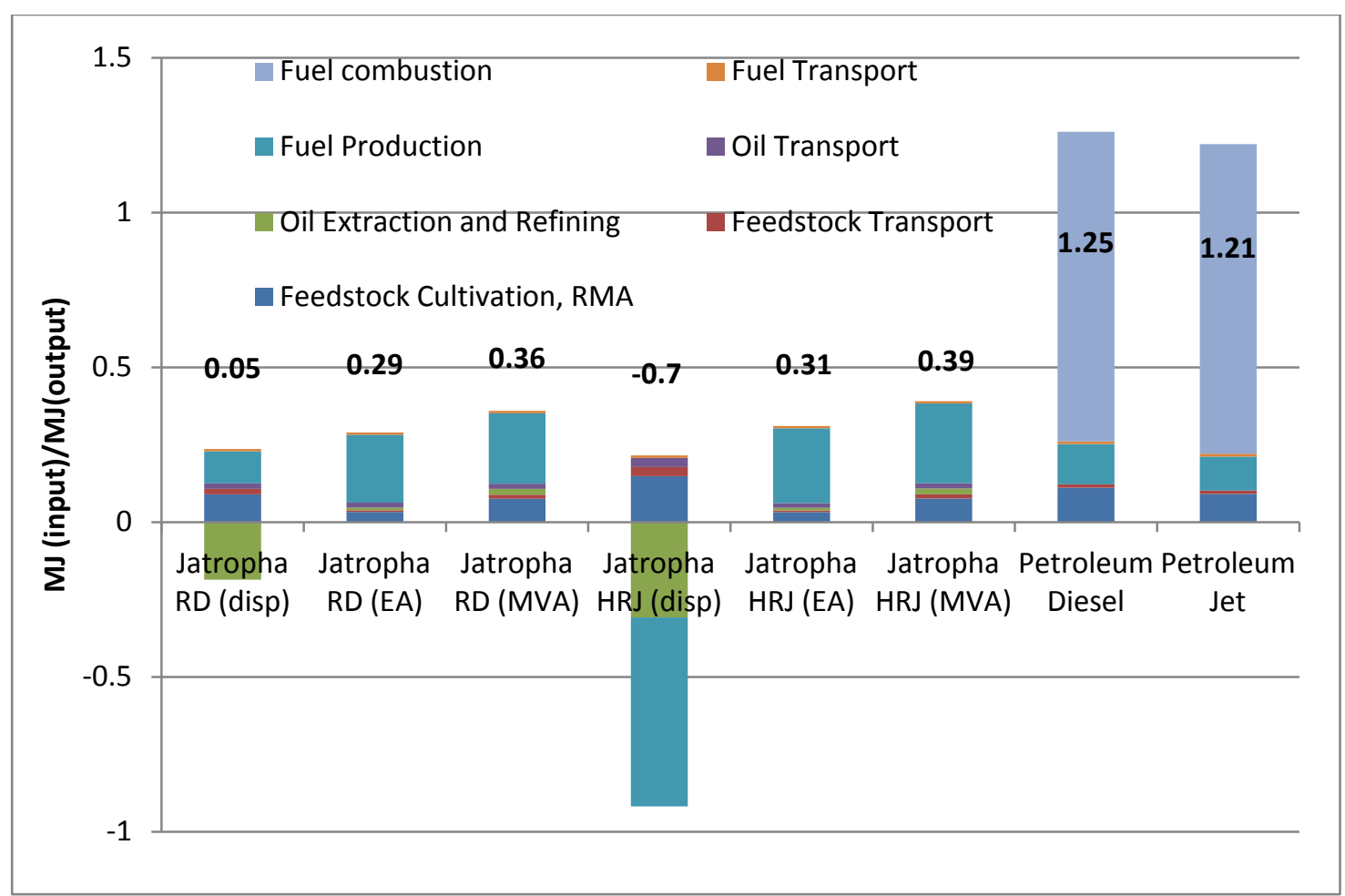

Figure 3.3: FED results (base case) of jatropha derived RD and HRJ, compared to petroleum fuels

\subsection{Sensitivity analyses}

\subsubsection{Fertilize application rates}

In the base case, the fertilizer inputs were obtained from the GCEH confidential data.

Because the jatropha husks are put back to the soil as nutrients supplement, the synthetic fertilizer inputs are much reduced. A sensitivity analysis was conducted to investigate the impact of different fertilizer application rates, which assumes fertilizer inputs are set at the theoretical application rate that would be needed to replace nutrients lost though the annual harvest of seeds. The fertilizer requirements were calculated by multiplying the percent of nutrient in harvested seeds and the amount of seeds consumed during oil extraction. The fertilizer input data were obtained from the Bailis and Baka study ${ }^{64}$ which studied jatropha plantations in Brazil. The percent of $\mathrm{N}, \mathrm{P}_{2} \mathrm{O}_{5}$ and $\mathrm{K}_{2} \mathrm{O}$ in harvested jatropha seeds are $2.1 \%, 0.84 \%$ and $2.3 \%$, respectively. $\mathrm{N}$-fertilizer is assumed to be applied as urea, which is the most common $\mathrm{N}$-fertilizer currently used in Brazil. $\mathrm{P}_{2} \mathrm{O}_{5}$ is 
assumed to be a mix of single- and triple-super phosphate (SSP and TSP), which are consumed in a 60:40 proportion. K-fertilizer is almost entirely imported as Potassium chloride. The life cycle GHG emissions of jatropha RD and HRJ results are illustrated in Figure 3.4. The fertilizer application rates have a significant impact on the total GHG emissions of final fuel products, especially when displacement or market value allocation method was used for the co-products. This is because all the emission burdens from additional fertilizer are applied to the final fuel products. When energy allocation method was used, a smaller fraction of the emission burdens of cultivation are allocated to the final fuel products, therefore, the increase in life cycle GHG emissions is smaller.

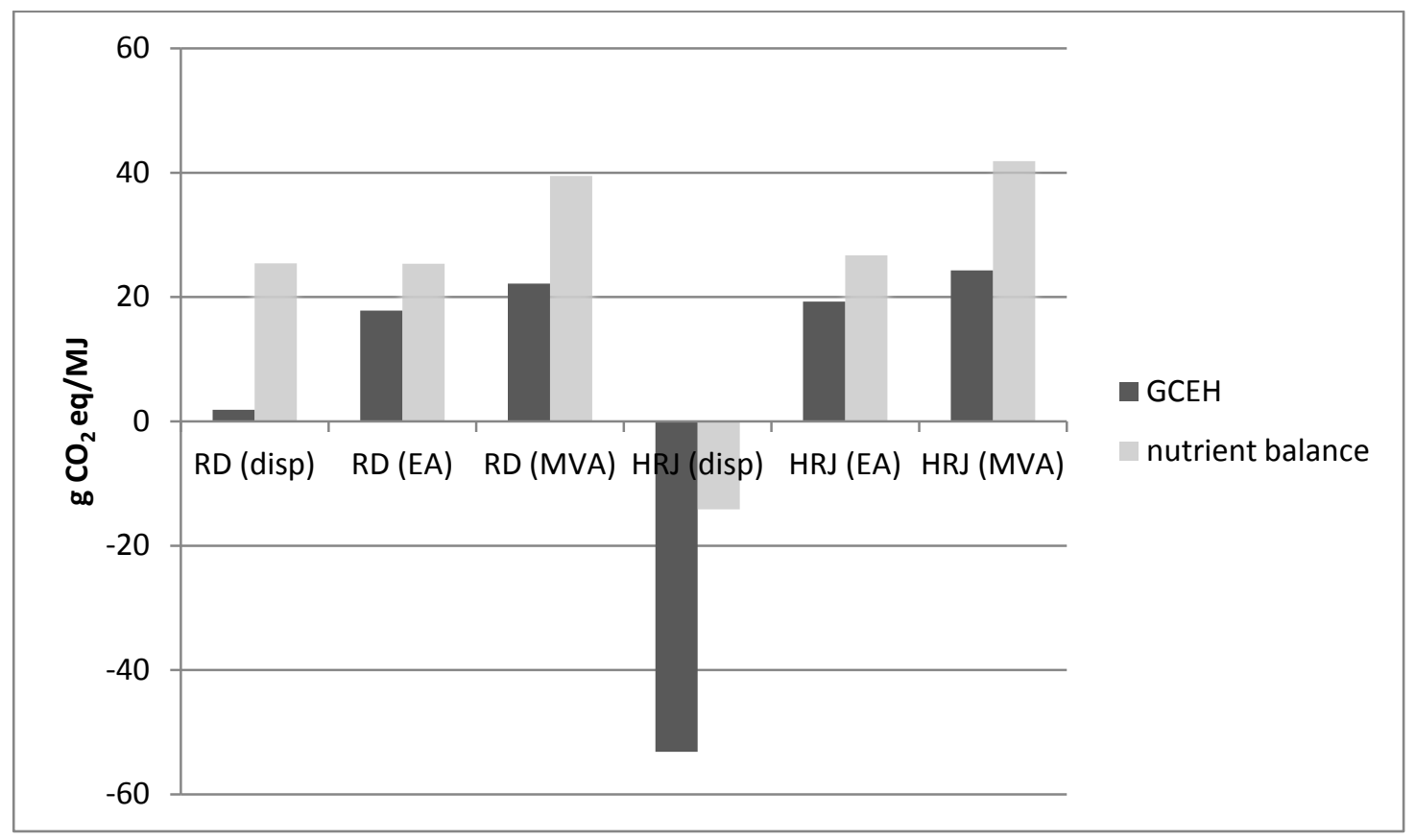

Figure 3.4: Life cycle GHG emissions of jatropha RD and HRJ, with different fertilizer application rates

\subsection{2. $\mathrm{H}_{2}$ sources}

In the base case, $\mathrm{H}_{2}$ required in the Ecofining process is imported from a natural gas SMR plant. A sensitivity study assuming $\mathrm{H}_{2}$ from other sources was also included in the study. The second scenario assumes the $\mathrm{H}_{2}$ is produced in the integrated $\mathrm{H}_{2}$ production plant, using co-products from the Ecofining process such as fuel gas, LPG and naphtha as feedstocks. All the co-products of RD production (fuel gas, LPG and naphtha) are 
consumed in the integrated $\mathrm{H}_{2}$ plant, thus all the environmental burdens of fuel production is allocated to $\mathrm{RD}(\mathrm{EAF}=1)$. The fuel gas, $\mathrm{LPG}$, and a portion of naphtha and diesel produced in the HRJ production process are consumed to produce $\mathrm{H}_{2}$, the EAF and MAF were calculated as 0.657 and 0.637 , respectively. The GHG emissions results are illustrated in Figure 3.5. When $\mathrm{H}_{2}$ is produced on-site with the co-products of the process, $\mathrm{RD}$ and HRJ show more favorable GHG reductions with respect to the GHG emission burdens. This is because $\mathrm{H}_{2}$ from the process co-products have much lower emission and energy burdens than the $\mathrm{SMR}_{2}$, which is derived from fossil natual gas. However, if displacement method is used, the GHG credits of the co-products decrease because they are consumed internally to produce $\mathrm{H}_{2}$, instead of displacing their petroleum counterparts.

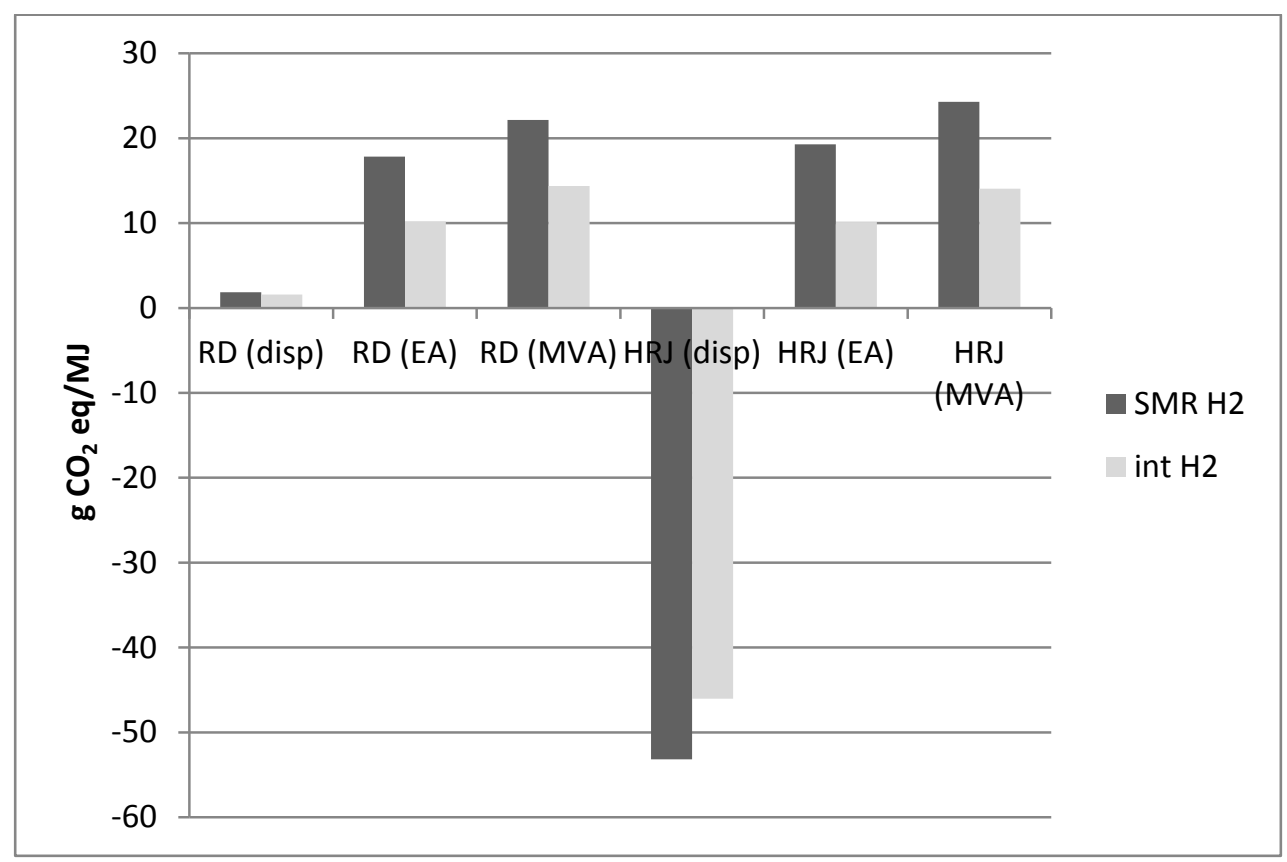

Figure 3.5: Life cycle GHG emissions of jatropha RD and HRJ, with different $\mathrm{H}_{2}$ sources

\subsection{Land use change}

iLUC impact is neglected because jatropha is planted on fallow land not suitable for agricultural production. The GHG emissions due to dLUC of jatropha cultivation were calculated based on assumed carbon stocks data for native vegetation on three categories of land in the Yucatan (Table 3.3). The dLUC impact was calculated by the following formula (modified from the European Renewable Energy Directive ${ }^{54}$ ): 


$$
d L U C \text { emissions }=\frac{\text { plantation area }(\text { ha }) \times\left(C S_{i}-C S_{j)} \times 44 / 12\right.}{R D(H R J) \text { yield over } 40 \text { years }(M J)}
$$

where $\mathrm{CS}_{\mathrm{i}}$ is the carbon stocks of the land prior to jatropha planting ( $\left.\mathrm{t} \mathrm{C} / \mathrm{ha}\right), \mathrm{CS}_{\mathrm{j}}$ is

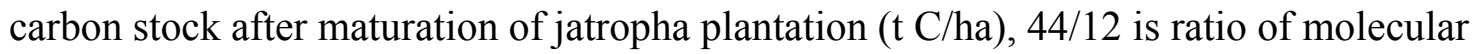
weight of $\mathrm{CO}_{2}$ to $\mathrm{C}$, and the plantation life of 40 years are assumed to calculate the average dLUC impact of the RD and HRJ.

Table 3.3: Land category classes of native vegetation of the green bordered area, as well as of future jatropha plantations planted in this area (Personal communication David Shonnard 2012)

\begin{tabular}{|l|l|l|}
\hline Prior Land Cover & $\begin{array}{l}\text { Carbon } \\
\text { Content } \\
(\mathbf{t} \text { C/ha) }\end{array}$ & $\begin{array}{l}\text { Plantation } \\
\text { Fraction }\end{array}$ \\
\hline $10 \%$ or less tree canopy cover & 4.8 & 0.20 \\
\hline $10-20 \%$ or tree canopy cover & 13.65 & 0.40 \\
\hline $20-30 \%$ or tree canopy cover & 21 & 0.40 \\
\hline Jatropha plantation cover & 17.5 & 1.00 \\
\hline
\end{tabular}

The GHG emissions due to dLUC are tabulated in Table 3.4. The RD and HRJ offer a GHG credit, because jatropha is grown on degraded low carbon stock lands in the regions, more carbon is stored in soil due to the jatropha plantation. When allocation methods (EA and MVA) are used, the dLUC credit is lower because a portion of the credit is given to the co-products. The life cycle GHG emission results of jatropha RD and HRJ are illustrated in Figure 3.6.

Table 3.4: GHG emissions ( $\mathrm{g} \mathrm{CO}_{2} \mathrm{eq} / \mathrm{MJ}$ ) due to dLUC of jatropha plantation

\begin{tabular}{|l|l|l|l|l|l|l|}
\hline & $\begin{array}{l}\text { RD } \\
(E A)\end{array}$ & $\begin{array}{l}\text { RD } \\
(\text { MVA })\end{array}$ & $\begin{array}{l}\text { RD } \\
(\text { disp })\end{array}$ & $\begin{array}{l}\text { HRJ } \\
(\text { EA })\end{array}$ & $\begin{array}{l}\text { HRJ } \\
(\text { MVA })\end{array}$ & $\begin{array}{l}\text { HRJ } \\
(\text { disp })\end{array}$ \\
\hline dLUC & -5.03 & -5.22 & -5.64 & -4.98 & -5.30 & -9.34 \\
\hline
\end{tabular}




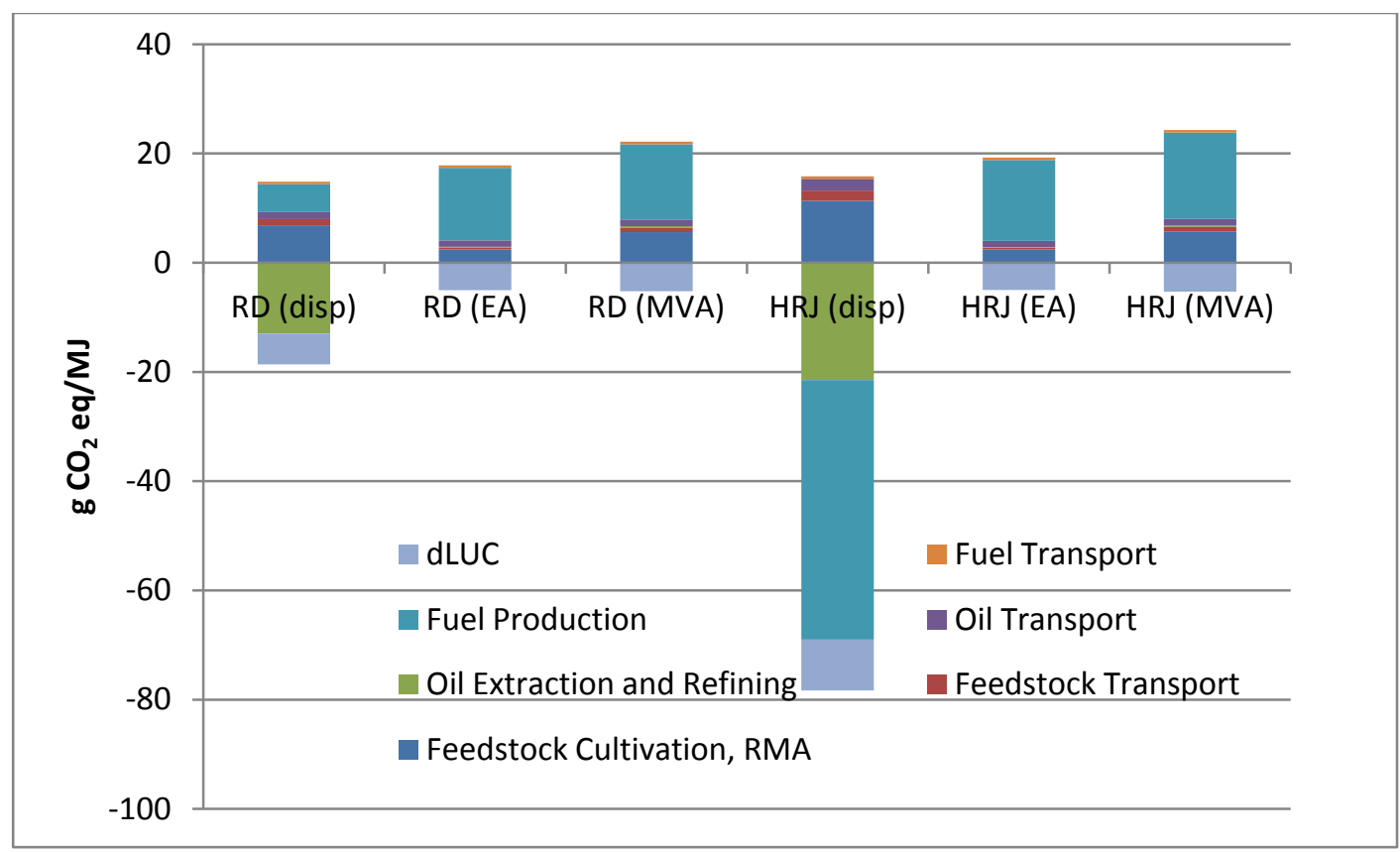

Figure 3.6: Life cycle GHG emissions of jatropha RD and HRJ, including dLUC impact

Bailis \& Baka $^{64}$ studied jatropha derived jet fuel compared to petroleum jet fuel in Brazil. When no land use change was included in the analysis, jatropha oil results in $40 \mathrm{~kg} \mathrm{CO}_{2} \mathrm{e}$ per GJ of fuel produced. When direct land use change was considered, the type of land being replaced by jatropha has a large impact on the GHG emissions. The study found that converting annual crop land to jatropha can have a net increase in carbon stocks, which results in life-cycle GHG reductions of $83 \%$ compared to petroleum jet fuel. However, converting areas like shrublands can make the jatropha jet fuel shows $59 \%$ more GHG emissions than petroleum jet fuel. Therefore, jatropha's sustainability is very dependent upon what type of land is chosen for its growth.

\subsection{Conclusions}

Based on the results from this LCA study, RD produced from jatropha have $75 \%$ to $98 \%$ savings in GHG emissions over the life cycle compared to petroleum diesel, depending on how the co-products are accounted for. Jatropha derived HRJ show slightly lower GHG savings compared to petroleum jet fuels when allocation methods are used. Displacement method yields much higher GHG reductions because of the large yield of 
co-products, including fuel gas, LPG and naphtha. Sensitivity analyses were also conducted in this LCA to investigate the impact of fertilizer application and $\mathrm{H}_{2}$ sources. In the base case, $\mathrm{H}_{2}$ was assumed to be imported from a SMR plant. In the sensitivity analysis, it was assumed to be produced in an integrated $\mathrm{H}_{2}$ plant using co-products of the Ecofining process as feedstock. The integrated $\mathrm{H}_{2}$ scenario reduces life cycle GHG emissions by 14 to $40 \%$ compared to the base case, depending on the allocation methods. This is because of the low carbon intensity of the $\mathrm{H}_{2}$ produced from biofuels co-products as oppose to fossil natural gas. The dLUC impact due to jatropha plantation is also studied. This study found that jatropha plantation on degraded land not suitable for agricultural production provides a GHG credit because it stores more carbon in the soils over the life of the plantation, which further reduces the life cycle GHG emissions of jatropha derived RD and HRJ. Therefore, under the assumptions of this study, jatropha oil will be a promising biomass feedstock to replace fossil energy for transportation fuels. The GHG emission results of jatropha derived biofuels were also compared to the literature and LCA models, the details are presented in the next chapter. 


\section{Chapter 4: A Review of Life Cycle GHG Emissions of HRJ from Renewable Oils and Fats ${ }^{4}$}

\subsection{Introduction}

\subsubsection{Background}

World jet fuel consumption reached 840 million L per day in $2008^{75}$. This demand is expected to increase as the aviation industry will continue to grow over the coming decades with an annual growth rate of $5 \%{ }^{76}$. The United States consumed $614 \mathrm{MMbbl}$ of conventional kerosene jet fuels in 2005 , only $30 \%$ of which was produced from domestic crude oil resources ${ }^{77}$. The aviation fuels demand in the U.S is also expected to expand as the Federal Aviation Administration (FAA) projected an average annual growth rate of 3.7 percent over the next 5 years, followed by 2.5 percent per year through $2031^{78}$. Global $\mathrm{CO}_{2}$ emission from the aviation sector accounted for $2 \%$ of global $\mathrm{CO}_{2}$ emissions in $2010^{79}$. There is considerable pressure on international communities and the aviation industry to reduce the carbon footprint of aviation fuels ${ }^{80}$. The Energy Independence and Security Act of 2007 (EISA) mandates the use of 36 billion gallons (136 GL) of renewable transportation fuel by $2022^{4}$, and the European Emissions Trading Scheme (ETS) is also encouraging the international production of renewable jet fuel ${ }^{6}$. The International Air Transport Association (IATA) has set a goal of 10\% alternative fuel use by 2017 , carbon neutral growth in 2020, and $50 \%$ reductions of $\mathrm{CO}_{2}$ emissions (to 2005 baseline) by $2050^{81}$. On July $1^{\text {st }} 2011$, ASTM gave final approval for blending of hydrotreated jet fuels (HRJ) (also referred to as synthetic paraffinic kerosene (SPK) from Hydroprocessed Esters and Fatty Acids, HEFA) up to $50 \%$ in aviation fuels ${ }^{7}$, thus facilitating a commercial pathway to sustainable aviation fuels.

\footnotetext{
${ }^{4}$ This chapter has been published in International Journal of Environmental Science and Engineering Research. Reprinted with permission from the journal editor Thomas White for use in dissertation (Figure D.4). Citation: Fan J, Handler RM, Shonnard DR, Kalnes TN. A review of life cycle greenhouse gas emissions of hydroprocessed jet fuels from renewable oils and fats. IJESER Vol 3(3):114-138, 2012
} 


\subsubsection{Hydroprocessed renewable jet (HRJ)}

Renewable fats and oils can be catalytically converted to drop in hydrocarbon biofuels by combination of hydrogenation, deoxygenation, isomerization and hydrocracking reactions. Feedstocks are primarily composed of triacylglycerols (TAGs) and free fatty acids (FFAs) ${ }^{33,82}$. An overview of the required processing steps is illustrated in Figure 4.1.

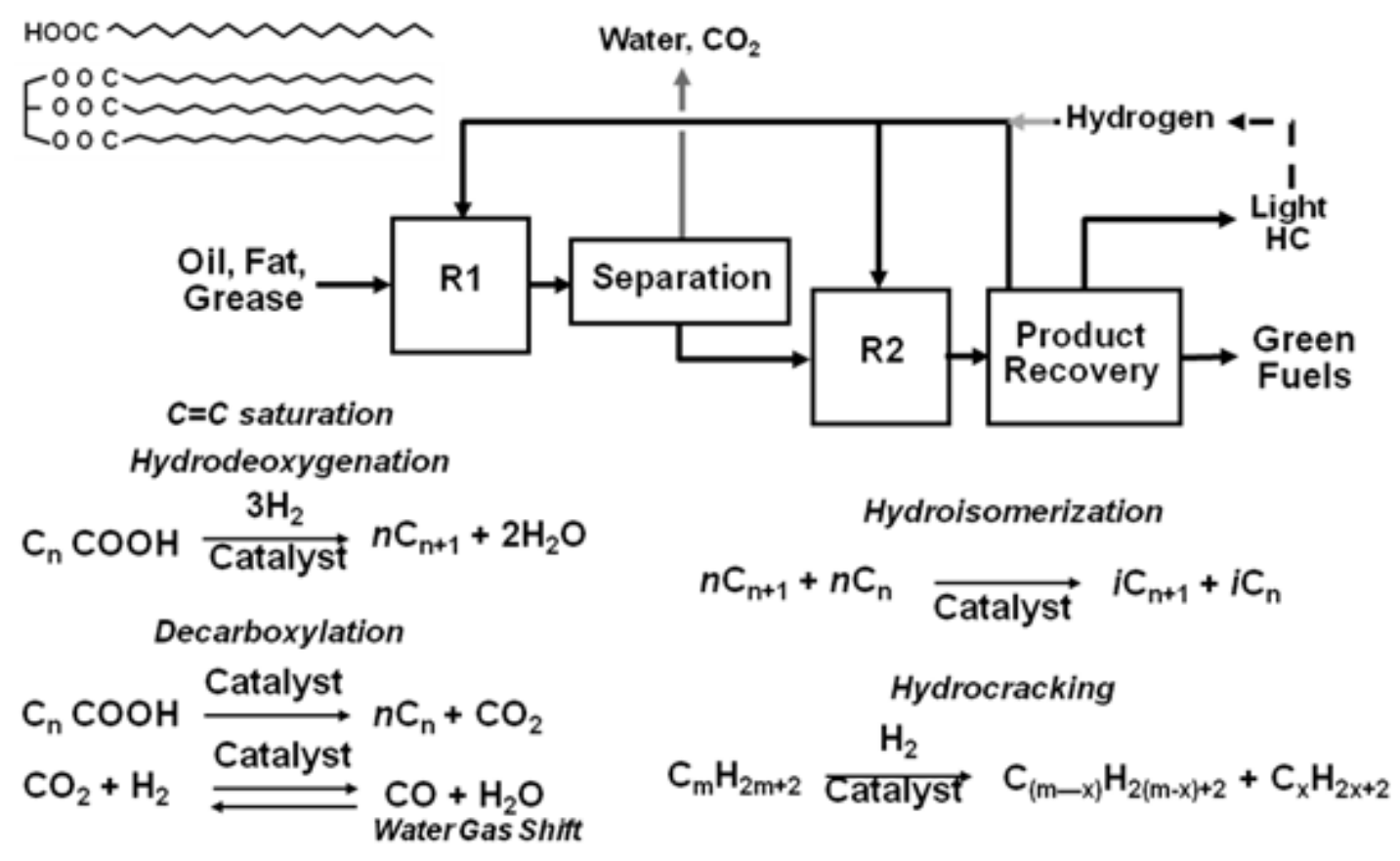

Figure $4.1^{5}$ : Overview of the UOP Renewable Jet Fuel Process ${ }^{83}$

In reaction zone $\mathrm{R} 1$, renewable fats and oils are hydrogenated and deoxygenated. After separation of the resultant water and carbon oxides, the deoxygenated oil is catalytically hydrocracked and isomerized in reaction zone R2. The HRJ is then recovered from the R2 effluent using commercially proven separation and fractionation technology. Excess hydrogen provided to the reactor system is recovered and recycled back to the reactor.

\footnotetext{
${ }^{5}$ This figure was prepared by Tom Kalnes of UOP LLC for Conference 2008 Pacific Rim Summit on Industrial Biotechnology and Bioenergy and published online. Permission for use in this dissertation was provided by Tom Kalnes via email (Figure D.5). Copyright clearance from UOP Honeywell is shown is Figure D.3
} 
Make-up hydrogen is added to the process to balance both chemical consumption and solution losses ${ }^{31}$. Existing on-site hydrogen production facilities in petroleum refineries can be expanded to supply the hydrogen required for the hydroprocessing process ${ }^{38}$. Otherwise, hydrogen can be produced from natural gas in a steam methane reforming (SMR) plant ${ }^{84}$. Renewable co-products such as propane, butane (LPG) and naphtha from the HRJ production can also be steam reformed to meet the hydrogen need. A renewable diesel co-product can also be produced. Table 4.1 summarizes the range of material and energy inputs for HRJ production that is currently available in the open literature. These values represent the average inputs and co-products for all feedstocks studied in those studies. However, some inputs such as $\mathrm{H}_{2}$ will depend on the molecular characteristics of the oils, most importantly the double bonded carbon $(\mathrm{C}=\mathrm{Cs})$. Co-products yields also depend on the hydrocracking process and catalyst. 
Table 4.1: Inputs and outputs of HRJ production from renewable oils* (per kg of HRJ)

\begin{tabular}{|c|c|c|c|c|c|c|c|}
\hline & \multicolumn{3}{|c|}{ Stratton et al ${ }^{85}$} & \multirow[t]{2}{*}{$\begin{array}{l}\text { Agusdina } \\
\text { ta et } \mathrm{al}^{40}\end{array}$} & \multirow[t]{2}{*}{$\begin{array}{l}\text { GREET } \\
2012^{86}\end{array}$} & \multirow[t]{2}{*}{$\begin{array}{l}\text { GHGen } \\
\text { ius } 87\end{array}$} & \multirow[t]{2}{*}{$\mathrm{EPA}^{88}$} \\
\hline & Low & Base & High & & & & \\
\hline \multicolumn{8}{|l|}{ Inputs } \\
\hline Oils (kg) & 1.73 & 1.71 & 1.67 & & 1.39 & 1.7 & 2.033 \\
\hline $\mathrm{H}_{2}(\mathrm{~kg})$ & 0.037 & 0.058 & 0.075 & 0.046 & 0.056 & 0.058 & 0.013 \\
\hline $\begin{array}{l}\text { electricity } \\
(\mathrm{kWh})\end{array}$ & 0.071 & 0.092 & 0.114 & 0.061 & 0.061 & 0.092 & 0.088 \\
\hline $\begin{array}{l}\text { natural } \\
\text { gas (L) }\end{array}$ & 10.81 & 11.62 & 12.33 & 4.58 & 214.85 & 315.37 & 387.16 \\
\hline
\end{tabular}

\section{Co-products (kJ)}

\begin{tabular}{|l|l|l|l|l|l|l|l|}
\hline Diesel & & & & & & & 20558 \\
\hline propane & 1602 & 3786 & 3864 & 3086 & 6125 & & 3638 \\
\hline naphtha & 20059 & 20058 & 20106 & 4194 & 4318 & & 6274 \\
\hline butane & & & & 1207 & & & \\
\hline LPG & & & & & & 13920 & 5716 \\
\hline gasoline & & & & & & 5165 & \\
\hline
\end{tabular}

* renewable oils include pure vegetable oils, recycles products, animal fats

\subsubsection{Life cycle assessment (LCA) of biofuels}

LCA is considered one of the best methodologies to evaluate the environmental impacts associated with biofuel and bioenergy production ${ }^{89}$. Researchers have been using this general methodology to evaluate renewable transportation biofuels and comparing them against conventional petroleum fuels ${ }^{3,39,90}$. Two main approaches for conducting LCA on biofuels are attributional and consequential analyses. Attributional LCA considers only the inputs and emissions from the product stages, while consequential analysis also includes direct effects to soils and indirect effects of biofuel production such as changes to food prices and indirect land use change emissions. There are several LCA tools 
available to simulate the environmental burdens of chemicals, fuels, and processes. SimaPro $7.2^{41}$ is a LCA software integrated with the Ecoinvent database ${ }^{91}$, which allows the user to model products, processes and services from a life cycle perspective following ISO 14040 guidelines. The Greenhouse Gases, Regulated Emissions, and Energy Use in Transportation (GREET) Model estimates the energy and emission impacts of transportation fuels on a full wells-to-wheels fuel cycle ${ }^{92}$. The latest version of GREET $2012{ }^{86}$ includes the HRJ pathways from various feedstock sources, such as camelina, jatropha, algae, etc. GHGenius $4.01^{87}$ is a LCA model for specific regions (east, central or west) of Canada, the United States and Mexico, which analyzes the air emissions and energy use associated with the production and use of traditional and alternative transportation fuels.

The consideration of co-products along the life cycle is essential to fairly address the energy and emission burdens of the primary product, and the methodology to credit the co-products can have a significant impact on the final LCA results ${ }^{89}$. The most commonly used methods are system expansion (displacement) and allocation (mass, energy, or market value) method. The system expansion (SE) method involves identifying a product displaced by the co-product of the process, and determining the energy and emissions associated with the displaced product. The credits are then subtracted from the environmental burdens of the primary product under evaluation. The ISO $14041^{50}$ standards and Roundtable on Sustainable Biofuels (RSB) ${ }^{93}$ both recommend using this approach to deal with co-products. The U.S.EPA also states that this is the preferred method for life-cycle energy and greenhouse gas (GHG) analyses in its analysis of the Renewable Fuel Standard (RFS2) Program ${ }^{51}$. The allocation methods split the burdens between the primary product and co-products on the basis of mass, energy content, or economic value of the product relative to co-products. The European Commission divides the GHG emissions of biofuels and the co-products (except for agricultural crop residues and residues from processing) in proportion to their energy content (based on lower heating value $)^{54}$. The RSB recommends use of allocation based on economic value when necessary data are not available to perform SE method. When multiple applications of 
various co-products are involved, a sensitivity analysis should be conducted to investigate the impacts of various allocation methods ${ }^{50}$.

\subsubsection{Land use change (LUC)}

Studies have shown that use of food crops for biofuels production may result in land use change (LUC) emissions of greenhouse gases, including direct and indirect effects, which can significantly change the GHG profiles of biofuels ${ }^{94-96}$. A consequential approach is applied by the U.S EPA to estimate both direct LUC (dLUC) and indirect LUC (iLUC) impacts of bioethanol and biodiesel derived from corn, soybean, and other biofuel feedstocks, such as switchgrass. The Forestry and Agricultural Sector Optimization Model (FASOM) and the Food and Agricultural Policy Research Institute (FAPRI) model have been used by the EPA to estimate the impacts of biofuels feedstock production on domestic and international agricultural and livestock production, respectively. Then the change in agricultural land and livestock are converted to GHG emissions based on GHG emissions factors from IPCC. GHG emissions due to LUC are finally joined with fuel production emission to calculate the life cycle emissions of

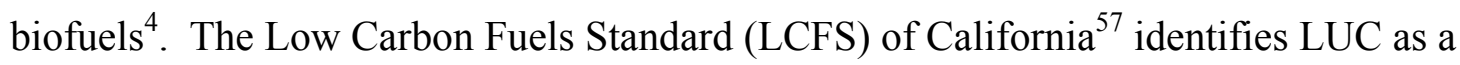
significant source of additional GHG emissions and includes the carbon intensity values assigned to those fuels in the regulation. The Global Trade Analysis Project (GTAP) model is used by the California Air Resource Board (CARB) to evaluate the worldwide land use conversion associated with biofuel production. The European Renewable Energy Directive $^{54}$ calculates annualized carbon emissions from dLUC over 20 year period. GHG emissions due to iLUC are also analyzed. The RSB GHG accounting scheme ${ }^{93}$ uses the same method to calculate the dLUC emissions, while not including iLUC impact in the scope of their study.

\subsubsection{Goal and scope}

In the literature, a limited number of LCAs have been conducted on the life cycle GHG emissions of HRJ produced from renewable oil feedstocks ${ }^{38-40,97}$. Here, we present an overview of the GHG emissions of HRJ produced from soybean, camelina, jatropha, 
palm, algae, pennycress, tallow, and corn oil. The results are either from literature sources, LCA models such as GREET 2012 and GHGenius 4.01 (inputs from existing fuel pathway in the models), or from simulation we conducted based on literature data using SimaPro 7.2, and all are compared to the 2005 petroleum jet fuel baseline ${ }^{77}$. The inputs, assumptions, and allocation methods used in those sources are also presented and compared. Furthermore, the authors identify the key drivers of the GHG emissions of HRJ. The system scope of this study includes the full life cycle of the HRJ, from biomass farming (exclude iLUC, but including dLUC), feedstock transport, oil extraction, refining and distribution, HRJ production, distribution and storage, and final use in aircraft engines. Life cycle GHG emissions are based on $1 \mathrm{MJ}$ of final fuel product, which is the functional unit of this study.

\subsection{HRJ from renewable feedstocks}

\subsubsection{HRJ from soybean oil}

Soybean oil is extensively used in U.S and Europe for biodiesel production ${ }^{38}$. Soybean crops have an oil content of about $18 \mathrm{wt} \%{ }^{98}$ and produce about $430 \mathrm{~L}$ of soybean oil per hectare per annum ${ }^{99}$. However, use of soybeans for fuel production competes with food markets, and thus may cause emissions due to LUC. The Stratton study ${ }^{85}$ shows that HRJ from soybean oil has GHG savings ranging from $32 \%$ to $69 \%$ compared to the petroleum jet fuel, depending on the soybean yield and farming energy inputs. According to this reference, the savings decrease to $7 \%$ to $-62 \%$ if dLUC are included, assuming the soybean fields are converted from Cerrado grassland in Brazil. If the soybean fields are converted from tropical rainforests, the GHG emissions due to LUC are even larger.

The life cycle GHG emission results for soybean HRJ are summarized in Table 4.2. The life cycle emissions are organized into two stages: well-to-pump (WTP) and pump-towake (PTW). It is assumed that carbon is sequestered during biomass growth, thus gaining a credit (-) in the WTP stage, and then is emitted to the atmosphere as $\mathrm{CO}_{2}$ when the biofuel is combusted in the jet engines. Stratton ${ }^{85}$ uses market value allocation methodology to split the energy and emissions between soybean meal and oil, while 
splitting emissions between HRJ and the co-products (naphtha and propane) based on their energy contents. In addition to the literature results, we ran the GREET 2012 model using the same allocation assumptions as in Stratton article ${ }^{85}$ as a comparison. GHGenius uses displacement methodology to calculate the life cycle GHG emissions of soybean derived HRJ. Displacement methodology was also applied in the GREET 2012 to compare to the GHGenius model. The Stratton and GHGenius model results show greater GHG savings (compared to GREET). The reasons for the differences in emissions are due to differences in the inputs (see Table 4.1 and Tables A1-A3), $\mathrm{N}_{2} \mathrm{O}$ emission from crop residues (Appendix A.1), co-product outputs (Table 4.1 and A3), economic value factors, and emission factors used within each of these models for fuels, chemicals, and electricity as discussed in Appendix A.1.

Table 4.2: Life cycle GHG emissions of soybean-derived HRJ

\begin{tabular}{|l|l|l|l|l|}
\hline $\mathrm{g} \mathrm{CO}_{2}$ eq/MJ LHV & $\begin{array}{l}\text { Stratton } \\
\text { (baseline) }^{85}\end{array}$ & $\begin{array}{l}\text { GREET } \\
\text { (allocation) }^{86}\end{array}$ & $\begin{array}{l}\text { GREET } \\
(\mathrm{SE})^{86}\end{array}$ & $\begin{array}{l}\text { GHGenius 4.01 } \\
(\mathrm{SE})^{87}\end{array}$ \\
\hline WTP & -33.5 & -25.6 & -30.3 & \\
\hline Soybean farming & & 8.91 & 23.53 & 89.2 \\
\hline Biomass credit & & -70.42 & -70.42 & \\
\hline Seed transport & & 1.27 & 3.35 & 2.12 \\
\hline Oil extraction & & 9.63 & -0.02 & -50.3 \\
\hline Oil transport & & 0.73 & 0.91 & 1.06 \\
\hline Fuel production & & 23.67 & 11.8 & -9.1 \\
\hline Fuel distribution & & 0.6 & 0.6 & 1.05 \\
\hline Fuel dispensing & & & & 0.63 \\
\hline PTW & 70.4 & 70.5 & 70.5 & \\
\hline Total & 37.0 & 44.9 & 40.2 & 34.6 \\
\hline GHG savings (\%) & 60.2 & 51.7 & 56.7 & 62.8 \\
\hline
\end{tabular}

* SE: system expansion (displacement) 


\subsubsection{HRJ from camelina}

Camelina is an oilseed plant (oil content $28-40 \mathrm{wt} \%$ ) of the Brassicaceae family which is native to northern Europe and central Asia ${ }^{100,101}$. Camelina has a relatively short growing season and is well suited to be planted as a spring annual or in milder winter ${ }^{88}$, thus it has the potential to be gown as a rotation crop with wheat on acres that would otherwise remain fallow. It can effectively reduce the insect and weed pressure and provide extra moisture and nutrient to the soil ${ }^{88}$. Moreover, camelina can be grown on marginal agricultural land. Therefore, studies have shown that no additional farm land is required to grow the camelina, thus no significant direct land use change impact is expected ${ }^{88,102}$. No significant indirect LUC impact is expected either since the limited non-biofuels use of camelina will not result in significant change on crop production or commodity markets ${ }^{88}$. In addition, it is tolerant to drought stress conditions, thus minimizing irrigation requirement ${ }^{23,102}$. Camelina crops can produce about $570 \mathrm{~L}$ of camelina oil per hectare per annum ${ }^{99}$ as an additional crop grown on wheat acreage. Camelina received preliminary acceptance as renewable feedstock by the EPA and the corresponding biofuels are expected to qualify as biomass-based diesel and advanced biofuels ${ }^{88}$.

Shonnard ${ }^{102}$ uses energy allocation (EA) to distribute GHG impacts among the various products and co-products. It was assumed that combustion of biofuels is carbon neutral because biogenic carbon is sequestered by photosynthesis during the biomass growth. This assumption is also applied by the EPA RFS2 ${ }^{103}$ and the LCFS of California ${ }^{57}$. The EPA ${ }^{88}$ allocates the GHG emissions of HRJ and RINs-generating co-products (diesel, LPG and naphtha) based on their energy contents, while using displacement for other coproducts (propane). All the EPA inputs and assumptions were applied in the SimaPro 7.2 ${ }^{41}$ to simulate the life cycle GHG emissions of camelina-derived HRJ. EA methodology was used in the GREET 2012 with all its default values to simulate the life cycle GHG results (EA), which are compared to the results simulated by SimaPro. Displacement methodology was also applied in the GREET model to compare with the GHGenius model. The results are summarized in Table 4.3. The GREET model generates comparatively higher results, mainly because the process requires high energy inputs 
(natural gas) but include less co-products (Table 4.1). GREET also shows higher farming emissions compared to the Shonnard et al. (2010) study and SimaPro simulation with EPA inputs, because of the $\mathrm{N}$ fertilizer requirement (Table A.4) and higher allocation factor of camelina oil assumed in GREET as discussed in Appendix A.2. GHGenius predicts the highest cultivation emissions, mainly because the high $\mathrm{N}$ fertilizer input (Table A.4) yields more $\mathrm{N}_{2} \mathrm{O}$ emission.

Table 4.3: Life cycle GHG emissions of camelina derived HRJ from various sources

\begin{tabular}{|l|l|l|l|l|l|}
\hline g CO $_{2}$ eq/MJ & $\begin{array}{l}\text { Shonnard } \\
\text { et al }\end{array}{ }^{102}$ & $\begin{array}{l}\text { SimaPro (EPA } \\
\text { data })^{88}\end{array}$ & $\begin{array}{l}\text { GREET } \\
(\text { EA) }\end{array}$ & $\begin{array}{l}\text { GREET } \\
(\mathrm{SE})^{86}\end{array}$ & $\begin{array}{l}\text { GHGenius } \\
(\mathrm{SE})\end{array}$ \\
\hline Camelina farming & 8.53 & 12.98 & 19.3 & 39.1 & 57.78 \\
\hline Biomass credit & & & -70.42 & -70.42 & \\
\hline Seed transport & 0.64 & 2.42 & 0.89 & 1.8 & 1.17 \\
\hline $\begin{array}{l}\text { Oil extraction } \\
\text { (refining) }\end{array}$ & 2.80 & 2.17 & 2.54 & -5.08 & -25.25 \\
\hline Oil transport & 2.02 & & 0.54 & 0.67 & 0.58 \\
\hline Fuel production & 9.04 & 6.22 & 23.82 & 11.8 & -3.77 \\
\hline Fuel distribution & 0.4 & 0.74 & 0.6 & 0.6 & 1.05 \\
\hline Fuel dispensing & & & 70.5 & 70.5 & \\
\hline Fuel combustion & & & 47.6 & 48.9 & 31.9 \\
\hline Total & 23.5 & 21.37 & 77.0 & 47.4 & 65.7 \\
\hline GHG savings (\%) & 74.7 & 78.8 & 0.63 \\
\hline
\end{tabular}

* The feedstock and fuel distribution emissions were obtained from EPA soybean results, as EPA assumes the same distribution inputs for camelina as for soybean

\subsubsection{HRJ from jatropha}

Jatropha presents promising properties as oil feedstock for biofuel production ${ }^{97}$ and can produce about $1850 \mathrm{~L}$ of oil per hectare per annum ${ }^{99}$. 
Stratton ${ }^{85}$ obtained the cultivation data from a test-plot in India. The authors assumed solvent based oil extraction and that the co-products (husks, shell and meal) were burned for electricity. Energy allocation was used to account for all the products and co-products along the life cycle. LUC impact was neglected because marginal land was used and no estimates of root carbon sequestration from jatropha were available. Bailis and $\mathrm{Baka}^{97}$ studied Brazilian jatropha for jet production, and long distance transport by truck for seeds $(750 \mathrm{~km})$ and transoceanic freighter for oil (U.S. market). The jatropha cake/husk was either considered as fertilizer to displace synthetic fertilizer or as energy source to generate electricity. The HRJ showed a GHG reduction of 55\% relative to conventional jet fuel if dLUC impacts are excluded ${ }^{97}$. However, the impact of dLUC significantly changed the total emissions, when the jatropha plantation land was converted from various land types. Land converted from tropical forests emitted the highest amount of GHG to the atmosphere. Sensitivity analyses were also performed to explore the effect of jatropha yield and allocation methodologies. Table 3.4 summarizes the life cycle GHG emissions of jatropha HRJ. The displacement method generates lower GHG emissions because of the credits from the jatropha cake/husk, especially if they are combusted for electricity generation. The fuel co-products of HRJ production also give GHG credit when they displace their petroleum counterparts. But GREET 2012 exhibits low GHG credit at the fuel production stage because it assumes low co-product yields (Table 4.1). GHGenius shows the highest GHG emissions, especially at the farming stage even though it assumes the lowest fertilizers requirement (Table A.6). This seemingly contradictory result is because GHGenius shows high emission factors for the fertilizers and includes $\mathrm{N}$ from crop residues, which are converted to $\mathrm{N}_{2} \mathrm{O}$ emissions (Appendix A.3). In addition, GHGenius doesn't account for the jatropha cake/husk credit due to the toxicity, and thus no credit is given at the oil extraction stage. 


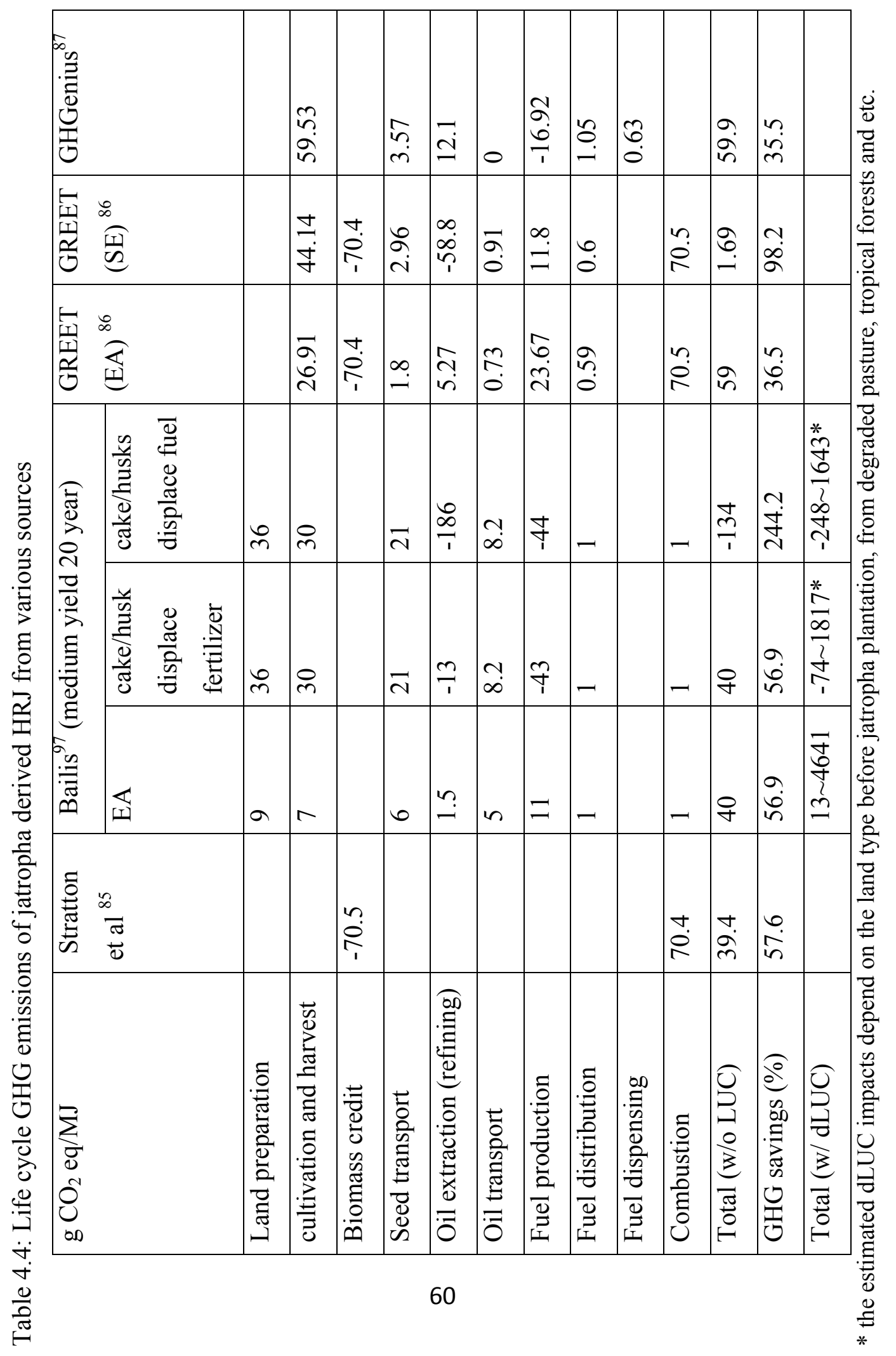




\subsubsection{HRJ from rapeseed/canola}

Rapeseed (Brassica napus) is a widely cultivated annual crop with high oil (44\%) and protein $(23 \%)$ content $^{104}$. Rapeseed crops produce about $1135 \mathrm{~L}$ of oil per hectare per annum ${ }^{99}$. The oil can be used for human consumption and HRJ production ${ }^{85}$, and rapeseed meal produced after oil extraction is a high protein $\left(38-43 \%{ }^{105}\right)$ animal feed and fertilizer. The word "canola" was adopted in 1979 to describe "double low" (low erucic acid and low glucosinolate) rapeseed cultivar ${ }^{106}$. EPA analyzed the canola oil biodiesel pathway and qualified it as biomass-based diesel ${ }^{107}$.

Stratton ${ }^{85}$ used market allocation for the rapeseed meal as it is used as animal feed. The emissions of HRJ and co-products were allocated based on their energy contents. We ran the GREET 2012 model using the same allocation approach as a comparison. In addition, we obtained canola cultivation and oil extraction data from the EPA ${ }^{107}$ and a CARB report ${ }^{108}$. Both the U.S and Canada scenarios studied by the EPA were simulated using SimaPro 7.2 (energy allocation). Certain inputs, such as electricity grid mix, were adjusted to be consistent with facility location. In their LCA analyses, CARB assumes that canola oils are produced in Canada and shipped 1200 miles $(1930 \mathrm{~km})$ by rail for fuel production. This assumption was applied in our study as well. Energy allocation method was applied in GREET to compare to results generated using SimaPro software. Generally, the HRJ produced from rapeseed/canola shows higher GHG emissions than other oil plants (Table 4.5), mainly because of the high fertilizer inputs (Table A.8). Rapeseed straws contain $0.75 \mathrm{wt} \% \mathrm{~N}^{109}$, which also contributes to $\mathrm{N}_{2} \mathrm{O}$ emissions (direct and indirect). The GREET model generates higher GHG emissions than the SimaPro software for two reasons: (1). GREET uses a lower value for rapeseed meal LHV making the allocation factor of oil higher (Appendix A.4) (2). GREET assumes much higher natural gas use and lower co-products yield during HRJ production (Table 4.1). Therefore, the HRJ has higher feedstock and fuel production emission. Canola oil produced in Canada shows a more favorable result to that produced in U.S, because Canadian canola has a lower fertilizer requirement. The emission factor of Canadian electricity is also lower because the electricity generation uses more renewable sources. 
Stratton also considered GHG emission due to LUC from rapeseed cultivation. The rapeseed is assumed to be planted on set-aside agricultural land (land removed from agricultural use to benefit the ecosystem and wildlife). When the land is returned for agricultural use, the sequestered $\mathrm{C}$ and $\mathrm{N}$ in soils are depleted over time. The GHG emission (43 $\left.\mathrm{g} \mathrm{CO}_{2} \mathrm{eq} / \mathrm{MJ}\right)$ due to this impact was estimated by Stratton.

Table 4.5: Life cycle GHG emissions of rapeseed derived HRJ from various sources

\begin{tabular}{|c|c|c|c|c|c|c|}
\hline \multirow{2}{*}{$\mathrm{g} \mathrm{CO}_{2} \mathrm{eq} / \mathrm{MJ}$} & \multirow{2}{*}{$\begin{array}{l}\text { Stratton } \\
\text { (baseline) } \\
85\end{array}$} & \multirow{2}{*}{$\begin{array}{l}\text { GREET } \\
2012 \\
\text { (Stratton } \\
\text { allocation) } \\
86\end{array}$} & \multirow{2}{*}{$\begin{array}{l}\text { GREET } \\
2012 \\
(\mathrm{EA})^{86}\end{array}$} & \multicolumn{3}{|c|}{ SimaPro (EA) } \\
\hline & & & & $\begin{array}{l}\text { Canada } \\
\text { case }^{107}\end{array}$ & $\begin{array}{l}\text { U.S } \\
\text { case } \\
107\end{array}$ & $\begin{array}{l}\text { CARB } \\
108\end{array}$ \\
\hline $\begin{array}{l}\text { Seed cultivation } \\
\text { and harvest }\end{array}$ & & 30.31 & 27.24 & 21.34 & 20.6 & 15.33 \\
\hline Biomass credit & -70.5 & -70.42 & -70.42 & & & \\
\hline Seed transport & & 0.82 & 0.74 & 0.15 & 0.15 & 0.15 \\
\hline $\begin{array}{l}\text { Oil extraction and } \\
\text { refining }\end{array}$ & & 5.44 & 3.79 & 4.18 & 4.74 & 3.15 \\
\hline Oil transport & & 0.54 & 1.65 & 1.9 & 0.9 & 1.9 \\
\hline Fuel production & & 23.67 & 23.67 & 13.8 & 13.8 & $13.16^{b}$ \\
\hline Fuel distribution & & 0.59 & 0.60 & 0.4 & 0.4 & 0.4 \\
\hline Combustion & 70.4 & 70.5 & 70.5 & & & \\
\hline Total (w/o LUC) & 54.9 & 61.4 & 57.7 & 41.3 & 41.0 & 34.1 \\
\hline GHG savings (\%) & 40.9 & 33.9 & 37.9 & 55.5 & 55.9 & 63.3 \\
\hline Total (w/ LUC) & $97.9^{\mathrm{a}}$ & & & & & \\
\hline
\end{tabular}

a: assume rapeseed planted on set-aside agricultural land

b: California electricity mix obtained from EERE ${ }^{110}$ 


\subsubsection{HRJ from palm oil}

Oil palm is a perennial crop, which produces fresh fruit bunches (FFB) containing 20

$\mathrm{wt} \%$ oil ${ }^{111}$. Palm oil is the largest and least expensive edible oil in the global oils and fats market $^{112}$. Roughly 5600 L of palm oil can be produced per hectare per annum ${ }^{99}$, which demonstrates high productivity for palm acreage compared to other conventional oilseed crops. It is considered the most promising biodiesel feedstock and the production is expanding, especially in Malaysia and Indonesia, where $90 \%$ of global palm oil is produced $^{112}$.

In the oil mills, palm kernel, mesocarp fiber, shell and empty fruit bunches (EFB) are coproduced as well as palm oil. Palm kernel is further processed to produce kernel oil, and kernel expeller is produced as a co-product, which can be used as animal feed. The fibers and shell are usually burned on-site for heat and power. The EFB are returned to soils as organic fertilizers. A waste stream called palm oil mill effluent (POME) is also produced. The POME is treated in a series of anaerobic lagoons or tanks before discharged, which results in methane emissions. If the oil mills employ covered lagoons or closed digester tanks, the methane can be captured and then either flared or used to generate electricity and/or steam ${ }^{85,113}$.

Stratton ${ }^{85}$ used the same allocation approach for palm oil as for soybean and rapeseed (market value and energy allocation). The same allocation approach was applied by our study here using the GREET 2012 model, and utilizing palm inputs from its existing pathway. The EPA study ${ }^{113}$ assumes that palm kernel $(0.27 \mathrm{~kg} / \mathrm{kg}$ oil $)$ are used as animal feed (no credit is given), and it allocates the energy and emission burdens between the HRJ and RIN-generating co-product (diesel) based on their energy content, while assuming propane and LPG displace natural gas, and naphtha displaces conventional gasoline. This allocation approach employed by the EPA along with their inputs was used by our study to calculate GHG emissions using SimaPro 7.2. System expansion approach was also used in GREET and the results compared to the emissions from GHGenius, which assumes system expansion. The GHG emissions of palm oil HRJ are shown in 
Table 4.6. GHGenius yields the highest emission result because: 1. the emission factors of fertilizers are higher; 2. Seed yield is lower but the fertilizer use is much higher (Table A.11), $\mathrm{N}$ in crop residues is also included in the model (Appendix A.5), which contributes to $\mathrm{N}_{2} \mathrm{O}$ emission; 3. Oil extraction emission includes $\mathrm{CH}_{4}$ emission from POME treatment (Appendix A.5). SimaPro model using the EPA inputs generates the lowest emission because of the low fertilizers use (Table A.11) and the allocation method the EPA assumes. The EPA ${ }^{113}$ estimates the GHG emissions due to LUC based on land cover types projected for conversion. Forest and mix land cover types (equal shares of forest, grassland, shrubland and cropland) would account for over $80 \%$ of land cover impacted by oil palm expansion in Indonesia and Malaysia, and thus results in a large carbon debt due to dLUC. LUC emission also comes from tropical peat swamp drainage to prepare land for palm plantation. The tropical peat soils sequester approximately 20 times more carbon than forest biomass on a per hectare basis because the peat forest removes $\mathrm{CO}_{2}$ from atmosphere and stores it in biomass and peat deposits ${ }^{113}$. Stratton also concluded that large amounts of GHG would be emitted, especially if tropical forests are converted to palm plantations. 
Table 4.6: Life cycle GHG emissions of palm oil derived HRJ from various sources

\begin{tabular}{|c|c|c|c|c|c|}
\hline $\mathrm{g} \mathrm{CO}_{2} \mathrm{eq} / \mathrm{MJ}$ & $\begin{array}{l}\text { Stratton } \\
\text { (baseline) }^{85}\end{array}$ & $\begin{array}{l}\text { SimaPro } \\
\left(\mathrm{EPA}^{113}\right)\end{array}$ & $\begin{array}{l}\text { GREET (EPA } \\
\text { allocation) }\end{array}$ & $\begin{array}{l}\text { GREET } \\
(\mathrm{SE})^{86}\end{array}$ & $\begin{array}{l}\text { GHGenius }^{87} \\
\text { (SE) }\end{array}$ \\
\hline $\begin{array}{l}\text { Seed } \\
\text { cultivation and } \\
\text { harvest }\end{array}$ & & $6.49 / 8.69^{b}$ & 10.16 & 12.76 & 30.07 \\
\hline Biomass credit & -70.5 & & -70.4 & -70.4 & \\
\hline Seed transport & & 1.18 & 0.54 & 0.68 & 0.49 \\
\hline Oil extraction & & $-3.01^{c}$ & 1.29 & 0.81 & $34.56^{\mathrm{e}}$ \\
\hline Oil transport & & 1.95 & 2.87 & 3.55 & 3.45 \\
\hline $\begin{array}{l}\text { Fuel } \\
\text { production }\end{array}$ & & -0.33 & 23.67 & 11.8 & -15.56 \\
\hline $\begin{array}{l}\text { Fuel } \\
\text { distribution }\end{array}$ & & 1.56 & 0.6 & 0.6 & 1.05 \\
\hline $\begin{array}{l}\text { Fuel } \\
\text { dispensing }\end{array}$ & & & & & 0.63 \\
\hline Combustion & 70.4 & & 70.5 & 70.5 & \\
\hline $\begin{array}{l}\text { Total (w/o } \\
\text { LUC) }\end{array}$ & 30.1 & $7.84 / 10.03$ & 39.2 & 30.3 & 54.7 \\
\hline $\begin{array}{l}\text { GHG savings } \\
(\%)\end{array}$ & 67.6 & $91.6 / 89.2$ & 57.8 & 67.4 & 41.1 \\
\hline $\begin{array}{l}\text { Total (w/ } \\
\text { LUC) }\end{array}$ & $39.8 / 166^{\mathrm{a}}$ & $69.9 / 72.1^{\mathrm{d}}$ & & & \\
\hline
\end{tabular}

a: assuming palm field converted from logged over forest and tropical rainforest, respectively.

b: represent Indonesia and Malaysia respectively

c: does not include $\mathrm{CH}_{4}$ emission from POME treatment, which is $41.71 \mathrm{~g} \mathrm{CO}_{2}$ eq/MJ HRJ ${ }^{113}$

$\mathrm{d}$ : LUC calculated from mean LUC of palm oil RD (44.55 $\left.\mathrm{g} \mathrm{CO}_{2} \mathrm{eq} / \mathrm{MJ} \mathrm{RD}\right)$

e: includes $\mathrm{CH}_{4}$ emission from POME treatment 


\subsubsection{HRJ from pennycress}

Field Pennycress (Thalaspi arvense L.) is a winter annual native to Eurasia and now widely distributed throughout temperate North America ${ }^{114}$. It has the potential to be grown between traditional summer crops (soybeans, wheat) to produce renewable biomass for fuel production ${ }^{115}$. Phippen et al ${ }^{116}$ has shown that soybean planted after the spring pennycress harvest show normal plant growth, flowering, pod formation, oil constituents and protein profiles, while the soybean yields are slightly higher possibly due to increased soil moisture. Approximately 16.2 million hectares of land are available each year for the winter production of pennycress with no impact to the food supply or critical wildlife habitats ${ }^{26}$. The harvested seeds contain up to $36 \mathrm{wt} \%$ of oil ${ }^{13}$, which could become a sustainable alternative for advanced biofuels production. Pennycress crops can produce about $935 \mathrm{~L}$ of oil per hectare per annum as an additional crop for soybean acreage $^{117}$. The de-oiled presscake has high energy content, suitable for direct combustion, gasification, or pyrolysis oil production ${ }^{13}$, and it can also be used as animal feed $^{117}$.

Fan et $\mathrm{al}^{117}$ analyzed the GHG emissions of pennycress HRJ (Table 4.7). The pennycress is assumed to be grown in the Midwestern United States as a winter annual. After harvest, the seeds are trucked to a centralized processing facility where the oil is recovered and a de-oiled meal displaces soybean meal as animal feed. The oil is then transported 200 miles $(320 \mathrm{~km})$ by rail to a hydroprocessing plant for HRJ production. Final fuel product is distributed to market over a distance of 75 miles $(120 \mathrm{~km})$ by truck. Both SE and allocation approaches (energy and market value) were employed. The $\mathrm{H}_{2}$ is assumed to be either from an external source using SMR or produced internally using the fuel co-products. The GHG emissions are summarized in Table 4.7. The SE (displacement) method yields the most favorable results because of two reasons: the soy meal displaced by presscake represents a significant GHG credit, and the co-products of the conversion process have much lower carbon intensity than the fossil fuels they displace. MVA method generates the highest results because of the high value of pennycress oil, majority of the emission burdens from cultivation and oil extraction are 
allocated to the oil. The GHG emissions of the internal $\mathrm{H}_{2}$ scenario are lower than for SMR $\mathrm{H}_{2} . \mathrm{H}_{2}$ from SMR has GHG burden of $11.4 \mathrm{~kg} \mathrm{CO}_{2} \mathrm{eq} / \mathrm{kg} \mathrm{H}_{2}$, while the fuel coproducts used for $\mathrm{H}_{2}$ production carry much lower GHG burdens. The integrated (int) $\mathrm{H}_{2}$ scenario calculated by SE method yields less GHG savings (compared to SMR scenario) because the co-products are used internally, instead of displacing the petroleum counterparts, thus the GHG credit of the co-products are reduced.

Table 4.7: Life cycle GHG emissions of pennycress HRJ ${ }^{117}$

\begin{tabular}{|l|l|l|l|l|l|l|}
\hline & \multicolumn{5}{|c|}{$\begin{array}{l}\text { Integrated } \mathrm{H}_{2} \text { (from fuel co- } \\
\text { products) }\end{array}$} \\
\hline $\mathrm{g} \mathrm{CO}_{2}$ eq/MJ & HRJ (SE) & HRJ (EA) & HRJ (MVA) & HRJ (SE) & HRJ (EA) & HRJ (MVA) \\
\hline $\begin{array}{l}\text { cultivation and } \\
\text { harvest }\end{array}$ & 70.35 & 16.25 & 28.34 & & & \\
\hline Seed transport & 1.66 & 0.38 & 0.67 & & & \\
\hline Oil extraction & -41.45 & 1.36 & 2.37 & & & \\
\hline Oil transport & 0.61 & 0.31 & 0.35 & & & \\
\hline Fuel production & -49.77 & 14.02 & 15.65 & & & \\
\hline Fuel transport & 0.35 & 0.35 & 0.35 & & & \\
\hline Total & -18.3 & 32.7 & 47.7 & -12.2 & 26.4 & 40.3 \\
\hline GHG savings (\%) & 119.6 & 64.8 & 48.6 & 113.1 & 71.6 & 56.6 \\
\hline
\end{tabular}

\subsubsection{HRJ from algae oil}

Microalgae has received a significant level of renewed interest as an alternative fuel feedstock, because many species exhibit significant oil contents and biomass yields are predicted to be several orders of magnitude larger than terrestrial crops. In addition, microalgae can be grown on marginal lands thus not competing with food production ${ }^{118,119}$ and utilize non-potable water resources. Optimal algae growth and oil content observed in laboratory settings have yet to be achieved on a commercial scale, but several companies and researchers are actively investigating ways to streamline 
various segments of the algae fuels value chain. In addition to the factors mentioned above, best practices in algae dewatering and efficient re-use of the non-lipid algae fraction (often termed 'lipid-extracted algae or LEA) are critical to economic and environmental sustainability of the energy and nutrient-intensive algae cultivation and harvesting process. Estimates for algae indicate the potential to produce more than 58,700 to $136,900 \mathrm{~L}$ of algae oil per hectare per annum ${ }^{118}$, much greater compared to all oilseed crops.

Stratton ${ }^{85}$ reviewed current literature as well as technical processing information that arose during the last major algae biofuels research period 20-30 years ago. GREET 2012 also includes life-cycle pathways of algal biofuels, including HRJ, and the algae specific GREET model integration tool will continue to undergo changes as the industry evolves ${ }^{120,121}$. The baseline algal HRJ life cycle of these comprehensive studies assumes a $25 \%$ oil content for algae cultivation in open pond raceways, but several different assumptions are made concerning unit operations for harvesting, dewatering, and oil extraction. Stratton assumes that cultivation will be followed by settling and centrifugation to achieve $4 \%$ and $25 \%$ solids, respectively, followed by thermal drying to $90 \%$ solids. Hexane extraction isolates algal oils, which are then converted to HRJ. Energy allocation is used to divide burdens among conversion co-products. Anaerobic digestion of the LEA fraction provides internal heat for thermal drying operations, while also facilitating recovery and re-use of $50-75 \%$ of macronutrients required for algae cultivation. In the baseline GREET model, dissolved air flotation and centrifugation are used to achieve 6\% and $20 \%$ solids, respectively, and oil extraction is assumed to occur via a wet hexane extraction procedure. Anaerobic digestion is also utilized to decompose the LEA fraction into methane-containing biogas, $2 \%$ of which is assumed to escape as fugitive emissions. Electricity produced from biogas combustion supplements a majority of power requirements in the process (Table A.14). Anaerobic digestion solids are assumed to have value as a soil amendment and fertilizer displacement, and a credit is given for application of this material on farm fields. Energy allocation is used at the fuel conversion stage to divide impacts among HRJ co-products. Baseline results of both 
studies are displayed in Table 4.8. The differences in model assumptions presented above account for key differences in the overall life cycle, with the GREET model having larger overall emissions due to large extraction, fuel conversion, and algae growth emissions, despite a large credit for electricity production and export to the grid.

Table 4.8: Life cycle GHG emissions of algal oil derived HRJ

\begin{tabular}{|l|l|l|}
\hline $\mathrm{g} \mathrm{CO}_{2}$ eq / MJ HRJ & GREET 2012 & ${\text { Stratton et } \mathrm{al}^{85}}^{86}$ \\
\hline $\mathrm{CO}_{2}$ sequestration credit & -70.4 & -70.5 \\
\hline $\mathrm{CO}_{2}$ pumping & 4.4 & \\
\hline Growth / harvesting & 24.64 & \\
\hline Dewatering & 8.21 & \\
\hline Oil extraction & 33.14 & \\
\hline Subtotal & 70.4 & $37.7^{\mathrm{a}}$ \\
\hline Algae oil transport & 0.62 & 0.6 \\
\hline Fuel conversion & 29.9 & 10.3 \\
\hline LEA soil amendment credit & -0.16 & 0 \\
\hline LEA biogas recovery & 19.5 & $1.8^{\mathrm{b}}$ \\
\hline LEA biogas cleanup / combustion & -49.2 & $0^{\mathrm{c}}$ \\
\hline Total WTP emissions & 0.9 & -19.7 \\
\hline Fuel use & 70.5 & 70.4 \\
\hline Total WTW emissions & 71.4 & 50.7 \\
\hline GHG savings (\%) & 23.1 & 45.4 \\
\hline
\end{tabular}

a: includes $8.1 \mathrm{~g} \mathrm{CO}_{2} \mathrm{eq} / \mathrm{MJ}$ of $\mathrm{N}_{2} \mathrm{O}$ emissions that were aggregated for the entire life cycle of the HRJ process. The Stratton report assumes that the majority of $\mathrm{N}_{2} \mathrm{O}$ emissions occur in the algae cultivation stage from conversion of $\mathrm{N}$-containing fertilizers, so we place the $\mathrm{N}_{2} \mathrm{O}$ emissions burden here.

b: due solely to methane emissions. Methane emissions are reported separately in the Stratton report, but as in GREET we assume that most $\mathrm{CH}_{4}$ emissions occur during the anaerobic digestion gas recovery phase c: LEA biogas combusted for heat to dry algae to $90 \%$ solids 


\subsubsection{HRJ from tallow}

Inedible tallow is rendered from animal tissues by the application of heat. The raw materials are dehydrated and cooked, and then the protein and fat are separated. The final products include tallow, and carcass meal. The carcass meal can be used for livestock feed, soap, production of fatty acids, etc ${ }^{122}$. Currently, inedible tallow is mostly used as animal feed ${ }^{123}$. However, the Food and Drug Administration (FDA) is likely to ban the use of tallow and other animal based waste products due to bovine spongiform encephalopathy and other similar diseases. In addition, large amount of Distiller's Dried Grains with Solubles (DDGS) also reduces the use of processed animal waste as feed supplement ${ }^{123}$. Therefore, the use of inedible tallow to produce fuels is expected to expand while not causing any negative indirect effects (economic or LUC).

The CARB studied the inedible tallow derived renewable diesel. The rendering inputs (Table A.16) were obtained from the study and used to analyze tallow HRJ using SimaPro 7.2, and then compare results to the GHGenius model. The crude tallow is pretreated to remove the impurities and inorganic compounds. The pretreatment inputs were provided by a UOP licensee, which include chemicals such as citric acid, bleaching earth, Trisyl, and energy inputs such as electricity and steam. The pretreatment produces soap stocks as co-product. The inputs of HRJ production were obtained from confidential UOP design data, which are similar to the inputs reported by Stratton (Table 4.1). Both EA and SE approach were applied to give credits to the co-products, including the soap and fuel products. The CARB study doesn't consider the bone meal as a co-product of tallow rendering because they don't expect it to displace animal feed for the reasons aforementioned. However, the GHGenius assumes that the bone meal $(2.28 \mathrm{~kg} / \mathrm{L}$ crude tallow) are used as animal feed to displace soybean meal (412 $\mathrm{g} \mathrm{CO}_{2} \mathrm{eq} / \mathrm{kg}$ meal), results in a $\mathrm{GHG}$ credit of $27.3 \mathrm{~g} \mathrm{CO}_{2} \mathrm{eq} / \mathrm{MJ}$ crude tallow. The extra bone meal credit of GHGenius makes tallow rendering emissions comparable to the SimoPro-CARB simulation, even when GHGenius assumes much higher natural gas and electricity use than does CARB (Table A.16). The GHGenius model predicts higher fuel production emissions (Table 4.9) compared to SimaPro (displacement), mainly because it assumes 
higher energy requirement and lower fuel co-products (Table 4.1). Energy allocation leads to the highest emissions. Although the rendering impact is smaller because some of the impacts are allocated to the fuel co-products, it has higher fuel production emission because it is not subtracting the GHG credit from the fuel co-products.

Table 4.9: Life cycle GHG emissions of tallow derived HRJ

\begin{tabular}{|l|l|l|l|}
\hline $\mathrm{g} \mathrm{CO}_{2}$ eq/MJ & SimaPro (EA) & SimaPro (SE) & GHGenius $^{87}(\mathrm{SE})$ \\
\hline Tallow rendering & 17.29 & 27.54 & 25.55 \\
\hline Tallow transport & & & 5.58 \\
\hline Tallow pretreatment & 0.92 & 1.03 & 0 \\
\hline Fuel production & 12.72 & -27.81 & -16.38 \\
\hline Fuel distribution & 0.4 & 0.4 & 1.05 \\
\hline Fuel dispensing & & & 0.63 \\
\hline Total & 31.42 & 1.30 & 16.43 \\
\hline GHG savings (\%) & 66.2 & 98.6 & 82.3 \\
\hline
\end{tabular}

\subsubsection{HRJ from fuel grade corn oil}

Fuel grade corn oil can be extracted from whole stillage, thin stillage or distillers grains with solubles (DGS) after the ethanol distillation process. The corn oil extraction system can be added to existing corn ethanol plants with no impact on the ethanol yield while increasing plant energy efficiency and total fuel yield ${ }^{124,125}$. Biodiesel, renewable diesel and jet fuel from fuel grade corn oil have been accepted by the EPA as RINs generating pathways ${ }^{88}$.

Our study analyzed the life cycle GHG emissions of HRJ from fuel grade corn oil. The feedstock is produced at a corn ethanol plant, and all the emissions associated with corn farming and harvest, iLUC, and ethanol production are allocated to the ethanol as ethanol is the target product. Corn oil only carries energy and emission burden from the oil extraction step. The oil extraction inputs reported by both Mueller ${ }^{124}$ and CARB ${ }^{125}$ 
(Appendix A.8 and Table A.17) were analyzed in our study. The oil is then pretreated to remove impurities and inorganics (metals). The pretreatment inputs (Table A.18) were assumed to be the same as camelina oil reported by Shonnard ${ }^{102}$. The refined oil is then catalytically converted to HRJ in the integrated hydroprocessing facility. Input data for HRJ production were obtained from confidential UOP design, which are similar to those reported by Stratton ${ }^{38}$ (Table 4.1). Energy allocation was applied for the co-products. The $\mathrm{H}_{2}$ was assumed to be produced from SMR using natural gas. Final fuel products are distributed to the market within a radius of $150 \mathrm{~km}$.

The GHG emissions of corn oil derived HRJ are shown in Table 4.10. The oil extraction system reported in the CARB report presents a more favorable result, because of the GHG credit from the energy savings from DDGS drying process due to corn oil extraction (Appendix A.8). The other stages show the same results because of the same inputs used.

Table 4.10: Life cycle GHG emissions of HRJ from fuel grade corn oil (EA)

\begin{tabular}{|l|l|l|}
\hline $\mathrm{g} \mathrm{CO}_{2}$ eq/MJ & SimaPro $\left(\right.$ Mueller $\left.^{124}\right)$ & SimaPro $\left(\mathrm{CARB}^{125}\right)$ \\
\hline Oil extraction & 10.9 & $-5.01^{*}$ \\
\hline Oil refining & 0.61 & 0.61 \\
\hline HRJ production & 13.7 & 13.7 \\
\hline HRJ distribution & 0.4 & 0.4 \\
\hline Total & 26 & 9.7 \\
\hline GHG savings (\%) & 72 & 89.6 \\
\hline
\end{tabular}

* oil extraction emission includes the reduction in the DDGS co-product credit

\subsection{Discussion}

HRJ from renewable oils show a wide range of life cycle GHG emissions, especially when the range includes the potential LUC impact. HRJ from algae shows the highest GHG burdens among all the feedstocks we reviewed, mainly because of the high cultivation and oil extraction impacts. Current estimates of algae production and refining 
have taken a conservative approach when estimating the potential requirements from immature technologies being investigated for several stages of the algae value chain, but a great deal of promising research is being conducted in this area to minimize external inputs and increase algae productivity and yield. Rapeseed also shows higher emissions than other feedstocks because of the $\mathrm{N}_{2} \mathrm{O}$ emission from higher $\mathrm{N}$ fertilizer requirement and $\mathrm{N}$ left in straw. However, SimaPro simulations that reflect an optimized hydroprocessing process indicate that rapeseed derived HRJ could still achieve more than $50 \%$ GHG savings. HRJ from waste products such as corn oil and tallow show the most favorable results because the feedstocks carry very little environmental burdens. Plantation of jatropha and palm could result in negative LUC impacts which offset the GHG savings of HRJ, especially if the plantation land is converted from peat soil and tropical forest. Oil crops cultivated on marginal agricultural land such as algae and jatropha, rotation crops such as camelina and pennycress, and waste products such as fuel grade corn oil and tallow strive to eliminate unwanted LUC impacts because they do not compete with food production.

In addition to the LUC, cultivation is often the major GHG contributor, especially for the oil plants such as camelina and rapeseed. $\mathrm{N}$ fertilizer (and $\mathrm{N}$ in crop residues) is responsible for most of the emissions in the cultivation stage due to direct and indirect $\mathrm{N}_{2} \mathrm{O}$ emissions. Stratton, GREET 2012 and our simulation in SimaPro all use the IPCC tier 1 methodology to calculate the $\mathrm{N}_{2} \mathrm{O}$ emissions, conversion rate for $\mathrm{N}$ from synthetic fertilizers is $1.325 \%$ ( $1 \%$ from direct emission, $0.1 \%$ from volatilization, $0.225 \%$ from leaching and runoff), and nitrogen from crop residues $1.225 \%$ (no volatilization). The GHGenius assumes different direct and indirect (volatilization+leaching) emission factors for different crops. Different $\mathrm{N}$ fertilizers have very different emission factors, for example, ammonium nitrate has a much higher emission factor than urea ( $8.55 \mathrm{vs} 3.3 \mathrm{~kg}$ $\mathrm{CO}_{2}$ eq $/ \mathrm{kg} \mathrm{N}^{91}$ ). The choice of fertilizer can change the final GHG emissions of HRJ product as well. It is expected that the GHG emissions of HRJ will be further reduced in the future as advancements in agriculture are realized. Examples of these advancements include increased oilseed yield and reduction in the application of nitrogen fertilizer. 
Fuel production emissions vary from different models and SimaPro simulation, based on the utilities and $\mathrm{H}_{2}$ inputs, and the amount of co-products. If the fuel production process is integrated with the $\mathrm{H}_{2}$ production process to minimize natural gas inputs, the emissions from this stage can be significantly reduced.

LCA models can predict very different GHG emission results, because different process inputs and emission factors they assume. For example, the emission factors of electricity in GHGenius, GREET and SimaPro are 229, 677 and $745 \mathrm{~g} \mathrm{CO}_{2} \mathrm{eq} / \mathrm{kWh}$, respectively. The GREET model generates higher fuel production emissions than other sources because of higher natural gas required in HRJ production and lower co-products yields. GHGenius generally predicts high GHG emissions for HRJ production, mainly because of the larger fertilizer and energy inputs it assumes.

Use of displacement method or allocation method (mass, energy and market value) can also significantly change the energy and emission burdens allocated to the primary product HRJ. Displacement method is the most recognized approach to deal with the coproducts. It generally yields lower emission because of the negative credit. When allocation approach is chosen, the method should be determined by their potential use. For example, co-products with high protein contents such as soybean meal and rapeseed meal are likely to be used as animal feed, the energy and emission burdens should be allocated based on the market values. If the co-products are used for energy production, such as fuel gas and LPG, the burdens are best allocated based on their energy contents. Sensitivity analyses should be included in the LCA study to investigate the impacts of various allocation methods on the life cycle GHG emissions of HRJ.

\subsection{Conclusion}

HRJ produced from soybean, camelina, pennycress, fuel grade corn oil, and tallow all show over 50\% GHG savings compared to the 2005 petroleum jet baseline, which could qualify them as advanced biofuels according to the EPA RFS2 standard. Crops planted on marginal land, rotation crops, and waste materials such as tallow should be better 
utilized to produce biofuels and bioenergy, while avoiding competition with food based crops and the associated negative LUC impacts. 


\section{Chapter 5: Emission Reduction using RTP Green Fuel in Industry Facilities ${ }^{6}$}

\subsection{Introduction}

Heavy fuel oils are blends of the residues and distillates that are derived from various refinery distillation, cracking and reforming processes ${ }^{126}$. In 2011, the U.S industrial consumption of distillate fuel oil and residual fuel oil reached 2427 and 870 million gallons respectively ${ }^{127}$, which together result in greenhouse gas (GHG) emissions of 40 million metric ton $\mathrm{CO}_{2}$ eq approximately $\left(85 \mathrm{~g} \mathrm{CO}_{2} \mathrm{eq} / \mathrm{MJ}^{128}\right)$. Although responsible for only a small fraction of total domestic industrial GHG emissions (778 million metric ton $\mathrm{CO}_{2} \mathrm{eq}^{129}$ ), combustion of fuel oils calls for attention from an environmental perspective. In addition to greenhouse gas emissions, fuel oil combustion produces air pollutants such as $\mathrm{CO}, \mathrm{SOx}, \mathrm{NOx}$, particulate matters (PM) and organic compounds ${ }^{130}$. U.S electricity generation $^{47}$ is heavily dependent on fossil fuels such as coal, oil and natural gas. As a result, the power sector is the leading GHG contributor, responsible for 2414 million metric ton $\mathrm{CO}_{2}$ eq. Large amounts of criteria pollutants such as NOx (2.2 million metric ton) and $\mathrm{SO}_{2}$ (6.1 million metric ton) are emitted as well.

Fast pyrolysis technologies have been developed to produce renewable liquid fuels from lignocellulosic biomass ${ }^{131}$. Pyrolysis oil shows great promise to reduce the consumption of petroleum derived fuels and the resultant air emissions. It can be combusted in boilers and furnaces for heating to replace heavy fuel oil. ASTM D7544 standard specification ${ }^{132}$ covers detailed requirements for the pyrolysis oil in various heating applications. In addition to traditional heating oil uses, pyrolysis oil can also be combusted in a stationary diesel engine or gas turbines to generate electricity ${ }^{133}$. Similarly, pyrolysis oil can be cofired with coal and natural gas at conventional power plants for commercial electricity generation $^{131,134}$. It has also been demonstrated that pyrolysis oil can be upgraded to transportation fuels by deoxygenation reaction ${ }^{131}$. The upgrading technology has been

\footnotetext{
${ }^{6}$ This chapter was submitted to Energy \& Fuels for publication. Citation: Fan J, Shonnard DR, Kalnes TN, Streff M, Hopkins G. Emission Reduction using RTP Green Fuel in Industry Facilities: A Life Cycle Study.
} 
proven at laboratory scale by UOP and will be demonstrated at pilot scale by the end of 2013 in the Integrated Biorefinery (IBR) unit being built in Kapolei, Hawaii backed by a \$25 million award from the U.S. Department of Energy.

Fast pyrolysis is a fast thermal degradation process whereby biomass is rapidly heated and then rapidly cooled within seconds in the absence of oxygen ${ }^{135}$. The process generates mostly vapors, aerosols and some charcoal (char), and then upon condensation a liquid pyrolysis bio-oil is obtained. Maximum liquid yields are obtained with high heating rates, at reaction temperatures around $500^{\circ} \mathrm{C}$ and with short vapor residence times to minimize secondary cracking of the primary products ${ }^{135}$. A yield (weight) of liquid bio-oil (pyrolysis oil) up to $85 \%$ (wet basis or $70 \%$ dry basis) from forestry or agricultural biomass is reported in the literature ${ }^{136}$. The elemental and chemical composition of the pyrolysis oil depends on the reaction conditions and biomass feedstock, and typical properties and characteristics are presented in Table 5.1 and compared to the crude oil. The by-product char and non-condensable gas are used to provide process heat and to dry the input biomass ${ }^{134,135}$. 
Table 5.1: Typical properties and compositions of pyrolysis oil ${ }^{135,137,138}$

\begin{tabular}{|l|l|l|}
\hline & Pyrolysis oil & Crude oil \\
\hline Water content $(\mathrm{wt} \%)$ & $20-25$ & $<0.1$ \\
\hline Specific gravity & $1.15-1.2$ & $0.86-0.92$ \\
\hline Viscosity $(\mathrm{cp})$ at $50{ }^{\circ} \mathrm{C}$ & $40-100$ & 180 \\
\hline Acidity $(\mathrm{pH})$ & $2-3$ & $\mathrm{NA}$ \\
\hline Flash point $\left({ }^{\circ} \mathrm{C}\right)$ & $40-65$ & \\
\hline Lower heating value $(\mathrm{MJ} / \mathrm{kg})$ & $13-19$ & 44 \\
\hline $\mathrm{C}(\mathrm{wt} \%)$ & $44-52$ & $83-86$ \\
\hline $\mathrm{H}(\mathrm{wt} \%)$ & $6-7$ & $11-14$ \\
\hline $\mathrm{N}(\mathrm{wt} \%)$ & 0.2 & $<1$ \\
\hline $\mathrm{S}(\mathrm{wt} \%)$ & $<0.01$ & $<4$ \\
\hline $\mathrm{O}(\mathrm{wt} \%)$ & $28-40$ & $<1$ \\
\hline Ash (wt \%) & $<0.2$ & 0.1 \\
\hline
\end{tabular}

This study is based on one of the commercially practiced fast pyrolysis technologies, RTPTM Rapid Thermal Processing. This process utilizes a circulating transported bed reactor system, in which properly sized and dried lignocellulosic biomass is contacted with circulating hot sand in the reactor. The pyrolytic vapor is rapidly quenched to produce a high yield of liquid renewable fuel, or RTP green fuel. A basic process schematic of the RTP unit can be viewed in Figure 5.1 below. 


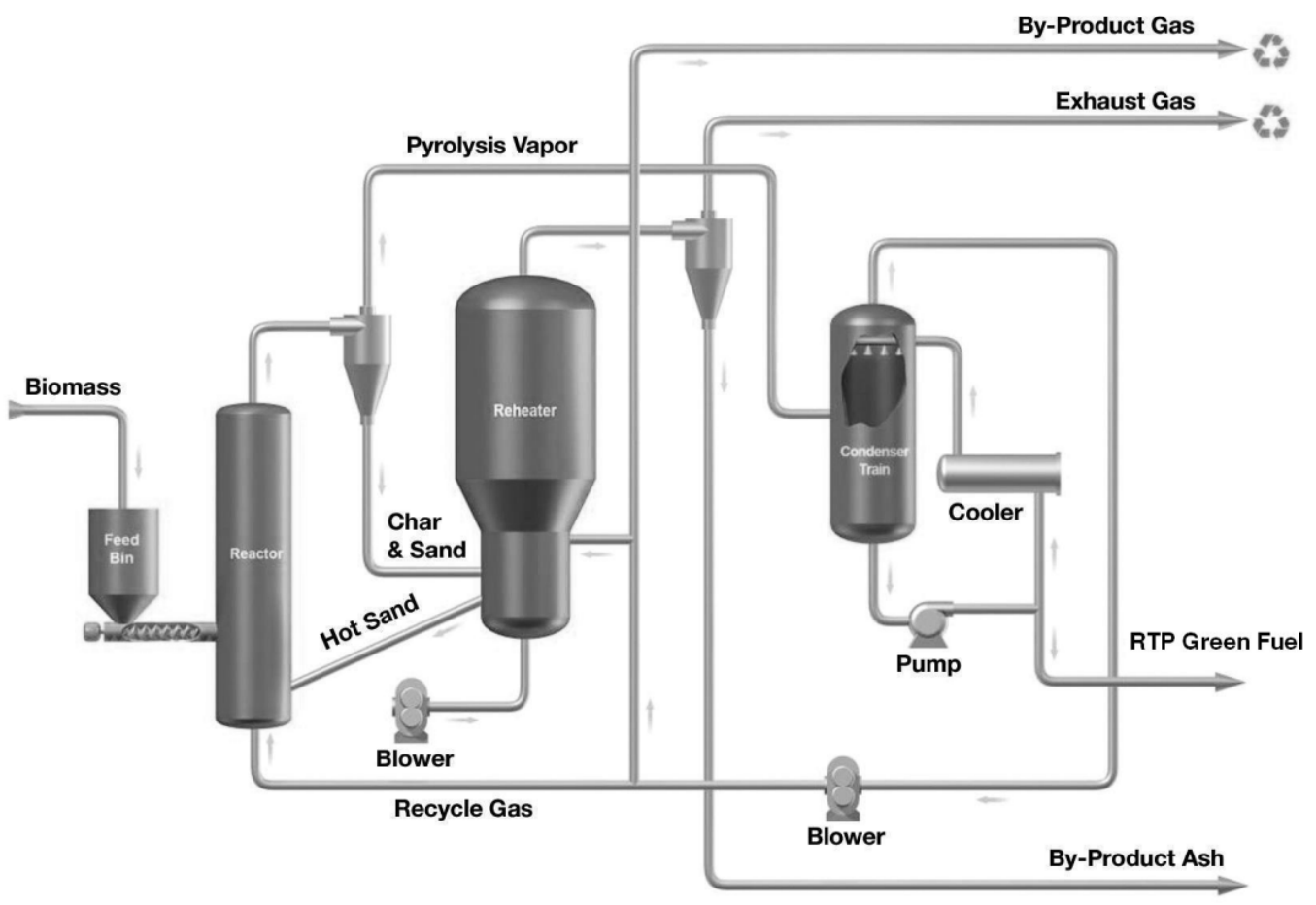

Figure $5.1^{7}$ : Process schematic diagram of the RTP unit ${ }^{139}$

As-received biomass is dried and mechanically milled to the appropriate moisture content (5-6 \%) and size (3-6 mm) prior to feeding in the RTP reactor by means of an auger or screw conveyor. The prepared feed contacts the circulating hot sand in the reactor where heat is transferred and the conversion of the biomass to useful products occurs. The biomass is rapidly converted to a pyrolytic vapor and a solid char by-product (a powderlike charcoal material) in the RTP reactor, which is operating at nearly atmospheric pressure and a temperature of approximately $500^{\circ} \mathrm{C}$. The product and by-product vapors are separated from the solid char and the sand in a cyclone separation system which transfers the captured solids to the RTP reheater. The vapors are sent to the condensing section of the unit. Air is provided to the reheater for both fluidization of the sand and also to provide the oxygen necessary for the combustion of the char. The combustion

\footnotetext{
${ }^{7}$ This figure was prepared by Tom Kalnes of UOP LLC for Conference $\mathrm{CO}_{2}$ Summit: Technology \& Opportunity 2010 and published online. Permission for use in this dissertation was provided by Tom Kalnes via email (Figure D.5). Copyright clearance from UOP Honeywell is shown in Figure D.3
} 
flue gases exit the reheater and are separated from the ash in another cyclone separation system. Reheater flue gas can be used to raise steam in a waste heat recovery steam generation system or it can be used to provide part or all of the heat required to dry the incoming wet biomass. The flue gas is cleaned up by the appropriate pollution abatement technologies before being exhausted to the atmosphere. The circulating sand exiting this vessel is sufficiently reheated to enter the reactor without additional heat input during stable operations. By-product ash is collected in bins for possible commercial use or disposal. The pyrolytic vapor produced in the RTP reactor is directed to the condensing section where the liquid RTP green fuel product is collected and sent to storage. Similar to ranges presented in Table 5.1, the RTP green fuel has an approximate specific gravity of 1.2. Water is a significant component, which helps maintain its viscosity at less than $125 \mathrm{cSt}$ at $40^{\circ} \mathrm{C}$. The higher heating value of the fuel is typically $40 \%$ of fossil fuel oils at about $19 \mathrm{MJ} / \mathrm{kg}$. Non-condensable gas is recycled and used as a transport/lift gas in the reactor. Any net by-product gas can be used as a fuel to dry the incoming wet biomass feedstock or sold to an external consumer.

One objective of this study is to determine the emissions, cumulative energy demand (CED) and fossil energy demand (FED), and other environmental impacts of RTP green fuel as produced in Cote-Nord region of Quebec by the RTP process. Another research objective is to explore the impacts of model assumptions and parameter uncertainty in the calculation of GHG emissions. A series of scenario analyses will probe the effects of various LCA inputs: type of biomass feedstock, biomass transportation distance and modes, and electricity sources.

\subsection{Research methods}

\subsubsection{System scope, methods, and impact assessment}

The baseline pathway diagram of this LCA study is illustrated in Figure 5.2. The scope of this study encompasses the entire life cycle from biomass collection through the production and use of pyrolysis oil. The pyrolysis inputs were obtained from confidential design data (personal communication with Envergent Sep 21, 2012). The RTP green fuel 
is sold to local industrial operators within a $70 \mathrm{~km}$ radius from the pyrolysis plant located in the Cote-Nord region of Quebec in the base case study. All the inventory data were assembled based on energy content of $1 \mathrm{MJ}$ of final fuel product, which was the functional unit of this LCA. The software used for this LCA was SimaPro 7.2. The GHG impact assessment method used was the IPCC 2007 GWP 100a V1.01 method ${ }^{44}$ whose output is in $\mathrm{g} \mathrm{CO}_{2}$ equivalents for all of the GHG emissions using global warming potentials (GWP) of 1 for $\mathrm{CO}_{2}, 25$ for $\mathrm{CH}_{4}, 298$ for $\mathrm{N}_{2} \mathrm{O}$. GWPs for refrigerants, solvents, and other compounds were included in the analysis. The major air pollutants (CO, NOx, $\mathrm{SO}_{2}$ and PM) are also calculated by the IPCC 2007 GWP 100a method. The CED and FED are calculated by using Cumulative Energy Demand 1.07 method in the SimaPro, the results include non-renewable fossil (coal, oil, natural gas) and nuclear energy use, renewable biomass energy use, and other renewable energy sources, which include solar, geothermal, and hydroelectric power, which are given as the amount of process energy inputs (MJ) along the life cycle per unit of energy in the fuel products. The RTP green fuel impacts on human health, ecosystem quality, and fossil resources are evaluated and compared to heavy fuel oil. These environmental impacts are simulated by the Ecoindicator 99 method $^{140}$ in SimaPro 7.2. The hierarchical version (H/A) is chosen because it is widely accepted in the scientific community and political bodies ${ }^{140}$. The human health effects are quantified by disability-adjusted life years (DALYs), which is the number of disability years caused by exposure to toxic material multiplied by the "disability factor", a number between 0 and 1 that describes severity of the damage ( 0 for being perfectly healthy and 1 for being fatal). Ecosystem quality is characterized in Potentially Disappeared Fraction (PDF) times area times year ( $\mathrm{PDF} \times \mathrm{m}^{2} \times$ year). $\mathrm{PDF}$ is a probability of the plants species to disappear from the area as a result of acidification. The fossil resources impact is quantified by "surplus energy" in MJ per kg extracted material. The total environmental damages are aggregated into a single score damage indicator by normalization and weighting. 


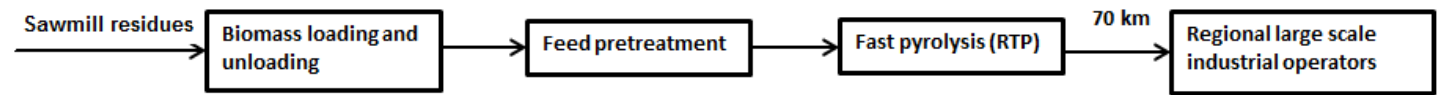

Figure 5.2: Pathway diagram of the pyrolysis oil LCA.

\subsubsection{Biomass loading, unloading, and storage}

The feedstock of pyrolysis is assumed to be sawmill residues from an adjacent mill located in the Cote-Nord region of Quebec. The residues represent a blend of bark (48\%) and white wood (52\%). The sawmill residues are assumed to be waste materials produced on-site, thus carrying no environmental impacts and the transport is minimal. The fuel inputs for residues loading and unloading were obtained from Mihalek ${ }^{141}$ and tabulated in Table 5.2.

Table 5.2: Inventory inputs of biomass loading, unloading and storage

\begin{tabular}{|l|l|l|}
\hline \multirow{2}{*}{ Loading } & Diesel (L/t) & $\mathbf{0 . 5 0 7}$ \\
\cline { 2 - 3 } & Lubricating oil (L/t) & $5.79 \mathrm{E}-3$ \\
\hline \multirow{3}{*}{ Unloading } & Diesel (L/t) & 0.507 \\
\cline { 2 - 3 } & Lubricating oil (L/t) & $5.79 \mathrm{E}-3$ \\
\hline & Diesel (L/t) & 0.507 \\
\cline { 2 - 3 } & Lubricating oil $(\mathrm{L} / \mathrm{t})$ & $5.79 \mathrm{E}-3$ \\
\hline
\end{tabular}

\subsubsection{RTP green fuel production and distribution}

The mill residues are sized and dried to the appropriate size and moisture content prior to feeding in the reactor. Then the biomass is heated by direct contact with circulating hot sand where the biomass is converted to RTP green fuel. Electricity is used in biomass pretreatment stage. RTP start-up and operation requires electricity and small amounts of fossil fuel. The co-products (char and non-condensable gas) are burned internally to reheat the circulating sand and to dry the biomass feed. Sand is also required to make up for attrition caused by the pyrolysis reactor operation. The RTP process emissions (char and by-product gas combustion) were obtained from the emission tests of flue exhaust and 
fuel combustor exhaust provided by Ensyn Corporation (confidential data), which include $\mathrm{CO}_{2}, \mathrm{CO}, \mathrm{NOx}, \mathrm{SO}_{2}, \mathrm{PM}$, metals, VOC, SVOC, PAH and D\&F emissions. RTP inputs were obtained from confidential design data (personal communication with Envergent, Sep 21 2012), however similar RTP inputs were reported in a former study ${ }^{134}$. Hydroelectric power is assumed in this study since the electricity in Eastern Quebec is supplied exclusively from a hydroelectric dam. For the base case, it is assumed that the RTP green fuel product will be sold to local industrial operators within a $70 \mathrm{~km}$ radius.

\subsubsection{Oil combustion}

The RTP green fuel is expected to be combusted in industrial boilers to replace heavy fuel oil (No.6 fuel oil). The most significant combustion pollutants from organic fuel combustion are carbon dioxide $\left(\mathrm{CO}_{2}\right)$, carbon monoxide $(\mathrm{CO})$, unburned hydrocarbons $(\mathrm{HC})$, nitrogen oxides (NOx), sulfur oxides ( $\mathrm{SOx})$, and particulate matter $(\mathrm{PM})^{142} \cdot \mathrm{CO}_{2}$ emissions from RTP green fuel are not accounted for in the GHG analysis as explained below in section 5.3.1. Researchers have been investigating the combustion of pyrolysis oil in industrial boilers and comparing the air emissions to either No.2 fuel oil or No.6 fuel oil. $\mathrm{CO}$ emissions are found to be similar or slightly higher in pyrolysis oil than No.2 fuel oil ${ }^{143-147}$. NOx emissions from pyrolysis oil combustion are found to be higher than No.2 fuel oil ${ }^{144-146}$ but lower than No.6 fuel oil ${ }^{148}$. However, NOx emissions from pyrolysis oil combustion can be successfully controlled by conventional technologies, such as staged combustion and low NOx burners ${ }^{143,149}$. Pyrolysis oil generally shows higher PM emission than the light fuel oil (No.2 fuel oil) ${ }^{131,147}$ but lower than the heavy fuel oil (No.6 fuel oil) ${ }^{147}$. Very low SOx emissions are reported for the pyrolysis oil because of the low $\mathrm{S}$ content in the oil ${ }^{146}$.

A Danstoker Model Global 5 heavy oil boiler (2009) was used to generate the combustion emissions data. The burner was manufactured by Oilon Oy, type RP-250 M XH (2011) and all measurements were made at the stack after the boiler in a test laboratory. The stack was horizontally installed and the measurements were done from side of the stack. Sampling locations followed ISO Standard 9096 requirements for the 
plane of bend with the plane of bend before the sampling line being more than 7 hydraulic diameters and after the sampling line more than 5 hydraulic diameters. In this case, the stack had a hydraulic diameter of 0.4 meters and the gas flow conditions were satisfactory for the isokinetic sampling. Particle concentrations were measured with EMES 3866 equipment using standard SFS 38661 /ISO 90962 and samples were collected with quartz filters. Temperatures were measured with K-type thermocouple and thermometer and the humidity of the stack gas was measured with gravimetric method. Volume flow rate was measured with S-pitot tube and micromanometer. Oxygen concentrations of the stack gas were measured with Testo $350 \mathrm{XL}$, which measures $\mathrm{O}_{2}$, $\mathrm{NO}$, and $\mathrm{CO}$ with electrochemical detector and $\mathrm{CO}_{2}$ with infrared detector. The criteria pollutants emissions of the RTP green fuel are presented in Table 5.3, and compared to a heavy fuel oil (No.6) combusted using the same burner in the same boiler. It shows higher $\mathrm{CO}$ emission but lower $\mathrm{NOx}, \mathrm{SO}_{2}$ and $\mathrm{PM}$ emissions than the No.6 fuel oil. $\mathrm{CO}_{2}$ emissions from RTP green fuel were not accounted for in the GHG analysis as explained below in section 5.3.1. Other $\mathrm{GHG}$ emissions such as $\mathrm{CH}_{4}$ and $\mathrm{N}_{2} \mathrm{O}$ were obtained from a study conducted by the $(\mathrm{S} \& \mathrm{~T})^{2}$ Consultant $\operatorname{Inc}^{150}$, which are 0.1 and $0.05 \mathrm{~g} / \mathrm{GJ}$ fuel respectively.

Table 5.3: Measured emission data (mg/MJ) of RTP green fuel and No. 6 fuel oil (Envergent)

\begin{tabular}{|l|l|l|l|l|l|}
\hline & test & $\mathrm{CO}$ & $\mathrm{NOx}$ as $\mathrm{NO}_{2}$ & $\mathrm{SO}_{2}$ & $\mathrm{PM}$ \\
\hline $\begin{array}{l}\text { RTP green } \\
\text { fuel }\end{array}$ & 1 & 37 & 107 & $\mathrm{ND} *$ & 58 \\
\hline & 2 & 37 & 108 & $\mathrm{ND}$ & 55 \\
\hline & 3 & 62 & 104 & $\mathrm{ND}^{*}$ & 58 \\
\hline \#6 fuel oil & 1 & 23 & 157 & 387 & 90 \\
\hline & 2 & 23 & 156 & 394 & 95 \\
\hline & 3 & 28 & 164 & 366 & 109 \\
\hline & 4 & 25 & 164 & 364 & 102 \\
\hline
\end{tabular}

* below detection limit 


\subsection{LCA results}

\subsubsection{GHG emissions}

The GHG emissions of RTP green fuel are tabulated in Table 5.4 by life cycle stage and compared to petroleum-based heavy fuel oil. In accordance with the EPA Renewable Fuel Standard (RFS2) ${ }^{51}$ and the Low Carbon Fuels Standard (LCFS) of California ${ }^{57}$, the net $\mathrm{CO}_{2}$ emissions of RTP green fuel at the combustion stage are considered carbon neutral because $\mathrm{CO}_{2}$ is sequestered by photosynthesis during the growth of biomass. The RTP green fuel shows over 98\% of GHG savings compared to heavy fuel oil. Biomass loading and unloading is responsible for approximately $25 \%$ of total emission due to the fuel use. In most scenarios, the pyrolysis process is the largest GHG contributor due to the use of fossil fuel for unit start-up. The emission from imported electricity use is minimal because of the low emission factor of hydroelectricity.

For comparison purpose, the RTP green fuel emissions simulated by SimaPro are compared to the pyrolysis oil results generated by the $(\mathrm{S} \& \mathrm{~T})^{2}$ Consultants Inc ${ }^{150}$. In the $(\mathrm{S} \& \mathrm{~T})^{2}$ report, wood residues are assumed as waste products produced and consumed onsite, thus carrying zero environmental burdens. The inputs of the pyrolysis process are tabulated in Table 5.5. Canada average grid mix is used for the analysis thus having a much higher emission impact than hydroelectricity (228.9 vs. $4.4 \mathrm{~g} \mathrm{CO}_{2}$ eq/kWh). The default setting of pyrolysis oil transport is $200 \mathrm{~km}$ by truck whereas a $70 \mathrm{~km}$ radius was assumed in this study. When the oil is combusted, greenhouse gases such as $\mathrm{CH}_{4}$ and $\mathrm{N}_{2} \mathrm{O}$ are emitted (Table 5.6). Consistent with the SimaPro model, the pyrolysis stage is the largest GHG contributor in the life cycle due to electricity and fossil fuel use. Oil transport impact is higher due to the longer distribution distance. 
Table 5.4: Life cycle GHG emissions of RTP green fuel, comparing to heavy fuel oil

\begin{tabular}{|l|l|l|l|}
\hline g CO$_{2}$ eq/MJ oil & RTP green fuel & $\begin{array}{l}(\mathrm{S} \& \mathrm{~T})^{2} \\
\text { pyrolysis oil }^{150}\end{array}$ & Heavy fuel oil $^{128}$ \\
\hline Biomass loading/unloading & 0.46 & 0 & \\
\hline Biomass pretreatment & 0.06 & $0 *$ & \\
\hline Oil production & 0.67 & 3.10 & \\
\hline Oil transport & 0.55 & 1.92 & \\
\hline Oil combustion & 0.02 & 0.11 & 85.3 \\
\hline Total & 1.76 & 5.12 & \\
\hline GHG savings & $98.0 \%$ & $94.0 \%$ & \\
\hline
\end{tabular}

* Biomass pretreatment emission is integrated with the fast pyrolysis in the GHGenius model

Table 5.5: Inputs of wood residues pyrolysis (per L of pyrolysis oil) ${ }^{150}$

\begin{tabular}{|l|l|}
\hline Dry wood $(\mathrm{kg})$ & 1.646 \\
\hline Electricity $(\mathrm{kWh})$ & 0.24 \\
\hline Natural gas $(\mathrm{L})$ & 0.02 \\
\hline
\end{tabular}

Table 5.6: Combustion emissions of pyrolysis oil (g/GJ pyrolysis oil) ${ }^{150}$

\begin{tabular}{|l|l|}
\hline $\mathrm{CH}_{4}$ & 0.1 \\
\hline $\mathrm{CO}$ & 0.07 \\
\hline $\mathrm{N}_{2} \mathrm{O}$ & 0.05 \\
\hline $\mathrm{NOx}\left(\mathrm{NO}_{2}\right)$ & 0.05 \\
\hline $\mathrm{SOx}\left(\mathrm{SO}_{2}\right)$ & 28.56 \\
\hline $\mathrm{PM}$ & 0.32 \\
\hline
\end{tabular}

\subsubsection{Air pollutants}

In addition to the combustion emissions listed in Table 5.3, major air pollutants (uncontrolled values) emitted during the life cycle of RTP green fuel are estimated and tabulated in Table 5.7, which include emissions from the production and use of fossil 
fuels, RTP process emissions, and combustion of RTP green fuel in the industrial furnace, and compared to heavy fuel oil. RTP green fuel shows higher $\mathrm{CO}$ emission, but lower $\mathrm{SO}_{2}, \mathrm{NOx}$ and particulates emissions. $\mathrm{SO}_{2}$ emission is particularly lower because of low sulfur content in the fuel. A lower $\mathrm{CO}$ emission is achievable with a change in boiler operation.

Table 5.7: Life cycle air pollutants (mg/MJ) of RTP green fuel and heavy fuel oil

\begin{tabular}{|l|l|l|}
\hline & RTP green fuel & Heavy fuel oil \\
\hline $\mathrm{CO}$ & 132.4 & 41.2 \\
\hline $\mathrm{SO}_{2}$ & 4.33 & 469.7 \\
\hline NOx & 184.4 & 198.7 \\
\hline $\mathrm{PM}$ & 88.81 & 107.1 \\
\hline
\end{tabular}

\subsubsection{Energy demand results (CED; FED)}

Figure 5.3 shows the CED and FED results of RTP green fuel from sawmill residues. The CED consists of four parts; non-renewable fossil, nuclear energy use, renewable biomass energy use, and other renewable energy sources, which include solar, geothermal, and hydroelectric power. FED has been broken into four process stages: biomass (loading and unloading), biomass pretreatment, fast pyrolysis, and oil transport. Although pyrolysis requires more total energy to produce the same unit of energy than heavy fuel oil, only a small fraction of energy ( $2 \%)$ is from fossil energy. Out of the total fossil energy requirement, oil transport is the largest contributor to the total fossil energy use. Approximately $30 \%$ of fossil energy is used in the biomass loading and unloading stage, because of the diesel use. RTP green fuel production accounts for another $30 \%$ fossil energy demand, while natural gas is the dominant contributor in this process. 


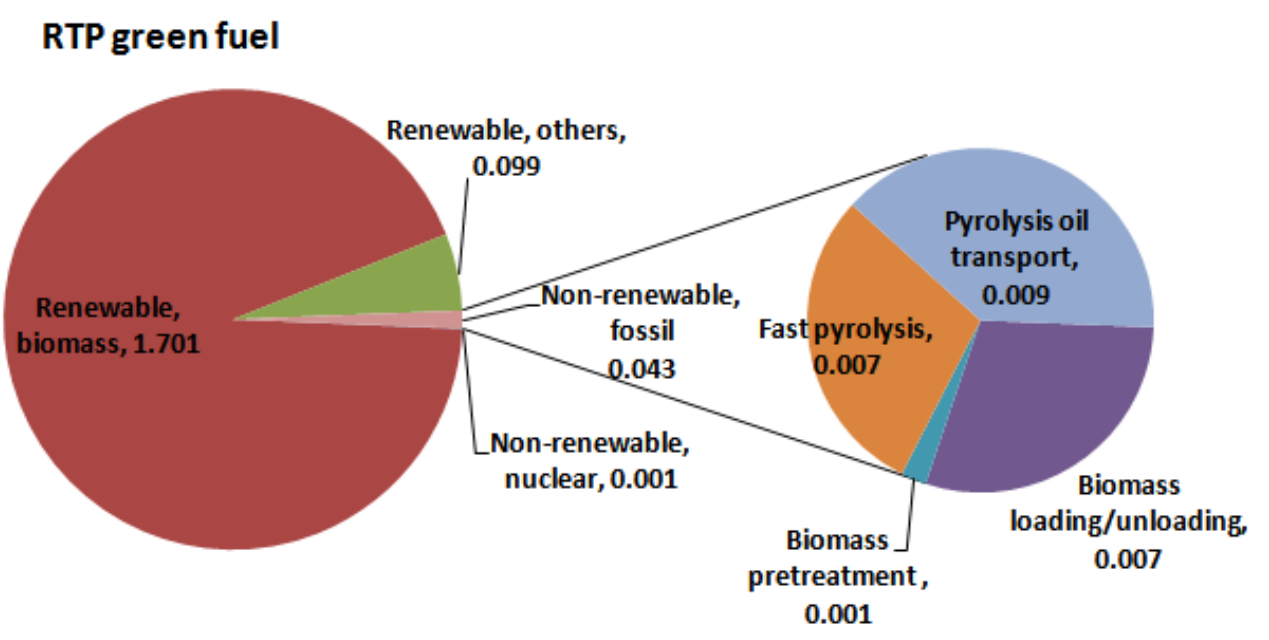

Heavy fuel oil

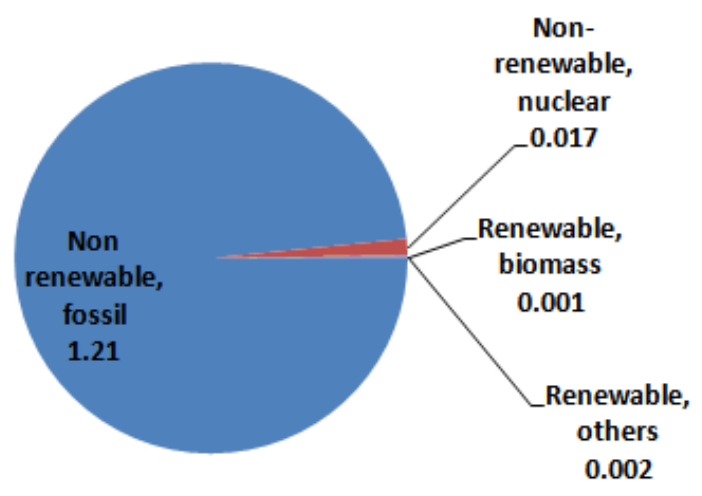

Figure 5.3: CED and FED results of RTP green fuel, in MJ (input)/MJ (output).

\subsubsection{Environmental damages}

As shown in Table 5.8, RTP green fuel shows lower impacts than heavy fuel oil in all three environmental damage categories. RTP green fuel shows an advantage in the human health category mainly because it releases less respiratory organics /inorganics and ozone depleting emissions. It also shows superior performance with regard to ecosystem quality because of lower acidification and land occupation impacts. RTP green fuel has lower fossil fuel depletion rate than heavy fuel oil because the majority of energy is derived from renewable biomass. Therefore, RTP green fuel has a lower total environmental damage impact than heavy fuel oil, as indicated by the single score normalized and weighted by the Eco-indicator 99 method. 
Table 5.8: Human health, ecosystem quality and resources impacts of RTP green fuel, compared to heavy fuel oil

\begin{tabular}{|l|l|l|}
\hline Damage category & RTP green fuel & Heavy fuel oil \\
\hline Human Health (DALY) & & \\
\hline Carcinogens & $1.02 \mathrm{E}-10$ & $6.77 \mathrm{E}-10$ \\
\hline Respiratory organics & $1.53 \mathrm{E}-12$ & $4.04 \mathrm{E}-11$ \\
\hline Respiratory inorganics & $2.65 \mathrm{E}-08$ & $5.72 \mathrm{E}-08$ \\
\hline Climate change & $4.15 \mathrm{E}-10$ & $1.88 \mathrm{E}-08$ \\
\hline Radiation & $1.99 \mathrm{E}-12$ & $3.44 \mathrm{E}-11$ \\
\hline Ozone layer & $2.08 \mathrm{E}-13$ & $1.09 \mathrm{E}-11$ \\
\hline Ecosystem Quality (PDF* $\left.\mathbf{m}^{2} \mathbf{y r}\right)$ & & \\
\hline Ecotoxicity & $2.44 \mathrm{E}-04$ & $2.21 \mathrm{E}-04$ \\
\hline Acidification/ Eutrophication & $1.06 \mathrm{E}-03$ & $1.63 \mathrm{E}-03$ \\
\hline Land use & $2.09 \mathrm{E}-05$ & $8.19 \mathrm{E}-04$ \\
\hline Resources (MJ surplus) & & \\
\hline Minerals & $4.55 \mathrm{E}-05$ & $1.02 \mathrm{E}-04$ \\
\hline Fossil fuels & $2.94 \mathrm{E}-03$ & $1.62 \mathrm{E}-01$ \\
\hline Single score (Pt) & 0.00088 & 0.006 \\
\hline
\end{tabular}

\subsection{Sensitivity analyses}

\subsubsection{Biomass transport}

In the base case scenario, the mill is assumed to be immediately adjacent to the RTP plant so that mill residue transport is minimal. In this biomass transport scenario, we investigate the impact of biomass transport distance and mode on the total GHG emissions. The biomass is assumed to be transported from the mills to pyrolysis plant by truck, rail and barge. The transport distances and modes considered in this scenario are shown in Table 5.9. 
Table 5.9: Transport mode and distance $(\mathrm{km})$ of mill residues

\begin{tabular}{|l|l|l|l|}
\hline Truck & 50 & 100 & 200 \\
\hline Rail & 100 & 250 & 500 \\
\hline Barge & 100 & 250 & 500 \\
\hline
\end{tabular}

The GHG emission results of the transport scenario are illustrated in Figure 5.4. The total emissions are sensitive to the distance of the biomass transport, especially for the truck scenario. The rail and barge scenarios are comparable because the emission factors of these transport modes are similar.

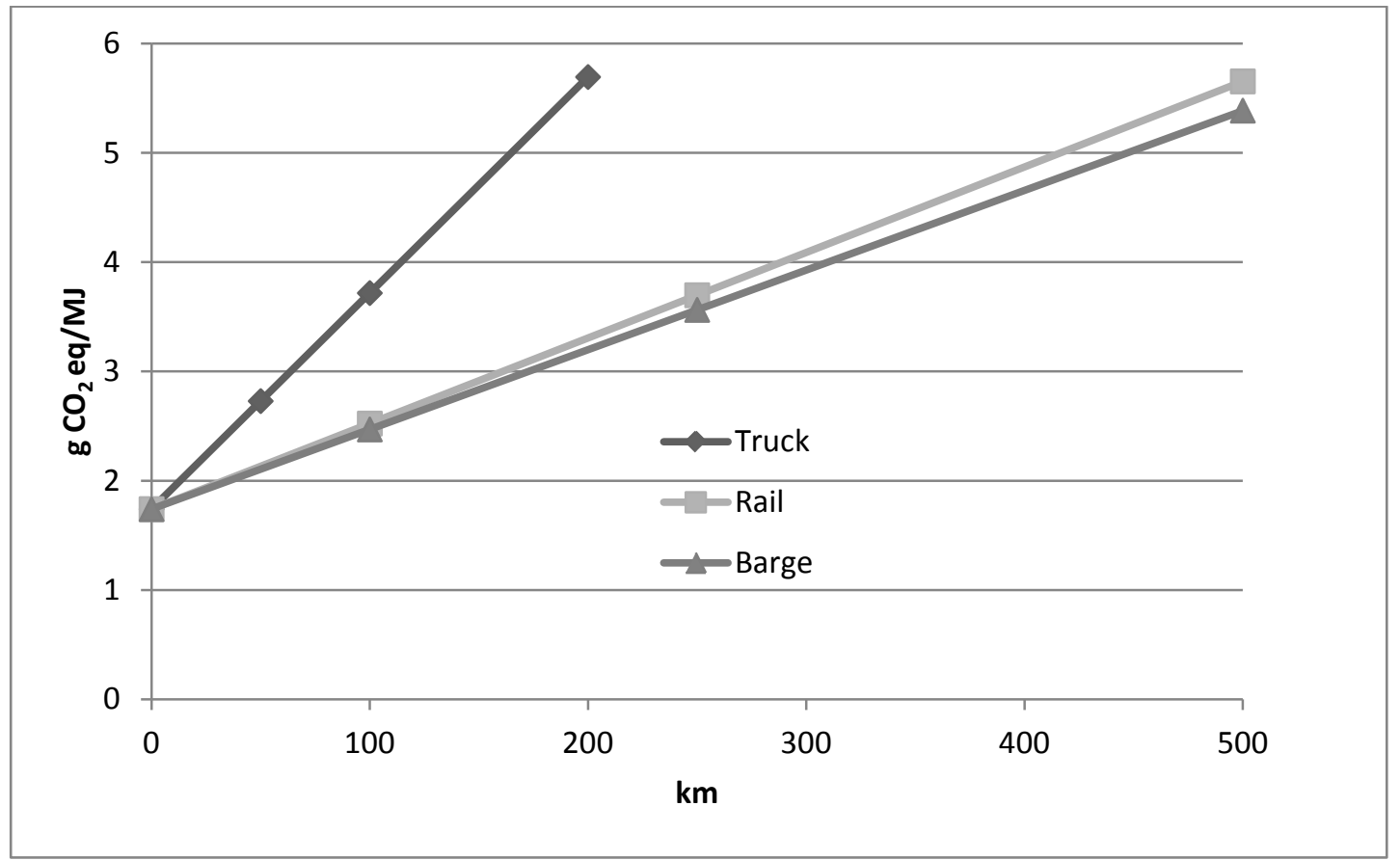

Figure 5.4: Impact of biomass transport on the total GHG emissions of RTP green fuel.

\subsubsection{Pyrolysis of sawmill residues in the U.S}

In this scenario, RTP green fuel is assumed to be produced in Maine, Georgia, Alabama, Washington, and Oregon because these states have the largest sawmill production capacities in the U.S $S^{151}$. Electricity is considered as a variable as an attempt to model different geographical settings. The fuel mixes of electricity production from these states 
were obtained from the U.S EPA eGRID ${ }^{47}$ and compared to the U.S average electricity $\operatorname{mix}^{47}$. The total GHG emissions of RTP green fuel are shown in Figure 5.5. The electricity source has a significant impact on the GHG results. Emissions from Alabama and Georgia are the highest among all the states investigated because over $50 \%$ of electricity in the two states is from coal. U.S average also has a high dependence on coal electricity. Washington and Oregon have higher percentages of hydroelectricity in the power grid, thus the emissions are lower compared to other states. However, RTP green fuel still shows over $70 \%$ GHG reductions compared to heavy fuel oil.

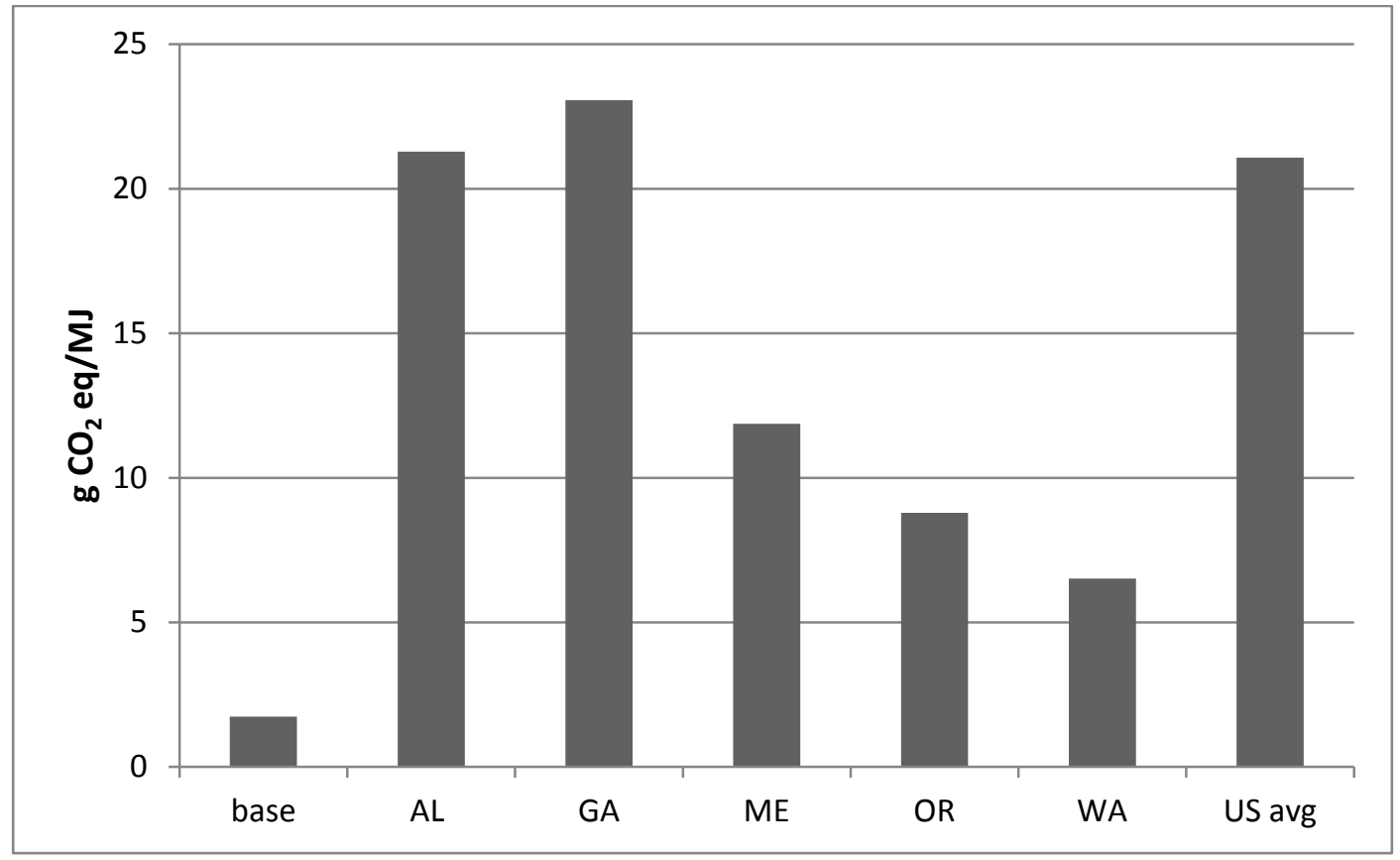

Figure 5.5: Life cycle GHG emissions of RTP green fuel from sawmill residue produced in the U.S.

\subsubsection{Other biomass feedstock}

Apart from sawmill residues, low ash corn stover, sugarcane bagasse and logging residues are also investigated as feedstocks for RTP green fuel production. Corn stover is assumed to be collected from corn field and converted to RTP green fuel Iowa, because Iowa is the top corn producing state in the U.S ${ }^{152}$. The inputs of corn stover (Table 5.10) were obtained from Morey et $\mathrm{al}^{153}$, which include biomass collection, transport and nutrients added to the field to replace the stover. Sugarcane bagasse is assumed to be 
pyrolyzed at the cane ethanol plants in Brazil, because of the abundant feedstock availability. The feedstock is waste materials available on site, the energy and emission burdens come from loading and unloading of the biomass. The inputs are assumed to be the same as sawmill residues. The inputs of logging residues (Table 5.11) were assumed similar to a study conducted for mixed hardwood logging residue collection from natural regeneration hardwood site near Trenary, MI, which include the fuel consumption associated with the forwarding and the grinding of the biomass and the production of equipment used. The logging residues are then transported $120 \mathrm{~km}$ to the pyrolysis plant, which is the default transport distance in the GREET $2012^{86}$. The pyrolysis inputs of corn stover, sugarcane bagasse and logging residues were obtained from Mihalek ${ }^{141}$, which represent UOP's future operation as optimized for these specific feedstocks. Steam is produced as a co-product in the RTP process, which presents a GHG credit to the RTP green fuel product. Electricity profiles were created based on the generation mix data from Iowa ${ }^{47}$, Brazil ${ }^{154}$ and Michigan ${ }^{47}$.

Table 5.10: Inputs of 1 dry metric ton low ash corn stover ${ }^{153}$

\begin{tabular}{|l|l|l|}
\hline Process & Inventory & Input \\
\hline \multirow{3}{*}{ Collection } & Lubricating oil (L/t) & $5.88 \mathrm{E}-3$ \\
\cline { 2 - 3 } & Diesel fuel (L/t) & 0.928 \\
\hline \multirow{3}{*}{ Baking } & Lubricating oil (L/t) & $1.18 \mathrm{E}-3$ \\
\cline { 2 - 3 } & Diesel fuel (L/t) & 0.222 \\
\hline Bale moving & Lubricating oil (L/t) & $4.71 \mathrm{E}-3$ \\
\cline { 2 - 3 } & Diesel fuel (L/t) & 0.939 \\
\hline Transport (round trip) & Lubricating oil (L/t) & $9.41 \mathrm{E}-3$ \\
\cline { 2 - 3 } & Diesel fuel (L/t) & 1.768 \\
\hline Nutrients Replacement & Ammonia $(\mathrm{kg} / \mathrm{t})$ & 85 \\
\cline { 2 - 3 } & Diammonium phosphate $(\mathrm{kg} / \mathrm{t})$ & 2.9 \\
\cline { 2 - 3 } & Potassium sulphate $(\mathrm{kg} / \mathrm{t})$ & 12.7 \\
\hline
\end{tabular}


Table 5.11: Inputs of 1 dry metric ton of logging residues ${ }^{134}$

\begin{tabular}{|l|l|l|l|}
\hline Diesel, low-sulfur & 3.34 & $\mathrm{~kg}$ & Consumed in harvesting logging residue \\
\hline Diesel, low-sulfur & 1.86 & $\mathrm{~kg}$ & Consumed in forwarding logging residue \\
\hline Diesel, low-sulfur & 2.10 & $\mathrm{~kg}$ & Consumed in chipping logging residue \\
\hline Building machine & $3.64 \mathrm{E}-6$ & $\mathrm{p}$ & For harvester machine manufacture \\
\hline Building machine & $9.26 \mathrm{E}-6$ & $\mathrm{p}$ & For forwarder machine manufacture \\
\hline Building machine & $5.51 \mathrm{E}-6$ & $\mathrm{p}$ & For chipper machine manufacture \\
\hline Transport, by truck & 80 & $\mathrm{~km}$ & Residues transport (round trip) \\
\hline
\end{tabular}

The life cycle GHG emissions of RTP green fuel from sugarcane bagasse, corn stover and logging residues are shown in Figure 5.6, and compared to heavy fuel oil. RTP green fuel from corn stover shows the highest emissions, because: 1. large environmental burdens from the fuel use and nutrient replacement at the biomass collection stage; 2 . The Iowa electricity is highly dependent on coal thus has high emission factor. RTP green fuel from logging residues shows the second highest emission, because of longer biomass transport distance and high emission factor of Michigan electricity. RTP green fuel from sugarcane bagasse has the lowest GHG impact because of the small fuel use at biomass loading and unloading stage. It also requires no biomass transport. In addition, Brazil electricity has a higher percentage of renewable sources. The savings of GHG emissions compared to fossil heavy fuel oil is greater than $80 \%$ for all of these biomass feedstocks. 


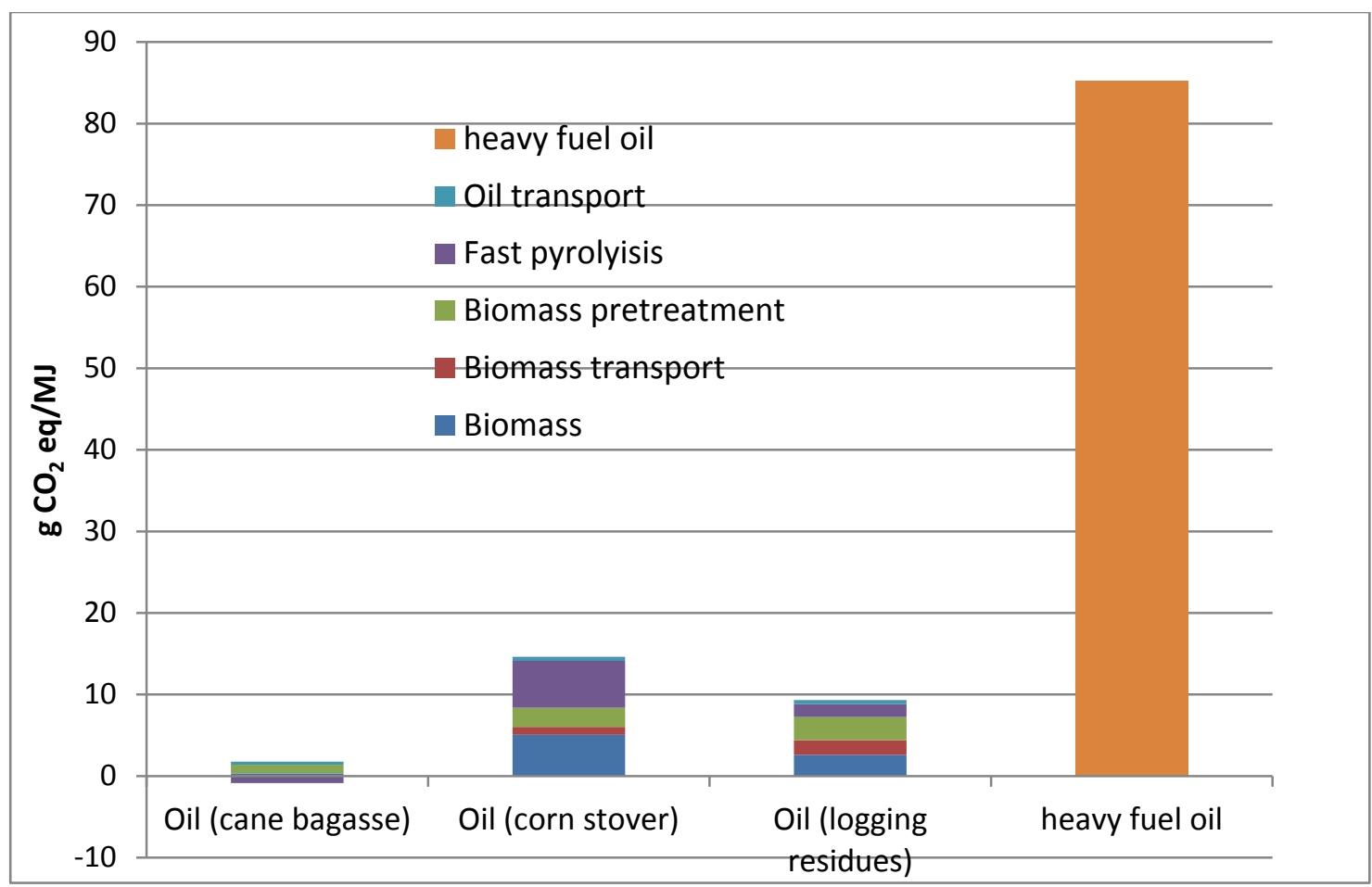

Figure 5.6: GHG emissions of RTP green fuel from various feedstocks, comparing to heavy fuel oil.

\subsection{Conclusion}

Sawmill residue is a promising feedstock for production of RTP green fuel. When hydroelectricity is used in the process, the life cycle GHG emission reductions of over 98\% compared to fossil heavy fuel oils are possible. RTP green fuel from other lignocellulosic biomass show over $70 \%$ of GHG reductions. Most of the energy required for oil production is from renewable biomass as opposed to non-renewable fossil. RTP green fuel also shows superior environmental performance with regard to human health, ecosystem quality, and fossil resources. 


\section{Chapter 6: LCA of Electricity Generation using Fast Pyrolysis Bio-Oil ${ }^{8}$}

\subsection{Introduction}

In 2007, 4,157 million MWh electric power was generated in U.S., and electricity demand is projected to increase by 26 percent from 2007 to 2030, or by an average of 1.0 percent per year ${ }^{155}$. Power generation emits significant amounts of greenhouse gases, mainly carbon dioxide $\left(\mathrm{CO}_{2}\right)$. Estimated $\mathrm{CO}_{2}$ emissions by U.S. electric generators and combined heat and power facilities increased by 2.3 percent from 2006 to 2007 (from 2,460 million metric tons to 2,517 million metric tons). To date, over $70 \%$ of electricity is generated by fossil fuels such as coal and natural gas, while renewable energy accounts only for about $8 \%$ of all electricity generated. Wood and wood derived fuels accounted for 39 million MWh or 0.9 percent of total net generation, and other biomass 17 million $\mathrm{MWh}^{156}$. To reduce power plant emissions of greenhouse gases, as well as reducing dependence on foreign fossil fuels, renewable energy such as wind and biomass is expected to play an important role in future electricity generation ${ }^{43}$.

Pyrolysis oil converted from residual biomass and post-consumer materials such as construction and demolition wastes is a potential substitute for petroleum to generate renewable power and process heat. Pyrolysis oil can be combusted directly to generate power, and the emissions at combustion stage are considered carbon neutral because $\mathrm{CO}_{2}$ is sequestered by photosynthesis during the growth of biomass, and thus the GHG emissions are significantly reduced compared to fossil fuels.

Upper Peninsula of Michigan is heavily forested, the timberland accounts for $77 \%$ and $84 \%$ of the eastern and western half of U.P of Michigan ${ }^{157}$. The large volume of timber resources are potential feedstocks for biofuels production. The by-products from pulp and

\footnotetext{
${ }^{8}$ This chapter was updated from a former study published in Renewable Energy. Figure D-1 shows copyright clearance allowing for use in dissertation. Citation: Fan JQ, Kalnes TN, Alward M, Klinger J, Sadehvandi A, Shonnard DR. Life cycle assessment of electricity generation using fast pyrolysis bio-oil. Renewable Energy 2011;36(2):632-641
} 
paper industry, such as logging residue, wood bark and chips, are usually considered as waste, or burned on site to provide heat. The forest residues alone can provide over two million dry $t$ of biomass for biofuels production ${ }^{158}$ (see Table 6.1). Black liquor produced at the end of kraft process is concentrated with lignin residues, hemicellulose, and the inorganic chemicals used in the process ${ }^{159}$, which could be a potential feedstock for biofuels production as well ${ }^{160}$.

Table 6.1: Forest residues supply in the Michigan Upper Peninsula ${ }^{158}$

\begin{tabular}{|l|l|l|}
\hline Dry t per year & Potential Supply & $\begin{array}{l}\text { Currently Available } \\
\text { and Utilized }\end{array}$ \\
\hline $\begin{array}{l}\text { Sawmill and pulp mill } \\
\text { residues }\end{array}$ & $1,493,601$ & Negl \\
\hline Logging residues & 503,243 & 503,243 \\
\hline Thinning residues & 853,800 & 853,800 \\
\hline Total & $2,850,644$ & $1,357,043$ \\
\hline
\end{tabular}

Forestland can also supply biomass feedstocks to the biofuels industry. Pulp and paper industry mainly use hardwood such as aspen and maple as wood feedstocks, while biofuels production is regardless of biomass property, it can use softwood ${ }^{161}$ or even low grade wood products ${ }^{162}$ as feedstocks. Thus biofuels production will not compete with pulp and paper industry directly in the biomass supply chain. The Forest Inventory and Analysis (FIA) Program of the U.S. Forest Service ${ }^{163}$ reports on the status and trends in forest area and location; in the species, size, and health of trees; in total tree growth, mortality, and removals by harvest; in wood production and utilization rates by various products; and in forest land ownership. This database gives us access to evaluate whether the forestland in the U.P of Michigan can sustainably supply biomass to the biofuels industry. There are approximately 15 billion cubic feet of live trees currently grown in the Upper Michigan (Table 6.2). The annual net growth, removals and mortality of live trees can be targeted for biofuels production. The total volumes of these three categories are approximately 146, 129 and 82 million cubic feet, respectively ${ }^{163}$. 
Table 6.2: Net volume of live trees (at least 5 inches d.b.h./d.r.c.), in cubic feet ${ }^{163}$

\begin{tabular}{|l|l|l|l|l|}
\hline Forest Service & $\begin{array}{l}\text { Other } \\
\text { Federal }\end{array}$ & $\begin{array}{l}\text { State/Local } \\
\text { Gov't }\end{array}$ & Private & Total \\
\hline $3,407,355,813$ & $316,484,013$ & $3,019,094,826$ & $7,726,437,384$ & $14,469,372,037$ \\
\hline
\end{tabular}

Short rotation forestry (SRF) such as willow and poplar is also an option as feedstocks of biofuels production in U.P of Michigan. SRF can be grown on abandoned or marginal agricultural land, thus providing biomass without competing with food production or disturbing carbon stocks in forests ${ }^{164}$. In addition, SRF have much lower fertilizer and irrigation water requirement than oil producing plants such as soybean and canola, thus the GHG emissions of biomass cultivation, especially $\mathrm{N}_{2} \mathrm{O}$ emission from application of $\mathrm{N}$ fertilizers are considerably reduced.

The abundant biomass resources from the forest sector are promising feedstock to produce bioenergy through pyrolysis. To better understand the environmental impacts of generating electricity from pyrolysis oil, this study evaluated the life cycle greenhouse gas emissions of electricity generation from pyrolysis oil combustion in various power conversion systems, and then compared these emissions with conventional fossil fuels as well as biomass direct combustion technologies.

\subsection{LCA Methods}

\subsubsection{System Scope, Functional Unit, Inventory, and Impact Assessment}

Life cycle assessment (LCA) is a methodology to evaluate environmental impacts, energy consumption, resource depletion, and other impacts for an entire product system. Standards to guide the conduct of LCA have been developed and published by the International Organization for Standardization (ISO 14040-14049). The purpose of LCA is to inform decision makers in industry and government on the best product or technology alternative to satisfy a particular customer or societal need in an environmentally sound manner ${ }^{165}$. 
The goals of this LCA study of pyrolysis oil combustion for power generation are to understand the relative importance of biomass cultivation, transportation, and combustion in the life cycle greenhouse emissions, investigate different feedstocks and technologies, and to evaluate the effects of power generation efficiency. The pathway diagram of this LCA study is illustrated in Figure 6.1. The system boundries include all the energy, fuels, chemicals , and transportation needed to operate all phases of the entire operation starting from the nursery for the biomass and finishing with the combustion of pyrolysis oil in power plant to generate electricity. Land use change (direct or indirect) was not included in the system. The functional unit is assumed to be $1 \mathrm{kWh}$ electricity generated. A complete set of inputs was utilized from literature sources, field measurements, and from Ensyn / UOP for pyrolysis oil production from wood chips.

The software used for this LCA was SimaPro $7.2^{41}$, which contains a large database of inventory data for material, chemical, and energy inputs. Inventory data is from the Ecoinvent database ${ }^{42}$, which is comprised of mostly European data that has close technology relevance to U.S. production, but whenever possible, these ecoprofiles were adjusted for U.S. conditions; for example electricity generation was modeled using a combination of current U.S. grid electricity primary energy sources ${ }^{43}$. The GHG impact assessment method used was the IPCC 2007 GWP 100a V1.01 method ${ }^{166}$ whose output is in $\mathrm{g} \mathrm{CO}_{2}$ equivalents for all of the $\mathrm{GHG}$ emissions using global warming potentials (GWP) of 1 for $\mathrm{CO}_{2}, 25$ for $\mathrm{CH}_{4}, 298$ for $\mathrm{N}_{2} \mathrm{O}$. GWPs for refrigerants, solvents, and other compounds were included in the analysis.

The effects of the percent of land area for biomass cultivation and transport were investigated in scenarios. An additional scenario evaluated reductions in GHG emissions when electricity is provided from an integrated pyrolysis oil production-electricity generation facility, thus avoiding the use of imported electricity from the U.S. grid for pyrolysis oil production. 


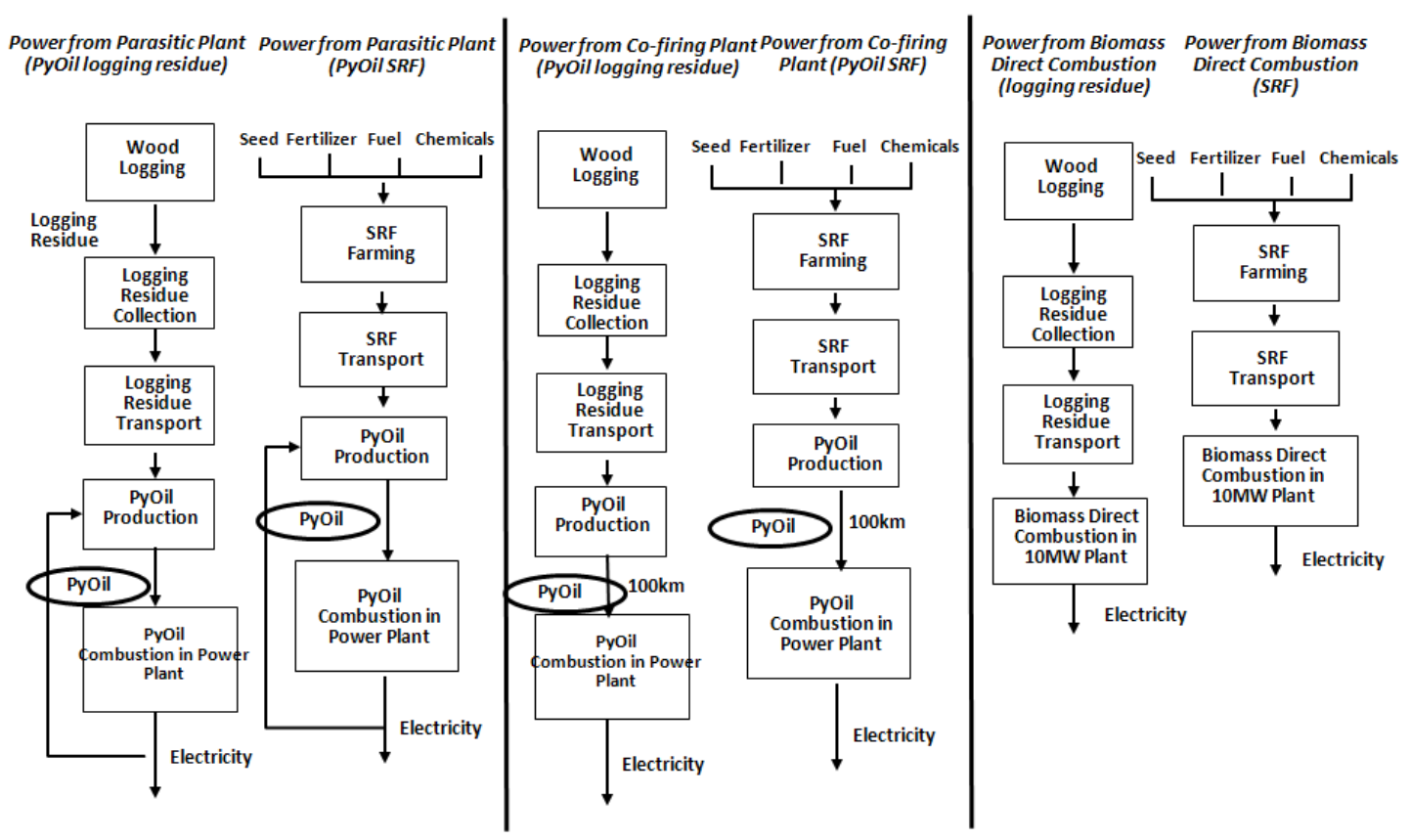

Figure 6.1: Pathway diagram of pyrolysis oil to power LCA study.

\subsubsection{Biomass cultivation and harvesting}

Biomass feedstock production LCAs were first performed in order to better understand the greenhouse gas impacts of biomass cultivation and harvesting. Four types of feedstocks were considered: short rotation forestry (SRF) willow, SRF poplar, collection of hardwood residue from existing forestry operations, and waste wood such as sawmill waste available at the site of pyrolysis oil production.

Willow cultivation as an energy crop was thoroughly studied by Heller et al. ${ }^{167}$, who analyzed the production of nursery stock used for plantation, fuel used by farming equipment, fertilization, weed and pest control, manufacture of the equipment and willow harvesting. The inputs of willow cultivation and harvesting stage were obtained from their study, and then entered into SimaPro on $1 \mathrm{~kg}$ dry biomass basis. The eco-profile of willow cultivation and harvesting stage in SimaPro is shown in Table 6.3. 
Table 6.3: Inventory inputs of willow cultivation and harvesting

\begin{tabular}{|c|c|c|}
\hline Products & & \\
\hline Hybrid willow & 1 & $\mathrm{~kg}$ \\
\hline \multicolumn{3}{|l|}{ Resources } \\
\hline Energy, gross calorific value, in biomass, primary forest & 19.8 & MJ \\
\hline \multicolumn{3}{|l|}{ Materials/fuels } \\
\hline Diesel, low-sulphur, at regional storage & 0.003762 & $\mathrm{~kg}$ \\
\hline Chemicals inorganic, at plant & $8.22 \mathrm{E}-06$ & $\mathrm{~kg}$ \\
\hline Glyphosate, at regional storehouse & $1.86 \mathrm{E}-05$ & $\mathrm{~kg}$ \\
\hline Pesticide unspecified, at regional storehouse & $1.34 \mathrm{E}-05$ & $\mathrm{~kg}$ \\
\hline Rye seed IP, at regional storehouse & 0.000216 & $\mathrm{~kg}$ \\
\hline Ammonium nitrate, as $\mathrm{N}$, at regional storehouse & 0.002554 & $\mathrm{~kg}$ \\
\hline Petrol, unleaded, at regional storage & $7.2 \mathrm{E}-05$ & $\mathrm{~kg}$ \\
\hline Heavy fuel oil, at regional storage & 0.000258 & $\mathrm{~kg}$ \\
\hline Heat, heavy fuel oil, at industrial furnace 1MW & 11.57 & KJ \\
\hline Wood chips, hardwood, from industry, $u=40 \%$, at plant & $6.61 \mathrm{E}-07$ & $\mathrm{~m}^{3}$ \\
\hline Heat, hardwood chips from industry, at furnace $50 \mathrm{~kW}$ & 0.002795 & MJ \\
\hline Ammonium nitrate, as $\mathrm{N}$, at regional storehouse & $6.02 \mathrm{E}-05$ & $\mathrm{~kg}$ \\
\hline Single superphosphate, as $\mathrm{P}_{2} \mathrm{O}_{5}$, at regional storehouse & $6.9 \mathrm{E}-05$ & $\mathrm{~kg}$ \\
\hline Thomas meal, as $\mathrm{P}_{2} \mathrm{O}_{5}$, at regional storehouse & $6.9 \mathrm{E}-05$ & $\mathrm{~kg}$ \\
\hline Potassium sulphate, as $\mathrm{K}_{2} \mathrm{O}$, at regional storehouse & 7.25E-05 & $\mathrm{kg}$ \\
\hline Urea, as $\mathrm{N}$, at regional storehouse & $1.42 \mathrm{E}-05$ & $\mathrm{~kg}$ \\
\hline Tap water, at user & 1.329844 & $\mathrm{~kg}$ \\
\hline U.S electricity mix (cultivation) & 0.001098 & $\mathrm{kWh}$ \\
\hline
\end{tabular}

Hybrid poplar, like willow, is a high yield short rotation forest system used for biomass production. The poplar system was investigated by Gasol et al. ${ }^{168}$. We took all operational inputs for 16-year poplar rotation cultivation from their study, and calculated 
all the material and energy used to produce $1 \mathrm{~kg}$ of dry poplar. The inventory inputs are shown in Table 6.4.

Table 6.4: Inventory inputs of poplar cultivation and harvesting

\begin{tabular}{|l|l|l|}
\hline Products & & \\
\hline Hybrid poplar & 1 & $\mathrm{~kg}$ \\
\hline Resources & & \\
\hline Energy, gross calorific value, in biomass, primary forest & 18.2 & $\mathrm{MJ}$ \\
\hline Materials/fuels & $1.30 \mathrm{E}-03$ & $\mathrm{~kg}$ \\
\hline Diesel, low-sulphur, at regional storage & $3.16 \mathrm{E}-05$ & $\mathrm{~kg}$ \\
\hline Glyphosate, at regional storehouse & $1.74 \mathrm{E}-05$ & $\mathrm{~kg}$ \\
\hline Pesticide unspecified, at regional storehouse & $1.91 \mathrm{E}-03$ & $\mathrm{~kg}$ \\
\hline Ammonium nitrate, as $\mathrm{N}$, at regional storehouse & $1.72 \mathrm{E}-03$ & $\mathrm{~kg}$ \\
\hline Single superphosphate, as $\mathrm{P}_{2} \mathrm{O}_{5}$, at regional storehouse & $1.72 \mathrm{E}-03$ & $\mathrm{~kg}$ \\
\hline Thomas meal, as $\mathrm{P}_{2} \mathrm{O}_{5}$, at regional storehouse & $2.71 \mathrm{E}-03$ & $\mathrm{~kg}$ \\
\hline Potassium sulphate, as $\mathrm{K}_{2} \mathrm{O}_{\text {, at regional storehouse }}$ & & \\
\hline
\end{tabular}

Analysis of woody logging residue as a feedstock involves collection of the residue after a lumber harvesting process. The inputs were assumed similar to a study conducted for mixed hardwood logging residue collection and transport from natural regeneration hardwood site near Trenary,MI, which include the fuel consumption associated with the forwarding and the grinding of the biomass and the production of equipment used. Information was compiled from multiple surveys and interviews of hardwood loggers on the fuel consumption of this equipment. The detailed inventory inputs are the same as those in Table 5.9.

Waste wood is assumed to be on site of pyrolysis plants, therefore, there are no materials or energy input involved, thus no environmental impact of this feedstock during biomass cultivation stage. 


\subsubsection{Biomass transportation}

A mathematical model shown in the equation below ${ }^{169}$ was used to simulate the transportation distance between biomass collection sites and pyrolysis plants.

$\mathrm{r}_{\text {circle }}=2 / 3 * \tau * \sqrt{\frac{F}{\pi * Y * f}}$

$\tau$ represents the tortuosity factor of the road (1.5), $\mathrm{f}$ is the fraction of land devoted to biomass crops $(0.10)$. Y represents biomass yield in short tons per acre, which was directly obtained from the literature referenced. $\mathrm{F}$ is the biomass required to generate the requred amount of power for each case. It is assumed that wet biomass, which contains $40 \mathrm{wt} \%$ moisture, is transported by $16 \mathrm{t}$ semi-trucks. For biomass direct combustion cases, $\mathrm{F}$ was calculated from the power plant size, plant efficiencies and low heating value (LHV) of dry biomass. For GTCC and diesel generator systems, F was calculated from the power output, thermal efficiencies of facilities, LHV of pyrolysis oil, and the biomass-to-pyrolysis oil production ratio. For co-firing cases, 400 metric ton bone dry biomass per day were assumed to be combusted in fossil fuels plants. The transportation distances of three feedstocks for each power plant are shown in Table 5.5. Waste wood are produced on site of pyrolysis plant, and therefore no feedstock transportation is required.

Table 6.5: Biomass transportation distances for power conversion systems

\begin{tabular}{|c|c|c|c|c|c|}
\hline Distances $(\mathrm{km})$ & $\mathrm{BC} 1$ & $\mathrm{BC} 2$ & GTCC & $\begin{array}{l}\text { Diesel } \\
\text { generator }\end{array}$ & Fossil fuels plants \\
\hline SRF poplar & 6.18 & 5.25 & 11.60 & 8.16 & 17.67 \\
\hline SRF willow & 6.58 & 5.58 & 12.34 & 8.69 & 18.81 \\
\hline Logging residue & 28.91 & 24.53 & 54.22 & 38.17 & 82.61 \\
\hline
\end{tabular}

$\mathrm{BC} 1$ and $\mathrm{BC} 2$ represent biomass direct combustion in 10MW capacity Rankine power plant, 107291 and 77250 t biomass are required for BC1 and BC2 per year, respectively. F are 62907 and 31170 for the pyrolysis oil combustion cases GTCC and diesel 
generator, and 146000 metric ton biomass are combusted in the fossil fuels plants. For the biomass yield data Y, SRF poplar, SRF willow and logging residue are 14.88, 13.12 and 0.69 metric ton per hectare, respectively.

\subsubsection{Pyrolysis oil production}

Wood chips are heated by direct contact with hot sand and, after pyrolysis, rapidly cooled within seconds to maximize liquid yield. Some electricity (wood drying and pyrolysis oil production) and natural gas are used during start-up and RTP operation. Inputs for this step were obtained from a report provided by Ensyn and UOP process inputs, which are presented in a former study ${ }^{134}$. The pyrolysis process also produces by-products char and gas, however, in this study, both are combusted to provide heat to pretreat the wood feedstock and maintain the process. We therefore assumed that pyrolysis oil was the only output in our analysis. U.S. grid mix electricity ecoprofile was compiled in SimaPro using breakdown of current U.S. grid electricity ${ }^{43}$.

\subsubsection{Power generation}

In order to better understand the advantage of power generation from pyrolysis oil from an environmental perspective, life cycle GHG emissions of chipped biomass direct combustion in a conventional Rankine power plant and pyrolysis oil combustion in existing and new power plants were evaluated. For the biomass direct combustion cases, three biomass feedstocks: logging residue, SRF willow, and SRF poplar, are directly combusted in a power generation facility with $10 \mathrm{MW}$ output capacity. The efficiencies of the stand-alone direct biomass combustion cases (BC1 and $\mathrm{BC} 2)$ were assumed to be 18 and $25 \%{ }^{134}$, representing existing and modern dedicated biomass combustion facility at a nominal 400 metric tons dry biomass per day scale, respectively. Three power conversion systems were considered for pyrolysis oil combustion cases in our LCA study, conventional power plants burning fossil fuels, including coal, natural gas and fuel oil, gas turbine combined cycle (GTCC) with heat recovery and a stationary diesel generator. Pyrolysis oil substitution cases (co-firing) represent pyrolysis oil combusted in conventional power plants as feedstock displacing fossil fuels. The electricity generation 
efficiencies for the substitution cases were assumed to be the same as the fossil fuel power plants, which is a good assumption for low biomass displacement of fossil resources $(<20 \%)^{170}$. Electricity generation efficiencies of coal and natural gas plants were taken from the dissertation of Jaramillo ${ }^{171}$, and efficiency of an oil plant was taken from a LCA software tool, the GHGenius model ${ }^{172}$. Wet biomass (40 wt $\%$ moisture) is transported a standard distance of $100 \mathrm{~km}$ to the power plant. It was assumed that 400 metric tons dry biomass per day is processed in the pyrolysis oil substitution cases, with the pyrolysis oil replacing the fossil fuel feedstock used in the power plants. The power outputs of these systems were calculated by the biomass feedstock, LHV of the biomass and thermal efficiencies of the power plants. The plant size and thermal efficiencies of GTCC and stationary diesel generator were obtained from RTP preliminary design data and literature references ${ }^{131,133}$. Table 6.6 shows the power output and efficiency of each system.

Table 6.6: Plant size and efficiency of each power generation system

\begin{tabular}{|l|l|l|l|l|l|l|l|}
\hline & BC1 & BC2 & GTCC & Generator & Coal plant & $\begin{array}{l}\text { Natural gas } \\
\text { plant }\end{array}$ & Oil plant \\
\hline $\begin{array}{l}\text { Power Output } \\
\text { (MW) }\end{array}$ & 10 & 10 & & & & & \\
\hline$\%$ Efficiency & 18 & 25 & 42.9 & 45 & 33 & 42 & 34 \\
\hline
\end{tabular}

The GTCC and stationary diesel generator were assumed to be parasitic systems, in which the energy required for pyrolysis is supplied by the integrated pyrolysis oil combustion power plant. An estimated of $0.012 \mathrm{kWh}$ generated electricity is consumed at the pyrolysis plant to produce $1 \mathrm{MJ}$ pyrolysis oil, and therefore, more pyrolysis oil is required to be combusted to generate $1 \mathrm{kWh}$ electricity. The net efficiency of GTCC facility is $39 \%$ while stationary diesel generator $40.9 \%$ after factoring in parasitic losses. The biomass feedstocks required were calculated by the power output and plant net thermal efficiencies. 


\subsection{Results and discussion}

\subsubsection{Biomass cultivation and harvesting}

GHG emissions during the biomass cultivation and harvesting stages is shown in Figure 6.2 for each major greenhouse gas. Harvesting logging residue exhibits a lower GHG footprint per kg of harvested and chipped biomass, followed by poplar and then by willow; $27.5<43.2<56.2 \mathrm{~g} \mathrm{CO}_{2}$ eq./kg chipped dry biomass, respectively. Logging residues obtained from natural regeneration forests avoid inputs of fertilizers and pesticides that are found in intensively cultivated systems such as willow and poplar. The $\mathrm{N}_{2} \mathrm{O}$ emissions account for the majority of GHG emission, mostly due to the application of nitrogen fertilizers during poplar and willow cultivation. However, systems such as willow and poplar have the advantage of much higher productivities per acre (per hectare) which translates into fewer transportation emissions, as will be shown in the next section. Thus, there is a tradeoff between productivity and transportation that emerges as the scale of biomass production increases.

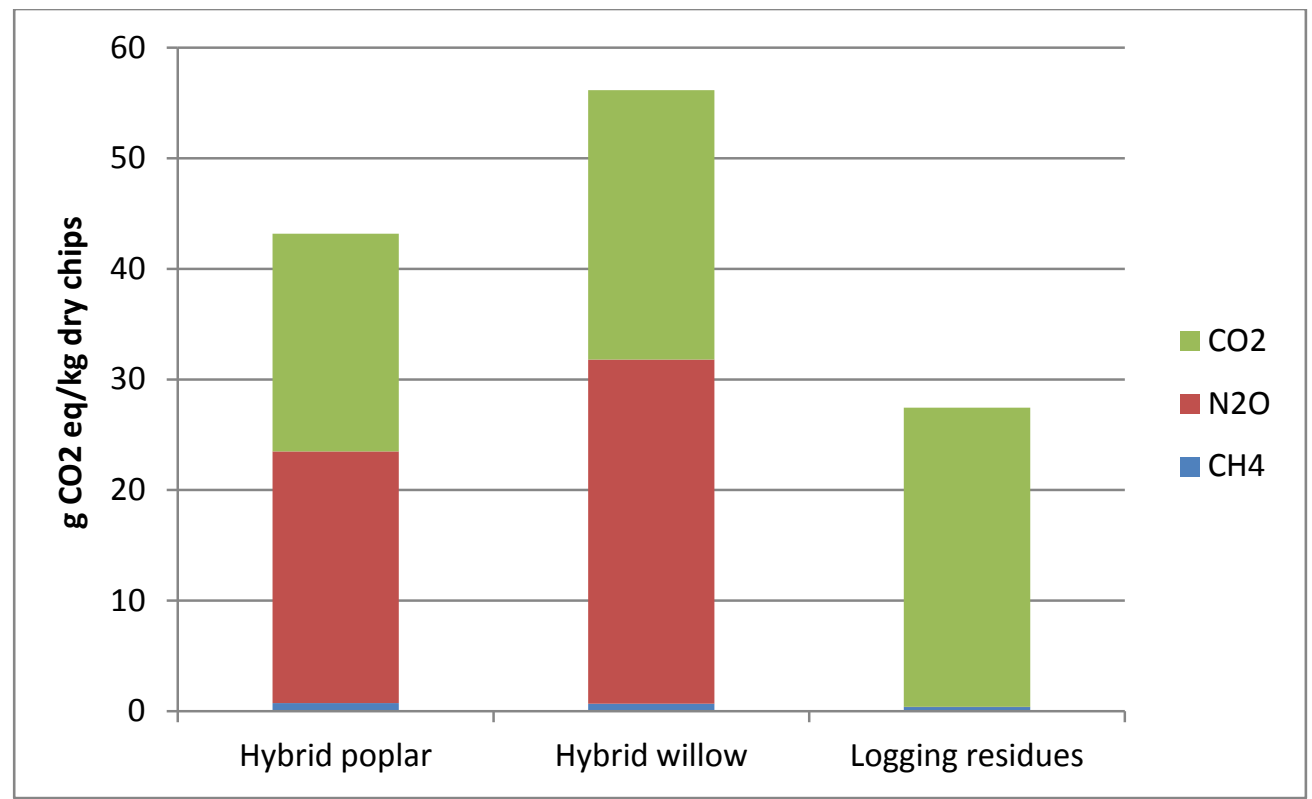

Figure 6.2: GHG emission of biomass cultivation and harvesting (no transport). 


\subsubsection{Pyrolysis oil production}

In this study, pyrolysis oil production was divided into four life cycle stages: biomass cultivation and harvesting, feedstock transportation, pyrolysis, and bio-oil distribution and storage. 400 metric tons dry biomass per day were assumed to be consumed to produce pyrolysis oil. The feedstock transport distances were described in former section. The GHG emissions results are shown in Table 6.7. Pyrolysis step is the leading contributor of GHG emissions of pyrolysis oil production, primarily due to the consumption of electricity imported from the U.S. grid. Pyrolysis oil produced from waste wood has the least environmental impact, because the feedstock itself does not introduce any GHG emission.

Table 6.7: GHG emissions results of PyOil production from 4 biomass feedstocks

\begin{tabular}{|l|l|l|l|l|}
\hline $\mathrm{g} \mathrm{CO}_{2}$ eq./MJ pyrolysis oil & $\begin{array}{l}\text { logging } \\
\text { residues }\end{array}$ & poplar & willow & $\begin{array}{l}\text { wawmill } \\
\text { waste }\end{array}$ \\
\hline Feedstock cultivation & 2.08 & 3.28 & 4.26 & 0 \\
\hline Feedstock transport & 1.31 & 0.28 & 0.30 & 0 \\
\hline Pyrolysis & 9.39 & 9.39 & 9.39 & 9.39 \\
\hline Pyrolysis oil distribution and storage & 0.34 & 0.34 & 0.34 & 0.34 \\
\hline Total & 13.13 & 13.30 & 14.30 & 9.73 \\
\hline
\end{tabular}

\subsubsection{Sensitivity analysis of $f$ value}

When the value of $f$ (fraction of land devoted to biomass crops) changes, the transportation distances of biomass feedstocks adjust accordingly, as a result, the cradle to gate GHG emissions of pyrolysis oil production change. The base case value of $\mathrm{f}=0.1$ was used as the basic case, and $f$ was changed for a sensitivity study. The biomass transportation distances under different $f$ values are shown in Table 6.8. 
Table 6.8: Transportation distances of biomass feedstock under different $\mathrm{f}$ values

\begin{tabular}{|l|l|l|l|l|l|}
\hline $\mathrm{r}_{\text {circle }}(\mathrm{km})$ & $\mathrm{f}=0.03$ & $\mathrm{f}=0.1$ & $\mathrm{f}=0.3$ & $\mathrm{f}=0.6$ & $\mathrm{f}=0.9$ \\
\hline Poplar & 32.26 & 17.67 & 10.20 & 7.21 & 5.89 \\
\hline Willow & 34.34 & 18.81 & 10.86 & 7.67 & 6.28 \\
\hline Residue & 150.83 & 82.61 & 47.69 & 33.72 & 27.53 \\
\hline
\end{tabular}

The cradle to gate GHG emissions of pyrolysis oil production results are shown in Figure 5.3. Effects of transportation distance on life cycle GHG impacts for pyrolysis oil production are most pronounced for small values of $f ; 0.03<f<0.6$. At low values of $f$, where transportation distances are largest, logging residues emit the largest amount of GHG even though residue cultivation is small compared to SRF biomass. At high values of $f(f>0.6)$, logging residue-derived pyrolysis oil becomes similar in terms of GHG emissions as the SRF feedstock-derived pyrolysis oil. However, such high values of $f$ are not likely to be realized for most applications. Because waste wood such as sawmill waste is produced on site, no biomass transportation required and changes of $\mathrm{f}$ value do not impact on the life cycle emission of pyrolysis oil production from waste wood.

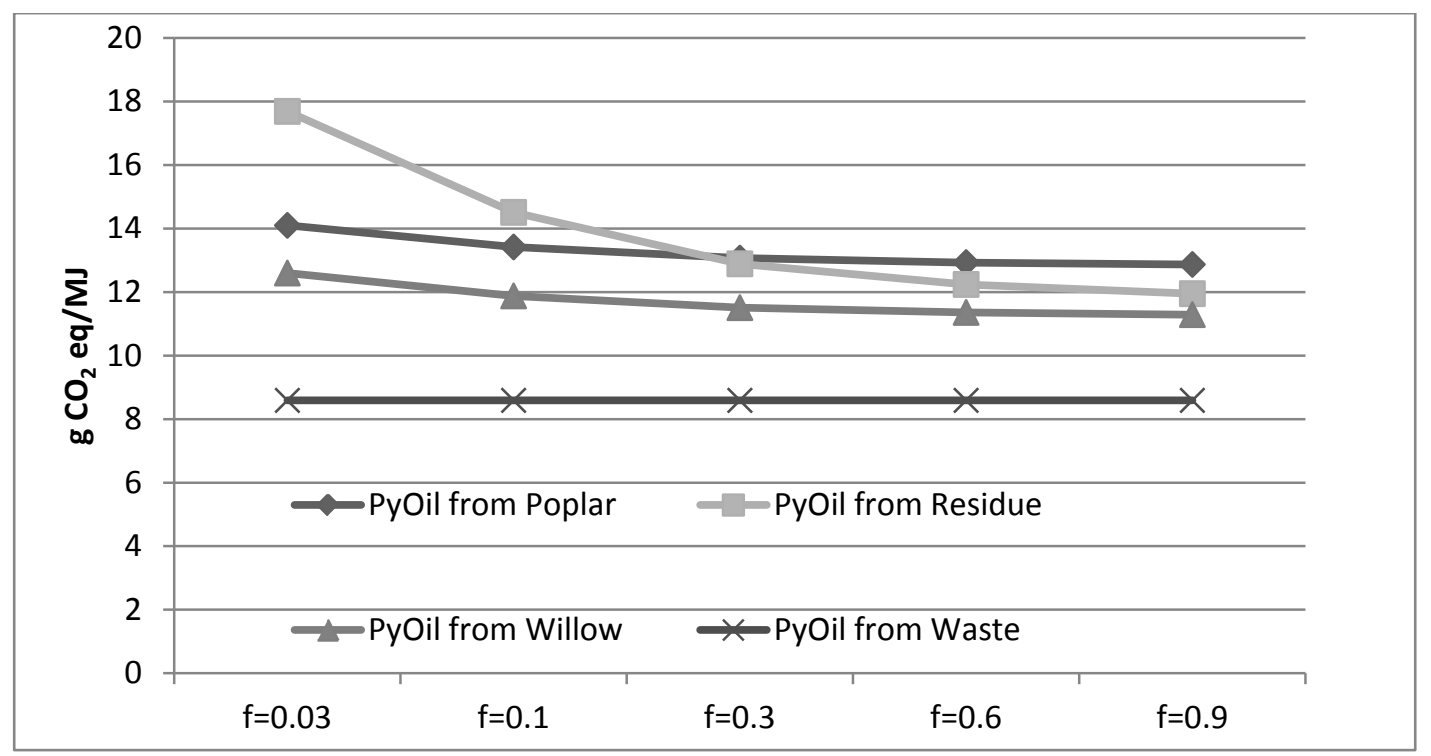

Figure 6.3: Cradle to gate GHG emission of pyrolysis oil production with different $\mathrm{f}$ values. 


\subsubsection{Pyrolysis oil production in a parasitic plant}

The location of power source and pyrolysis plant has a large impact to the LCA study results. If the pyrolysis plant is integrated with the power plant, the electricity generated in the power plant can be consumed internally to meet the energy demand of pyrolysis. Even though the overall efficiency of power generation will decrease, the GHG emission caused by U.S. grid electricty use can be avoided. Table 6.9 shows the GHG emissions of pyrolysis oil production when this "parasatic power" scenario was considered. The GHG emissions due to pyrolysis production is considerably lower; by slightly more than $8 \mathrm{~g}$ $\mathrm{CO}_{2}$ eq. $/ \mathrm{MJ}$ pyrolysis oil, compared to the results in Table 6.6.

Table 6.9: GHG emissions results of pyrolysis oil production in parasitic plant

\begin{tabular}{|l|l|l|l|l|}
\hline $\begin{array}{l}\mathrm{g} \mathrm{CO}_{2} \text { eq/MJ } \\
\text { PyOil }\end{array}$ & Poplar & Residue & Willow & $\begin{array}{l}\text { Waste } \\
\text { wood }\end{array}$ \\
\hline Feedstock & 4 & 2.08 & 2.41 & 0 \\
\hline $\begin{array}{l}\text { Feedstock } \\
\text { Transportation }\end{array}$ & 0.82 & 3.84 & 0.87 & 0 \\
\hline Pyrolysis & 0.42 & 0.42 & 0.42 & 0.42 \\
\hline Total & 5.25 & 6.34 & 3.7 & 0.42 \\
\hline
\end{tabular}

\subsubsection{Power generation from pyrolysis oil combustion}

Pyrolysis oil is assumed to be combusted in GTCC, diesel generator, and co-fired in fossil fuel plant to generate electricity. GHG emissions data for fossil fuel plant (coal, natural gas and fuel oil plant) were obtained from the GREET model ${ }^{55}$, and used as baseline to compare to the pyrolysis oil substitution case.

\subsubsection{GTCC with heat recovery}

For the GTCC system, part of the final electricity is used internally to power the pyrolysis plant, the overall efficiency decreases from $42.9 \%$ to $39 \%$, but the GHG emission caused by imported U.S. grid electricity is avoided. In addition, no GHG emission is caused due 
to pyrolysis oil transportation because the pyrolysis plant and GTCC facility are integrated. The overall GHG emissions show significant advantage compared. The life cycle GHG emissions are shown in Table 6.10. For poplar and willow GHG emissions are the largest for biomass cultivation and harvesting, whereas transportation and pyrolysis are about an order of magnitude lower and nearly equal. For logging residues, harvesting/cultivation and transportation are nearly the same magnitude due to large distances needed for the relatively low productivity feedstock. Waste wood is available without burden and needs no transportation since it is assumed that biomass is available at the site of pyrolysis and electricity generation. The GHG savings compared to U.S. coal baseline range from $96 \%$ to $99 \%$, depending on the biomass feedstock used. Coal electricity was selected as the comparison baseline because new renewable electricity generation capacity is likely to displace the most polluting electricity source.

Table 6.10: Life cycle GHG emissions of electricity from pyrolysis oil in GTCC

\begin{tabular}{|l|l|l|l|l|l|}
\hline $\mathrm{g} \mathrm{CO}_{2}$ eq/kWh & $\begin{array}{l}\text { logging } \\
\text { residues }\end{array}$ & poplar & willow & $\begin{array}{l}\text { sawmill } \\
\text { waste }\end{array}$ & $\begin{array}{l}\text { U.S coal } \\
\text { electricity }^{55}\end{array}$ \\
\hline Feedstock cultivation & 19.23 & 30.28 & 39.35 & 0.00 & \\
\hline Feedstock transport & 7.94 & 1.70 & 1.81 & 0.00 & \\
\hline Pyrolysis & 3.77 & 3.77 & 3.77 & 3.77 & \\
\hline $\begin{array}{l}\text { Pyrolysis oil distribution } \\
\text { and storage }\end{array}$ & 3.18 & 3.18 & 3.18 & 3.18 & \\
\hline Pyrolysis combustion & 0.01 & 0.01 & 0.01 & 0.01 & \\
\hline Total & 34.12 & 38.94 & 48.12 & 6.96 & 1087 \\
\hline GHG savings & $96.9 \%$ & $96.4 \%$ & $95.6 \%$ & $99.4 \%$ & \\
\hline
\end{tabular}

\subsubsection{Stationary diesel generator}

The stationary diesel generator case is also a parasitic system similar to the GTCC case, and factoring in parasitic loss of electricity, $0.52 \mathrm{~kg}$ pyrolysis oil is combusted to generate $1 \mathrm{kWh}$ net electricity. The life cycle GHG emission results are shown in Table 6.11. Similar results as to Case GTCC are exhibited: impacts of cultivation and harvesting are 109 
greater for poplar and willow crops, with emissions from feedstock transportation and pyrolysis oil production being nearly equal. Electricity generated from logging residuederived pyrolysis oil show relatively large transportation impacts and waste woodderived pyrolysis oil is lowest in GHG emissions. For the same reason as given in Section 6.3.5.1, coal electricity was selected as the comparison baseline. The GHG savings vary from $95 \%$ to $99 \%$ compared to U.S. coal electricity baseline, depending on the feedstock used.

Table 6.11: Life cycle GHG emissions of electricity from pyrolysis oil in diesel generator

\begin{tabular}{|l|l|l|l|l|l|}
\hline g CO 2 eq/kWh & $\begin{array}{l}\text { logging } \\
\text { residues }\end{array}$ & poplar & willow & sawmill waste & $\begin{array}{l}\text { U.S coal } \\
\text { electricity }\end{array}$ \\
\hline Feedstock cultivation & 18.34 & 28.87 & 37.52 & 0.00 & \\
\hline Feedstock transport & 5.33 & 1.14 & 1.21 & 0.00 & \\
\hline Pyrolysis & 3.59 & 3.59 & 3.59 & 3.59 & \\
\hline Pyrolysis oil distribution & & & & & \\
and storage & 3.03 & 3.03 & 3.03 & 3.03 & \\
\hline Pyrolysis combustion & 0.01 & 0.01 & 0.01 & 0.01 & 1087 \\
\hline Total & 30.30 & 36.64 & 45.37 & 6.63 & \\
\hline GHG savings & $97.2 \%$ & $96.6 \%$ & $95.8 \%$ & $99.4 \%$ & \\
\hline
\end{tabular}

\subsubsection{Pyrolysis oil substituting coal}

Pyrolysis oil is combusted in the coal power plant to replace coal as feedstock, the generation efficiency was assumed to be the same as a typical U.S. coal plant $(33 \%)^{171}$. The life cycle GHG emission results are shown in Table 6.12. Because pyrolysis oil production is remote from power generation and uses grid electricity, GHG emissions of pyrolysis oil production contributes the most to the life cycle impacts.

Harvesting/cultivation impacts are second largest followed by pyrolysis oil transport and feedstock transport. For logging residues, feedstock transportation emission is higher than the other two feedstocks due to the low area productivity of residues. The lowest GHG 
emission is for sawmill waste as feedstock because it does not incur feedstock cultivation/harvesting or transportation impacts. The GHG savings compared to U.S. coal baseline range from $84 \%$ to $89 \%$, depending on the biomass feedstock used.

Table 6.12: Life cycle GHG emissions of pyrolysis oil combustion in coal-fired plant

\begin{tabular}{|c|c|c|c|c|c|}
\hline $\mathrm{g} \mathrm{CO}_{2} \mathrm{eq} / \mathrm{kWh}$ & residue & poplar & willow & $\begin{array}{l}\text { sawmill } \\
\text { waste }\end{array}$ & $\begin{array}{l}\text { U.S coal } \\
\text { electricity }^{55}\end{array}$ \\
\hline Feedstock & 22.73 & 35.79 & 46.51 & & \\
\hline Feedstock transport & 14.30 & 3.06 & 3.26 & & \\
\hline Pyrolysis & 102.44 & 102.44 & 102.44 & 102.44 & \\
\hline Pyrolysis oil transport & 5.39 & 5.39 & 5.39 & 5.39 & \\
\hline Pyrolysis oil distribution \& storage & 3.76 & 3.76 & 3.76 & 3.76 & \\
\hline Pyrolysis oil combustion & 0.02 & 0.02 & 0.02 & 0.02 & \\
\hline Total & 148.63 & 150.44 & 161.36 & 111.60 & 1087 \\
\hline GHG savings & $86.3 \%$ & $86.2 \%$ & $85.1 \%$ & $89.7 \%$ & \\
\hline
\end{tabular}

\subsubsection{Pyrolysis oil substituting natural gas}

In this case, pyrolysis oil is combusted in the natural gas power plant as feedstock, with the same efficiency as an average natural gas fired plant ${ }^{173}$, we assumed the median point efficiency of natural gas plant, which is $42 \%{ }^{171}$. The life cycle GHG emission results are shown in Table 6.13. These GHG results are qualitatively similar to those presented for coal substitution, except that overall emissions are lower in comparison due to the higher electricity generation efficiency. The higher efficiency translates to reduced feedstock demand per unit of electricity output. The GHG savings compared to U.S. natural gas baseline range from $78 \%$ to $85 \%$, depending on the biomass feedstock used. 
Table 6.13: Life cycle GHG emissions of pyrolysis oil combustion in natural gas plant

\begin{tabular}{|l|l|l|l|l|l|}
\hline & & & & vis natural \\
sawmill & residue & poplar & willow & $\begin{array}{l}\text { gas } \\
\text { waste } \\
\text { electricity }\end{array}$ \\
\hline Feedstock & 17.86 & 28.12 & 36.54 & & \\
\hline Feedstock transport & 11.23 & 2.40 & 2.56 & & \\
\hline Pyrolysis & 80.49 & 80.49 & 80.49 & 80.49 & \\
\hline Pyrolysis oil transport & 4.24 & 4.24 & 4.24 & 4.24 & \\
\hline $\begin{array}{l}\text { Pyrolysis oil distribution and } \\
\text { storage }\end{array}$ & 2.95 & 2.95 & 2.95 & 2.95 & \\
\hline Pyrolysis oil combustion & 0.01 & 0.01 & 0.01 & 0.01 & \\
\hline Total & 116.78 & 118.21 & 126.78 & 87.69 & 509 \\
\hline GHG savings & $77.1 \%$ & $76.8 \%$ & $75.1 \%$ & $82.8 \%$ & \\
\hline
\end{tabular}

\subsubsection{Pyrolysis oil substituting fuel oil}

In this case, pyrolysis oil is combusted in the fuel oil power plant as feedstock, the efficiency was assumed to be $35 \%{ }^{55}$. The life cycle GHG emission results are shown in Table 6.14. GHG emission of fuel oil plant data obtained from the GREET model was used as a benchmark. GHG emissions for the oil substitution case are very similar to that for coal substitution because electricity generation efficiency is very comparable. The GHG savings compared to U.S. fuel oil baseline range from $82 \%$ to $87 \%$, depending on the biomass feedstock used. 
Table 6.14: Life cycle GHG emissions of pyrolysis oil combustion in fuel oil-fired plant

\begin{tabular}{|l|l|l|l|l|l|}
\hline & residue & poplar & willow & $\begin{array}{l}\text { sawmill } \\
\text { waste }\end{array}$ & $\begin{array}{l}\text { U.S fuel oil } \\
\text { electricity }\end{array}$ \\
\hline Feedstock & 21.43 & 33.74 & 43.85 & & \\
\hline Feedstock transport & 13.48 & 2.88 & 3.07 & & \\
\hline Pyrolysis & 96.59 & 96.59 & 96.59 & 96.59 & \\
\hline Pyrolysis oil transport & 5.08 & 5.08 & 5.08 & 5.08 & \\
\hline $\begin{array}{l}\text { Pyrolysis oil distribution and } \\
\text { storage }\end{array}$ & 3.54 & 3.54 & 3.54 & 3.54 & \\
\hline Pyrolysis oil combustion & 0.02 & 0.02 & 0.02 & 0.02 & \\
\hline Total & 140.14 & 141.85 & 152.15 & 105.23 & 835 \\
\hline GHG savings & $83.2 \%$ & $83.0 \%$ & $81.8 \%$ & $87.4 \%$ & \\
\hline
\end{tabular}

\subsubsection{Sensitivity analysis of pyrolysis oil transportation distance}

For substitution cases, pyrolysis oil is produced in distributed pyrolysis plants and then transported to the power plant to generate electricity. In this sensitivity study, the transportation distance of pyrolysis oil between pyrolysis and power plant range from $50 \mathrm{~km}$ to $200 \mathrm{~km}$, where the base case distance was $100 \mathrm{~km}$. The life cycle GHG emission results are shown in Figures 6.4. As the pyrolysis oil transportation distances increase from 50 to $200 \mathrm{~km}$, life cycle GHG emissions for $1 \mathrm{kWh}$ electricity increase roughly by $16 \mathrm{~g} \mathrm{CO}_{2}$ eq. 


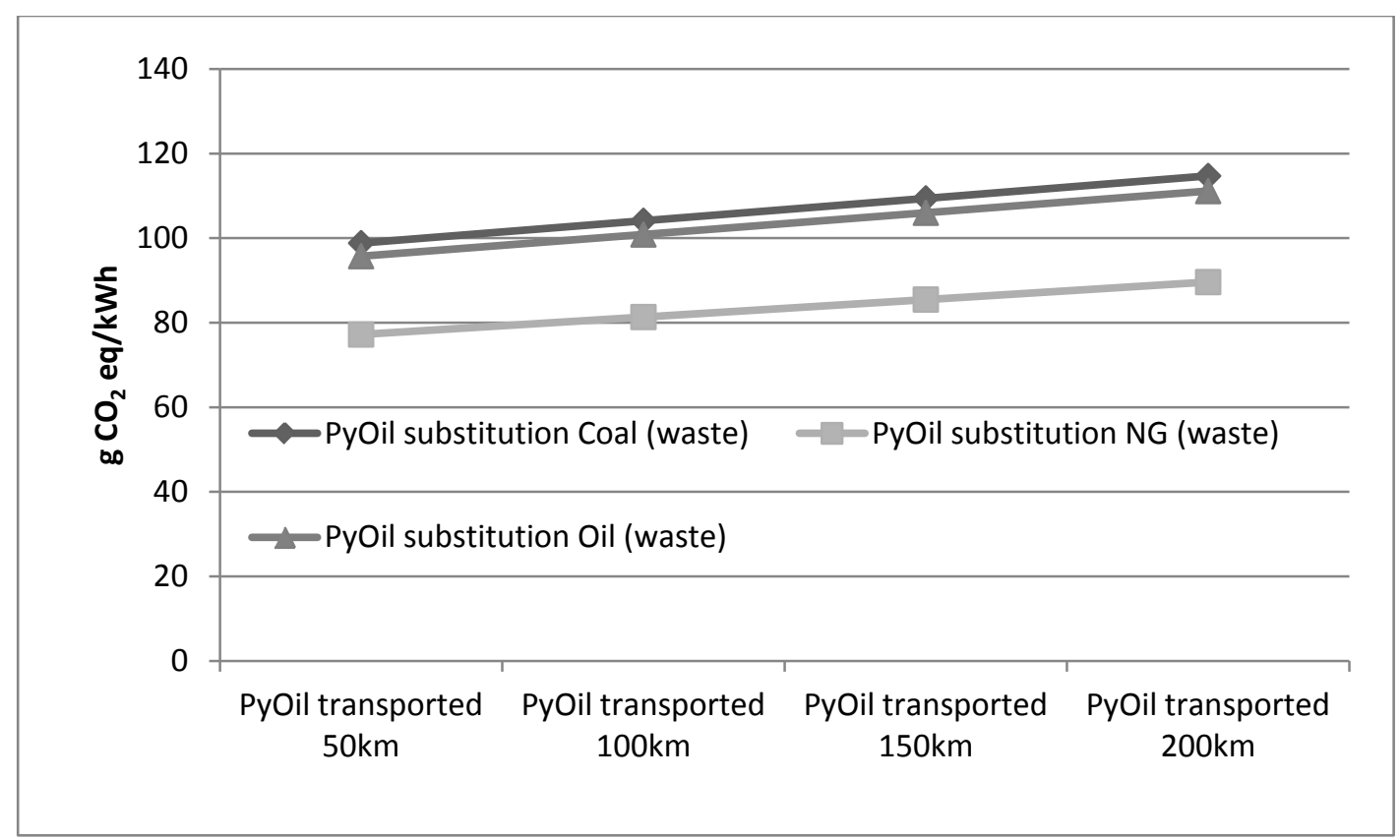

Figure 6.4: Life cycle GHG emissions of pyrolysis oil combusted in power plant with different pyrolysis oil transportation distances.

\subsubsection{Biomass direct combustion}

Biomass are collected and transported to the power plant, generating electricity by direct combustion. The biomass transport distances are presented in Table 6.5. GHG emissions of $\mathrm{BC} 1$ and $\mathrm{BC} 2$ were calculated and the results are shown in Table 6.15. Feedstock cultivation exhibits the largest GHG emissions and minimal impacts from transportation. In all cases, biomass combustion emits relatively few $\mathrm{GHG}$ emissions. $\mathrm{BC} 2$ case, being of higher efficiency, shows lower GHG emissions than the $\mathrm{BC} 1$ case. Both the $\mathrm{BC} 1$ and BC2 cases show more than $90 \%$ GHG savings compared to coal electricity emissions. 
Table 6.15: Life cycle GHG emissions of electricity from biomass direct combustion

\begin{tabular}{|l|l|l|l|l|l|l|l|}
\hline $\mathrm{g} \mathrm{CO}_{2}$ eq/kWh & $\begin{array}{l}\mathrm{BC} 1 \\
\text { (residue) }\end{array}$ & $\begin{array}{l}\mathrm{BC} 1 \\
\text { (poplar) }\end{array}$ & $\begin{array}{l}\mathrm{BC} 1 \\
\text { (willow) }\end{array}$ & $\begin{array}{l}\mathrm{BC} 2 \\
\text { (residue) }\end{array}$ & $\begin{array}{l}\mathrm{BC} 2 \\
\text { (poplar) }\end{array}$ & $\begin{array}{l}\mathrm{BC} 2 \\
\text { (willow) }\end{array}$ & $\begin{array}{l}\text { U.S coal } \\
\text { electricity }\end{array}$ \\
\hline Feedstock & 30.56 & 48 & 62.44 & 22 & 34.56 & 44.96 & \\
\hline $\begin{array}{l}\text { Feedstock } \\
\text { transport }\end{array}$ & 4.02 & 0.86 & 0.91 & 2.45 & 0.52 & 0.56 & \\
\hline $\begin{array}{l}\text { Biomass } \\
\text { combustion }\end{array}$ & 4.13 & 4.13 & 4.13 & 2.97 & 2.97 & 2.97 & \\
\hline Total & 38.70 & 52.99 & 67.49 & 27.42 & 38.05 & 48.49 & 1087 \\
\hline GHG savings & $96.4 \%$ & $95.1 \%$ & $93.8 \%$ & $97.5 \%$ & $96.5 \%$ & $95.5 \%$ & \\
\hline
\end{tabular}

\subsection{Discussion}

Power generation by biomass direct combustion, by co-firing in fossil fuels plant, by GTCC and stationary diesel generator are compared together to determine GHG emissions and savings compared to conventional fossil fuel-generated electricity. The results are shown in Figure 6.5. Pyrolysis oil co-fired in fossil fuels plants (coal, natural gas or fuel oil) has the highest emissions, although the emissions are significantly lower than fossil fuels electricity baseline. The major contributor to life cycle GHG emissions is electricity used in the pyrolysis plant. Pyrolysis oil produced in a parasitic configuration and combusted in either a GTCC or stationary diesel generator release the lowest GHG emission; even lower than the direct biomass combustion cases presented above, because the GHG emission caused by grid electricity used for production of pyrolysis bio-oil is avoided. Biomass direct combustion in steam turbines reside in between, but the leading contributor to the life cycle GHG releases in this case are biomass cultivation/harvesting and transportation. The low energy density of raw biomass relative to pyrolysis oil becomes increasingly important as transportation distance increases. 


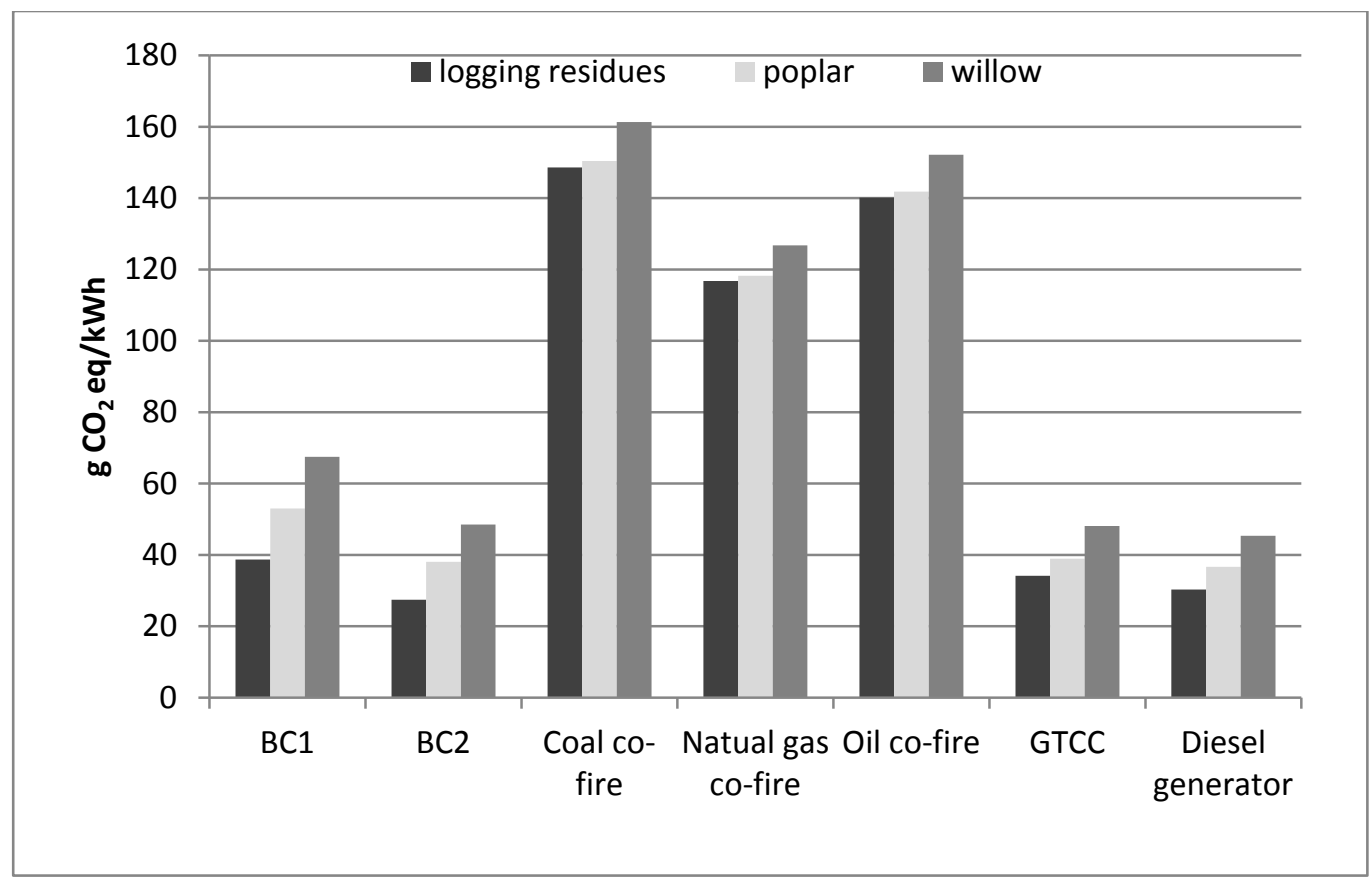

Figure 6.5: Life cycle GHG emissions of power generation.

As shown in other studies, power generation from direct combustion of biomass produced by urban sources, normal land filling and mulching operations has great advantage with regard to GHG emissions compared to the fossil fuel plants ${ }^{174}$. However, problems and limitations of direct biomass combustion remain. High nitrogen oxides $\left(\mathrm{NO}_{\mathrm{x}}\right)$ emission is one of the top air quality concerns. Biomass power plants show a relatively high $\mathrm{NO}_{\mathrm{x}}$ emission rate per $\mathrm{kWh}$ generated compared to other combustion technologies. Carbon monoxide (CO) is also emitted, sometimes at levels higher than those for coal plants. Another air quality concern is PM emission, as burning biomass will release relatively large amounts of particulates. Furthermore, ash produced from biomass co-combustion is not yet certified for reuse in cement manufacturing, and hence, ash from co-processing may become a solid waste rather than a useful co-product. In addition, volatile alkali salts produced during biomass co-processing have been shown to hurt the effectiveness of catalysts used in selective catalytic reduction $(\mathrm{SCR})^{175}$, and as a resykt, NOx emission from the power plant may further increase. Solid and wet biomass fuels are of relatively low energy density, compared with fossil alternatives, and 
consequently large volumes are typically required to be stored and transported, hence the emission and cost due to biomass transportation are much higher than other feedstocks, for example pyrolysis bio-oil. In addition, biomass will usually absorb moisture if exposed, thus it may naturally biodegrade in storage ${ }^{176}$. Using pyrolysis oil instead of biomass as feedstock to generate electricity can eliminate many of the problems associated with direct biomass combustion. Because of low ash content in pyrolysis oil (often well below 1\%), it can also minimize ash related issues caused by biomass combustion $^{177}$. In addition, pyrolysis oil is more flexible in power plant application, as it can be combusted in coal, oil, and natural gas-fired plants ${ }^{133}$, as compared to wood chips that can most easily displace solid fossil fuels (coal).

\subsection{Conclusion}

Pyrolysis bio-oil can be produced through fast pyrolysis step from solid biomass, and then combusted to generate power, replacing fossil fuels as feedstock. Combusting pyrolysis oil as a liquid biofuel to generate power can reduce the climate changing greenhouse emissions significantly because the $\mathrm{CO}_{2}$ emission at the pyrolysis oil combustion stage is considered carbon neutral as $\mathrm{CO}_{2}$ is sequestered during feedstock growth. In this LCA study, life cycle GHG savings of $80 \%$ to $99 \%$ were estimated for power generation from pyrolysis oil combustion relative to fossil fuels combustion, depending on the biomass feedstocks and combustion technologies used. A parasitic system scenario in which electricity is provided from an integrated pyrolysis oil production-electricity generation facility was also considered, and it shows more GHG savings because use of imported electricity from the U.S. grid is avoided. With expected improvement of pyrolysis technology, and more efficient power generation technology, the life cycle GHG emissions of power generation using pyrolysis oil can be further reduced. Pyrolysis oil has the potential to replace fossil fuels as an alternative energy source to generate power, reducing GHG emissions caused at power plant, as well as the dependence on fossil fuels. 


\section{Chapter 7: LCA of transportation fuels produced from pyrolysis oil}

\subsection{Introduction}

Pyrolysis oil can be upgraded to transportation fuels by deoxygenation reaction ${ }^{131}$. However, it is not suitable for direct use in most combustion engines due to limited storage capability and large amounts of water (up to $50 \mathrm{wt} \%$ ) and corrosive organic acids (up to $10 \mathrm{wt} \%)^{178}$. It also shows other undesired properties for fuel application such as low heating value, immiscibility with hydrocarbon fuels, thermal and chemical instability, and high density ${ }^{179}$. The pyrolysis oil is unstable due to the oxygen containing components, especially the carbonyl compounds ${ }^{137}$. Polymerization of organic matters present in oil may occur which will increase the viscosity if stored for an extended period of time under wide temperature fluctuations ${ }^{137,180}$. Therefore, the pyrolysis oil needs to be stabilized by reducing the oxygen content via catalytic hydrotreating first. This hydrotreatment also avoids catalyst deactivation in the upgrading step ${ }^{181}$. The hydrotreated pyrolysis oil can be used to produce liquid fuels such as gasoline and diesel through hydroprocessing in the presence of hydrogen and heterogeneous catalysts ${ }^{138,182}$. Hydroprocessing of pyrolysis oil differs from petroleum crudes processing because of the importance of hydrodeoxygenation, as opposed to nitrogen and sulfur removal ${ }^{183}$. The hydrodeoxygenation process is performed at high temperature (up to $20 \mathrm{MPa}$ ), high pressure (up to $400^{\circ}$ ) and in presence of catalyst to remove oxygen as $\mathrm{H}_{2} \mathrm{O}^{179,184}$. The hydrodeoxygenation process can be represented as follows: ${ }^{179,185}$

$$
\mathrm{C}_{6} \mathrm{H}_{8} \mathrm{O}_{4}+6 \mathrm{H}_{2} \rightarrow 6 \mathrm{CH}_{2}+4 \mathrm{H}_{2} \mathrm{O}
$$

The oil is then distilled to separate light and heavy oil fractions. Hydrocracking process is a process performed to convert the heavy components to light oil fraction, which is joined with the light oil fraction separated at the first distillation process. The final light oil products are distilled to separate gasoline, diesel and etc ${ }^{186}$. 
The flow diagram of the biomass fast pyrolysis to produce liquid fuels is shown in the Figure 7.1. The biomass is dried and ground to a small size prior to being fed into a pyrolyzer. Char particles are removed from the vapor exiting pyrolyzer by a cyclone. The vapors are condensed in the heat exchanger to yield liquid pyrolysis oil, which is then stabilized (less than $2 \% \mathrm{O}$ ) by hydrotreatment prior to upgrading to liquid transportation fuels. Bio-char produced in the reactor is used internally to provide process heat. The hydrogen required for the hydrotreating, hydroprocessing and hydrocracking reactions are either purchased externally, or produced in-situ by reforming external natural gas and co-product fuel gas ${ }^{180,187}$.

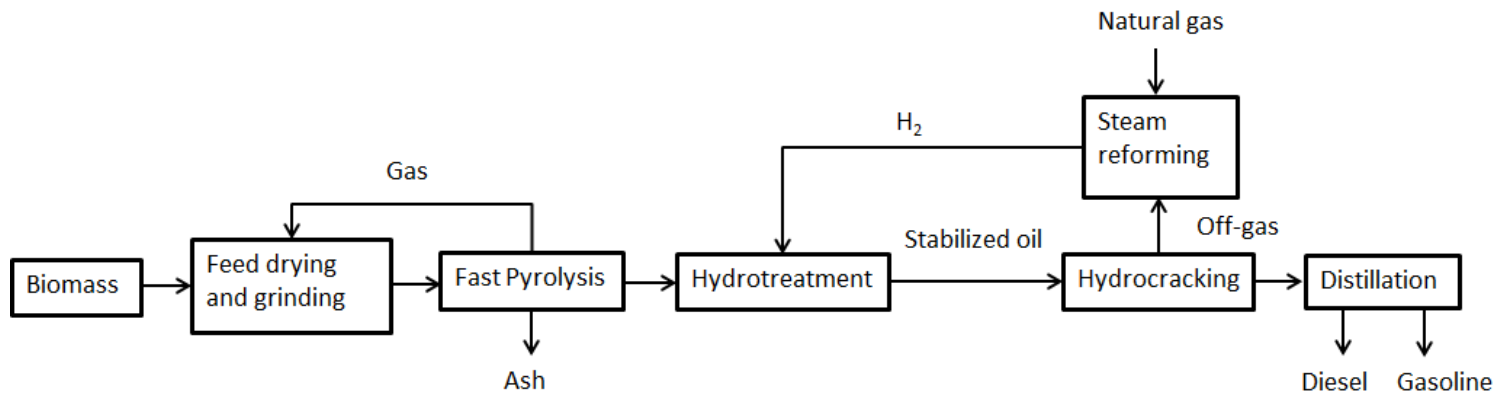

Figure 7.1: Flow diagram of liquid fuels production via fast pyrolysis of biomass. Adapted from Jones et $\mathrm{al}^{188}$

The final products are compatible with the current transportation fuel distribution infrastructure and current vehicle technologies ${ }^{180}$. Pyrolysis oil can also be upgraded to hydroprocessed jet fuels (HRJ), which is prominently composed of aromatic compounds. However, it has not been certified to use in jet engines because of the aromatic content limit (25 vol\%) specified by the ASTM D1655 standard ${ }^{189}$. Therefore, the pyrolysis based jet fuels are not expected to be blended with conventional jet fuels, but may be certified in a blend with SPK to increase aromatic content ${ }^{190}$. 


\subsection{LCA methods}

\subsubsection{Research objectives}

Life cycle assessment studies have been conducted by researchers to estimate the GHG emissions and net energy values of pyrolysis gasoline and diesel. Hsu ${ }^{191}$ examined forest residues as a feedstock to produce gasoline and diesel using the fast pyrolysis and subsequent hydrotreating and hydrocracking processes described in the PNNL (Pacific Northwest National Laboratory) report ${ }^{188}$. No indirect land use change or change in soil carbon was included in this study as a result of production and harvesting of forest residues. The pyrolysis gasoline and diesel products showed 53\% of GHG reduction compared to the 2005 conventional gasoline baseline. A well-to-wheels (WTW) analysis of pyrolysis-based gasoline was conducted and compared with petroleum gasoline by Han et $\mathrm{al}^{192}$. The pyrolysis and oil stabilization \& upgrading process from corn stover and forest residues were investigated in the GREET 2012 model, which are based on the study conducted by Wright et $\mathrm{al}^{187}$ and the PNNL ${ }^{188}$ research group respectively. The impacts of two different hydrogen sources for pyrolysis oil upgrading were investigated. Reforming fuel gas/natural gas for $\mathrm{H}_{2}$ reduces WTW GHG emissions by $60 \%$ (range of 55-64\%) compared to the petroleum fuels. Reforming pyrolysis oil for $\mathrm{H}_{2}$ increases the WTW GHG emissions reduction up to $112 \%$. The goal of this LCA study is to investigate the life cycle GHG emissions, cumulative energy demand (CED), and fossil energy demand (FED) of gasoline and diesel produced from pyrolysis of corn stover and logging residues, and the results are compared to those generated by the GREET 2012. The differences in GHG emission results generated by the two models are explored to understand the impact of emission factors of the LCA inputs and co-products credits.

\subsubsection{System Scope, Functional Unit, Inventory, and Impact Assessment}

The pyrolysis gasoline and diesel production from logging residues and corn stover described by Wright et al ${ }^{187}$ and PNNL ${ }^{188}$ are considerd in this study. The system boundries include all the energy, fuels, chemicals, and transportation needed to operate all phases of the entire operation starting from biomass collection and finishing with the combustion of biofuels in the engines. Land use change (direct or indirect) was not 
included in the system because the feedstocks are considered as waste materials, and in the case of stover, are harvested within allowable limits to assure soil health and erosion control. The functional unit is assumed to be $1 \mathrm{MJ}$ of fuels combusted. A complete set of inputs was utilized from literature sources. The software used for this LCA was SimaPro 7.2. The GHG impact assessment method used was the IPCC 2007 GWP 100a V1.01 method ${ }^{44}$ whose output is in $\mathrm{g} \mathrm{CO}_{2}$ equivalents for all of the GHG emissions using global warming potentials (GWP) of 1 for $\mathrm{CO}_{2}, 25$ for $\mathrm{CH}_{4}, 298$ for $\mathrm{N}_{2} \mathrm{O}$. GWPs for refrigerants, solvents, and other compounds were included in the analysis, which are from the Ecoinvent database within SimaPro. The CED and FED are calculated by using Cumulative Energy Demand 1.07 method in SimaPro, the results include non-renewable fossil (coal, oil, natural gas) and nuclear energy use, renewable biomass energy use, and other renewable energy sources, including solar, geothermal, and hydroelectric power, which are given as the amount of process energy inputs (MJ) along the life cycle per unit of energy in the fuel products.

Two scenarios of pyrolysis oil upgrading are considered: 1 . Distributed refinery scenario in which the pyrolysis oil is produced and stabilized in distributed refineries, and then transported to a centralized oil upgrading facility for liquid fuel production. 2. Integrated refinery scenario in which the pyrolysis oil production is integrated with the fuel production. The pathway diagram of this LCA study is illustrated in Figure 7.2. 


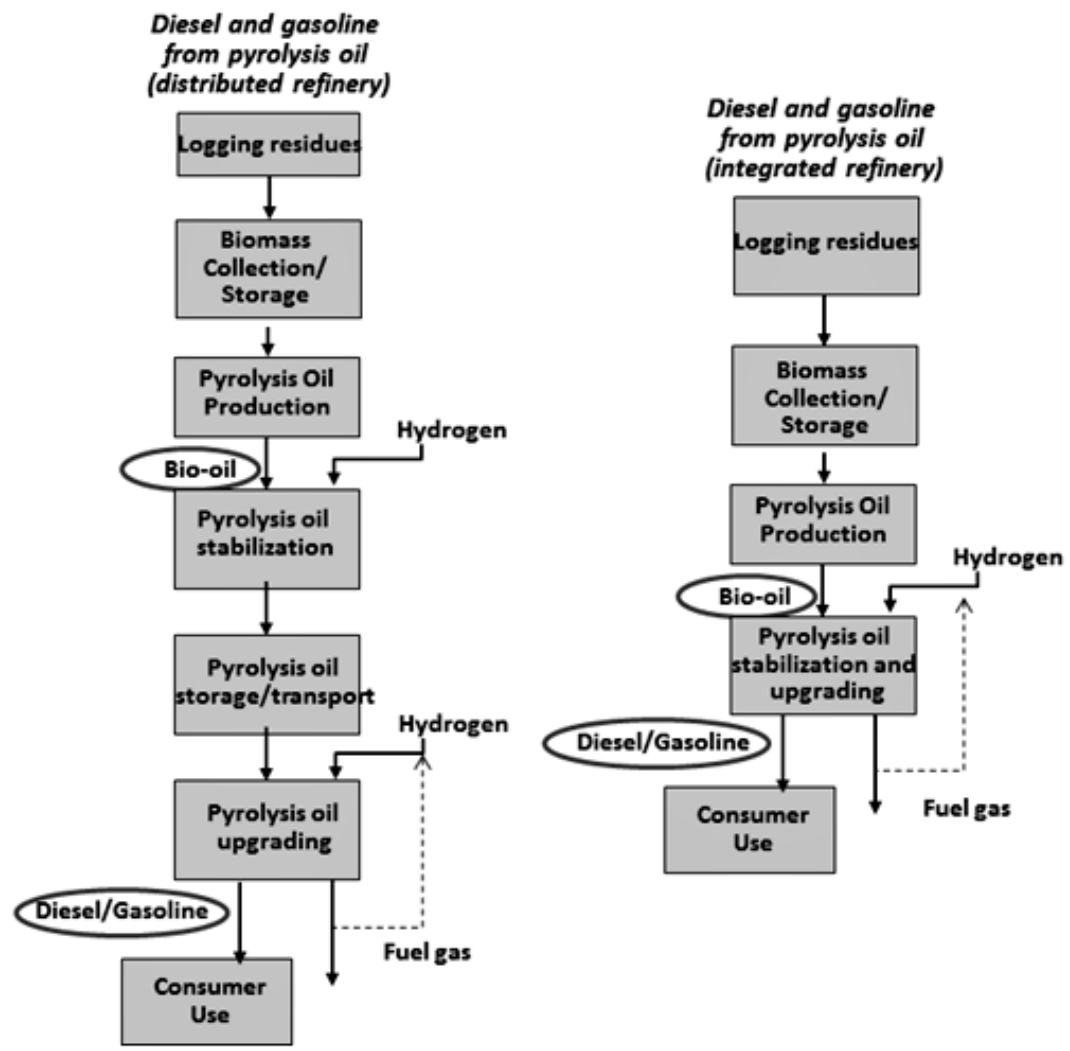

Figure 7.2: Pathway diagram of pyrolysis oil to liquid fuels LCA study

\subsubsection{Pyrolysis gasoline and diesel production}

The inputs of gasoline and diesel production process were obtained directly from GREET $2012^{86}$. The $\mathrm{H}_{2}$ required in the reactions is assumed to be supplied externally from a steam methane reforming (SMR) plant. The co-product fuel gas is available for other uses, and energy allocation method is used to distribute the environmental impacts between liquid fuel product (gasoline and diesel blend) and fuel gas. A second scenario assumes that the $\mathrm{H}_{2}$ is reformed from a mix of external natural gas and co-product fuel gas. There is no co-product in this scenario, and all the emissions and energy burdens are allocated to the fuel product. In the distributed system, transport of hydrotreated pyrolysis oil to the biorefinery is assumed to be the same as that in the GREET $2012^{86}$, which includes rail and truck transport of $480 \mathrm{~km}$ and $80 \mathrm{~km}$ respectively. The final product 
contains pyrolysis gasoline and diesel, which are assumed to be distributed to customers within a $150 \mathrm{~km}$ radius.

\subsubsection{Logging residues as feedstock}

Logging residues as the pyrolysis feedstock was presented in Chapter 5. The feedstock is mixed hardwood logging residue collected from natural regeneration hardwood site near Trenary, MI, which is assumed to be available as waste in the forest. The inputs include biomass collection, forwarding, grinding, and transportation. No land use change impact (direct or indirect) is included. The residues (20\% moisture) are transported 120 and 240 $\mathrm{km}$ by truck to the distributed and integrated pyrolysis plant respectively. This assumption was obtained from the GREET $2012^{86}$ for forest residues transport to the biorefinery. The inputs of the pyrolysis gasoline and diesel production from logging residues in both integrated and distributed systems were obtained from the GREET 2012 model $^{86}$ and tabulated in Table 7.1. Energy allocation method was used to account for the co-product fuel gas. LHV of the hydrotreated pyrolysis oil and pyrolysis gasoline/diesel are 17450 and $17756 \mathrm{btu} / \mathrm{lb}^{86}(40.6$ and $41.3 \mathrm{MJ} / \mathrm{kg})$ respectively.

Table 7.1: Inputs of pyrolysis gasoline and diesel production from logging residues ${ }^{86}$

\begin{tabular}{|l|c|c|c|c|}
\hline & \multicolumn{2}{|c|}{ distributed process } & \multicolumn{2}{c|}{ Integrated process } \\
\hline Inputs & external $\mathrm{H}_{2}$ & internal $\mathrm{H}_{2}$ & external $\mathrm{H}_{2}$ & internal $\mathrm{H}_{2}$ \\
\hline Biomass (dry kg/kg fuel) & 3.15 & 3.15 & 3.15 & 3.15 \\
\hline Elec (kWh/kg fuel) & 0.504 & 0.51 & 0.5 & 0.509 \\
\hline $\mathrm{NG}$ for $\mathrm{H}_{2}(\mathrm{MJ} / \mathrm{kg}$ fuel) & & 9.36 & & 9.345 \\
\hline $\mathrm{H}_{2}$ (g/kg fuel) & 113.6 & & 113.4 & \\
\hline Co-product & & & & \\
\hline Fuel gas (MJ/kg fuel) & 9.67 & & 9.645 & \\
\hline
\end{tabular}

* the inputs include oil production \& stabilization and oil upgrading at a standalone bio-refinery 


\subsubsection{Corn stover as feedstock}

In addition to the logging residues, corn stover was investigated as a feedstock for pyrolysis gasoline and diesel production. Corn stover as a pyrolysis feedstock was studied in section 5.4.3. The feedstock is assumed to be collected from corn fields in Iowa. The inputs of corn stover production were obtained from Morey et $\mathrm{al}^{153}$, which include biomass collection, transport and nutrients added to the field to replace the stover. Corn stover is transported 48 and $96 \mathrm{~km}$ by truck to the distributed and integrated pyrolysis plant respectively. Inputs of pyrolysis gasoline and diesel production in the distributed and integrated system were tabulated in Table 7.2. Energy allocation method was used for the co-products.

Table 7.2: Inputs of pyrolysis gasoline and diesel production from corn stover ${ }^{86}$

\begin{tabular}{|l|c|c|c|c|}
\hline & \multicolumn{2}{|c|}{ distributed process* } & \multicolumn{2}{c|}{ Integrated process } \\
\hline Inputs & external $\mathrm{H}_{2}$ & internal $\mathrm{H}_{2}$ & external $\mathrm{H}_{2}$ & internal $\mathrm{H}_{2}$ \\
\hline Biomass (dry kg/kg fuel) & 3.61 & 3.61 & 3.61 & 3.61 \\
\hline Elec (kWh/kg fuel) & 0.551 & 0.549 & 0.548 & 0.547 \\
\hline $\mathrm{NG}$ for $\mathrm{H}_{2}(\mathrm{MJ} / \mathrm{kg}$ fuel) & & 11.43 & & 11.42 \\
\hline $\mathrm{H}_{2}$ (g/kg fuel) & 86.28 & & 86.25 & \\
\hline Co-product & & & & 11.45 \\
\hline Char (MJ/kg fuel) & 11.47 & 11.47 & 2.26 & 2.26 \\
\hline Steam (MJ/kg fuel) & 2.43 & 2.43 & 2.76 & \\
\hline Fuel gas (MJ/kg fuel) & 2.57 & & & \\
\hline
\end{tabular}

* the inputs include oil production \& stabilization and oil upgrading at a standalone bio-refinery

\subsection{LCA results}

\subsubsection{GHG emissions}

The GHG emissions of pyrolysis gasoline/diesel produced from logging residues are tabulated in Table 7.3. These results also include those generated by GREET for comparison. SimaPro generates comparable GHG results to the GREET model. SimaPro 
shows higher biomass collection emissions because of the larger inputs such as diesel use compared to GREET ( 8.62 vs $6.72 \mathrm{~L}$ diesel/t dry residues). The biomass transport emissions generated by SimaPro are lower compared to GREET because of the lower emission factor of the truck transport. Fuel production emissions include both pyrolysis and oil stabilization/upgrading process. The differences in fuel production emission also lie in the emission factors assumed by GREET and SimaPro. The emission factors of electricity, natural gas and $\mathrm{H}_{2}$ in GREET are $677.5 \mathrm{~g} \mathrm{CO}_{2} \mathrm{eq} / \mathrm{kWh}, 3.52 \mathrm{~kg} \mathrm{CO} 2 \mathrm{eq} / \mathrm{kg}$ and $12.155 \mathrm{~kg} \mathrm{CO}_{2} \mathrm{eq} / \mathrm{kg}$, respectively. In SimaPro, the emission factors are $745 \mathrm{~g} \mathrm{CO}_{2}$ eq $/ \mathrm{kWh}, 4.275 \mathrm{~kg} \mathrm{CO} 2$ eq $/ \mathrm{kg}$ and $11.4 \mathrm{~kg} \mathrm{CO}$ eq $/ \mathrm{kg}$, respectively. The system using external SMR $\mathrm{H}_{2}$ generates higher life cycle GHG emissions than the internal $\mathrm{H}_{2}$ system, because $\mathrm{H}_{2}$ from process co-products have lower carbon intensity than its counterpart produced from fossil natural gas. Distributed system and integrated system have similar life cycle GHG emission, the main difference is due to the transport, where the integrated system shows a higher biomass transport impact because of the longer biomass transport distance to the centralized facility, while the fuel transport emissions in the integrated system are lower because there is no transport of hydrotreated pyrolysis oil as in the distributed system. 
Table 7.3: GHG emissions of pyrolysis gasoline/diesel from logging residues

\begin{tabular}{|l|c|c|c|c|c|c|c|c|}
\hline & \multicolumn{3}{|c|}{ Distributed process } & \multicolumn{3}{c|}{ Integrated process } \\
\hline $\mathrm{g} \mathrm{CO}_{2}$ eq/MJ & \multicolumn{2}{|c|}{ external $\mathrm{H}_{2}$} & \multicolumn{2}{c|}{ internal $\mathrm{H}_{2}$} & \multicolumn{2}{c|}{ external $\mathrm{H}_{2}$} & \multicolumn{2}{c|}{ internal $\mathrm{H}_{2}$} \\
\hline & SimaPro & GREET & SimaPro & GREET & SimaPro & GREET & SimaPro & GREET \\
\hline Biomass & 1.68 & 1.54 & 2.1 & 1.91 & 1.7 & 1.55 & 2.1 & 1.91 \\
\hline $\begin{array}{l}\text { Biomass } \\
\text { transport }\end{array}$ & 0.88 & 1.89 & 1.45 & 2.35 & 2.21 & 3.8 & 2.89 & 4.7 \\
\hline Fuel & & & & & & & & \\
production & 32.95 & 34.62 & 29.76 & 25.30 & 32.66 & 33.74 & 29.70 & 25.31 \\
\hline Fuel & 1.75 & 1.14 & 1.08 & 1.14 & & & & \\
transport* & $(1.33$, & $(0.53$, & $(0.66$, & $(0.53$, & 0.42 & 0.61 & 0.42 & 0.58 \\
\hline Total & $0.42)$ & $0.61)$ & $0.42)$ & $0.61)$ & & & & \\
\hline
\end{tabular}

* the two numbers in parentheses represent transport emissions of hydrotreated pyrolysis oil and liquid product, respectively

The GHG emissions of pyrolysis gasoline/diesel produced from corn stover are tabulated in Table 7.4. The results generated by SimaPro are higher than the GREET, mainly due to the comparatively high fuel production emission. This is because GREET assumes a lower emission factor of $\mathrm{H}_{2}$ (86.3 vs $\left.95 \mathrm{~g} \mathrm{CO}_{2} \mathrm{eq} / \mathrm{MJ}\right)$. In addition, GREET assumes that the co-product char is used as soil amendment thus gaining a $\mathrm{GHG}$ credit $(80 \%$ of $\mathrm{C}$ in char are sequestrated). As in SimaPro, energy allocation method was applied to the coproduct char, as opposed to gain a credit by the displacement method. The steam coproduct in GREET is either exported to produce natural gas or discarded on-site. The efficiency of natural gas boiler is $80 \%$. Fuel gas can be either used to generate electricity for internal use, or exported to gain a GHG credit. In SimaPro, the internal $\mathrm{H}_{2}$ scenario generates higher GHG emission than the external $\mathrm{H}_{2}$ scenario. This is because internal $\mathrm{H}_{2}$ scenario includes a lower co-products yield, thus, even with a lower carbon intensity $\mathrm{H}_{2}$ source, more emissions are allocated to the gasoline/diesel product. As for GREET on the 
other hand, internal $\mathrm{H}_{2}$ scenario yields lower GHG emission, due to lower pyrolysis impacts and higher char credit. This is because the internal $\mathrm{H}_{2}$ scenario includes natural gas in the input, which has a lower emission factor (61.4 $\left.\mathrm{g} \mathrm{CO}_{2} \mathrm{eq} / \mathrm{MJ}\right)$, while $\mathrm{H}_{2}$ imported in the external $\mathrm{H}_{2}$ scenario has a higher emission factor $\left(86.3 \mathrm{~g} \mathrm{CO}_{2} \mathrm{eq} / \mathrm{MJ}\right)$. Fuel gas is produced as a co-product in the external $\mathrm{H}_{2}$ scenario, which allocates partial GHG credit from biochar sequestration away from the product hydrotreated pyrolysis oil. The GREET model shows higher corn stover impact because of the larger diesel requirement and nutrients required to replace the stover in the corn field (Table 7.5). GREET assumes urea as the $\mathrm{N}$ fertilizer as opposed to ammonium as assumed by Morey ${ }^{153}$, the former has a higher emission factor.

Table 7.4: GHG emissions of pyrolysis gasoline/diesel from corn stover

\begin{tabular}{|l|c|c|c|c|c|c|c|c|}
\hline & \multicolumn{4}{|c|}{ Distributed process } & \multicolumn{4}{c|}{ Integrated process } \\
\hline $\mathrm{g} \mathrm{CO}_{2}$ eq/MJ & \multicolumn{2}{|c|}{ external $\mathrm{H}_{2}$} & \multicolumn{2}{|c|}{ internal $\mathrm{H}_{2}$} & \multicolumn{2}{c|}{ external $\mathrm{H}_{2}$} & \multicolumn{2}{c|}{ internal $\mathrm{H}_{2}$} \\
\hline & SimaPro & GREET & SimaPro & GREET & SimaPro & GREET & SimaPro & GREET \\
\hline Biomass & 3.33 & 7.58 & 3.48 & 7.88 & 3.15 & 7.44 & 3.31 & 7.88 \\
\hline $\begin{array}{l}\text { Biomass } \\
\text { transport }\end{array}$ & 0.38 & 0.61 & 0.41 & 0.63 & 0.94 & 1.14 & 0.99 & 1.27 \\
\hline $\begin{array}{l}\text { Fuel } \\
\text { production }\end{array}$ & 26.3 & 14.14 & 28.28 & 11.21 & 24.08 & 14.36 & 26.2 & 10.62 \\
\hline Fuel transport & 1.45 & 0.61 & 1.27 & 0.61 & 0.42 & 0.61 & 0.42 & 0.61 \\
\hline Total & 31.46 & 22.94 & 33.45 & 20.33 & 28.6 & 22.4 & 30.92 & 20.38 \\
\hline
\end{tabular}


Table 7.5: Corn stover collection and additional nutrients added to soil

\begin{tabular}{|l|c|c|}
\hline & SimaPro & GREET \\
\hline Diesel $(\mathrm{L} / \mathrm{t})$ & 3.857 & 9.56 \\
\hline Lubricant oil $(\mathrm{L} / \mathrm{t})$ & 0.02 & 0 \\
\hline $\mathrm{N}(\mathrm{kg} / \mathrm{t})$ & 7.4 & 7.7 \\
\hline $\mathrm{P}_{2} \mathrm{O}_{5}(\mathrm{~kg} / \mathrm{t})$ & 2.9 & 2 \\
\hline $\mathrm{K}_{2} \mathrm{O}(\mathrm{kg} / \mathrm{t})$ & 12.7 & 12 \\
\hline
\end{tabular}

The life cycle GHG emissions of pyrolysis gasoline and diesel are illustrated in Figure 7.3. Pyrolysis gasoline and diesel produced from logging residues show GHG reductions ranging from 59 to $62 \%$ compared to the petroleum gasoline and diesel baseline, depending on the system and $\mathrm{H}_{2}$ source. Pyrolysis gasoline and diesel produced from corn stover show slightly higher GHG reductions because of lower fuel production emission as a result of co-products assumed in the study (char producted as co-product of pyrolysis process is applied to soil for $\mathrm{C}$ sequestration).

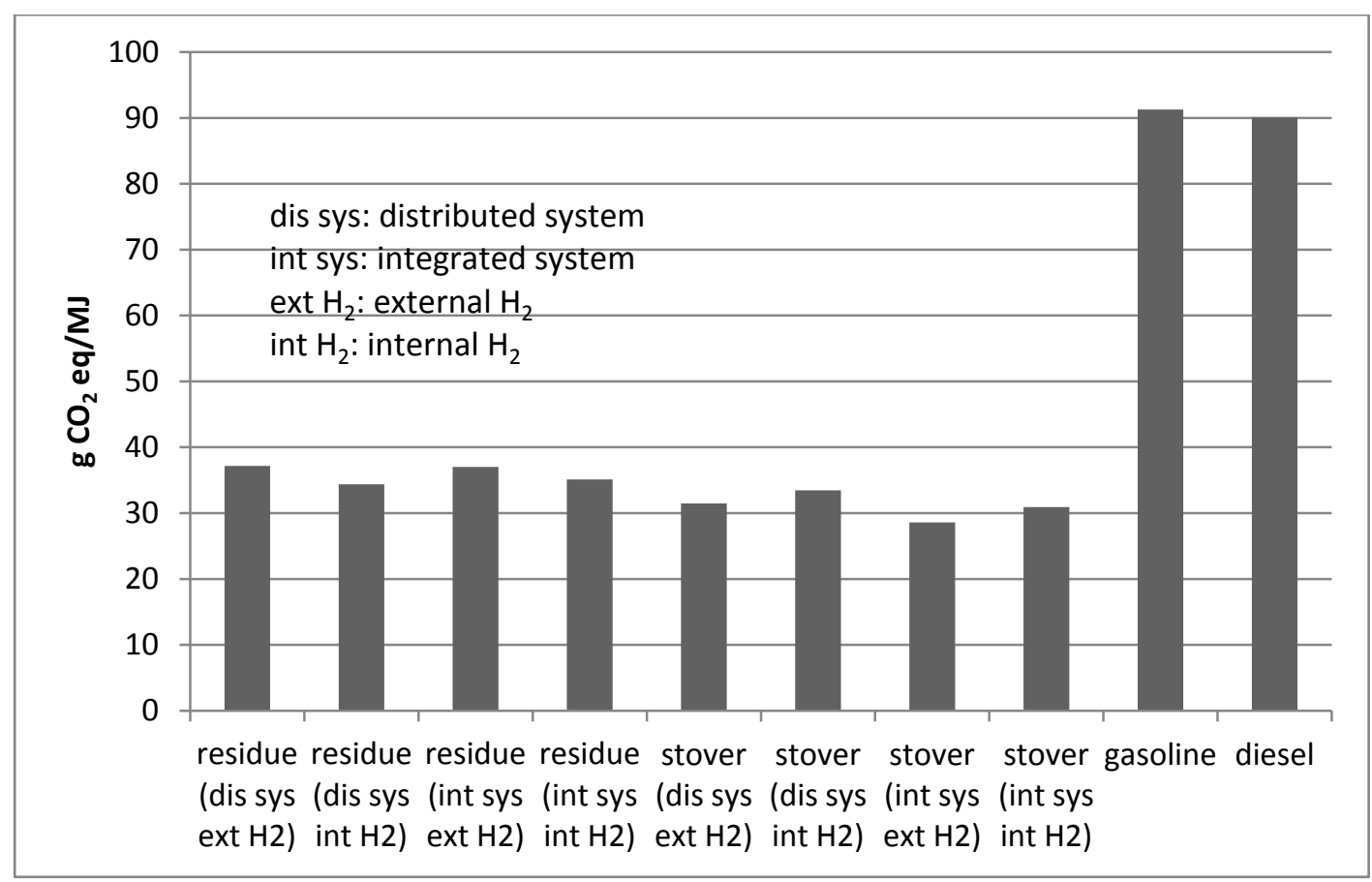

Figure 7.3: GHG emissions of pyrolysis gasoline and diesel, comparing to the petroleum fuels 


\subsubsection{Energy demands}

Figure 7.4 shows the CED results of pyrolysis oil derived transportation fuels. The CED consists of four parts; non-renewable fossil, non-renewable nuclear, renewable biomass, and other renewable energy sources, which include solar, geothermal, and hydroelectric power. Although it requires more total energy to produce the same amount of pyrolysis gasoline/diesel than conventional petroleum fuels, the majority of energy requirement of pyrolysis gasoline/diesel are from renewable biomass. The petroleum fuels consume more nonrenewable fossil energy to produce, which is illustrated in the FED results below.

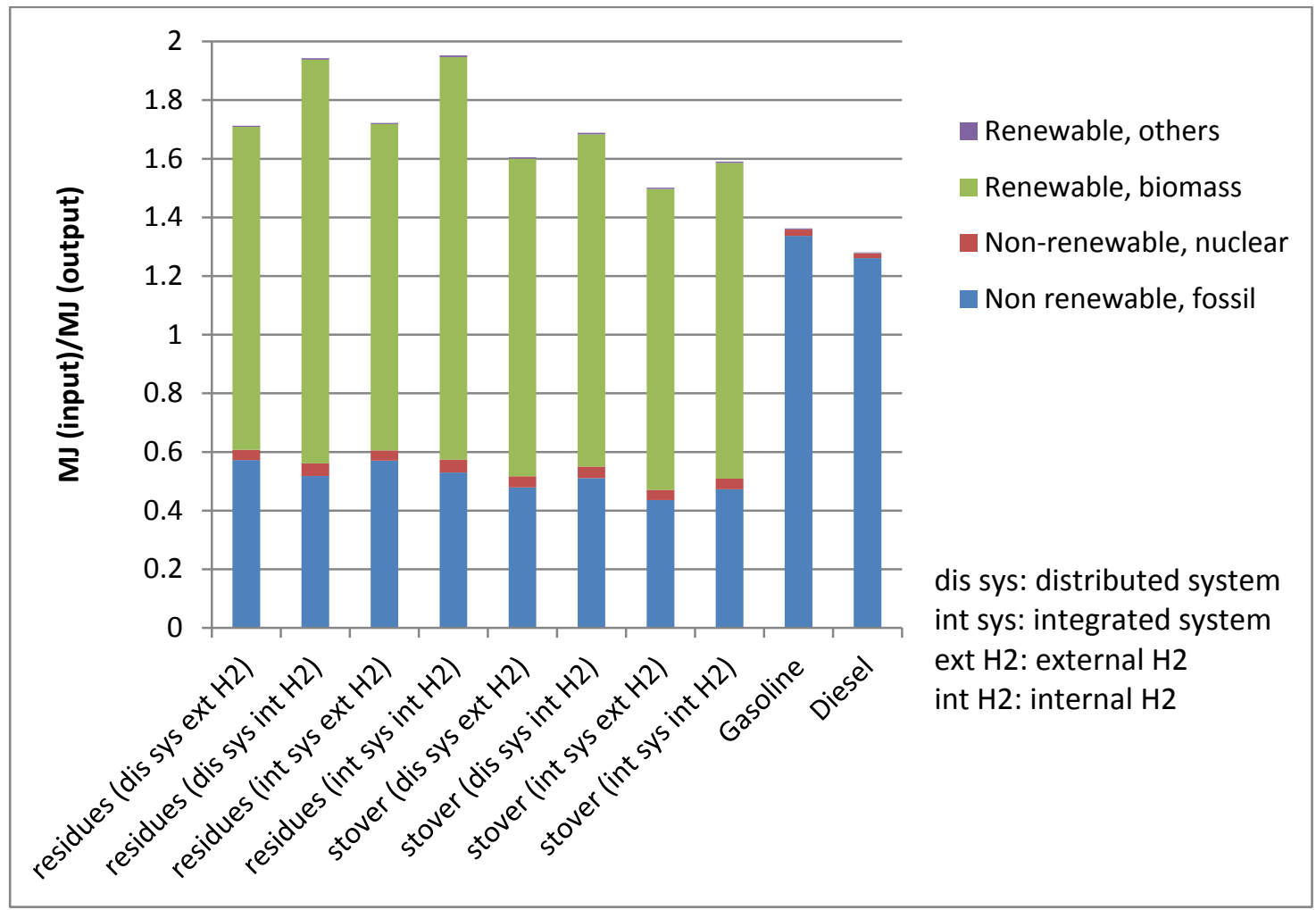

Figure 7.4: CED results of pyrolysis gasoline/diesel, comparing to petroleum gasoline and diesel

The FED results (Figure 7.5) have been broken into 4 process stages: biomass production, biomass transport, fuel production, and fuel transport. In the integrated system scenarios, oil production and fuel production are integrated together, and there is 
no oil transport. The majority of fossil energy demand occurs at the hydrotreated pyrolysis oil production stage, because of the $\mathrm{H}_{2}$ (natural gas) requirement. Pyrolysis oil upgrading also requires $\mathrm{H}_{2}$ (natural gas), which contributes to the fossil energy use at the fuel production stage. The next most important stage is biomass transport, especially for the integrated system where biomass is transported a relatively long distance to a central pyrolysis and upgrading facility. Apart from $\mathrm{H}_{2}$ (natural gas) used for hydrotreating and hydroprocessing process, diesel used in the biomass collection and transportation stages contribute to the total fossil energy demand as well.

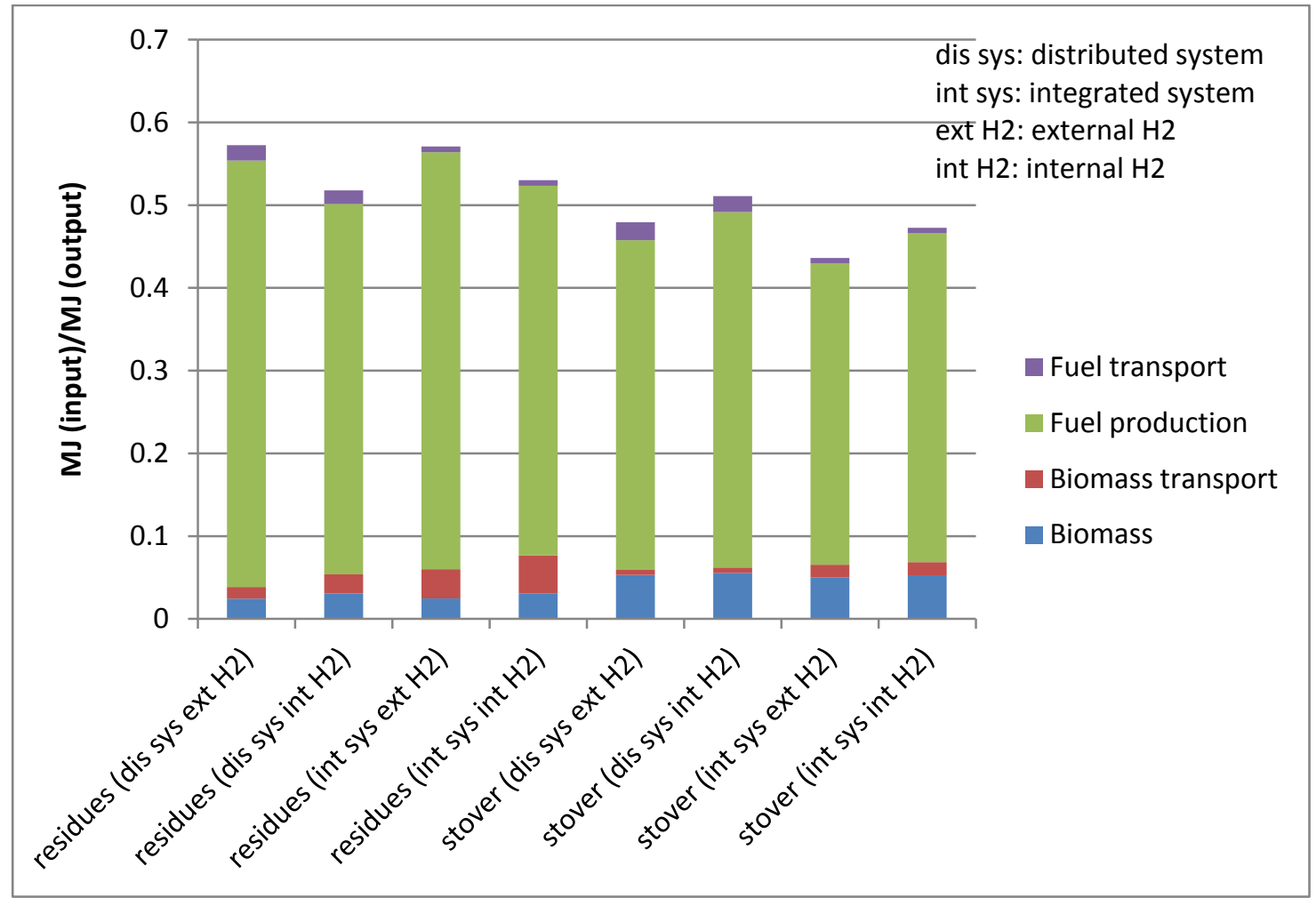

Figure 7.5: FED results of pyrolysis gasoline/diesel (Fuel transport includes transport of hydrotreated pyrolysis oil and final gasoline/diesel product)

\subsection{Discussion}

Pyrolysis gasoline and diesel produced from logging residues show similar GHG emission results between SimaPro and GREET 2012. The differences are results of emission burdens of residues feedstock and the emission factors assumed in the two 
models. However, gasoline and diesel produced from pyrolysis of corn stover show very different GHG results. GREET yields higher corn stover collection impact because of the higher diesel input and higher emission factor of the $\mathrm{N}$ fertilizer (urea). The emission burden of corn stover is sensitive to the choice of $\mathrm{N}$ fertilizer, as different $\mathrm{N}$ fertilizers have very different emission factors, application of urea also contributes to $\mathrm{CO}_{2}$ emission to the atmosphere. On the other hand, fuel production emission results generated from GREET are much lower than those from SimaPro. This is mainly because of the GHG credit of the co-product char. GREET assumes that the char is applied to soil as a carbon sequestration method, which offers a large GHG credit to the fuel products. Energy allocation method was applied in SimaPro, where a portion of the process emission burdens are distributed to the char. $\mathrm{H}_{2}$ source is found to affect the GHG emissions of the final fuel products. As opposed to importing $\mathrm{H}_{2}$ from external source, it can be produced internally from co-products of the hydrocracking process with additional natural gas. Natural gas has a lower emission factor than external $\mathrm{H}_{2}$ produced from steam reforming, therefore, the total emission can be reduces if $\mathrm{H}_{2}$ is produced internally. However, producing $\mathrm{H}_{2}$ internally can reduce the GHG credit of the co-product as the process consumes the fuel gas co-product. Distributed system where pyrolysis oil is produced and stabilized at distributed facilities first, and then transported to a centralized biorefinery for hydrocracking show similar GHG results to the integrated system, in which the biomass is transported to a centralized biorefinery where the feedstock is converted to gasoline and diesel by hydrotreating and hydrocracking. The main differences lie in the biomass transport and transport of the hydrotreated pyrolysis oil. In cases where biomass transport distance to a centralized facility are much greater than in this study, the distributed system emissions may be much small in comparison to a centralized system. Materials and energy requirements of the distributed and integrated system are similar.

\subsection{Conclusion}

Pyrolysis oil can be upgraded to transportation fuels by hydroprocessing (hydrodeoxygenation and hydrocracking reaction). The pyrolysis gasoline and diesel produced from logging residues and corn stover show approximately $60 \%$ of GHG 
reductions compared to their petroleum counterparts. If $\mathrm{H}_{2}$ used in the hydroprocessing reaction are produced from a mix of external natural gas and co-product fuel gas, the life cycle GHG emissions can be reduced. Although they consume more energy to produce the same energy of final product than gasoline and diesel produced from fossil crudes, they show much lower fossil energy demand than their petroleum counterparts. 


\section{Chapter 8: Direct land use change emissions associated with forest-based biofuels and bioenergy production in Michigan ${ }^{9}$}

\subsection{Introduction}

\subsubsection{Michigan Forest}

Michigan currently has 8.1 million hectares of forestland ${ }^{193}$. The majority of Michigan forests (5.06 million hectares) are owned by private landowners and managed in varying intensity. The State and local governments hold 1.86 million hectares and the Federal government holds the other 1.2 million hectares ${ }^{193}$. Michigan has one of the largest amounts of timber net growth in excess of removals of any state (3.84 million cubic meter ${ }^{194}$ ), which represents significant potential growth of the timber products industry ${ }^{195}$. Michigan has a rich history of using wood for bioenergy and bio-based products ${ }^{196}$. While current industrial wood use is in a down-cycle ${ }^{197}$, the excess timber wood can be a promising feedstock to address the state's growing energy needs while also creating a thriving renewable fuels industry.

\subsubsection{Land Use Change (LUC)}

The conversion of native habitats to biofuels production will result in disturbance of carbon stocks in the native biomass (aboveground and belowground) and soils, thus releasing $\mathrm{CO}_{2}$ into the atmosphere ${ }^{95}$. If pristine domestic or international lands are cleared and converted to farmland to compensate for the crop production loss due to biofuels production, a significant amount of $\mathrm{CO}_{2}$ will be emitted through burning or microbial decomposition of organic carbon stored in biomass and soils. These two mechanisms are called direct and indirect land use change (dLUC and iLUC), respectively. Studies have shown that use of food crops for biofuels production may

\footnotetext{
${ }^{9}$ This chapter will be prepared for peer-reviewed publication. Citation: Fan J, Froese R, Shonnard DR,Handler RM. Direct Land Use Change Emissions associated with Forest-based Biofuels and Bioenergy Production in Michigan.
} 
result in LUC emissions of greenhouse gases, which can significantly change the GHG profiles of biofuels $^{94-96}$.

A consequential approach is applied by the U.S EPA ${ }^{4}$ to estimate both dLUC and iLUC impacts of bioethanol and biodiesel derived from corn, soybean, and other biofuel feedstocks, such as switchgrass. The Forestry and Agricultural Sector Optimization Model (FASOM) and the Food and Agricultural Policy Research Institute (FAPRI) model have been used by the EPA to estimate the impacts of biofuels feedstock production on domestic and international agricultural and livestock production, respectively. Then the change in agricultural land and livestock are converted to GHG emissions based on the GHG emissions factors from the GREET model ${ }^{86}$ or IPCC guidance. The GHG emissions due to LUC are then incorporated with fuel production emission to calculate the life cycle emissions of biofuels. The life cycle year $2022 \mathrm{GHG}$ emissions results modeled by the EPA are shown in Table 8.1 for effects of large-scale production of biofuels meeting 2022 mandated volumes. It shows that the iLUC can cause significant GHG emissions due to land conversion, but these biofuels meet the $20 \%$ GHG reduction threshold mandated by the EISA, thus qualify as renewable fuels. 


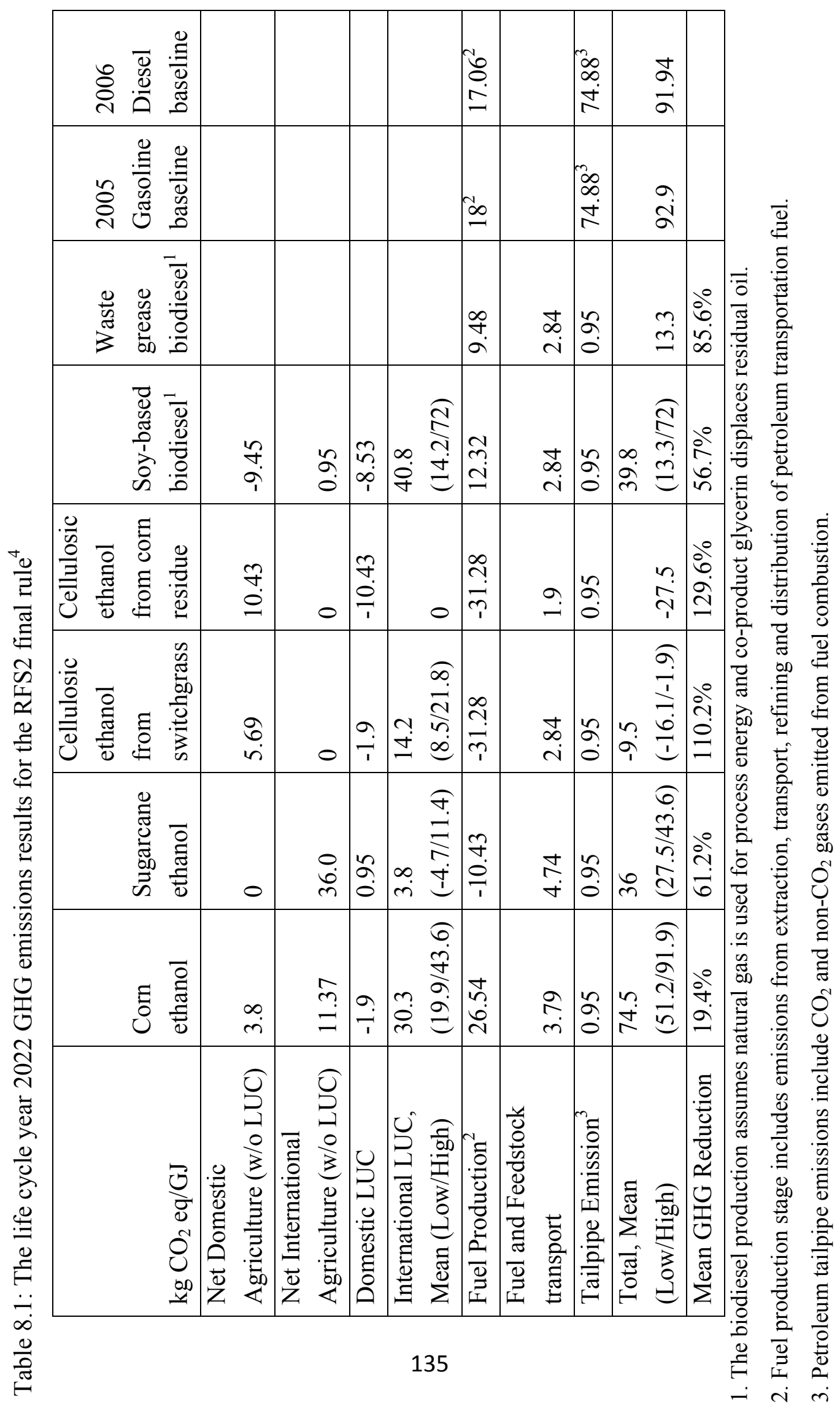


On April 23, 2009, the California Air Resources Board (CARB) proposed the California Low Carbon Fuel Standard (LCFS) ${ }^{57}$ in order to lower the carbon content of transportation fuels used in California. This standard identifies LUC as a significant source of additional GHG emissions and includes the carbon intensity values assigned to those fuels in the regulation. Figure 8.1 illustrates the process of quantifying GHG emissions due to LUC from some feedstocks. However, the LCFS states that corn stover and waste stream feedstocks such as yellow grease, waste cooking oils and municipal solid waste (MSW) are unlikely to lead to LUC impacts.

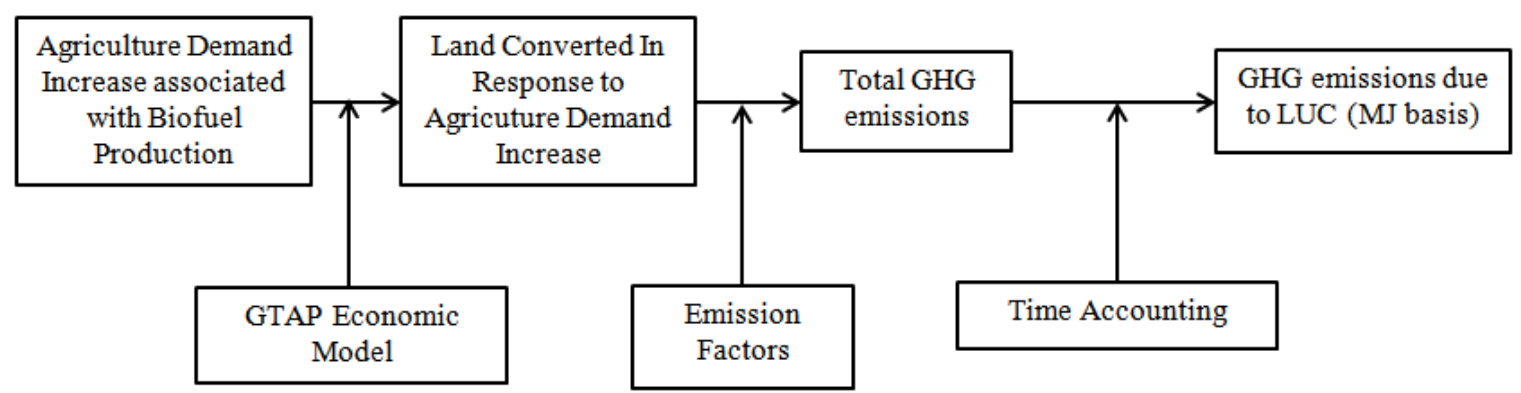

Figure 8.1: LUC impacts estimation process by CARB (adapted from CARB LCFS ${ }^{57}$ )

The Global Trade Analysis Project (GTAP) model is used by the California Air Resource Board (CARB) to evaluate the worldwide land use conversion in response to the increasing biofuels demand. The GHG emissions due to the land conversion are calculated by applying GHG emission factors to the acreage of land converted. LUC emissions vary substantially with time. For example, large near term GHG emissions are generated from combustion and decomposition of organic carbon stored in vegetations and soils. However, over the subsequent years biofuels produced from biomass grown on converted land can repay this carbon debt. These time-varying GHG flows are inputted into a time accounting model to convert to a LUC carbon intensity value. The carbon intensity and LUC of biofuels and their petroleum baselines are listed in Table 8.2. The LUC impacts are similar to those reported by EPA, with the exception of sugarcane ethanol. EPA assumes the sugarcane is planted in Brazil, thus most of impacts on agricultural land is distributed in the "Net International Agriculture" category. 
Table 8.2: Carbon intensity values of gasoline, diesel and fuels that substitute for them from $\mathrm{CARB}^{57}$

\begin{tabular}{|l|l|l|l|}
\hline & $\begin{array}{l}\text { Direct } \\
\text { emissions }\end{array}$ & LUC & $\begin{array}{l}\text { Total } \\
\text { carbon } \\
\text { intensity }\end{array}$ \\
\hline Corn ethanol (CA) & 50.7 & 30 & 80.7 \\
\hline Sugarcane ethanol & 27.4 & 46 & 73.4 \\
\hline Soybean biodiesel & 26.93 & 42 & 68.93 \\
\hline $\begin{array}{l}\text { Biodiesel/Renewable diesel derived from } \\
\text { waste }\end{array}$ & 15 & 0 & 15 \\
\hline California Gasoline & 95.86 & & 95.86 \\
\hline California Diesel & 94.71 & & 94.71 \\
\hline
\end{tabular}

The European Renewable Energy Directive ${ }^{54}$ calculates dLUC emissions as annualized carbon emissions from carbon stocks associated with the reference land prior use and the land use after conversion over 20 year period. The actual values of carbon stocks associated with the reference land use and the land use after conversion are based on the Intergovernmental Panel on Climate Change (IPCC) 2006 guidelines and data ${ }^{198}$. The annualized dLUC emissions are calculated by the following formula:

$$
e_{l}=\left(C S_{R}-C S_{A}\right) * 3.664 * \frac{1}{20} * \frac{1}{P}-e_{B}
$$

Where

$e_{l}$ : the annualized GHG emissions due to dLUC (as mass $\mathrm{CO}_{2}$ equivalent per unit biofuel);

$C S_{R}$ : carbon stock per unit area associated with the reference land use 20 years before the biomass raw materials are obtained;

$C S_{A}$ : carbon stock per unit area associated with the actual land use;

3.664 : the ratio of molecular weight of $\mathrm{CO}_{2}(44.010 \mathrm{~g} / \mathrm{mol})$ by molecular weight of $\mathrm{C}$ $(12.011 \mathrm{~g} / \mathrm{mol})$;

$P$ : the productivity of the crops (as biofuel energy per unit of area per year); 
$e_{B}$ : bonus of $29 \mathrm{~g} \mathrm{CO}_{2}$ eq/MJ biofuel if biomass is obtained from degraded land The Roundtable on Sustainable Biofuels (RSB) GHG accounting scheme ${ }^{93}$ uses the same method as the European Renewable Energy Directive to calculate the dLUC emissions, while not including iLUC impact in the scope of their study.

\subsubsection{Carbon Budget Model for the Canadian Forest Sector (CBM-CFS3)}

When trees grow, they remove $\mathrm{CO}_{2}$ from atmosphere through photosynthesis. In addition, a substantial amount of carbon is stored in forests as dead organic matter (DOM) in standing snags, on the forest floor, and in the soil until they are released back to the atmosphere by decomposition ${ }^{199}$. The IPCC provides guidelines ${ }^{198}$ for the calculation and reporting of changes in stocks of forest carbon. The IPCC identifies three tiers for reporting changes in forest carbon stocks that depend on sophistication of the data collection and estimation certainty. The Carbon Budget Model for the Canadian Forest Sector (CBM-CFS3) implements the highest tier, or Tier 3, approach to simulate the carbon dynamics in forest due to land use change ${ }^{200}$.

The IPCC Good Practice Guidance (GPG) ${ }^{201}$ specifies five carbon pools that must be accounted for: aboveground live biomass, belowground live biomass, dead wood, litter, and soil organic matter. The CBM-CFS3 tracks carbon transfers between 10 live biomass pools and 11 DOM carbon pools within a forest stand and the atmosphere. The correspondence between the pools in CBM-CFS3 and pools recommended by the IPCC are listed in Table 8.3. Living biomass pools are tracked for hardwood and softwood separately. The DOM pools are categorized by the materials they contain and the rate of decay. 
Table 8.3: Carbon pools in the CBM-CFS3 and pools recommended by IPCC GPG (adapted from Kurz $2009^{200}$ )

\begin{tabular}{|l|l|}
\hline CBM-CFS3 pools & IPCC GPG pools \\
\hline Merchantable \& bark (SW, HW) & Aboveground biomass \\
\hline Other wood \& bark (SW, HW) & Aboveground biomass \\
\hline Foliage (SW, HW) & Aboveground biomass \\
\hline Fine roots (SW, HW) & Belowground biomass \\
\hline Coarse roots (SW, HW) & Belowground biomass \\
\hline Snag Stems DOM (SW, HW) & Dead wood \\
\hline Snag branches DOM (SW, HW) & Dead wood \\
\hline Medium DOM & Dead wood \\
\hline Aboveground fast DOM & Litter \\
\hline Aboveground very fast DOM & Litter \\
\hline Aboveground slow DOM & Litter \\
\hline Belowground fast DOM & Dead wood \\
\hline Belowground very fast DOM & Soil organic matter \\
\hline Belowground slow DOM & Soil organic matter \\
\hline
\end{tabular}

SW=softwood; HW=hardwood

The CBM-CFS3 simulates carbon stock changes due to biomass growth, turnover, litterfall, transfer and decomposition. The relations of all carbon pools in the CBM-CFS3 are illustrated in Figure 8.2. Carbon is accumulated in the forest ecosystem and distributed among 10 biomass pools. Turnover and disturbances result in $\mathrm{C}$ transfer from live biomass to DOM pools. Disturbances also cause $\mathrm{C}$ loss to atmosphere as gaseous emissions or to the forest industry sector as products. Carbon is transferred between the DOM pools by decay, transfer and disturbances. 


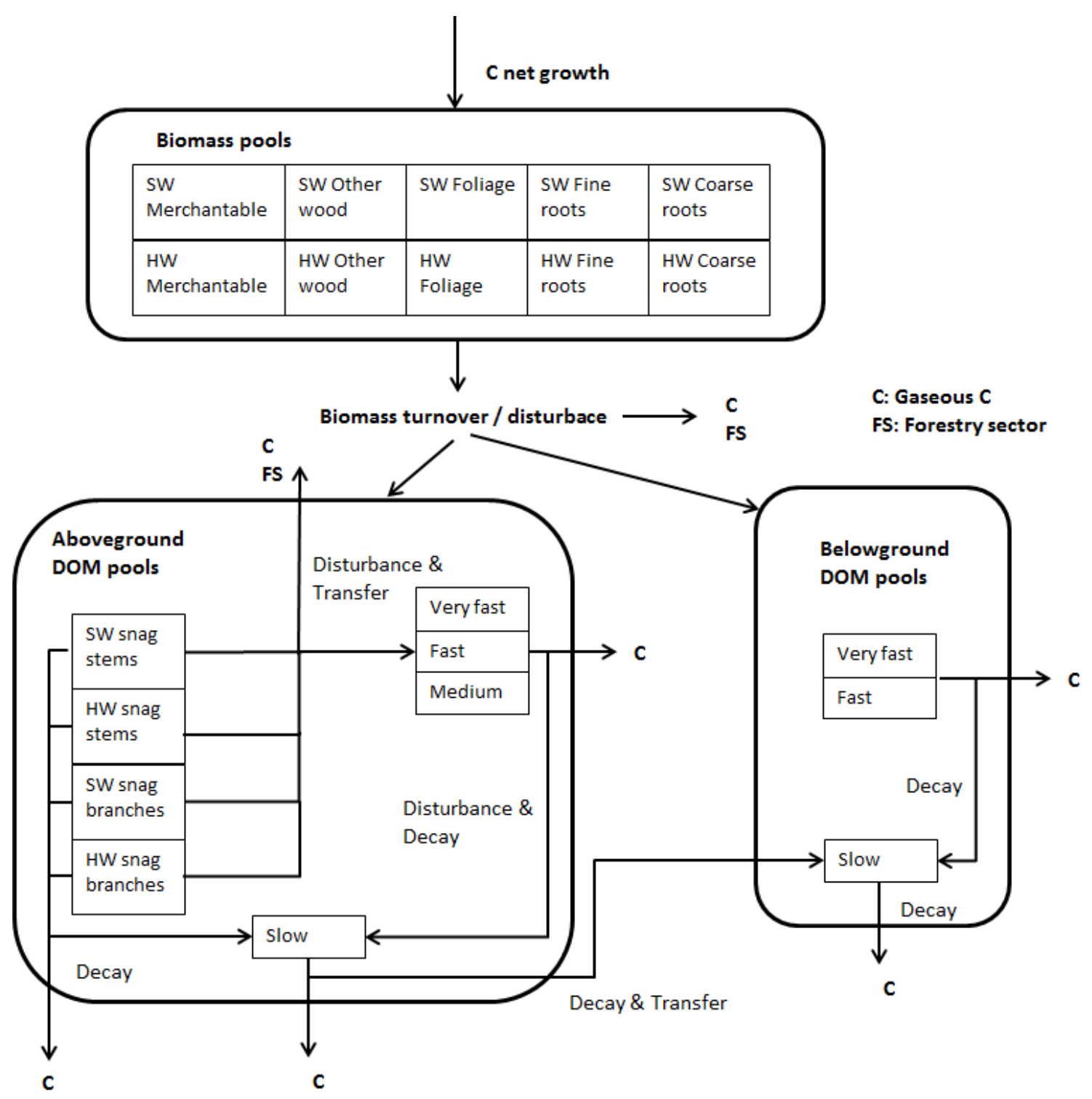

Figure 8.2: C flow between biomass and DOM pools in the CBM-CFS3 (adapted from Kurz et $\mathrm{al}^{200}$ )

Yield tables with data of merchantable timber volume over time are first entered as model inputs. The CBM model estimates the aboveground biomass from the yield tables based on yield-to-biomass equations developed by Boudewyn et $\mathrm{al}^{202}$. These equations convert stand-level volume to aboveground biomass for over 60 tree species found in Canada using 270 unique model parameters. First, the amounts of biomass for individual tree components is estimated as a function of diameter at breast height and tree height, which 
is then summed into per hectare plot totals. Plots are stratified by province, ecozone, leading species, predominant genus, and forest type. Finally, the proportions of total tree biomass in stem wood, stem bark, branches and foliage are estimated. The CBM-CFS then estimates aboveground $\mathrm{C}$ increments. The procedure starts with converting merchantable volume (softwood and hardwood) to biomass in units of dry matter, which is then converted to mass of $\mathrm{C}$ using conversion factor of $0.5 \mathrm{~g} \mathrm{C} / \mathrm{g}$ dry biomass. Once the aboveground $\mathrm{C}$ increment is estimated, belowground biomass and $\mathrm{C}$ increment are calculated using equations from $\mathrm{Li}$ et $\mathrm{al}^{203}$. The model estimates biomass turnover to represent biomass mortality using annual turnover rate. Then the model uses litterfall transfer rates to assign $\mathrm{C}$ to different DOM pools.

Decomposition is modeled by a temperature-dependent decay rate that determines the amount of organic matter that decomposes in a DOM pool every year. Applied decay rates $\left(a_{k}\right)$ are calculated for each DOM pool using the following equation:

$\mathrm{a}_{\mathrm{k}}=\mathrm{BDR}_{\mathrm{k}} *$ TempMod*StandMod

where $\mathrm{BDR}_{\mathrm{k}}$ is the base decay rate $\left(\mathrm{yr}^{-1}\right)$ at a reference annual temperature of $10^{\circ} \mathrm{C}$; TempMod is a temperature modifier, which reduces the decay rate for mean annual temperature below reference temperature; StandMod is a stand modifier which simulates enhanced decomposition occurs under an open canopy. The parameters used to simulate DOM dynamics are tabulated in Table 8.4. 
Table 8.4: The parameters used to simulate DOM dynamics in CBM-CFS3 ${ }^{200}$

\begin{tabular}{|l|l|l|l|l|}
\hline \multirow{2}{*}{ Pools } & \multicolumn{4}{l|}{ Decay parameters } \\
\cline { 2 - 5 } & BDR $\left(\mathrm{yr}^{-1}\right)$ & $\mathrm{P}_{\mathrm{atm}^{*}}{ }^{*}$ & $\mathrm{P}_{\mathrm{t}}{ }^{*}$ & Pool receiving $\mathrm{P}_{\mathrm{t}}$ \\
\hline Snag stems & 0.0187 & 0.83 & 0.17 & AG slow \\
\hline Snag branches & 0.0718 & 0.83 & 0.17 & AG slow \\
\hline Medium & 0.0374 & 0.83 & 0.17 & AG slow \\
\hline AG fast & 0.1435 & 0.83 & 0.17 & AG slow \\
\hline AG very fast & 0.355 & 0.815 & 0.185 & AG slow \\
\hline AG slow & 0.015 & 1 & 0 & N/A \\
\hline BG fast & 0.1435 & 0.83 & 0.17 & BG slow \\
\hline BG very fast & 0.5 & 0.83 & 0.17 & BG slow \\
\hline BG slow & 0.0033 & 1 & 0 & N/A \\
\hline
\end{tabular}

* $\mathrm{P}_{\mathrm{atm}}$ and $\mathrm{P}_{\mathrm{t}}$ are the proportions of $\mathrm{C}$ in the decayed materials that is released to atmosphere or transferred to the more stable slow DOM pools

The CBM-CFS3 uses a simulation initialization procedure that links biomass, DOM dynamics and historic disturbance regimes at the beginning of a model run. The model starts the initialization process with all pools containing zero $\mathrm{C}$ stocks. It simulates each stand through repeated growth following by stand replacing disturbance, gradually increase the $\mathrm{C}$ stock in the DOM pools. This cycle continues until the above+belowground slow DOM C pools at the end of two successive rotations differs by $1 \%$ or less. Once the quasi-steady state is reached, the model simulates one more rotation terminated by the stand replacing disturbance. The model then grows each stand to its current age. The default assumption for DOM pools initialization is that the historic natural disturbance regime is stand replacing fire.

In a stand replacing disturbance, the model sets all merchantable trees to age zero and the stand starts re-growing on the same growth curve, unless instructed otherwise by the users. Following a partial disturbance, the age of stand and corresponding growth 
increments remain the same. Transition rules can be determined by users to simulate regeneration delays, species change and other post-disturbance dynamics.

\subsubsection{Research objective}

Substitution of fossil fuel energy with forest-based biofuels and bioenergy is found to reduce the GHG emissions due to the assumption of "carbon neutrality", which assumes $\mathrm{CO}_{2}$ captured by growing trees balances the $\mathrm{CO}_{2}$ emissions during bioenergy combustion ${ }^{204}$. However, the forest can capture and store atmospheric $\mathrm{CO}_{2}$ in live biomass, dead organic matter and soil pools over many decades ${ }^{205}$. In contrast, $\mathrm{C}$ stored in biomass is quickly transferred to the atmosphere if biomass derived biofuels are combusted as bioenergy ${ }^{204}$. Harvest can arrest the $\mathrm{C}$ sequestration far short of the full potential of forests, which means that this practice could reduce terrestrial $\mathrm{C}$ storage and thereby increase atmospheric $\mathrm{CO}_{2}$ concentration in the near term ${ }^{206,207}$. Therefore, biofuel LCA should incorporate forest carbon stock assessment to estimate over a long time frame the total GHG emissions of forest-based bioenergy ${ }^{205}$. Mckechnie et $\mathrm{al}^{205}$ found that wood pellet and ethanol production from forest biomass result in a substantial reduction in forest carbon. The associated GHG emissions initially exceed the avoided fossil fuel related emission. Forest carbon dynamics are significant and an integrated LCA/forest carbon modeling approach is recommended for forest-based bioenergy studies. Mitchell et $\mathrm{al}^{206}$ studied the carbon debt caused by forest bioenergy production, and the results show bioenergy production increases the carbon losses from the forest. Initial landscape and land use history are of significance in determining the time required for forests to repay the carbon debt incurred from bioenergy production. The objective of this study is to model the impact of dLUC emissions on the life cycle GHG emissions of forest based biofuels and bioenergy in Michigan. In this study the CBM-CFS3 model is used to simulate the $\mathrm{C}$ stocks change in Michigan over a greater than 2 century time frame for aspen-dominated forest stands when aspen is intensively harvested for the biofuel (ethanol and pyrolysis oil) and bioenergy (electricity) production. 


\subsection{Methods}

\subsubsection{Forest carbon stocks}

The aspen and birch group is one of the leading forest types in the state of Michigan, covering more than 1.2 million hectares of forest land ${ }^{193}$, mainly in northern Lower Michigan and in the Upper Peninsula ${ }^{208}$. Aspen is one of the most commonly harvested tree species for timber industrial use in Michigan ${ }^{209}$. Therefore, aspen is chosen in this study to investigate the $\mathrm{C}$ dynamics of Michigan forest. The current age distribution of aspen is tabulated in Table 8.5.

Table 8.5: Current age distribution of aspen in Michigan ${ }^{193}$

\begin{tabular}{|l|l|l|l|l|l|l|l|}
\hline in ha & $\begin{array}{l}0-19 \\
\text { years }\end{array}$ & $20-39$ & $40-59$ & $60-79$ & $80-99$ & $100-119$ & Total \\
\hline $\begin{array}{l}\text { Aspen/ } \\
\text { birch } \\
\text { group }\end{array}$ & 225,325 & 311,562 & 385,081 & 278,318 & 86,737 & 13,115 & $1,299,138$ \\
\hline
\end{tabular}

Aspen is fast growing, shade intolerant species grown in forest openings created by disturbances such as wind, wildfire, harvesting, insects and diseases. When they are matured, their canopies provide shade for more shade tolerant species such as maple, beech, etc ${ }^{208}$. When aspen forests are managed, clearcut harvest is employed to allow regeneration from the root stock because it needs full sunshine to thrive, and thus cannot compete in mature forests ${ }^{210}$. When left undisturbed, aspen will either die or convert to more shade tolerant species such as maple, beech, balsam fir, and spruce ${ }^{208}$.

Mills and $\mathrm{Zhou}^{211}$ predicted the national forest inventories by projecting yield of each forest type within each region from the forest inventory analysis (FIA) plot data. The authors use empirical growth rates to reflect the impact of historical and recent management practices. By employing a series of regression functions, they were able to predict the net growth by age for major regional forest types. Yields of aspen and birch for the North Central Lake States region from their study were taken to represent the 
average growth curve of Michigan trembling aspen. Ek and Brodie ${ }^{212}$ published equations that allow for different yield curves, depending on assumptions about site quality (productivity) and initial tree spacing. In the Mills and Zhou inventory data, the merchantable volume of aspen remained constant after 120 years. However, senescence and succession to other species will decrease merchantable volumes as stands age. Therefore, the growth curve was updated with a decline after year 140 to represent the merchantable volume decrease due to senescence and succession to other species, which have lower accumulation of merchantable volume. The decline rate was set the same as that in the Ek and Brodie curve. The aspen growth curves used in our study are illustrated in Figure 8.3 below.

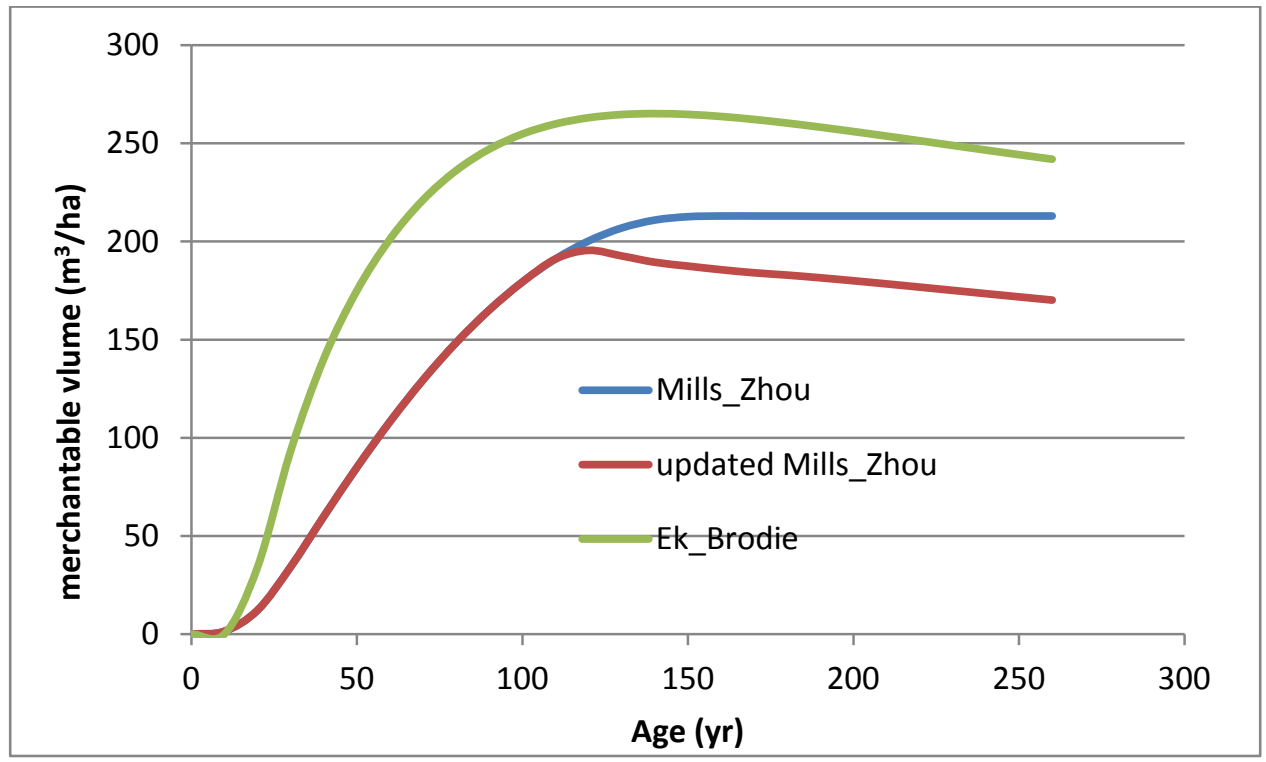

Figure 8.3: Growth curves of aspen in Michigan

The CBM-CFS3 simulates forest $\mathrm{C}$ dynamics based on different ecozones in Canada (Figure 8.4). The Ontario Mixedwood Plains is chosen in this study to represent the Michigan aspen forest because of the similarity of climate, cover type and soil conditions. 


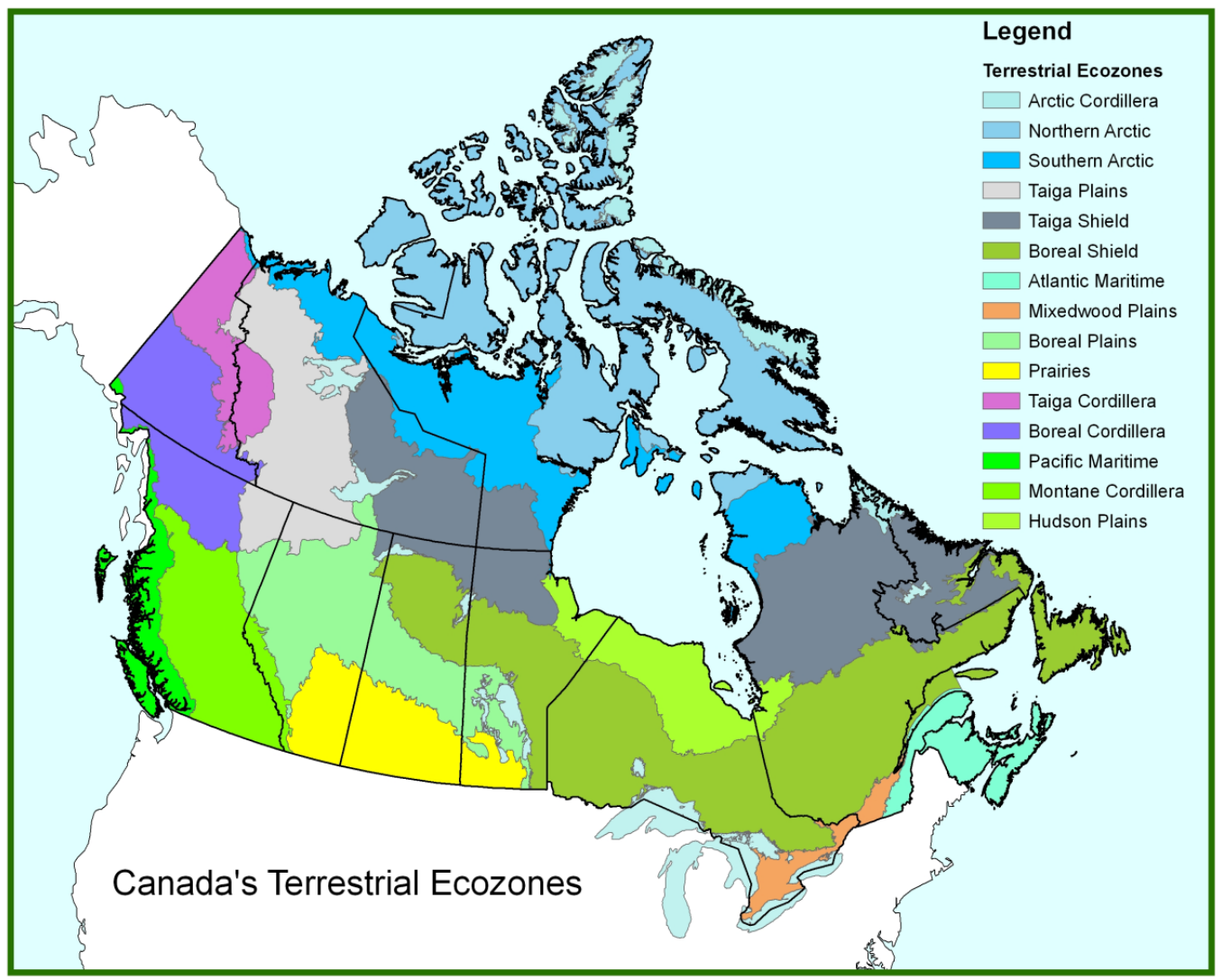

Figure $8.4^{10}$ : Canada's terrestrial ecozones ${ }^{213}$

The 6 age groups of aspen (Table 8.4) were created as 6 individual stands in the CBMCFS3 (Figure 8.5), each containing 13 age classes with intervals of 20 years. Each age class was assigned a merchantable volume based on the growth curve of aspen (Figure 8.3). At year 0 , stand 1 starts with only 225,325 hectares of aspen in age class 1 (year 0 20), and the aspen grow to other age classes through time.

10 This map was downloaded from Natural Resources Canada http://cfs.nrcan.gc.ca/pages/125. Reproduction for non-commercial purposes is allowed without charge or further permission. Clearance is available from http://www.nrcan.gc.ca/important-notices and shown in Figure D.6. 
Stand 1

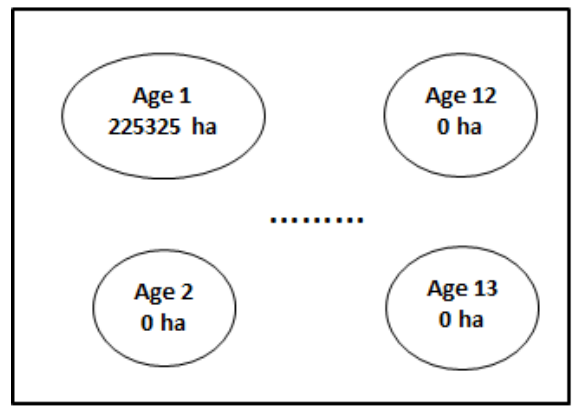

Stand 6

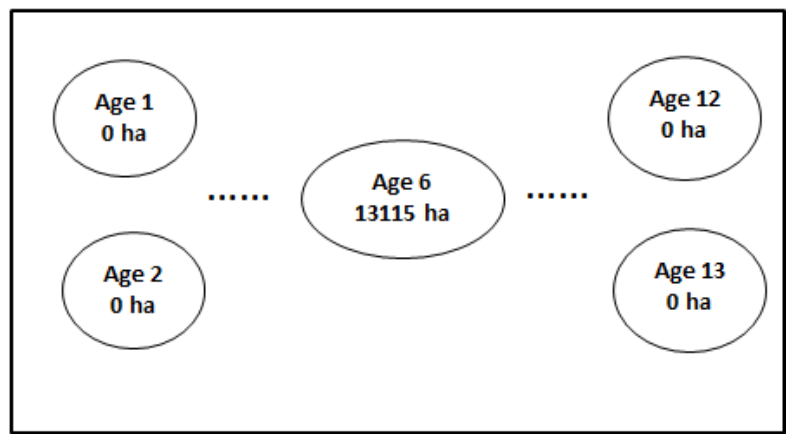

Figure 8.5: Conceptual design of trembling aspen forest in the CBM-CFS3

In reality, forest harvest occurs on an annual basis, so the forest can continuously produce feedstock for industry, including the future biofuels and bioenergy production. In order to reflect the realistic harvesting scenario, annual harvest is assumed. A business-as-usual (BAU) scenario was first established to represent the current aspen harvest levels, which mostly supply wood to the forest products industry. The ages of stand 5 and 6 are distributed from year 80 to 120 , which means these forests are less likely to be harvested, possibly because of the owners' unwillingness to cut or inaccessibility of the forest (Personal communication, Robert Froese 2012). Therefore, only the first 4 stands of aspen forests are modeled to be clear cut. In the BAU scenario, the CBM-CFS3 sets the age to zero after the clear cut, and the stand starts to regrow on the same growth curve (modified Mill and Zhou curve). Stand 5 and 6 are assumed to grow continually along the modified Mill and Zhou growth curve and eventually die or convert to other species. The annual removals of growing stock aspen on timberland during survey year 2011 are 58 million cubic feet (1.64 million cubic meter) ${ }^{193}$. The harvest intensity (hectares of forest) of BAU scenario is simulated in the model to match the total timber volume harvested over 250 years. The intensive harvest scenario (INT) is one where biomass additional to that used in conventional forest products industries (lumber, pulp and paper) is used for the bioenergy production. In this intensive harvesting scenario (INT), the area of annual aspen forest harvested is doubled. 
It is well known in forestry that when stands are placed under management that they produce higher yields than the stands that are not managed. Through management the composition and occupancy of a forest site can be controlled. Managed aspen forests will be more "pure" (higher percentage of aspen group), more regular, and more productive (Personal communication Robert Froese). Therefore, a new silvicultural regime was applied to the post-harvest aspen forest using the Ek_Brodie curve (Figure 8.3) to represent the faster growing of aspen under intensive forest management. The import files of the CBM-CFS model are presented in Appendix B.

\subsection{Results}

\subsubsection{Harvested biomass}

In the BAU scenario, 7200 ha of aspen is assumed to be clear-cut every year to match FIA data of 58 million cu $\mathrm{ft}$ (1.64 million cubic meter), while INT scenario doubles this area to 14400 ha. The total harvested biomass in the BAU and INT scenarios over the 250 years are illustrated in Figure 8.6, and compared to the FIA data. The up and down spikes of the harvested biomass are because after all the aspen in one stand are clear cut, the following harvest transfers to the next stand which has different merchantable volume. The harvested biomass increases by approximately $50 \%$ after 80 years because all the aspen stands are transferred to the fast growth curve (Ek_Brodie curve) by this time. Total biomass harvested in the INT scenarios over 250 years is approximately 2.3 times of that harvested in the BAU scenario, this is because aspen in the INT scenario grow faster after disturbance, thus generates more biomass on the same hectare. The extra biomass harvested in the INT scenario additional to the BAU scenario (205 million metric ton) is used for biofuel and bioenerrgy production. 


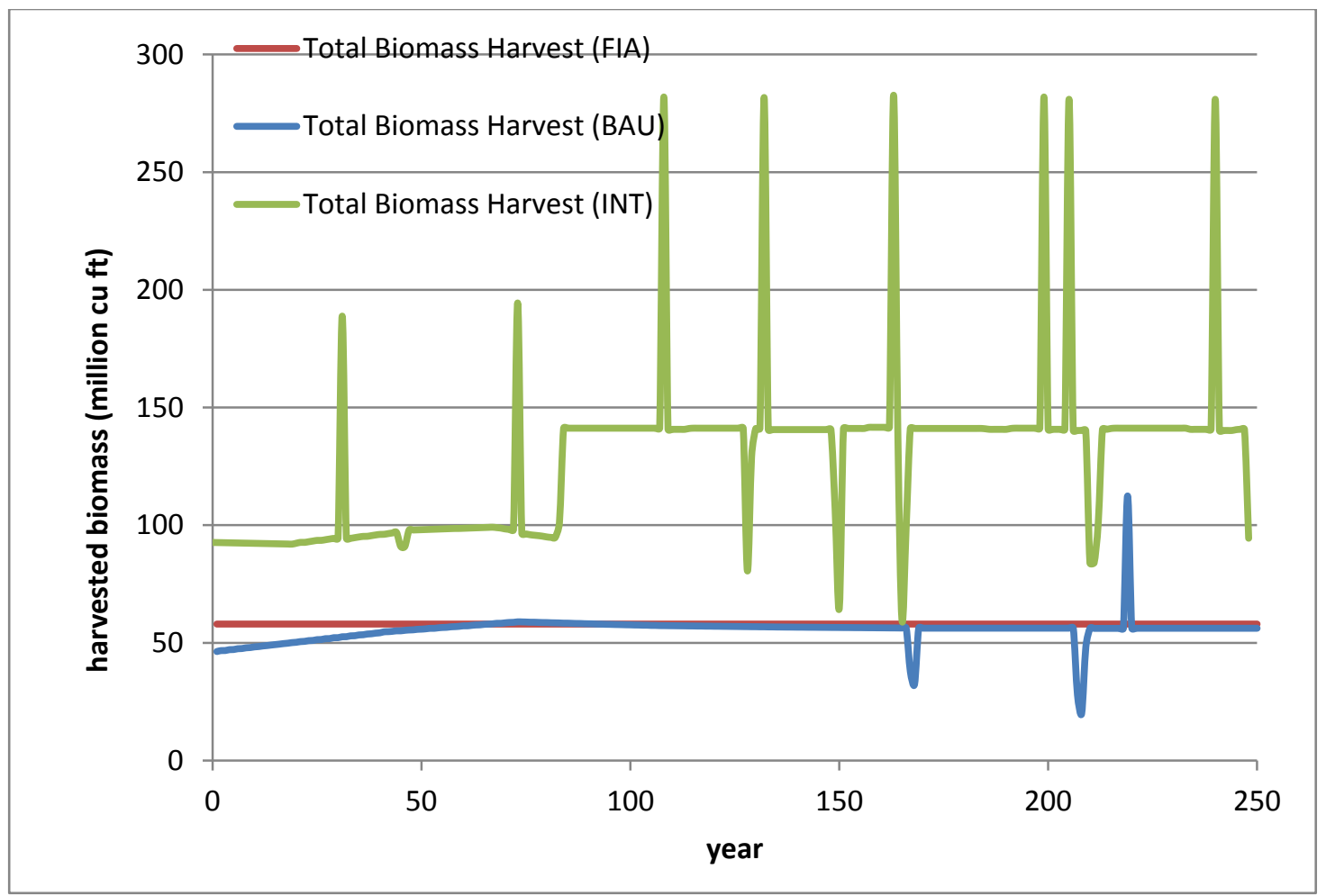

Figure 8.6: Total biomass harvested in the BAU and INT scenarios over 250 years

\subsubsection{Forest carbon stocks}

The carbon stocks of the BAU and INT scenarios are illustrated in Figure 8.7. The total C stocks in the MI forest ecosystem are divided into the $\mathrm{C}$ stored in live biomass (above and belowground) and DOM pools. More $\mathrm{C}$ is accumulated in the DOM pools in the INT scenario compared to the BAU scenario, because more $\mathrm{C}$ in live biomass pools are transferred to the DOM pools after disturbance. This also explains that initial ( $0-80 \mathrm{yrs})$ biomass pool carbon of the INT scenario is lower than that in the BAU scenario.

However, in the INT scenario, carbon in biomass pools exceeds that in the BAU scenario after 80 years, because the aspen are transferred to a faster growth curve (Ek and Brodie curve) after disturbance and accumulates more carbon. Overall, less carbon (total ecosystem C) is accumulated in the first 75 years due to the intensive harvest, which indicates a negative dLUC impact of the biofuel and bioenergy production. However, the INT scenario starts to store more carbon in the long run. 


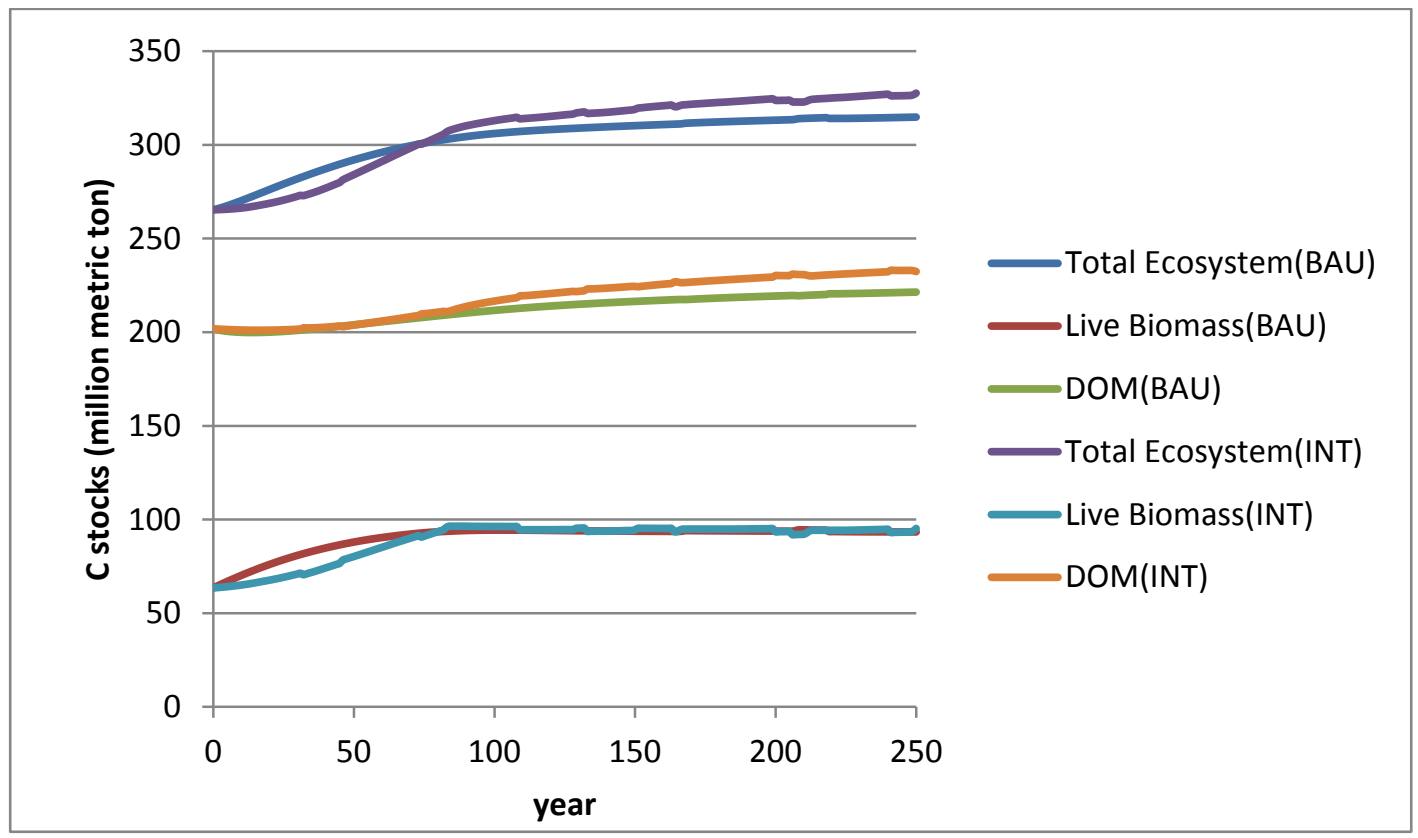

Figure 8.7: Ecosystem C stored in the BAU and INT scenarios

\subsection{3. dLUC of biofuels and bioenergy}

The differences of $\mathrm{C}$ in the ecosystem are due to the intensive harvest of aspen, which can be converted to the dLUC impact of the biofuel (bioenergy) derived from the extra biomass harvested. The biomass is assumed to be used for lignocellulosic ethanol $(0.79$ $\mathrm{kg} / \mathrm{L})$ or pyrolysis oil $(1.2 \mathrm{~kg} / \mathrm{L})$ production. Ethanol yield of 90 gal per dry metric ton of biomass $^{86}$ is assumed in this study. The pyrolysis oil yield was obtained from a former study ${ }^{134}$, which assumes $1.4 \mathrm{~kg}$ dry biomass is used to produce $1 \mathrm{~kg}$ oil. Pyrolysis oil is assumed to be burned in a diesel engine with $45 \%$ efficiency to generate electricity. The GHG emissions due to dLUC are calculated by Equation 8.1 below,

$\mathrm{CO}_{2}(t)=\frac{C_{\text {storage }(t)}^{B A U}-C_{\text {storage }(t)}^{I N T}}{\sum_{1}^{t} \text { biofuel }} * \frac{44 \mathrm{gCO}_{2}}{12 \mathrm{gC}}$

which assumes that all $\mathrm{C}$ harvested for biofuels is emitted as $\mathrm{CO}_{2}$, where $C_{\text {storage }(t)}^{B A U}$ is the amount of $\mathrm{C}$ stored in the BAU scenario at year $\mathrm{t}$; $C_{\text {storage }(t)}^{I N T}$ is the amount of $\mathrm{C}$ stored in 
the managed forest (INT scenario) at year $\mathrm{t} ; \sum_{1}^{t}$ biofuel is the cumulative biofuel yield (in MJ) from year 1 to year $t$, which was calculated by the productivity and LHV of ethanol $(26.95 \mathrm{MJ} / \mathrm{kg})$ and pyrolysis oil $(14.8 \mathrm{MJ} / \mathrm{kg})$.

The GHG emissions due to dLUC of the ethanol, pyrolysis oil and pyrolysis oil derived electricity are illustrated in Figure 8.8. In the short term, the biofuels (EtOH and pyrolysis oil) and bioenergy (electricity) result in a large amount of GHG emissions due to the forest carbon loss. In year 1, the dLUC GHG emissions for cellulosic ethanol produced from aspen in MI are $299 \mathrm{~g} \mathrm{CO}_{2} \mathrm{eq} / \mathrm{MJ}$ ethanol. Over the next several years, dLUC emissions rise due to increasing $\mathrm{C}$ storage gaps between the INT and BAU scenarios, but afterwards dLUC emissions fall as more biofuels and bioenergy are produced from the biomass, thus an increasing denominator. In addition, the intensive management and harvest of aspen helps accumulates more $\mathrm{C}$ in the ecosystem over a long period of time, which result in the negative dLUC emissions (credit) eventually. A similar trend is found for both pyrolysis oil and electricity generated from pyrolysis oil combustion. The overall trends over time are higher net GHG emissions early in the model simulation and smaller GHG emissions, even negative emissions, later in the model time domain. These simulation results indicate that an intensively managed aspen-birch landscape can yield renewable biofuel and biopower as well as realize net accumulation of forest $\mathrm{C}$ on the land compared to a BAU management and harvest. The biofuels start to offer consistent GHG credits from approximately year 76 . At year 250 , total C stored in the forest ecosystem are 327.6 and 314.8 million metric tons $\left(327.6^{*} 10^{6}\right.$ and $\left.314.8^{*} 10^{6} \mathrm{Mg}\right)$ for the INT and BAU scenarios respectively. The extra 12.7 million metric tons of $\mathrm{C}$ stored in the ecosystem is attributed to the intensive harvest of aspen, which contributes a dLUC credit of 31.5 and $21.6 \mathrm{~g} \mathrm{CO}_{2} \mathrm{eq} / \mathrm{MJ}$ for ethanol and pyrolysis oil, respectively. dLUC impact of pyrolysis oil is smaller because more oil (energy content) is produced from the same amount of biomass than ethanol. The dLUC credit of electricity is $172.6 \mathrm{~g} \mathrm{CO}_{2}$ $\mathrm{eq} / \mathrm{kWh}$. 


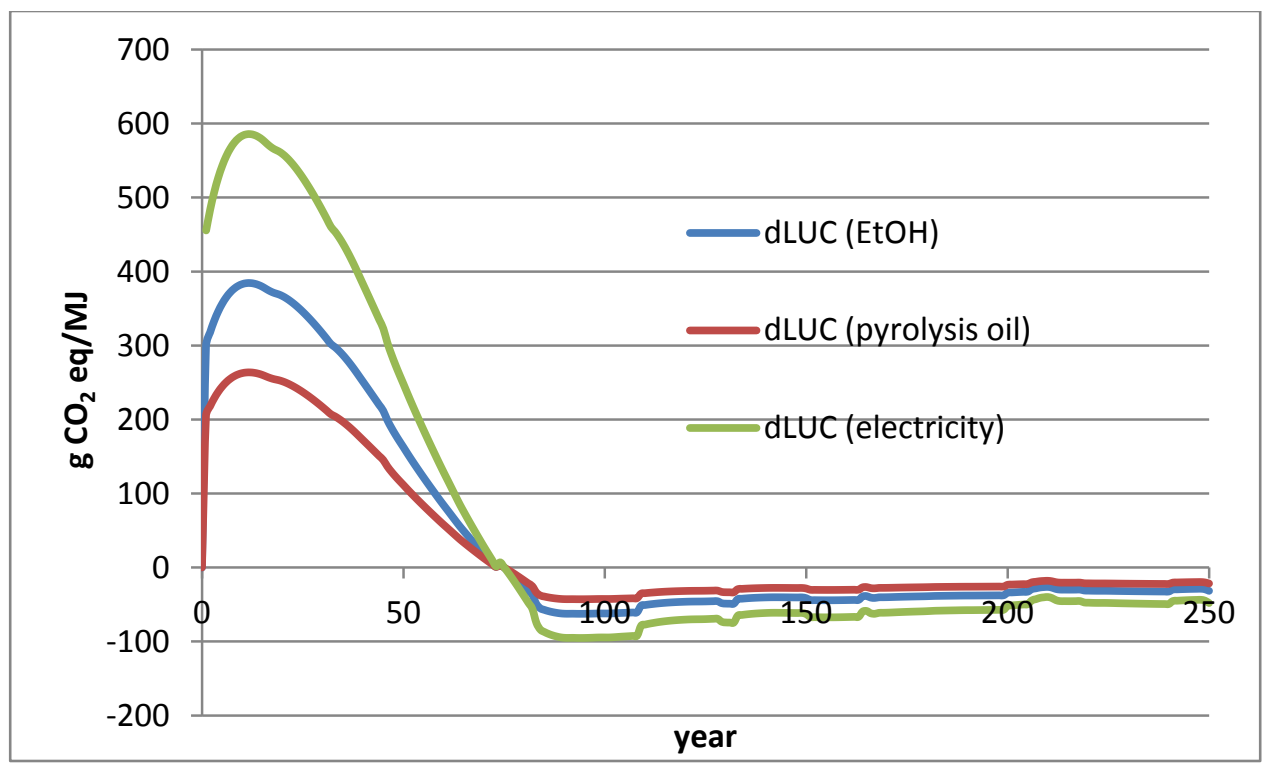

Figure 8.8: The GHG emissions due to dLUC of biofuel and bioenergy over 250 years

\subsubsection{Life cycle results, including dLUC}

LCA method was used to estimate the GHG emissions of biofuels (ethanol, pyrolysis oil) and bioenergy (electricity). Standing trees harvest and forest operations were assessed by Zhang et $\mathrm{al}^{214}$. The emission of biomass harvest includes forest harvest, forest renewal, road construction and maintenance, which was calculated as 35,093 $\mathrm{g} \mathrm{CO}_{2}$ eq/ODT biomass. Biomass transport, ethanol production and distribution were studied in GREET $2012^{86}$. Biomass is transported $120 \mathrm{~km}$ (one-way) to the ethanol plant for fermentation. Excess electricity is produced from lignin combustion, presenting an electricity credit of $2.28 \mathrm{kWh} / \mathrm{gal}$. The ethanol product is distributed $48 \mathrm{~km}$ (assumption from GREET ethanol) to fueling stations by truck. Total GHG emission of ethanol production (excluding dLUC) is $-3.74 \mathrm{~g} \mathrm{CO}_{2} \mathrm{eq} / \mathrm{MJ}$. Pyrolysis oil production and combustion for power generation are presented in Chapter 6. Total GHG emission of pyrolysis oil (excluding dLUC) is $16.35 \mathrm{~g} \mathrm{CO}_{2}$ eq/MJ. The GHG emission of the electricity from pyrolysis oil is $130.8 \mathrm{~g} \mathrm{CO}_{2} \mathrm{eq} / \mathrm{kWh}$, compared to coal electricity of $1020 \mathrm{~g} \mathrm{CO}_{2} \mathrm{eq} / \mathrm{kWh}$. Incorporating these emission results with the dLUC credits, the total GHG emissions of biofuels (ethanol and pyrolysis oil) and bioenergy (pyrolysis oil derived electricity) are illustrated in Figure 8.9, and compared to their petroleum and coal counterparts. The time 
for life cycle emissions of biofuels to equal and go below fossil products is approximately 60 years.

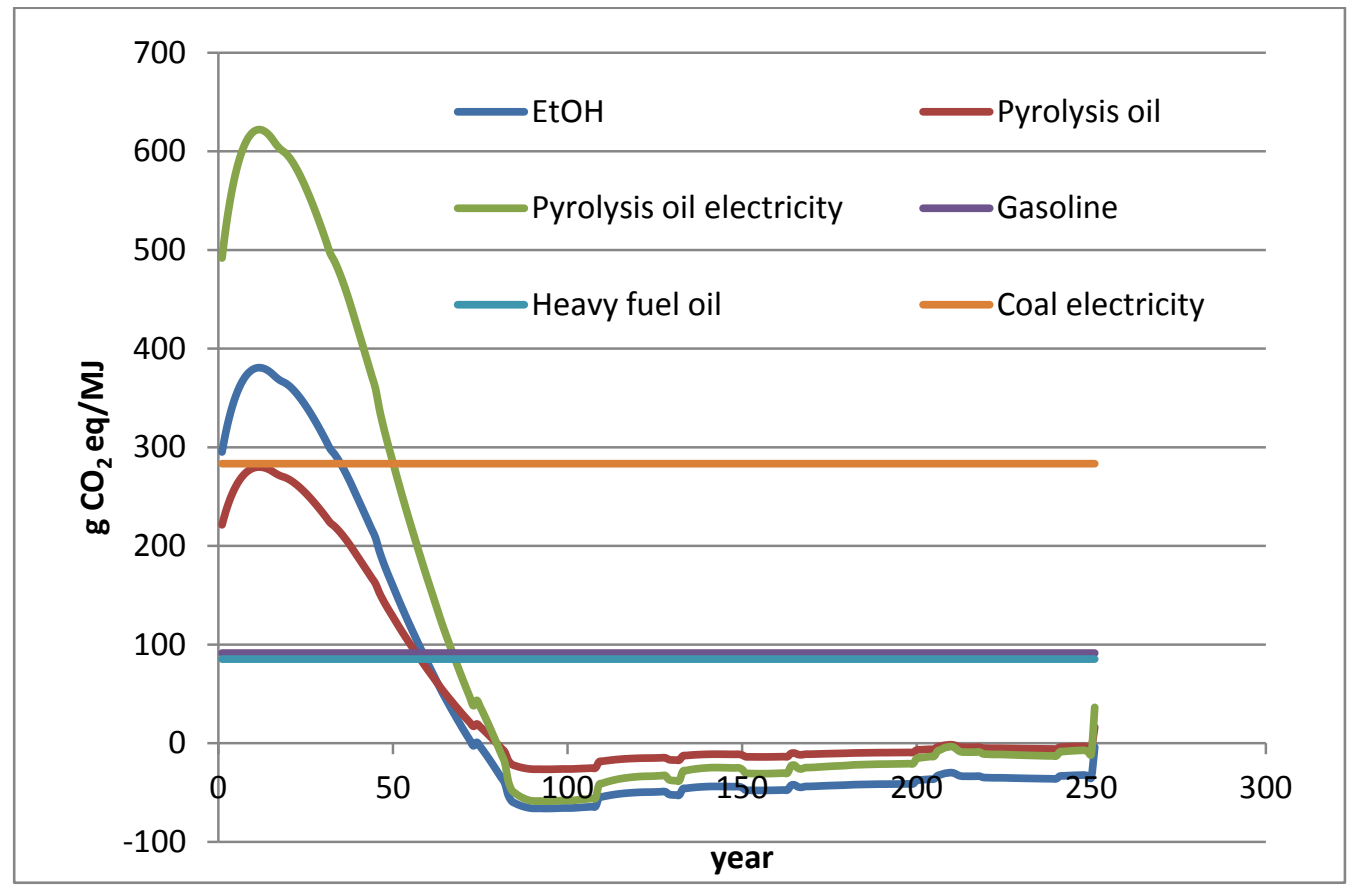

Figure 8.9: GHG emissions (w/dLUC) of EtOH, pyrolysis oil and electricity over 250 years, comparing to their petroleum counterparts

\subsubsection{Bioenergy system total emissions}

Mckechnie et al $^{205}$ estimated total emissions associated with a bioenergy system by combining GHG flows resulting from the life cycle inventory and those from forest carbon analysis, using the following equation.

$$
G H G_{t o t(t)}=\Delta F C(t)+G H G_{b i o(t)}
$$

$\triangle \mathrm{FC}(\mathrm{t})$ is the change in forest carbon due to biomass harvest for bioenergy, which was calculated by $C_{\text {ecosystem }}^{I N T}-C_{\text {ecosystem }}^{B A U}$. $\mathrm{GHG}_{\mathrm{bio}}$ is the net savings of $\mathrm{GHG}$ emissions for biofuels and bioenergy from displacing fossil fuel alternatives. The total GHG emissions calculated using Mckechnie's equation are illustrated in Figure 8.10. For the biofuels (EtOH and pyrolysis oil) produced from intensive harvest, total emissions initially exceed the fossil fuel pathway, which indicates a GHG emission increase due to the production 
and use of biofuels. This is because forest carbon loss due to biomass harvest exceeds the avoided emissions from substituting biofuels for fossil fuels. However, this emission increase associated with biofuels is temporary. The INT scenario eventually accumulates more carbon than the BAU scenario while the emission credits associated with utilizing biofuels continue to increase over the simulation time. The time required for bioenergy system total emissions to decrease below zero is about 60 years for both ethanol and pyrolysis oil pathways.

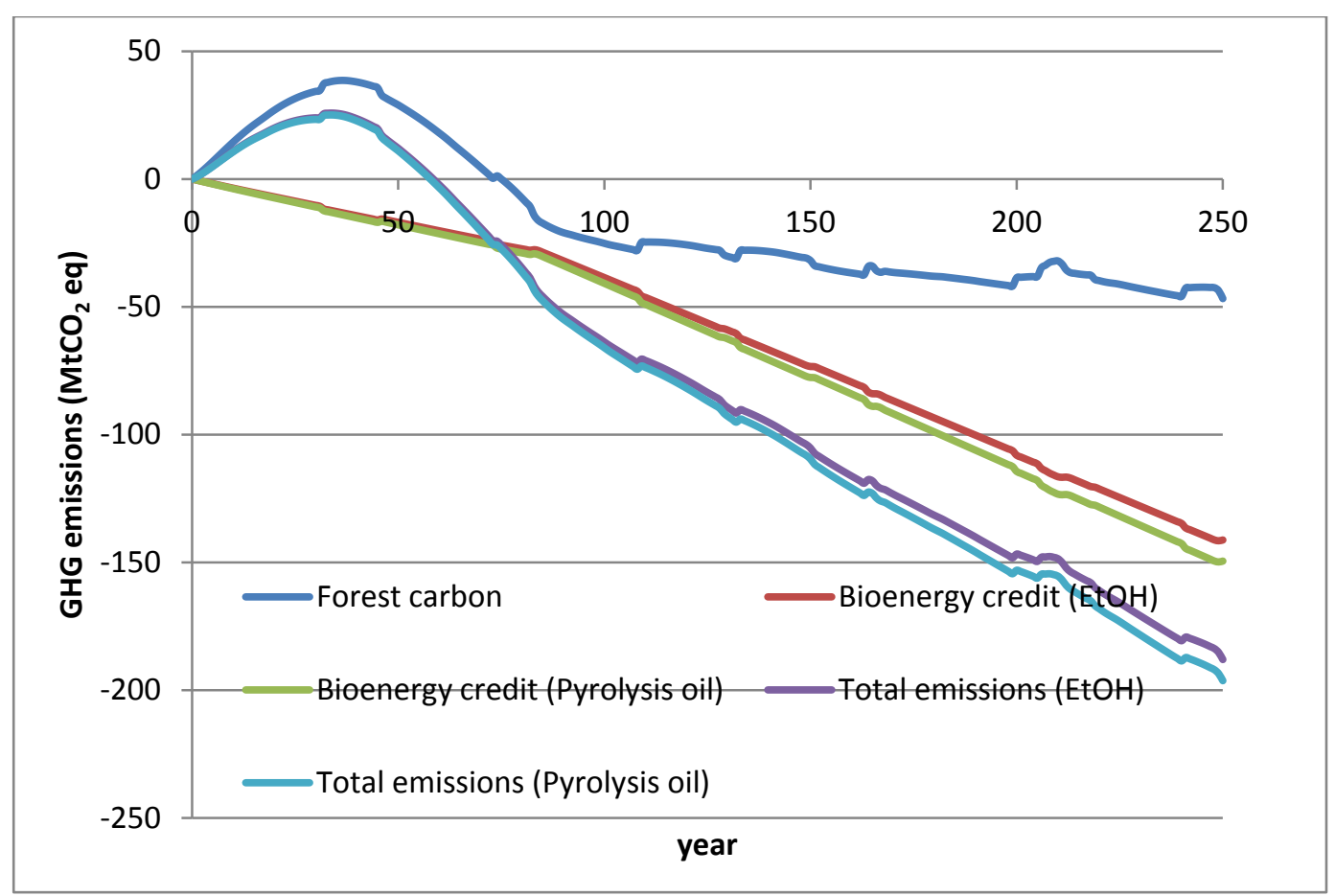

Figure 8.10: Total GHG emissions of EtOH and pyrolysis oil

\subsection{Sensitivity analyses}

\subsubsection{Post-disturbance growth curve uncertainty}

The $\mathrm{C}$ stock results from this model are highly sensitive to the post-disturbance growth curve. To investigate this model sensitivity, the Ek_Brodie curve was decreased by $10 \%$ and $20 \%$ respectively to represent slower growth (compared to original INT scenario) after the clear cut. The total ecosystem $\mathrm{C}$ dynamics of the four scenarios are illustrated in Figure 8.11 . When the growth rate of post-disturbance are decreased by $10 \%$ and $20 \%$, 
less $\mathrm{C}$ is stored in the ecosystem over the entire 250 years simulated, which indicates a positive dLUC impact (GHG emissions) due to the intensive harvest for biofuels and bioenergy production. The GHG emissions due to dLUC are presented in Figure 8.12 and 8.13 for ethanol and pyrolysis oil respectively. The dLUC impact increases significantly because of the decline of the growth curves in this sensitivity analysis. Both in the Ek_Brodie $-10 \%$ and $-20 \%$ scenarios, the intensive harvest contributes to a positive dLUC impact (GHG emission) because less $\mathrm{C}$ is stored in the INT scenario compared to the BAU scenario. Ek_Brodie -20\% curve results in the highest dLUC associated GHG emissions, because more ecosystem $\mathrm{C}$ is lost compared to the BAU scenario due to slower growing rate.

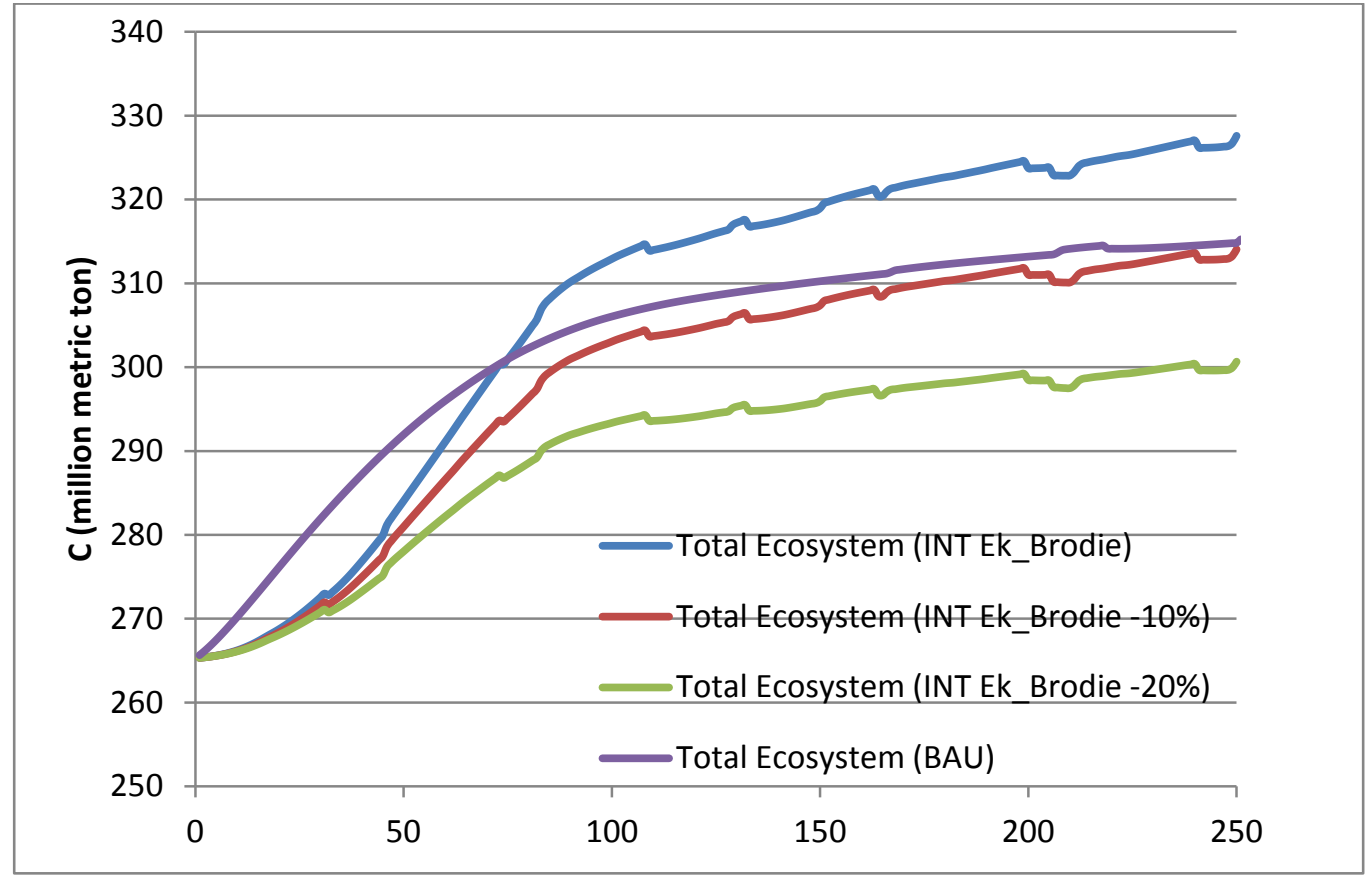

Figure 8.11: Total ecosystem $\mathrm{C}$ storage of the 4 scenarios 


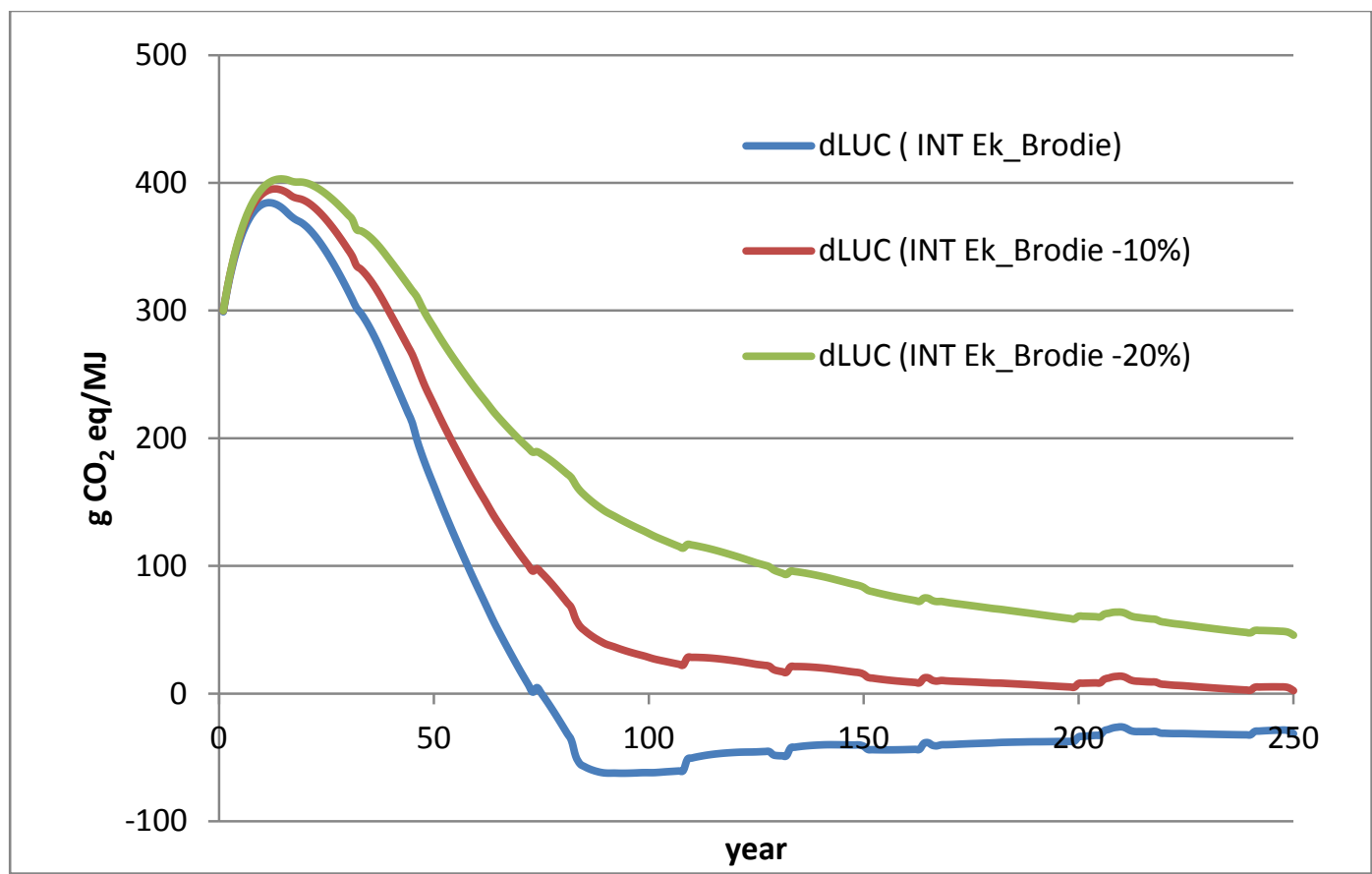

Figure 8.12: GHG emissions due to dLUC of ethanol, comparing 3 growth curve scenarios

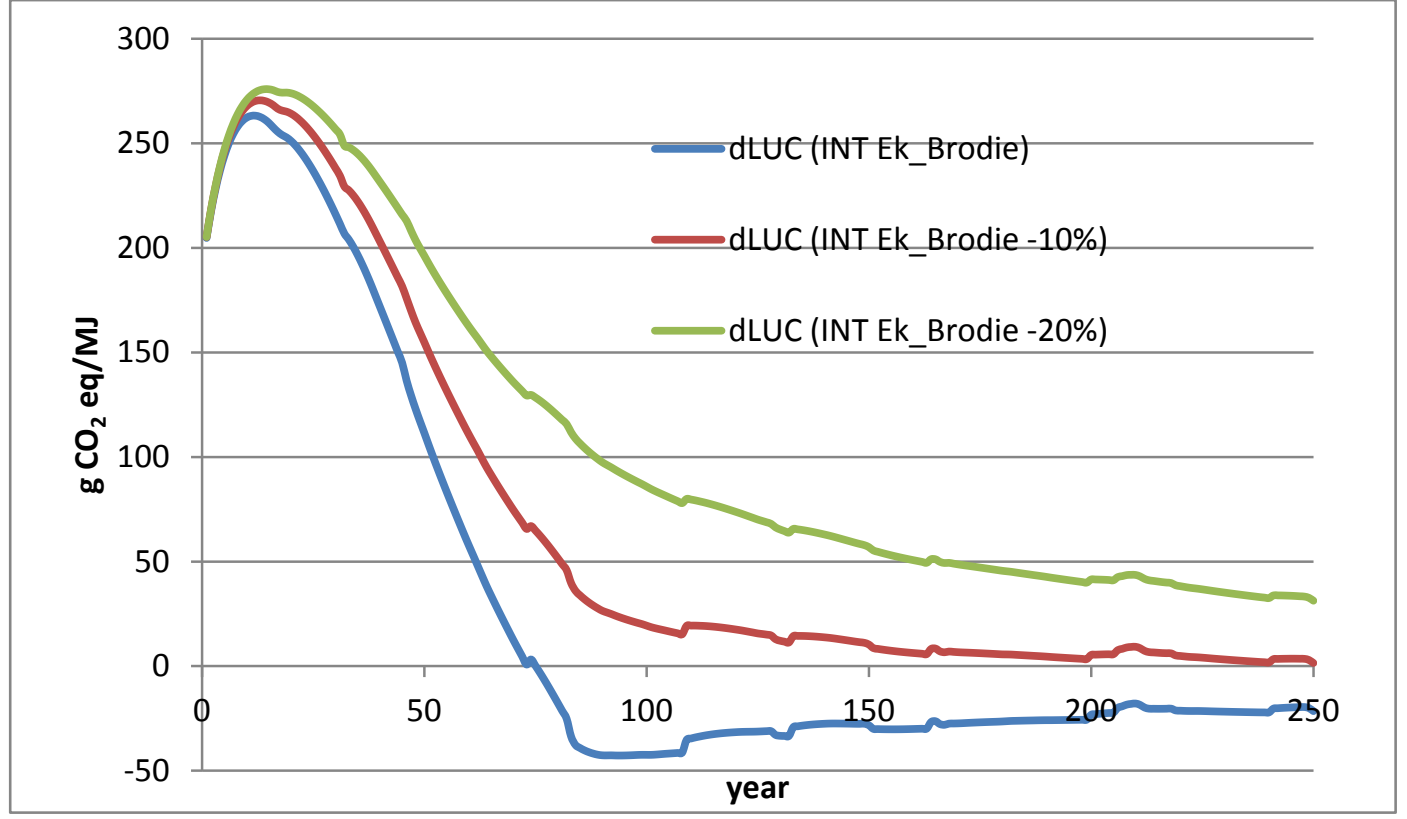

Figure 8.13: GHG emissions due to dLUC of pyrolysis oil, comparing 3 growth curve scenarios 
Total GHG emissions of EtOH and pyrolysis oil of this sensitivity analysis were calculated by the equation described in section 8.3.5, and the results are illustrated in Figure 8.14. Even though the Ek_Brodie -10\% and -20\% curves result in decrease of forest carbon, the biofuels produced from the harvested biomass provide carbon mitigation effect because of the avoided emissions from displacing fossil fuels. However, the time required to reach carbon neutrality are prolonged from 60 to 75 and to 130 years, when a slower post-disturbance growth curve is assumed.

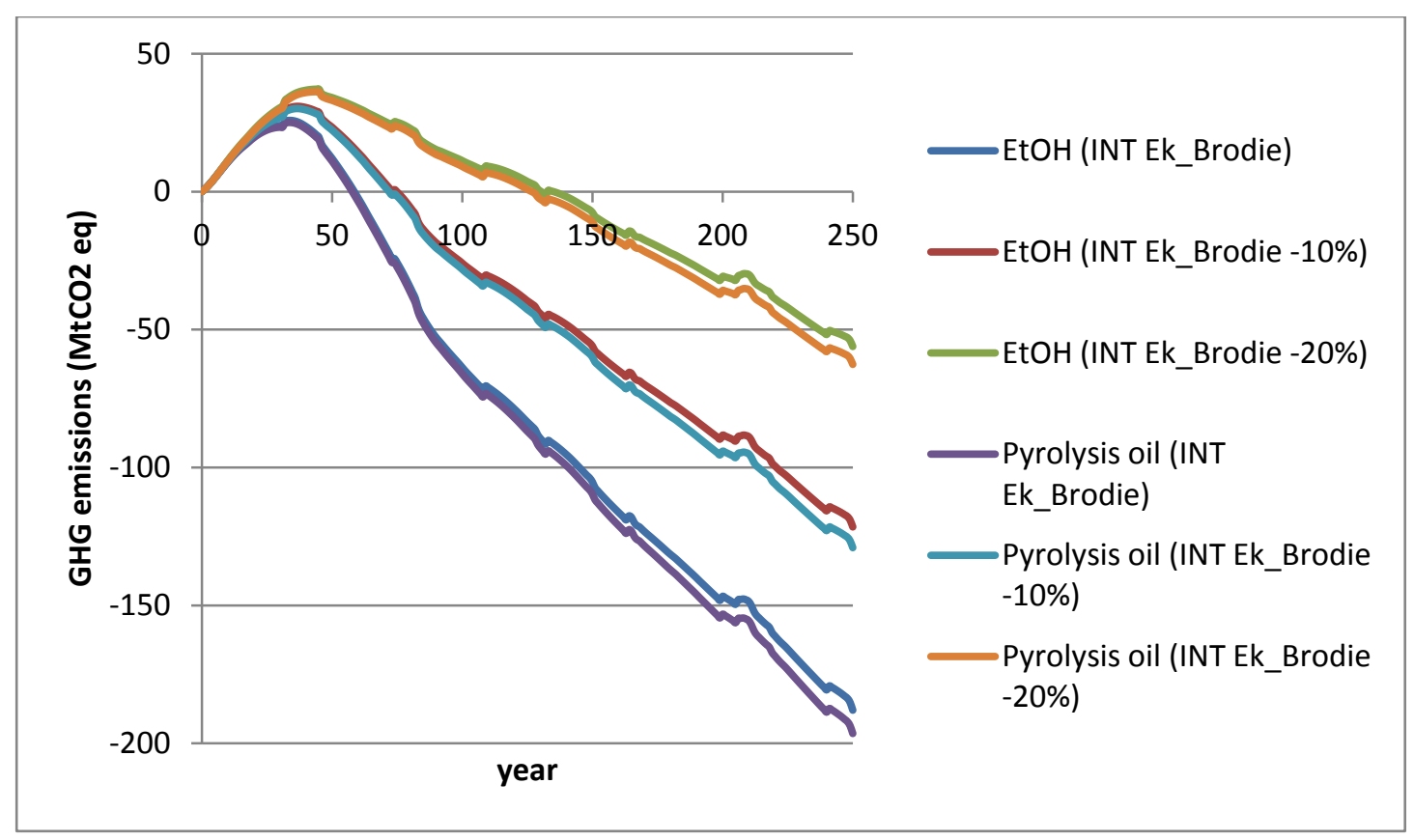

Figure 8.14: Total GHG emissions of EtOH and pyrolysis oil, comparing 3 growth curve scenarios

\subsection{Discussion}

Similar to other studies ${ }^{205,206}$, forest based biofuels and bioenergy from intensive harvesting compared to BAU result in increased GHG emissions compared to fossil fuels use in the near term because of the carbon stock loss. Biofuels production provides emission reduction eventually because the forests start to accumulate more carbon due to intensive management and the GHG credits from displacing fossil fuels. The time required for the biofuels to reach carbon neutrality vary depending on the biomass species, forest management, biofuel conversion technologies and the fossil energy 
displaced. Our study shows that ethanol and pyrolysis oil produced from intensive harvest of aspen forest reach carbon neutrality at approximately 60 years. While in the Mckechnie study ${ }^{203}$, ethanol from residues requires 75 years to reach carbon neutrality if it displaces gasoline (E85), while ethanol from standing trees (under the same forest management) never reach carbon neutrality over the 200 year simulation time because of the large carbon loss in the forest. Our study also shows that carbon dynamics are highly sensitive to the post-disturbance growth. Intensive harvest of biomass could, if managed poorly, cause a continual carbon loss in the forest carbon stocks, which may prolong the time required to reach carbon neutrality. However, our results also show that when aspen forest stands are managed after clear-cut harvest for maximum growth potential the time for $\mathrm{C}$ debt pay back can be significantly shortened. Therefore, future studies should focus on the validity of the post-disturbance growth of biomass. Collected data from managed aspen stands in Michigan are needed to verify the growth curve used and need to understand impacts of harvest strategy and forest management on C stocks in live and dead biomass pools.

GHG mitigation capability of biofuels (bioenergy) also depends on the technology routes and carbon intensity of the fossil fuels displaced. In this analysis, a higher yield (MJ basis) of pyrolysis oil than the ethanol was used, which means more fossil fuels can be displaced when the same amount of biomass are converted by thermochemical process as opposed to biochemical process. On the other hand, ethanol has a lower life cycle GHG emission mainly because of the credit from exported electricity, which means it has a larger GHG reduction than pyrolysis oil on the same energy basis when compared to their petroleum baseline. Pyrolysis oil derived electricity shows the most favorable GHG mitigation capability because of its large reduction compared to the coal electricity. However, ethanol will show a much larger GHG reductions compared to high carbon intensity petroleum fuels such as oil shale and tar sands, when conventional crude oils are depleted in the long run. GHG reduction also depends on the LCA assumption and method. If the co-product char is exported as a soil amendment, it will give a GHG credit to the pyrolysis oil product, which makes it a more favorable biofuel option with respect 
to GHG emission reduction. Allocation methods can change the life cycle GHG emissions of biofuels as well.

\subsection{Future work}

For future work, a yield curve for aspen from field data at multiple sites needs to be compiled to predict the carbon dynamics of Michigan aspen-birch forests. In addition, the study can be expanded to include all the available tree species in Michigan, namely white-red-jack pine, maple-beech-birch, spruce-fir, elm-ash-cottonwood, and oakhickory. Third, the model can be improved by simulating harvest by various owner groups (federal, state, industrial and non-industrial private) as they have different harvest agendas. Finally, the CBM model can be used to simulate the carbon stock changes of short rotation forestry (poplar and willow) planted on abandoned agricultural land. Short rotation forestry can provide fast growing biomass dedicated for energy production and may be the most promising biomass production strategy for minimizing dLUC impacts of forest-based biofuels and bioenergy. When planted on marginal agricultural land, it is expected to store more carbon in soils, but more field work needs to be carried out to study the LUC impact of this practice so that more accurate $\mathrm{C}$ modeling can be done.

\subsection{Conclusion}

The excess timber resources in Michigan can be a promising feedstock for biofuel and bioenergy production. When aspen forest is under management for intensive harvest, it can produce an extra18.46 billion gallons of ethanol to blend with gasoline for the transport sector over the next 250 years. The biomass can also be used to produce 32.26 billion gallons of bio-oil by fast pyrolysis process, which can be combusted to generate electricity or upgraded to renewable gasoline, diesel and jet fuels. In addition to the carbon credits from displacing fossil energy, our modeling study finds that intensive harvesting can result in carbon accumulation in the aspen forest, which translates to a $\mathrm{CO}_{2}$ credit from the dLUC impact. However, this credit is sensitive to the postdisturbance growth curve assumed. 


\section{Chapter 9: Depolymerization Kinetic Model for Dilute Acid Hydrolysis of Aspen}

\subsection{Introduction}

Research into ethanol production from lignocellulosic biomass has grown significantly over the last few decades ${ }^{215-218}$, for it offers a potential solution to replace conventional fossil fuels while not competing with food production. The potential benefits of using lignocellulosic ethanol include lowering the trade deficit, improvement of national energy security and price stability, as well as reducing greenhouse gas emissions ${ }^{219,220}$. Lignocellulosic biomass such as agricultural residues, forest residues and energy crops are abundantly available, providing a total of 1094 million dry metric tons of feedstock for biorefinery by 2030, which translates to annual production of 85 billion gallons of biofuel, enough to displace a third of the nation's transportation fuel demand ${ }^{5}$.

Lignocellulosic biomass is composed of three major polymers: namely lignin, cellulose and hemicellulose ${ }^{221}$. The structure of lignocellulosic biomass is shown in Figure 9.1. Cellulose is a homopolymer consisting of $\beta$-D-glucopyranose subunits linked by $\beta-1,4$ glycosidic bonds ${ }^{221}$, which can be decomposed to glucose monomer ${ }^{222}$. Hemicellulose is an amorphous carbohydrate structure that consists of pentoses (xylose and arabinose), hexoses (glucose, galactose, mannose, rhamnose, and fucose), and sugar acids ${ }^{222,223}$. Hemicellulose has a lower molecular weight and degree of polymerization, and less crystallinity than cellulose, which makes it easier to hydrolyze under milder reaction conditions $^{222}$. Lignin is a three dimensional amorphous polymer between cellulose and hemicellulose, which provides the plant structural support, impermeability, and resistance against microbial attack and oxidative stress ${ }^{223}$. Lignin contains approximately $40 \%$ of the possible energy of the biomass due to its higher carbon content ${ }^{222}$, thus it is usually burned to provide process heat at the biorefinery. However, it can also be used to produce value-added chemicals via catalytic valorization ${ }^{224}$. 


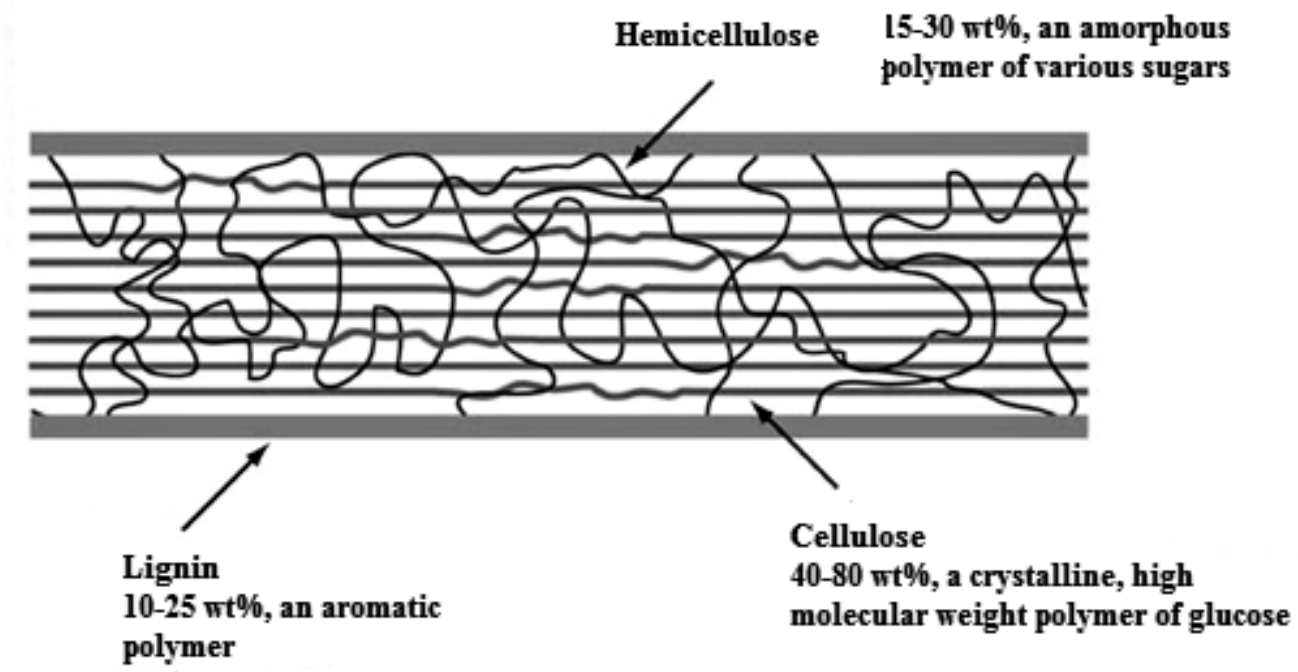

Figure 9.1: Components of lignocellulosic biomass (adapted from Yin 2012 225 )

Lignocellulosic ethanol production starts with pretreatment of the biomass feedstock. Depending on process, pretreatment is required to remove the lignin and hemicellulose, and disrupt the crystalline structure of cellulose, so that the enzymes have easier access to cellulose to convert them to fermentable sugars ${ }^{226,227}$. Pretreatment methods are either physical (comminution, pyrolysis), physicochemical (steam explosion, ammonia fiber explosion) or chemical (acid hydrolysis, alkaline hydrolysis), or a combination of these $\mathrm{e}^{226}$. Acid pretreatment has been well studied recently $\mathrm{y}^{227-229}$ as a process of hydrolysis for the hemicellulose. However, concentrated acids are corrosive and thus require expensive anti-corrosion equipment. Therefore, dilute acid pretreatment is more economically feasible while achieving high reaction rates ${ }^{230}$. Dilute acid hydrolysis appears to be one of the most promising options among all the pretreatment methods ${ }^{231}$. Dilute $\mathrm{H}_{2} \mathrm{SO}_{4}(0.5-2 \mathrm{wt} \%)$ is added to biomass at moderate temperatures $\left(140-190{ }^{\circ} \mathrm{C}\right)$ to hydrolyze hemicelluloses, producing xylose and other sugars, and then continues to break xylose down to form furfural and other degraded products ${ }^{227}$. Lignin structure is disrupted in the process as well $1^{231}$. 
Hemicellulose is a major component of lignocellulosic biomass, accounting for $25-35 \%$ of total mass ${ }^{231}$. Thus, the efficient conversion of hemicellulose to fermentable sugars is vital to ethanol yield and optimizes the economic performance of the production process. One of the challenges for dilute acid hydrolysis is to maximize production of xylose while minimizing furfural and tars through reaction process optimization. A kinetic mechanism for hemicellulose hydrolysis is highly desired as a tool to understand and improve lignocellulosic biorefining. The most common mechanism is a two-step pseudo first order irreversible reaction where xylan in hemicellulose $(\mathrm{XH})$ is hydrolyzed directly to xylose (X), which is dehydrated subsequently to furfural and eventually tars (D) $)^{232}$.

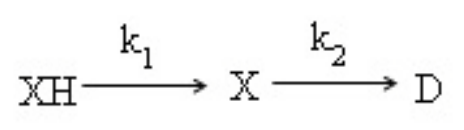

However, oligomers are found to be a significant fraction of the product for very dilute acid flow-through systems, especially at short times ${ }^{233-235}$. In addition, oligomers are not taken up by fermenting microorganisms unless the oligomers are hydrolyzed further. Recent study ${ }^{236}$ even shows that xylooligomers can be strong inhibitors to enzymatic hydrolysis of cellulose. Therefore, the formation and degradation of xylooligomers are vital components of the reaction kinetics of hemicellulose hydrolysis. Chen et $\mathrm{al}^{237}$ proposed a modified kinetic model which includes fast and slow hydrolyzing hemicellulose to oligomer intermediates $(\mathrm{O})$ followed by their breakdown to monomers and finally the decomposition of xylose monomers (D).

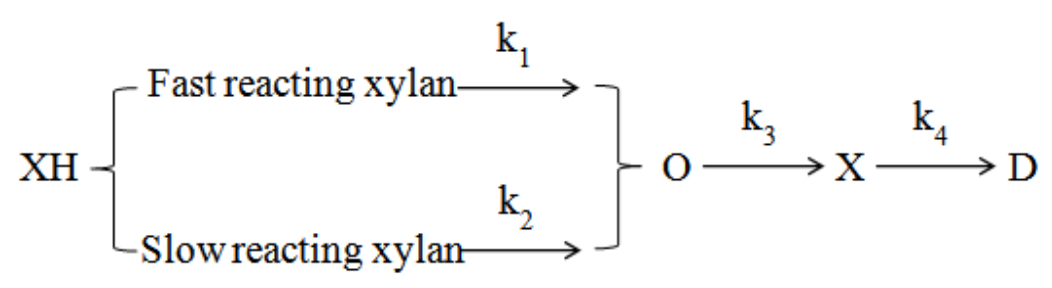

In one study by Morinelly et $\mathrm{al}^{238}$, a four-step first order irreversible reaction mechanism with constant rate constants at each step was proposed, where xylan is hydrolyzed to oligomer intermediates, and then to xylose, which is later dehydrated to furfural (F) and other degradation products. 


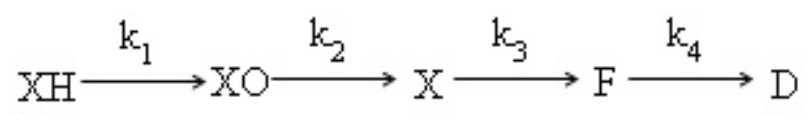

This kinetic model successfully described quantitatively and qualitatively the observed xylose monomer profile. This study used an indirect method to quantify the oligomer concentrations rather than direct measurement of oligomers of different degrees of polymerization. Oligomer data was described successfully at early stage, but the model underpredicted the elevated oligomer concentrations at long reactor times.

A depolymerization model was proposed by Lloyd and Wyman to describe the dilute acid hydrolysis of hemicellulose ${ }^{239}$. The bonds of a polymer composed of n-monomer units are broken during dilute acid hydrolysis. The polymer is first broken and form two molecules, then the molecules are further degraded to smaller oligomers, monomers are finally formed and then degraded into by-products such as furfural. The hydrolysis process can be described as follows:

$$
\begin{gathered}
\mathrm{N}_{\mathrm{n}} \stackrel{\mathrm{k}_{\mathrm{h}}}{\longrightarrow} \mathrm{N}_{\mathrm{j}}+\mathrm{N}_{\mathrm{n}-\mathrm{j}} \\
\mathrm{N}_{\mathrm{j}} \stackrel{\mathrm{k}_{\mathrm{h}}}{\longrightarrow} \mathrm{N}_{\mathrm{i}}+\mathrm{N}_{\mathrm{j}-\mathrm{i}} \\
\mathrm{N}_{\mathrm{n}-\mathrm{j}} \stackrel{\mathrm{k}_{\mathrm{h}}}{\longrightarrow} \mathrm{N}_{\mathrm{k}}+\mathrm{N}_{\mathrm{n}-\mathrm{j}-\mathrm{k}} \\
\mathrm{N}_{1} \stackrel{\mathrm{k}_{\mathrm{d}}}{\longrightarrow} \text { Degradation Products }
\end{gathered}
$$

where $\mathrm{N}$ is the number concentration of xylose monomer and oligomer, $\mathrm{n}$ is the chain length of the longest oligomer molecule, $\mathrm{i}, \mathrm{j}$, and $\mathrm{k}$ are the chain length of the i-mer, $\mathrm{j}$-mer and $\mathrm{k}-\mathrm{mer}, \mathrm{k}_{\mathrm{h}}$ is the probability of bond breakage during hydrolysis (hydrolysis rate constant), which is assumed to be constant regardless of chain length, and $\mathrm{k}_{\mathrm{d}}$ is the sugar degradation rate constant. 
The rate of change in concentration of any oligomer can be expressed by the following differential equations:

$$
\begin{gathered}
\frac{d N_{n}}{d t}=-k_{h} \times(n-1) N_{n} \\
\frac{d N_{j}}{d t}=\left(2 k_{h} \sum_{i=j+1}^{n} N_{i}\right)-k_{h}(j-1) N_{j} \\
\frac{d N_{1}}{d t}=\left(2 k_{h} \sum_{i=2}^{n} N_{i}\right)-k_{d} N_{1}
\end{gathered}
$$

The results of integrating these linear first-order differential equations are as follows (detail solutions are presented in Appendix C.1):

$$
\begin{gathered}
N_{n}=N_{n}^{0} \exp \left[-k_{h}(n-1) t\right] \\
N_{j}=N_{n}^{0}(1-\alpha)^{(\mathrm{j}-1)} \alpha[2+(n-j-1) \alpha] \text { with } \alpha=1-\mathrm{e}^{-\mathrm{k}_{\mathrm{h}} \mathrm{t}} \\
N_{1}=2 k_{h} N_{n}^{0}\left(\frac{(n-1)\left(e^{-k_{h} t}-e^{-k_{d} t}\right)}{k_{d}-k_{h}}-\frac{(n-2)\left(e^{-2 k_{h} t}-e^{-k_{d} t}\right)}{k_{d}-2 k_{h}}\right)
\end{gathered}
$$

Li et $\mathrm{al}^{225}$ measured the xylose monomer and oligomer yields from water-only hydrolysis of oat spelt xylan at 180 and $200^{\circ} \mathrm{C}$. It was found that longer chain xylooligomers depolymerize to shorter chains that ultimately result in release of soluble oligomers and monomers. Because of the low severity of reaction, no significant yields of oligomers were detected at early reaction time, suggesting the degree of polymerization (DP) of oligomers in solution are larger than 10. Yang and $\mathrm{Wyman}^{240}$ characterized the xylooligomers produced from water-only pretreatment of pure xylan and corn stover at 200, 220 and $240^{\circ} \mathrm{C}$. DP as high as 30 were separated using the Dionex DX-600 Ion Chromatograph system. The yields of lower DP $(<10)$ oligomers increased with temperatures. Kumar and Wyman ${ }^{241}$ modeled the kinetics of xylooligomers (up to DP 5) in dilute acid hydrolysis, assuming first order reaction of xylooligomers hydrolysis and 
xylose degradation. The yield of xylose increased with increasing acid concentration but decreased with increasing xylooligomer DP at a given acid concentration. The xylooligomers disappeared at a higher rate compared to xylose monomer and the hydrolysis rate constant increased with DP at all $\mathrm{pH}$.

Our study propose to use the depolymerization model developed by Lloyd and Wyman ${ }^{239}$ to predict the xylooligomers and xylose monomer concentrations over time in dilute acid hydrolysis. Aspen is used as the xylan source because it is widely available in Upper Peninsula area of Michigan and is a promising feedstock for future bioethanol production. The study here is new in that each xylooligomer (up to DP9) is tracked during the hydrolysis reaction to optimize the model, as opposed to using the total oligomers profile by Lloyd and Wyman ${ }^{239}$. The primary research objectives in this study are to evaluate whether the depolymerization model is able to predict the trends in the xylooligomers and xylose monomer concentrations over time and whether the predicted concentrations are a good match with measured values. Based on these comparisons between predicted and measured concentrations, recommendations will be made to improve model assumptions and quality of measured data.

\subsection{Hydrolysis experiments}

\subsubsection{Materials}

The aspen samples were obtained from forests in the Upper Peninsula area of Michigan. The biomass samples were debarked, flaked, dried, and milled in preparation for pretreatment according to the procedures described by Yat et al ${ }^{242}$. The aspen chips of mesh size $+28-20$ were collected by the W.S. TYLER ROTAP (Model RX-29, Serial 9774). Xylose (purity $>99 \%$ ), hydroxymethyl furfural (HMF) and furfural were purchased from Sigma Chemical Company (St. Louis, MO). A xylobiose standard of over 95\% purity was purchased from Megazyme International Ireland Ltd. (Bray, Co. Wicklow, Ireland, Cat No. O-XBI). Sulfuric acid (96 wt\%) purchased from Fisher Scientific (Pittsburgh, PA) was diluted with distilled water to designated concentration for dilute acid hydrolysis. 


\subsubsection{Experiment setup}

Experiments of dilute acid hydrolysis of aspen were conducted to measure the concentrations of monomer and oligomer xylose, and degradation products such as furfural and HMF over time. The experiment setup is illustrated in Figure 9.2 below. The pretreatment conditions (acid concentration and reaction temperature) were varied to evaluate the reaction profiles under different reaction severity. The proposed experiment matrix is shown in the Table 9.1 below and experiments were conducted in duplicate. The experiment apparatus are similar to those used in previous research ${ }^{219,238}$, which consists of a rack of 12 small-scale tubular reactors made out of stainless steel (Type 316) tubing and Swagelok fittings (o.d. $=3 / 8$ in., walls $=0.035$ in., inner volume $=6.75 \mathrm{~mL}$ ) and a silicon oil bath with Dow Corning 550 fluid heated by a Fisher Scientific HiTemp bath. $0.5 \mathrm{~g}$ of dry biomass and $4.5 \mathrm{ml}$ of dilute sulfuric acid were poured into each stainless tubular reactor. The reactor end-caps were tightened to 40 Newton-meters with a torque wrench before placed in the basket. The reactors were flipped twice in the next 30 minutes (10 min intervals) to ensure complete diffusion of the dilute acid solution through the biomass. The reactors were then submerged into a preheated silicon oil bath to undergo the acid hydrolysis. The initial bath temperature was set $10^{\circ} \mathrm{C}$ higher than the reaction temperature set point (determined by previous experiments) so that the reactors and the bath reached thermal equilibrium exactly at the target temperature after a short time (3-5 $\mathrm{min})$. The reactors were removed from the oil bath at various times, and once the reactors were removed, they were immediately placed in an ice bath to stop the hydrolysis reaction. Each sample, including biomass and solution, was transferred from the reactor into a 20-ml capped scintillation vial after it cooled down, and then the solution was filtered through $0.2 \mu \mathrm{m}$ pore size polycarbonate membrane filter (Whatman ${ }^{\circledR}$ ) for further analysis.

High Performance Liquid Chromatography-HPLC (Agilent 1200 series) coupled with a Hi-Plex Na column (Agilent) was employed to measure the oligomer sugar concentrations based on the NREL laboratory analytical procedure ${ }^{243}$. Two potions of aliquots of $1 \mathrm{ml}$ were taken from each filtered hydrolyzate. The first was neutralized by 
$10 \mathrm{~N} \mathrm{NaOH}$ solution in HPLC vial and sent to HPLC. The HPLC measures the peak signals of monomer xylose, oligosaccharides up to DP 9, and degradation products such as furfural and HMF. Calibration curves are determined by known concentrations of xylose, xylobiose, furfural and HMF prepared from the standards. Concentrations of these chemicals are calculated by the calibration curves. Concentrations of each xylooligomer specie (xylotriose, xylotretraose, xylopentaose, xylohexaose and etc) are calculated by taking the ratio of each peak height to the peak height of xylobiose and multiplying this ratio by the measured concentration of the latter, which is proved to be accurate in determining the xylooligomers concentrations ${ }^{225}$. This method also reduces the cost of purchasing expensive xylooligomers standards. The second aliquot is used to determine the concentration of total oligosaccharides, because the chain length of oligosaccharides during early time of the acid pretreatment may be too long for the column to detect ${ }^{225}$. The aliquot $(1 \mathrm{ml})$ was pipette into a $1.7 \mathrm{ml}$ centrifuge vial, $96 \% \mathrm{wt}$ of sulfuric acid was added in the vial to bring the acid concentration to $4 \%$, and the vial was sealed by autoclave tape and put in an autoclave for 60 minutes at $121^{\circ} \mathrm{C}$ for hydrolysis of oligomers. After 60 minutes, each sample was removed from the autoclave to cool in room temperature, and filtered and neutralized to a $\mathrm{pH}$ of $5 \sim 6$ by the $10 \mathrm{M}$ $\mathrm{NaOH}$ solution, then transferred to the HPLC for xylose analysis. By taking the difference between the xylose concentration determined from the samples after acid pretreatment, and the concentration determined from the samples that undergo the additional hydrolysis, while applying a "sugar recovery" factor ${ }^{243}$, concentrations of the total oligomeric sugar were determined. 


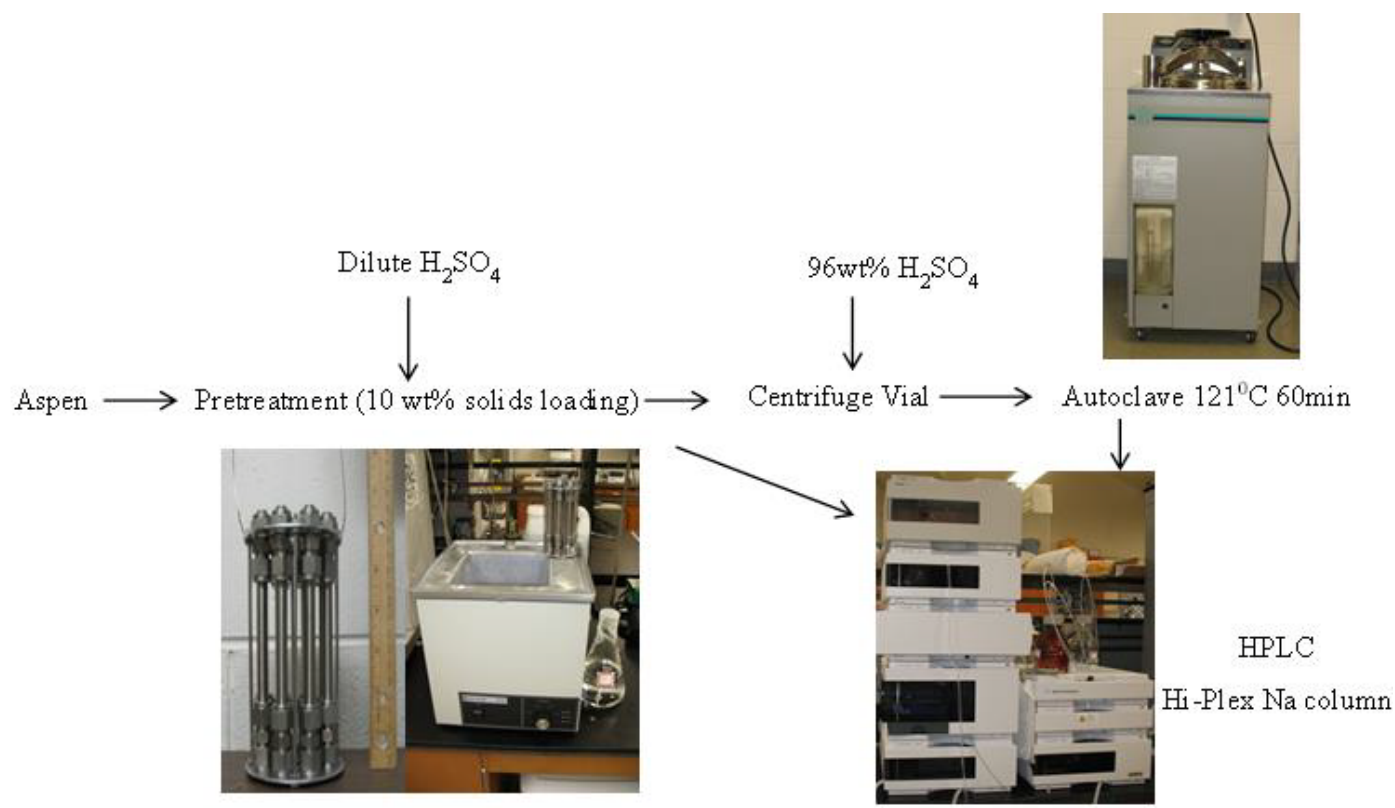

Figure 9.2: Experiment setup of aspen hydrolysis

Table 9.1: Pretreatment severities for acid concentration and temperature

\begin{tabular}{|l|l|l|}
\hline increasing severity $\longrightarrow$ & \multicolumn{2}{|l|}{} \\
\hline $150^{\circ} \mathrm{C}$ & $160^{\circ} \mathrm{C}$ & $175^{\circ} \mathrm{C}$ \\
\hline $0.5 \% \mathrm{wt}$ & $0.5 \% \mathrm{wt}$ & $0.5 \% \mathrm{wt}$ \\
\hline
\end{tabular}

The mass of initial xylan can be calculated by the xylan $\mathrm{wt} \%$ in aspen sample. Xylan usually accounts for $14.6 \%$ of the dry mass of aspen ${ }^{242}$. The measurements of monomer and oligomer xylose, furfural and HMF will be used to obtain the model parameter such as $\mathrm{k}_{\mathrm{h}}, \mathrm{k}_{\mathrm{d}}$, and $\mathrm{n}$ under different pretreatment conditions.

\subsection{Results}

The concentrations of xylose monomers at various temperatures during dilute acid hydrolysis are shown in Figure 9.3. The peak concentrations of xylose increase as the reaction temperature increases, and the time to reach the peak xylose concentration decreases with increasing temperature. At the highest temperature of $175^{\circ} \mathrm{C}$, xylan breaks down into monomer sugars more completely at this severe reaction condition, 
however at long times xylose disappears to form furfural (Figure 9.4) and tars. At relatively mild temperatures $\left(150\right.$ and $\left.160^{\circ} \mathrm{C}\right)$, the xylose continues to increase over time while xylose starts to break down at higher temperature, which are confirmed by the increase of furfural and $\mathrm{HMF}$ at $175^{\circ} \mathrm{C}$ (Figure 9.4). The increase in furfural concentration for the $175^{\circ} \mathrm{C}$ experiment achieves a high concentration of approximately 5 $\mathrm{g} / \mathrm{L}$ by 60 minutes while the decrease on xylose concentration from the peak to the low at 60 minutes is about $9 \mathrm{~g} / \mathrm{L}$. Apparently some of the xylose was converted to other degradation products such as tars by the end of the experiment.

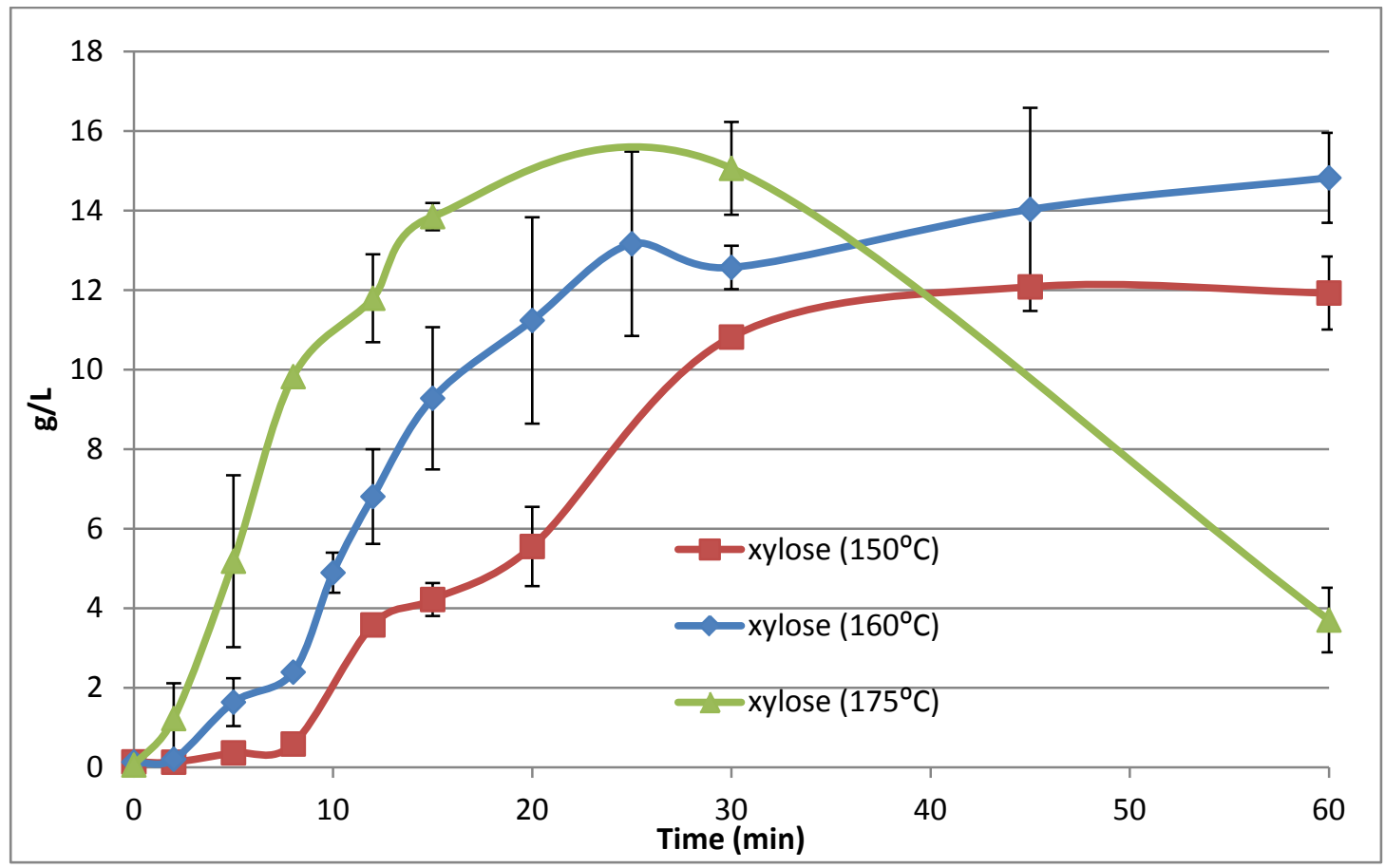

Figure 9.3: Concentrations of xylose monomers during dilute acid hydrolysis 


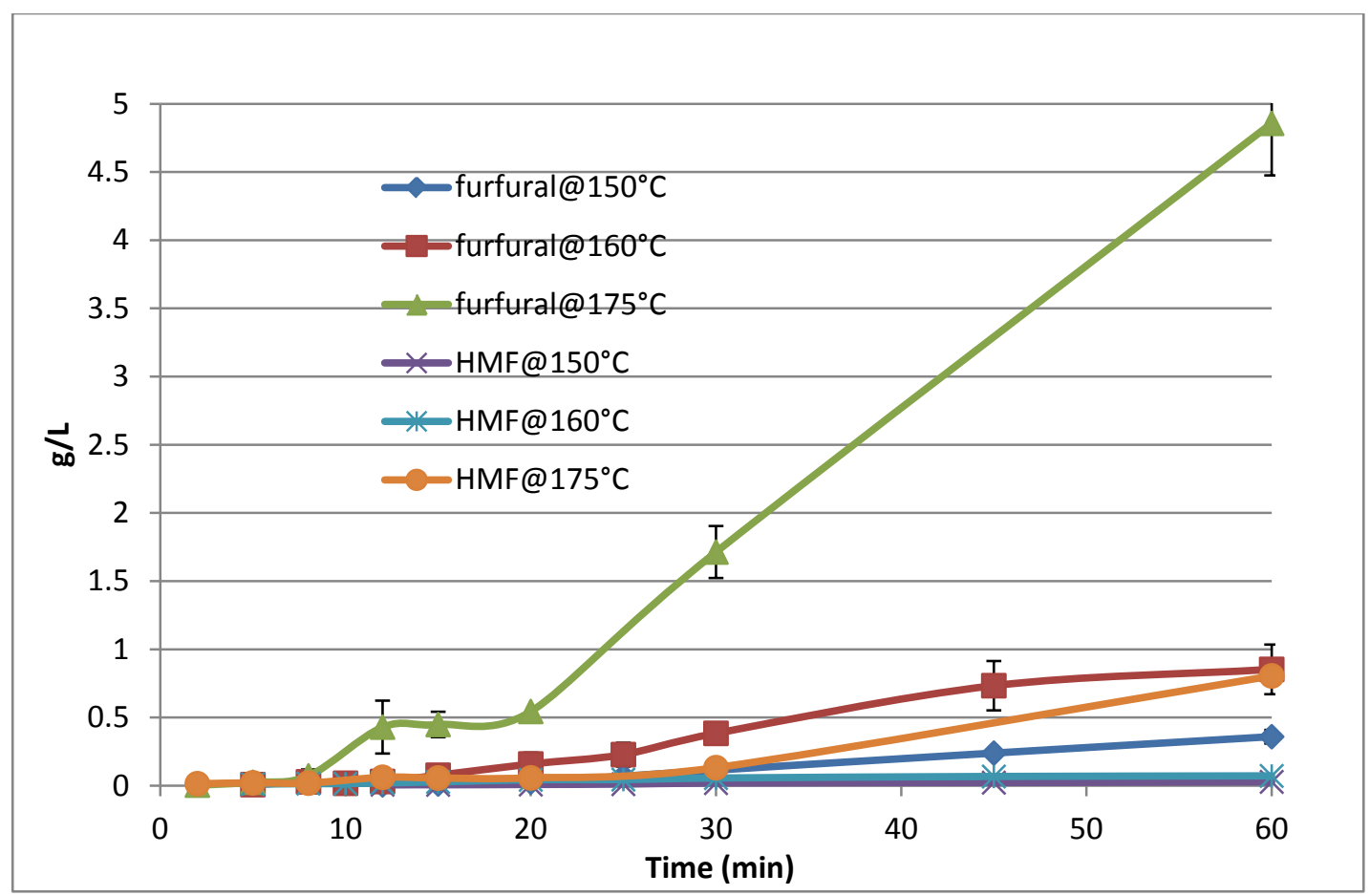

Figure 9.4: Furfural and HMF concentrations during dilute acid hydrolysis

Xylooligomers concentrations along the time axis for the hydrolysis reaction at $150^{\circ} \mathrm{C}$, $160^{\circ} \mathrm{C}$ and $175^{\circ} \mathrm{C}$ are shown in Figure 9.5, 9.6 and 9.7, respectively. At $150^{\circ} \mathrm{C}$, xylooligomers (xylobiose, xylotriose, xylotetraose and xylopentaose) peak at approximately 12 minutes, and then decrease due to breaking down into smaller oligomers. In general, the shorter the chain length, the higher peak concentration it has. The peak concentration of total xylooligomers measured by HPLC is $2.39 \mathrm{~g} / \mathrm{L}$, of which xylobiose accounts for $1.12 \mathrm{~g} / \mathrm{L}$. The reaction time required to reach peak concentrations decrease as the reaction temperature increase. At $160^{\circ} \mathrm{C}$ and $175^{\circ} \mathrm{C}$, xylobiose reach peak concentration at 10 minutes and 5 minutes respectively. The results also show that the longer chain length the oligomer has, the shorter the time required to reach peak concentration. For example, at $175^{\circ} \mathrm{C}$, xylobiose reaches peak concentration at 5 minutes while xylotetraose reaches peak concentration at 2 minutes. Comparing total xylooligomers (detected by HPLC) produced at 150 and $175^{\circ} \mathrm{C}$, higher temperature facilitates the hydrolysis reaction as more xylooligomers are produced from xylan, which are later converted to xylose monomer and degraded products. 


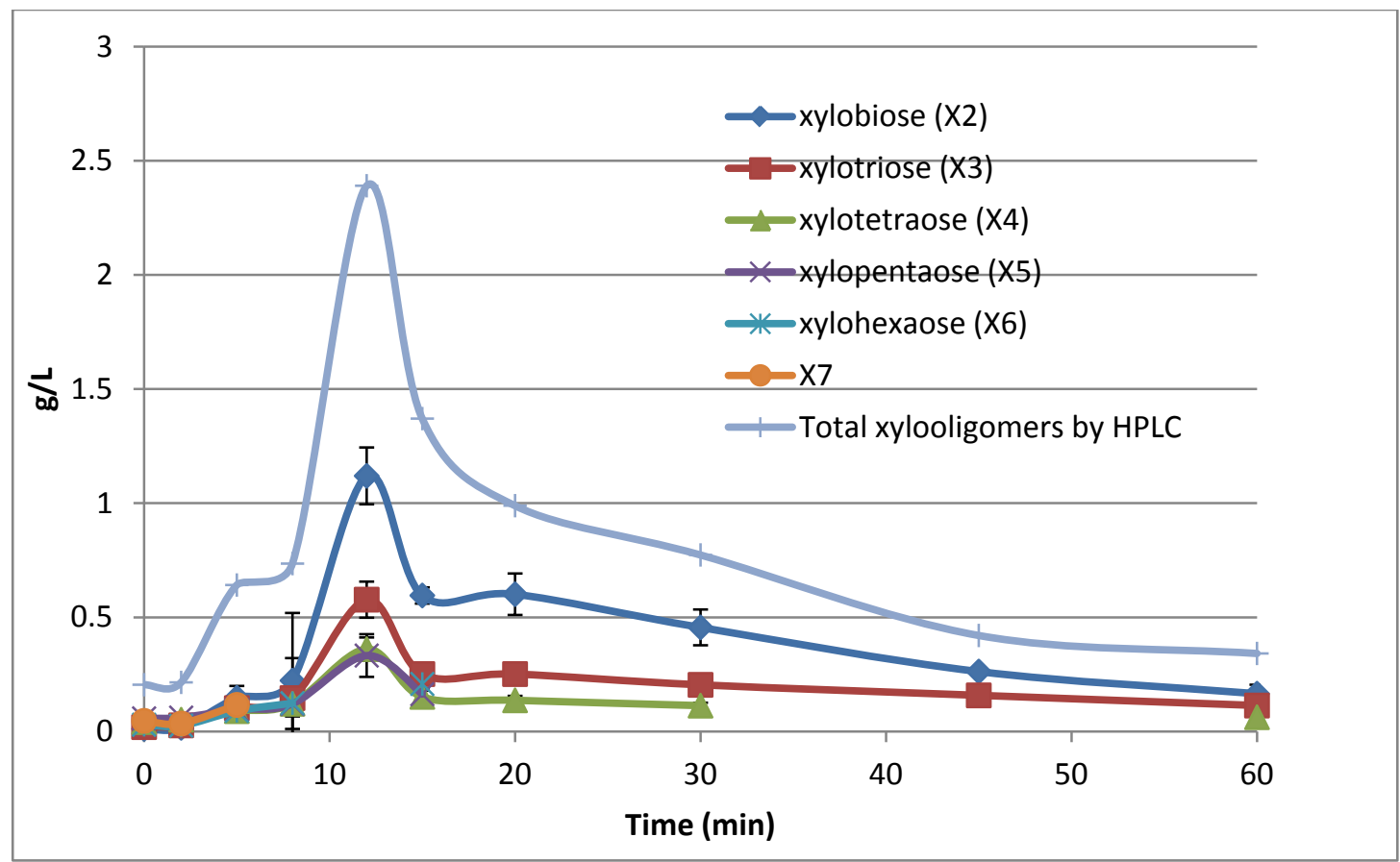

Figure 9.5: Concentrations of xylooligomers at $150^{\circ} \mathrm{C}$

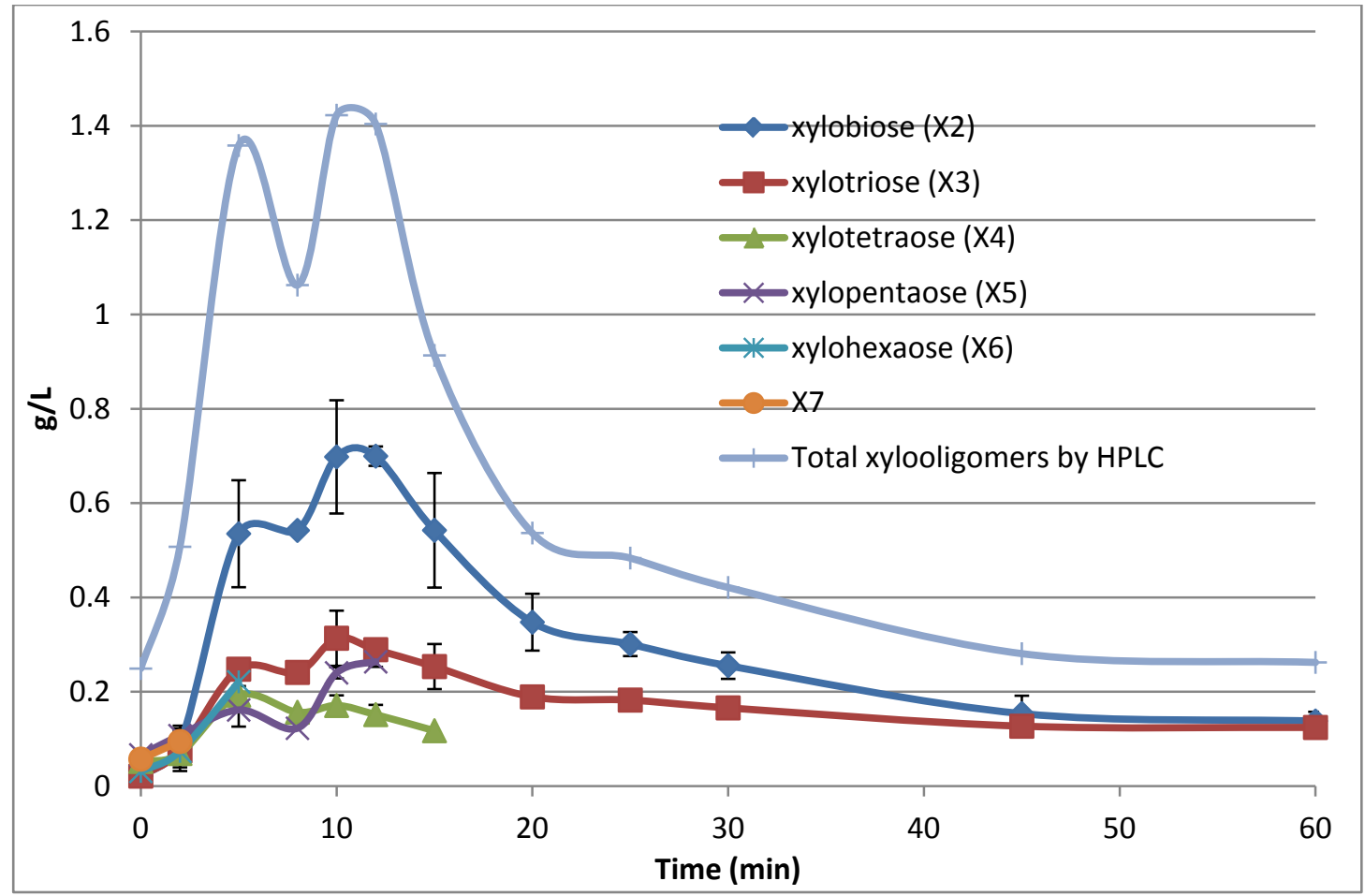

Figure 9.6: Concentrations of xylooligomers at $160^{\circ} \mathrm{C}$ 


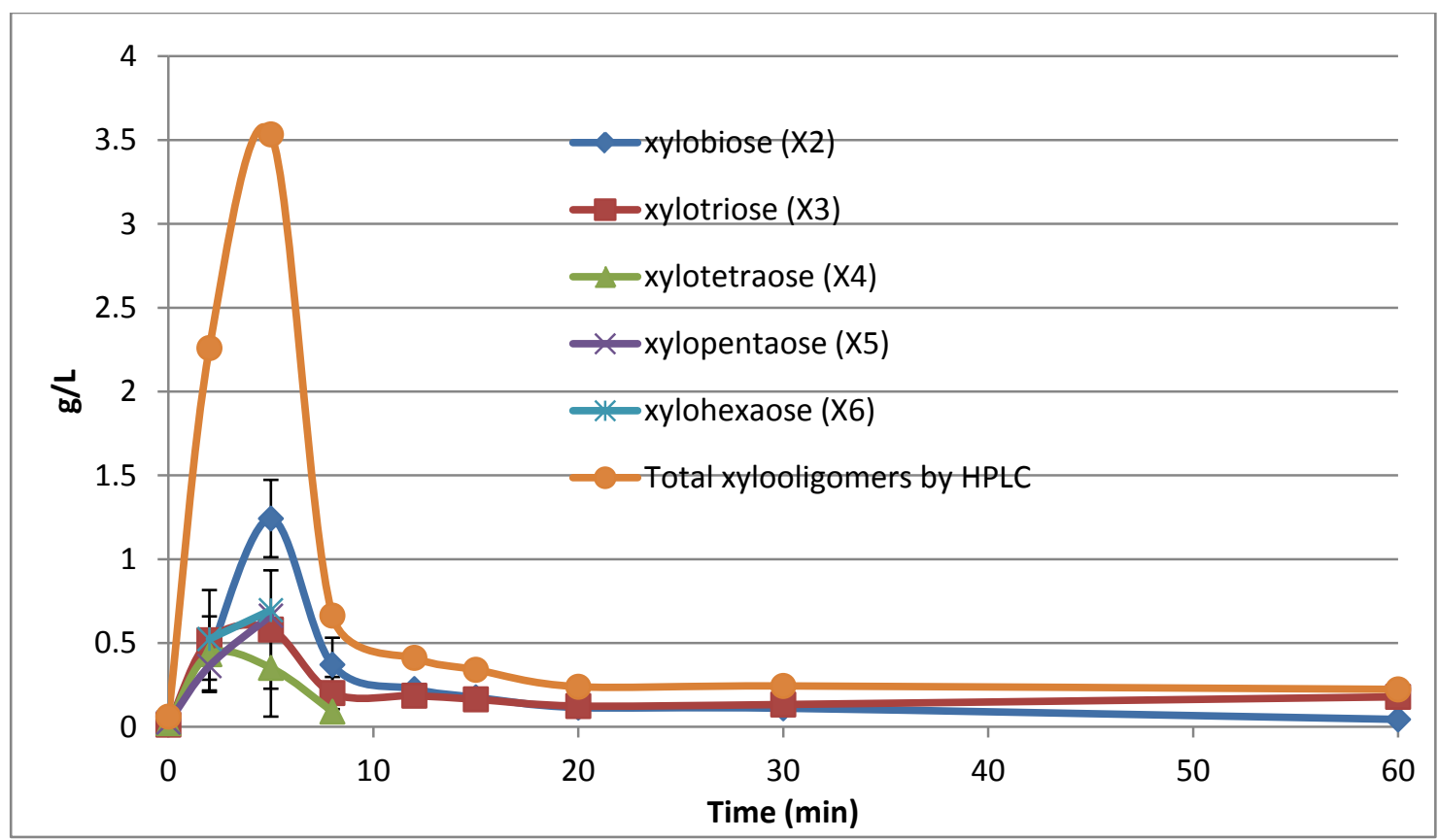

Figure 9.7: Concentrations of xylooligomers at $175^{\circ} \mathrm{C}$

Total oligomer concentrations are calculated by the xylose increase in the second stage acid hydrolysis coupled with the "sugar recovery factor" ${ }^{243}$. Total oligomers after dilute acid hydrolysis in oil bath are illustrated in Figure 9.8. Oligomers are produced from breaking down of xylan polymer, and then they further break down into smaller oligomers and finally to xylose monomer and degraded products. At lower temperature $\left(150\right.$ and $\left.160^{\circ} \mathrm{C}\right)$, there are a small amount of oligomers left at 60 minutes, while at a higher temperature $\left(175^{\circ} \mathrm{C}\right)$, all the oligomers disappear at 60 minutes as the hydrolysis reaction is more severe. The high variability of measured total oligomer concentration for the $150^{\circ} \mathrm{C}$ experiment at long times may be due to experiment error rather than a real outcome. The maximum concentrations of oligomers produced from xylan at different temperature are similar at approximately $4.5 \mathrm{~g} / \mathrm{L}$. However, when subjected to higher temperature, it takes less time to hydrolyze all the oligomers. For example, the time to reach peak concentration at $175^{\circ} \mathrm{C}$ is 5 minutes, while it takes approximately 15 to 20 minutes to produce the maximum amount of oligomers at $150^{\circ} \mathrm{C}$. 


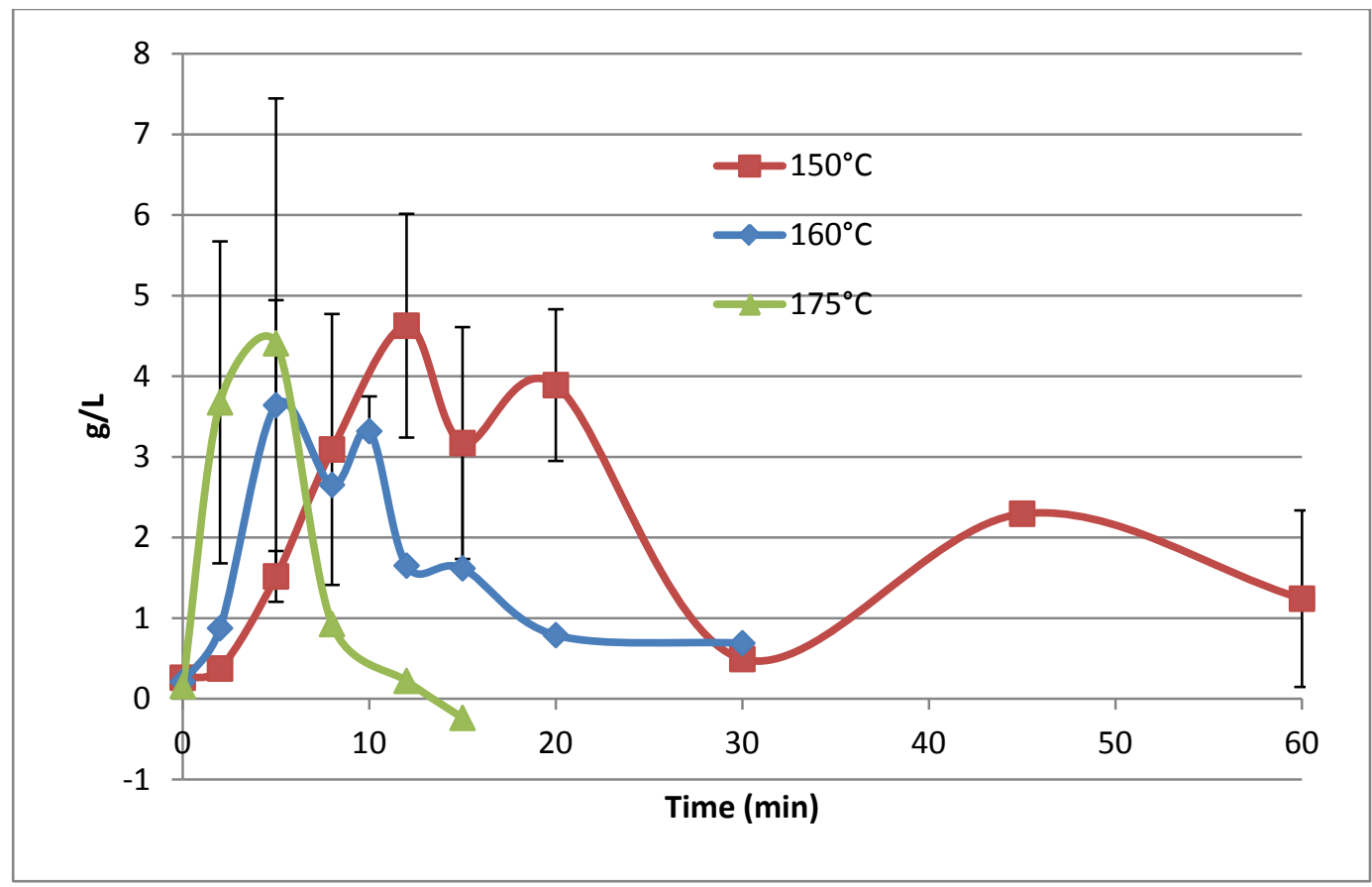

Figure 9.8: Total oligomers concentrations in the hydrolyzate using the NREL procedure.

The trends over time in the monomer and oligomer concentration data show that higher reaction temperature result in shorter peak times for each DP species and that oligomer species of lower DP achieve peak concentration as shorter time for all temperatures. The modeling results to be presented in the next section will be compared to the experimental results based on these observed trends.

\subsection{Depolymerization model}

The numbers of each xylooligomer $\left(\mathrm{N}_{1} \sim \mathrm{N}_{8}\right)$ vs. time were calculated based on the equations in section 9.1. Weights of the xylooligomers were then calculated by multiplying the numbers by the molecular weight of each xylooligomers. These weights were finally normalized by dividing the initial weight of xylan in the dilute acid solution, assuming hemicellulose accounts for $14.6 \mathrm{wt} \%$ of aspen ${ }^{242}$.

Solver function in Excel was used to adjust $\mathrm{n}, \mathrm{k}_{\mathrm{h}}$ and $\mathrm{k}_{\mathrm{d}}$ to minimize the difference between the model and the experiment data using sum of squared errors as the objective 
function: $\Sigma\left(\mathrm{X}_{\text {model }}-\mathrm{X}_{\text {data }}\right)^{2}$. Figure 9.9, 9.10 and 9.11 illustrated the experimental xylose concentrations and model predictions at 150,160 and $175^{\circ} \mathrm{C}$, respectively. The optimized parameters $k_{h}$ and $k_{d}$ determined by a best fit match of the model to the xylose data, are presented in the figures as well. As shown in the figures, the model can successfully predict the xylose concentrations over time during the experiments. The hydrolysis reaction is faster in higher reaction temperature as indicated by the increasing hydrolysis rate $\mathrm{k}_{\mathrm{h}}$. Simultaneously, xylose is subjected to more severe degradation process, which is indicated by the increasing degradation rate $\mathrm{k}_{\mathrm{d}}$, which is confirmed by the increasing concentrations of the degradation products furfural and HMF (Figure 9.4).

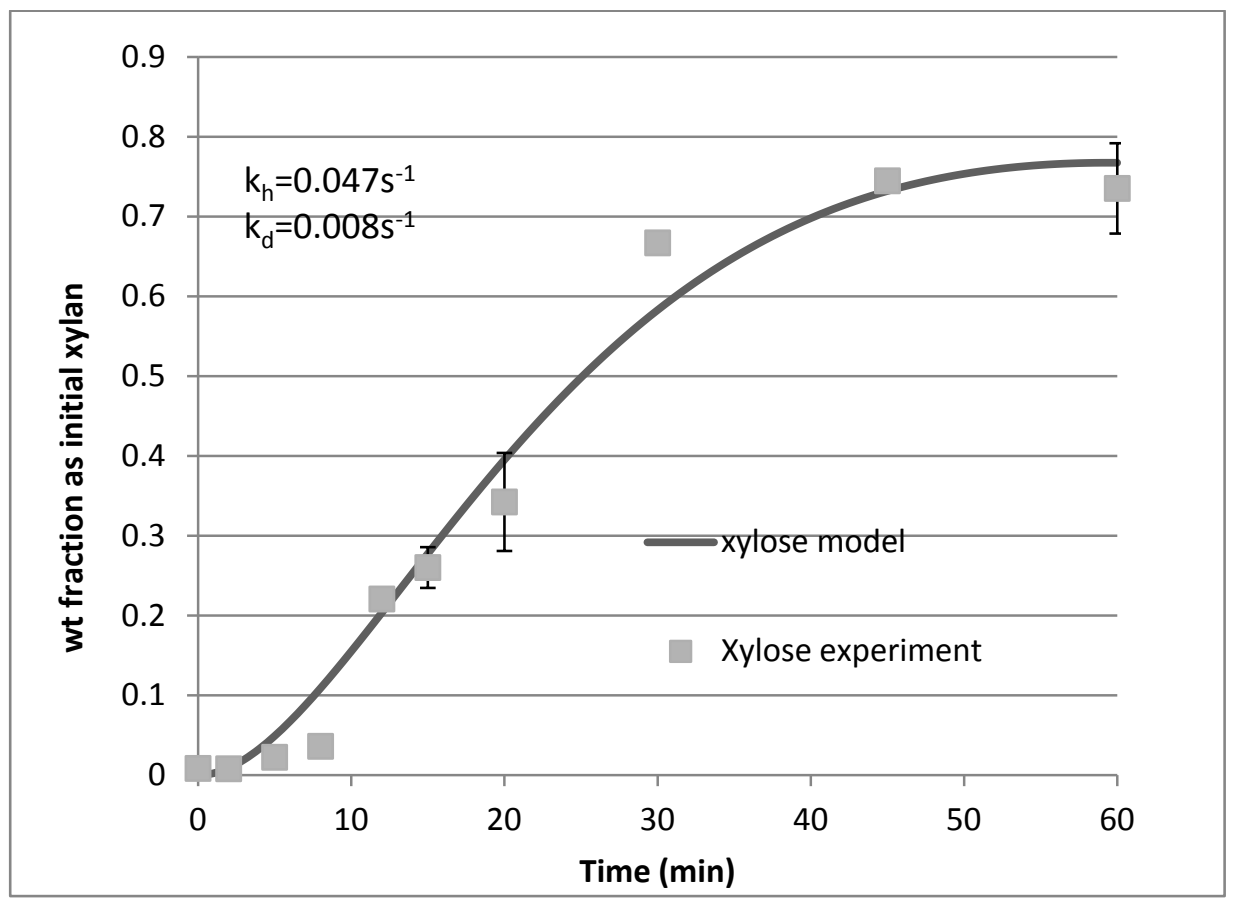

Figure 9.9: Xylose experiment data at $150^{\circ} \mathrm{C}$ and model prediction 


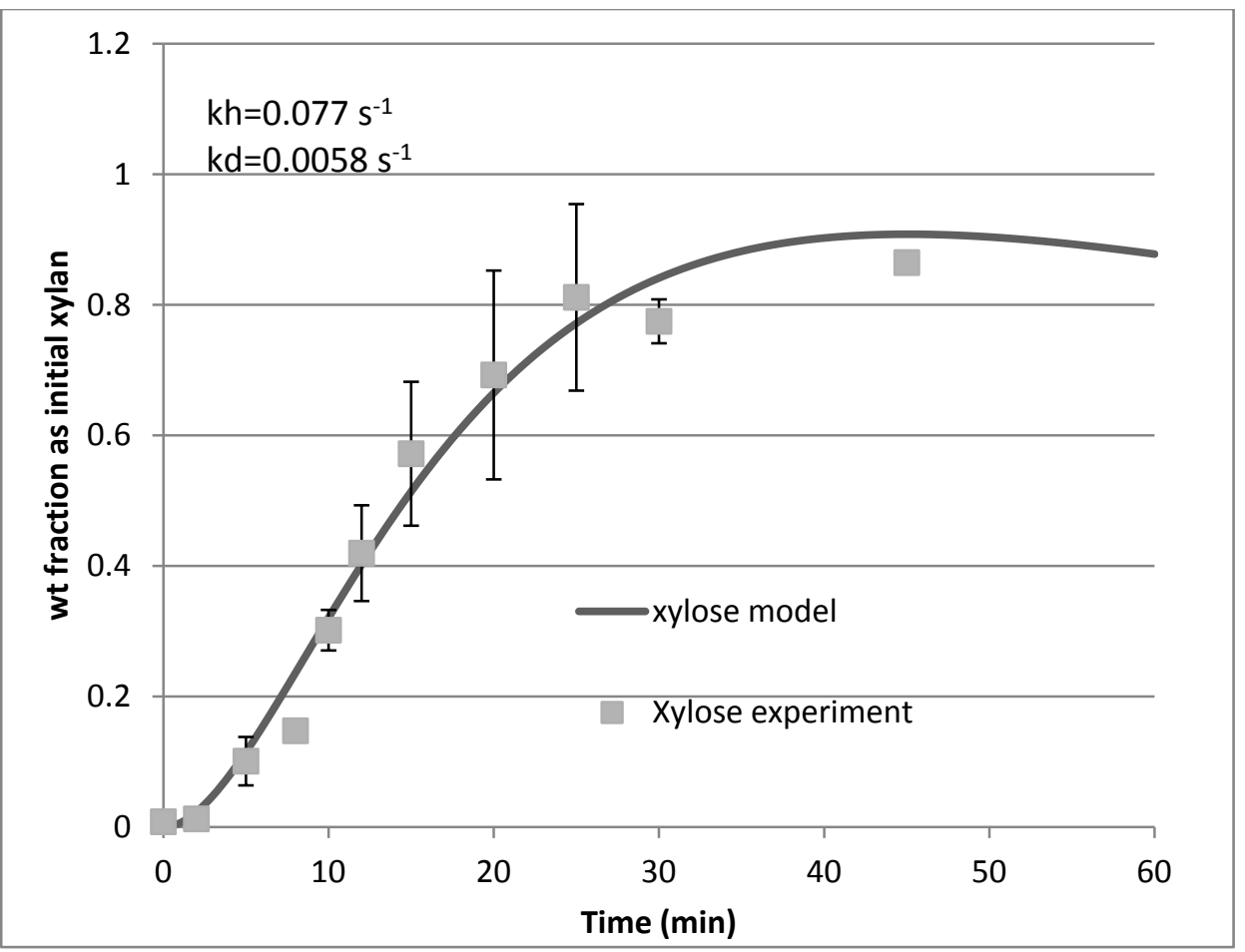

Figure 9.10: Xylose experiment data at $160^{\circ} \mathrm{C}$ and model prediction

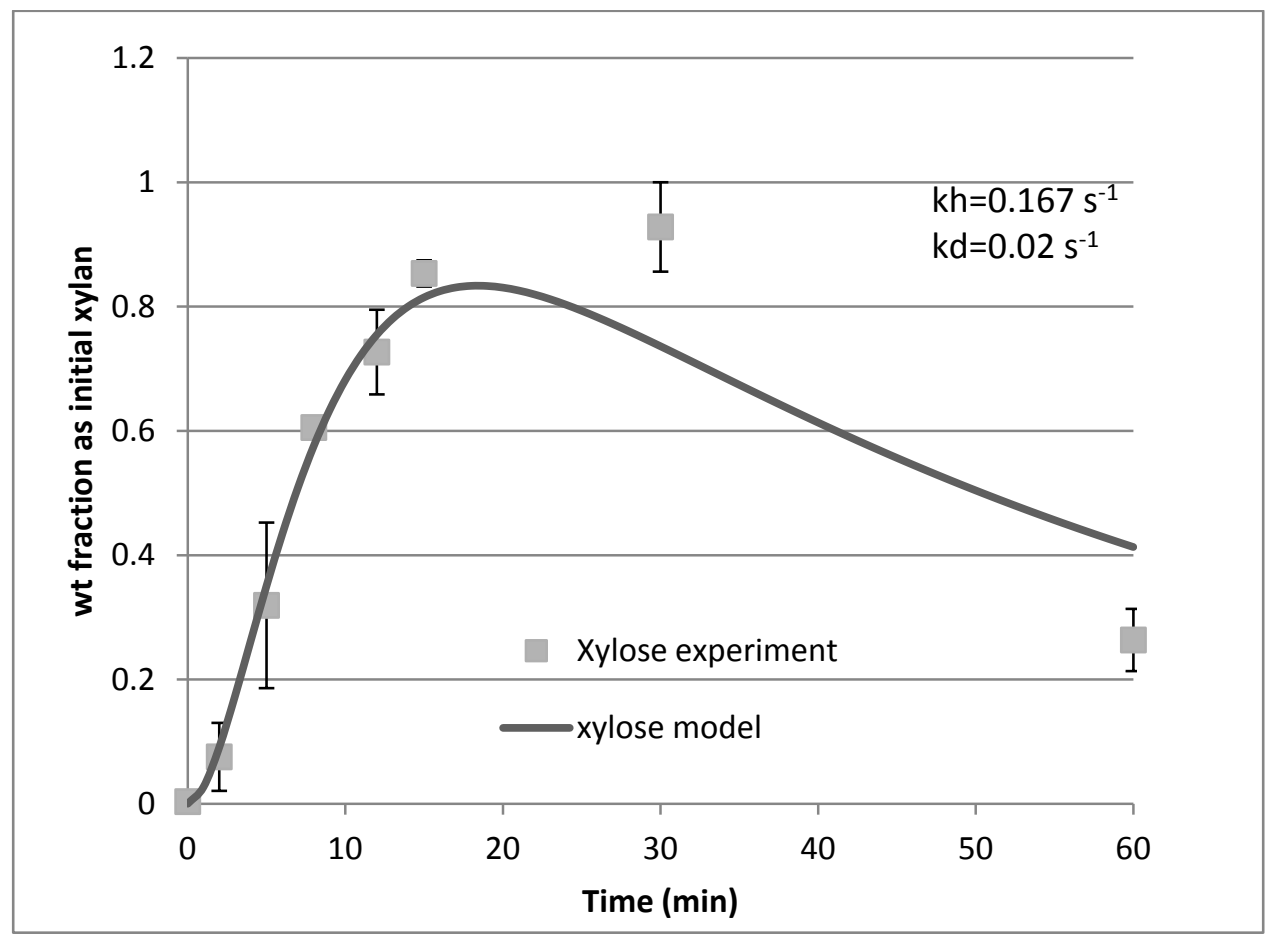

Figure 9.11: Xylose experiment data at $175^{\circ} \mathrm{C}$ and model prediction 
When $\mathrm{k}_{\mathrm{h}}$ and $\mathrm{k}_{\mathrm{d}}$ were optimized to match the xylose profiles, the model over predicts the concentrations of other xylooligomers, and over predicts the peak time. The xylobiose, xylotriose and xylotetrose profiles (wt fraction of initial xylan) for 150,160 and $175^{\circ} \mathrm{C}$ are illustrated in Figure 9.12, 9.13 and 9.14 respectively, and compared to their model predictions. At $150^{\circ} \mathrm{C}$ (Figure 9.12), there are important differences between the experimental data and predictions. The measured data shows a peak in wt fraction of each oligomer at the same time (12 minute), while the model predicts peak wt fractions of oligomers at different times. For example, the measured xylobiose peaks at 12 minutes, the peak concentration is $1.12 \mathrm{~g} / \mathrm{L}$ (approximately $0.069 \mathrm{wt}$ fraction of initial xylan). However, the model predicts xylobiose peaks at 23 minute, and predicts the peak concentration is approximately $0.316 \mathrm{wt}$ fraction of initial xylan. The model predicts xylotriose peak at $15 \mathrm{~min}$ for $0.196 \mathrm{wt}$ fraction of initial xylan, while the experiment shows that xylotriose peak at $12 \mathrm{~min}$ for $0.032 \mathrm{wt} \%$ of initial xylan. Xylotetrose is predicted to peak at $11 \mathrm{~min}$ for $0.143 \mathrm{wt}$ fraction of initial xylan, while the experiment shows that it reaches peak at $12 \mathrm{~min}$ for $0.022 \mathrm{wt}$ fraction of initial xylan. Similar trends as for the $150^{\circ} \mathrm{C}$ results are also found at 160 and $175^{\circ} \mathrm{C}$, in Figures 9.13 and 9.14. In one aspect the measured data and model predictions do agree; the time required to reach peak wt fraction for each oligomer decreases with increasing temperature. Also, at $175^{\circ} \mathrm{C}$, the data and model results show a similar trend in that higher DP oligomers peak in wt fraction at earlier times than lower DP oligomers. Based on these results, there are important similarities and differences when comparing measured wt fraction of oligomer in solution compared to predicted values. Although the model can describe the overall trend of the xylooligomers profiles, it over predicts the peak concentrations of xylooligomers. 


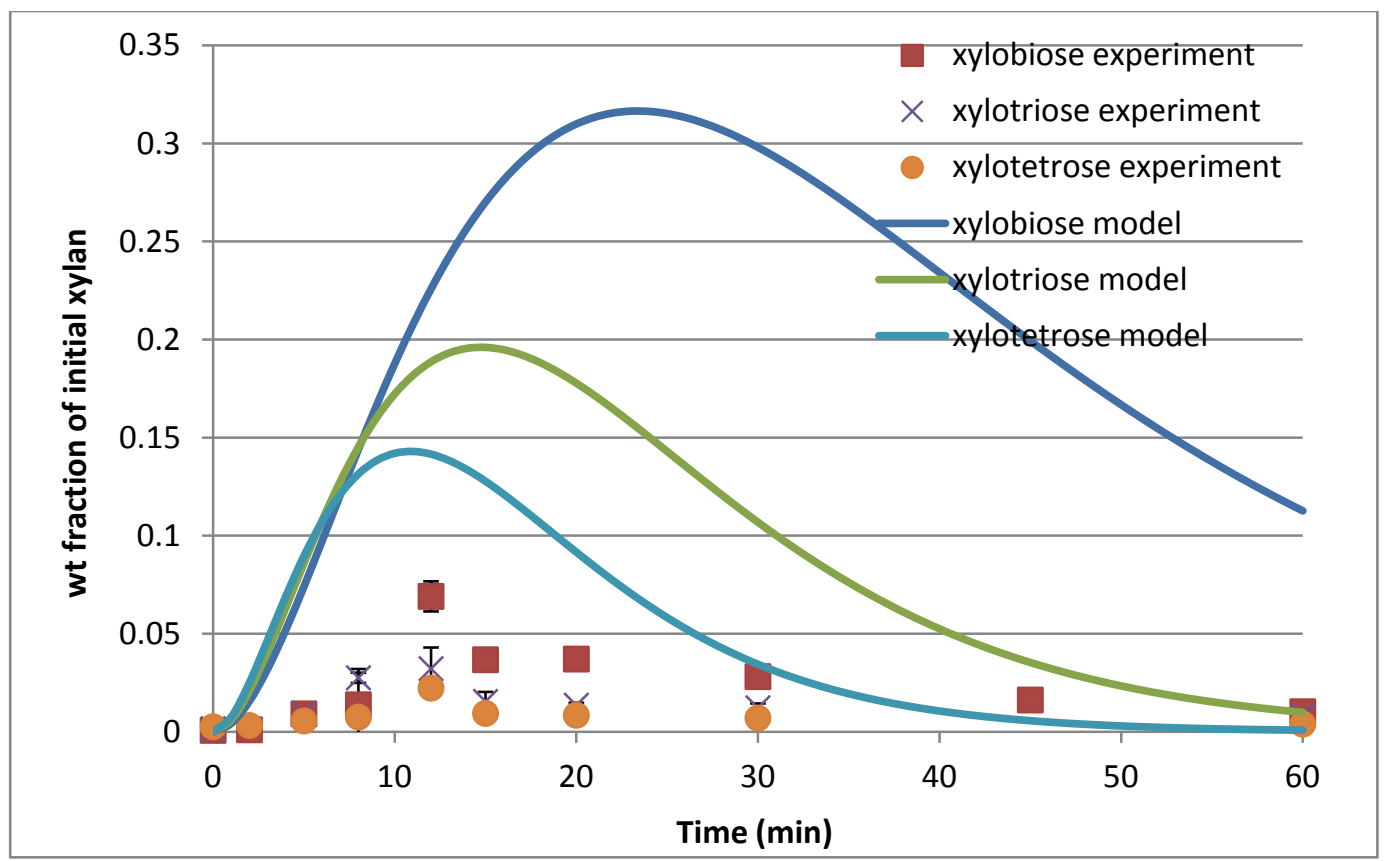

Figure 9.12: Xylobiose, xylotriose and xylotetrose concentrations at $150^{\circ} \mathrm{C}$, comparing to model predictions

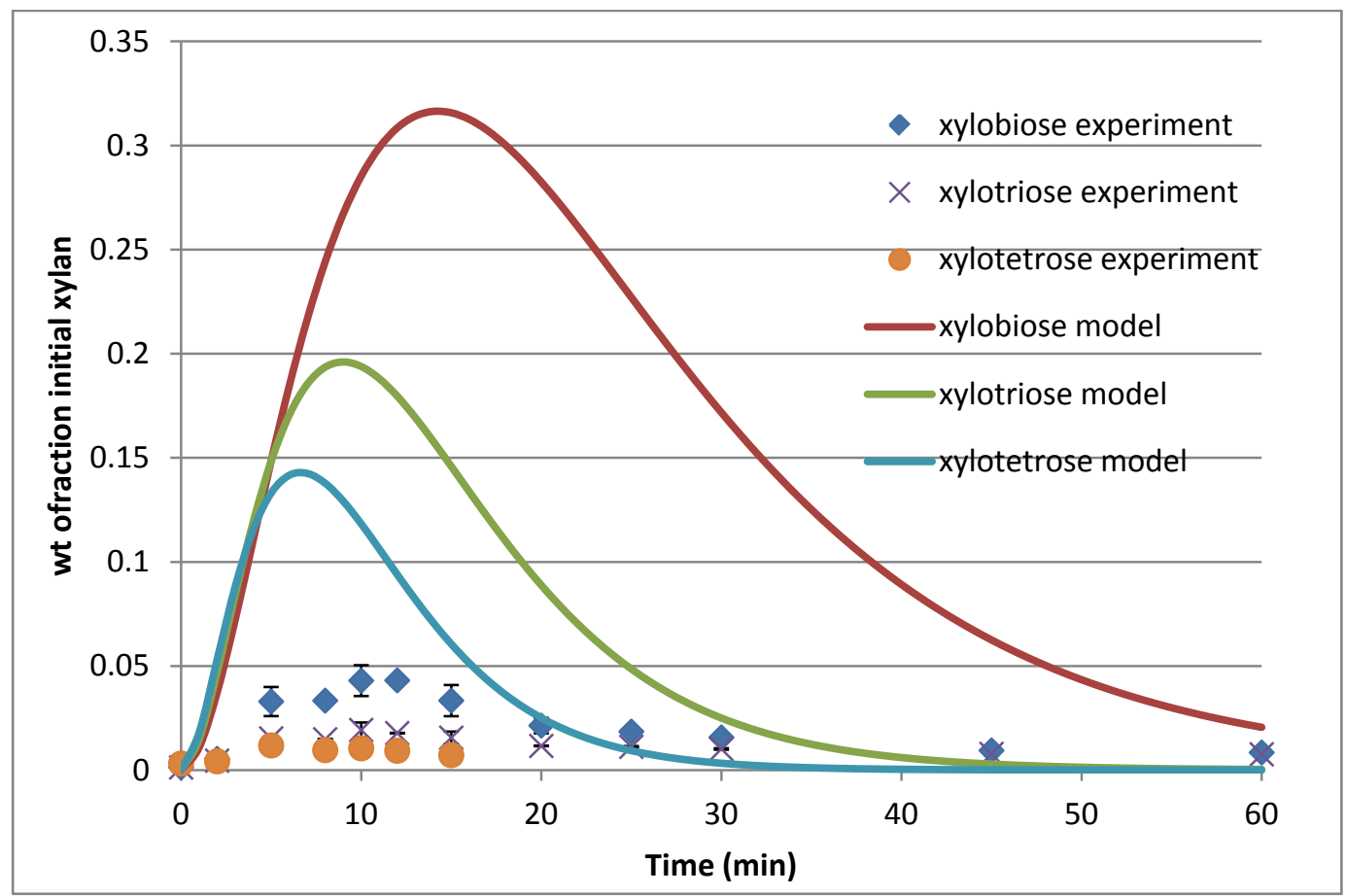

Figure 9.13: Xylobiose, xylotriose and xylotetrose concentrations at $160^{\circ} \mathrm{C}$, comparing to model predictions 


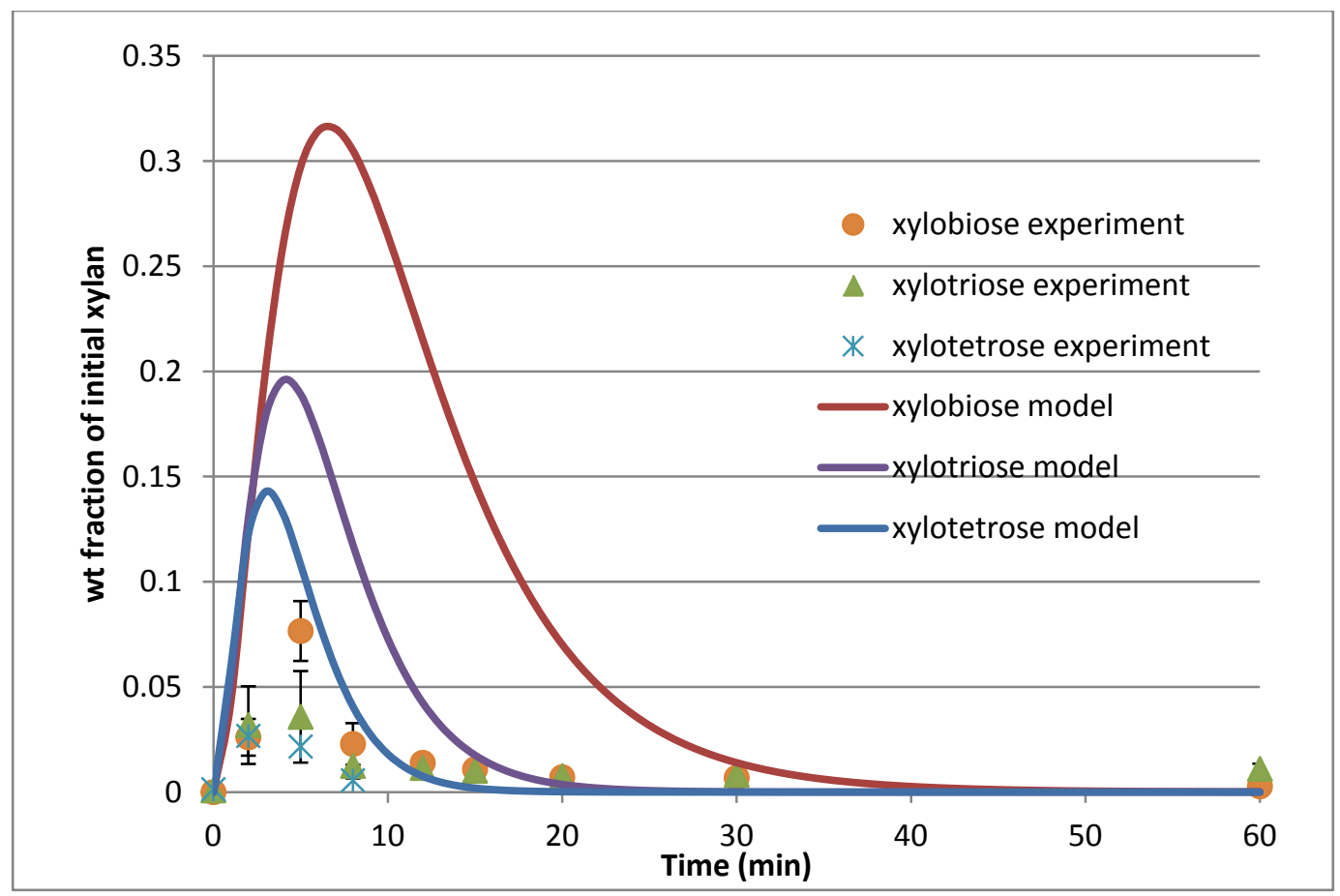

Figure 9.14: Xylobiose, xylotriose and xylotetrose concentrations at $175^{\circ} \mathrm{C}$, comparing to model predictions

Total xylooligomers concentrations measured by the NREL procedure at 150, 160 and $175^{\circ} \mathrm{C}$ are illustrated in Figure 9.15, 9.16 and 9.17 respectively, and are compared to the model prediction. There is a large difference between the experiment data and the model prediction: at $150^{\circ} \mathrm{C}$, the model predicts that total xylooligomers produced in hydrolysis reaction can reach $80 \mathrm{wt} \%$ of initial xylan, while the total oligomers calculated by the NREL procedure peak at $30 \mathrm{wt} \%$. The model over predicts the total oligomers concentration by approximately $267 \%$. The similar difference is also found at 160 and $175^{\circ} \mathrm{C}$. Lloyd and $\mathrm{Wyman}{ }^{239}$ also found a large discrepancy between the depolymerization model and the experiment data. Corn stover was hydrolyzed in their study by both water-only and dilute acid pretreatment. In the water-only hydrolysis study, the model prediction agreed well with data at early times, but xylooligomers were overpredicted at later times. There is an even larger difference between model prediction and xylooligomers data when dilute acid hydrolysis was used, a consequence of the addition of acid catalyst. 


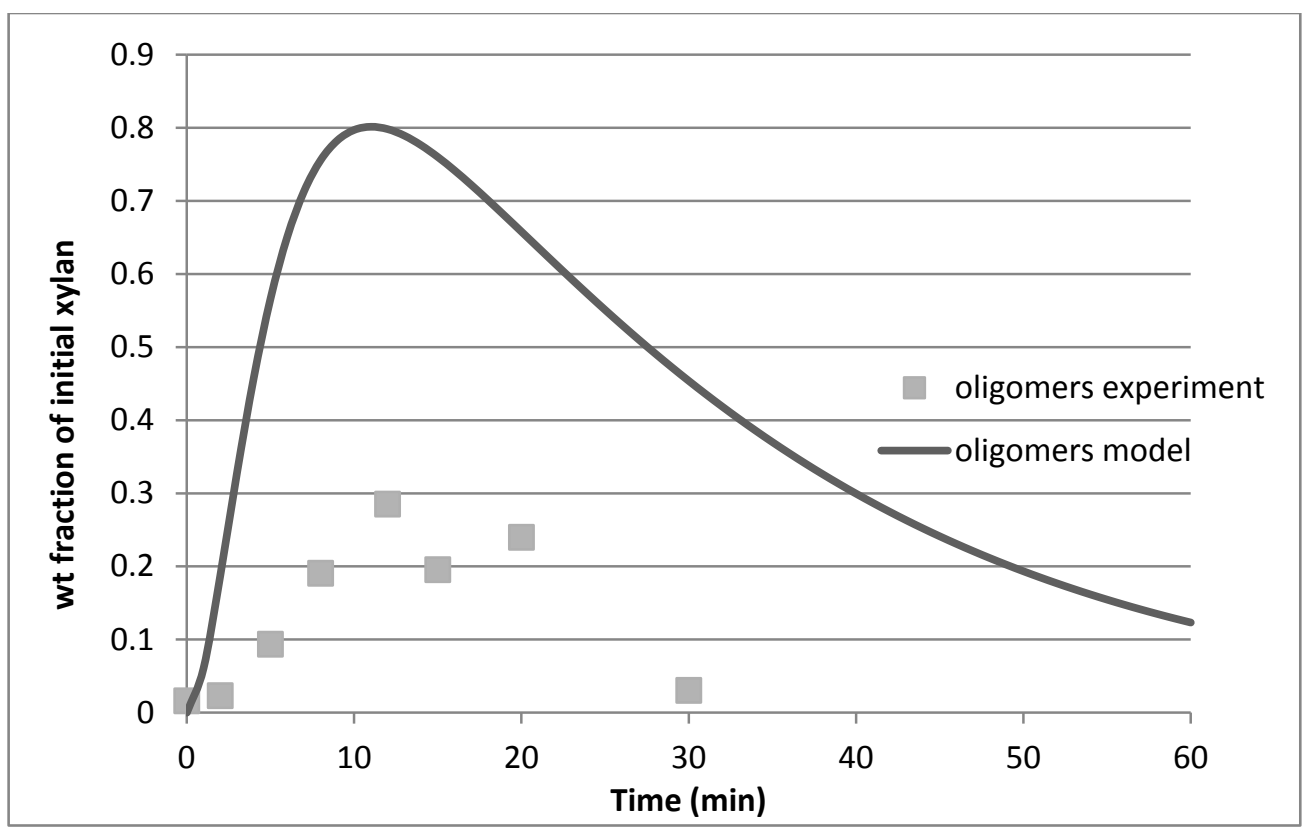

Figure 9.15: Total xylooligomers concentrations at $150^{\circ} \mathrm{C}$, comparing to model predictions

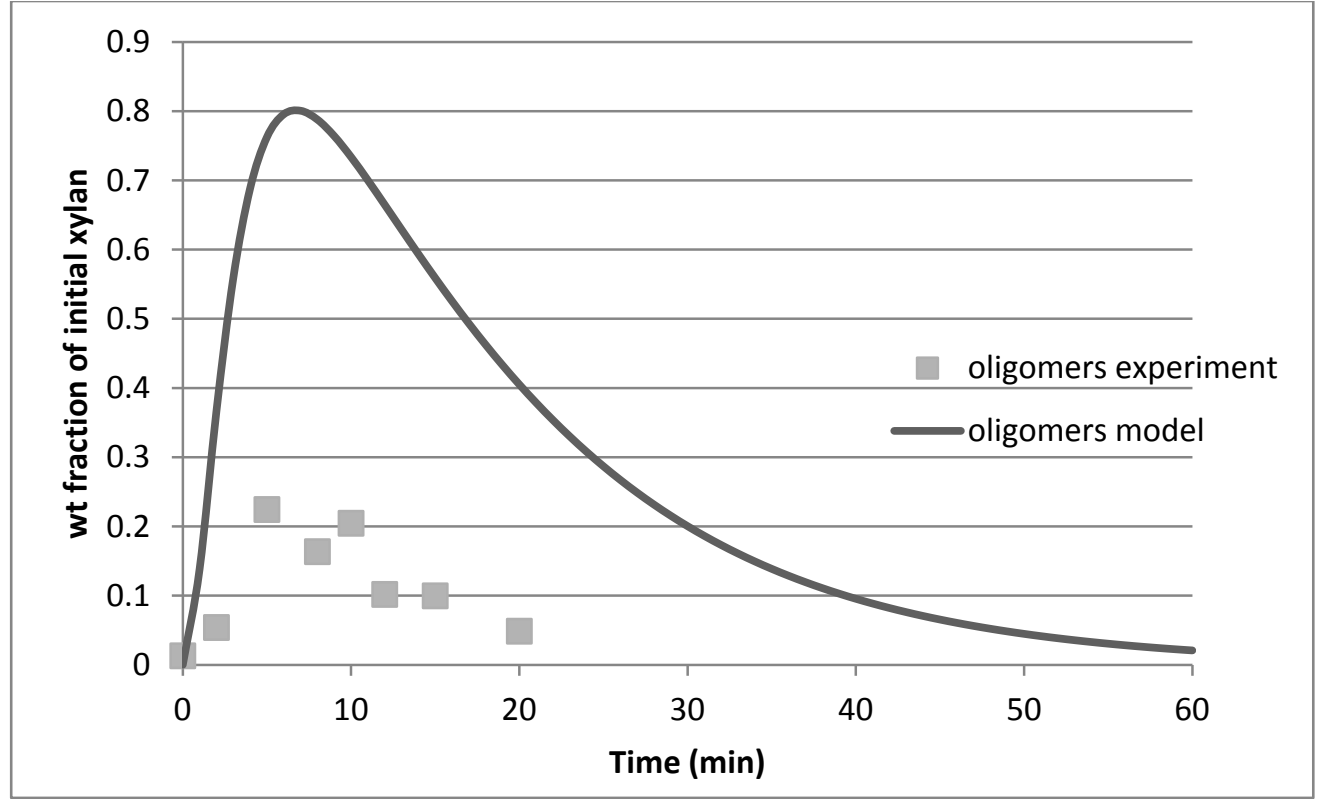

Figure 9.16: Total xylooligomers concentrations at $160^{\circ} \mathrm{C}$, comparing to model predictions 


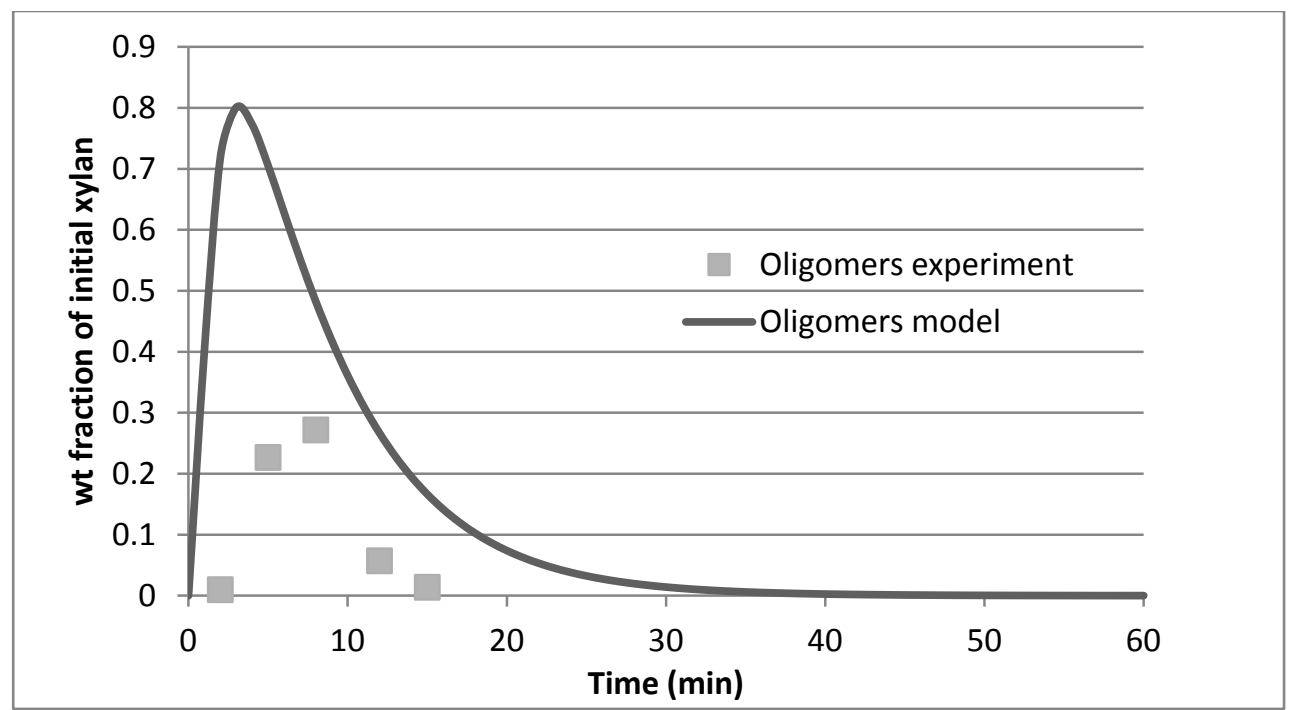

Figure 9.17: Total xylooligomers concentrations at $175^{\circ} \mathrm{C}$, comparing to model predictions

\subsection{Discussion}

Aspen is hydrolyzed in dilute acid at 150,160 and $175^{\circ} \mathrm{C}$, the concentrations of each xylooligomer (DP2-7) and xylose monomer are tracked by HPLC coupled with Hi-Plex Na column. The experiment results are used to develop the depolymerization model. The depolymerization model seems to capture the trend of xylooligomers in dilute acid concentrations. However, the experimental data are much lower than the model prediction, which is also found by Lloyd and Wyman in dilute acid hydrolysis of corn stover $^{239}$. This may results from the model itself or the experiment data. The sums of xylooligomers concentrations measured by HPLC (Figure 9.5-9.7) are lower than the total oligomers calculated by the NREL procedure (Figure 9.8). This could be an indication that the HPLC coupled with the Hi-Plex Na column is not capable of determining the concentrations of the oligomers, or there are many oligomers in the hydrolyzate whose chain length are longer than the detection limit of the Hi-Plex Na column. New equipment and experiment procedures need to be implemented to obtain more accurate measurements. A HPLC system employing Aminex-HP 42A column (BioRad) was used by $\operatorname{Kumar}^{241}$ for xylooligomers quantification (DP ranging from 2 to 5). A Dionex HPLC equipped with CarboPac PA100 anion exchange column was used by Qing 
et $\mathrm{al}^{236}$ to quantify xylooligomers over a DP range of 1 to 30 . The depolymerization model also needs to be modified to better describe the kinetic behavior of the xylooligomers. For example, xylobiose and xylotriose are found to directly degrade to degradation products ${ }^{241}$. In addition, presence of glucooligosaccharides, other pentose oligomers and even lignin could affect the hydrolysis of xylan and xylooligomers (Personal communication Wen Zhou). The depolymerization model should take these oligomer sugars and lignin into consideration, otherwise, pure xylan should be hydrolyzed to develop the kinetic model of xylooligomers hydrolysis. Finally, the assumption that all bonds react at equal rates can be modified to include differences in end bonds, also that hydrolysis rate depend on the chain length of xylooligomers. In appendix C.2 and C.3, two modifications of the model are proposed: depolymerization model with different reaction constants, and hydrolysis kinetics of each xylooligomer modified from Kumar et $\mathrm{al}^{241}$ (appendix C.4). The modified models can predict the overall trend of the xylooligomers. However, hydrolysis of each xylooligomer such as xylotriose and xylotetrose needed to be carried out to study the kinetic behavior of each xylooligomer under dilute acid conditions.

\subsection{Conclusion}

The depolymerization model can successfully predict the xylose profile under dilute acid hydrolysis. The hydrolysis reaction is faster in higher reaction temperature as indicated by the increasing hydrolysis rate $\mathrm{k}_{\mathrm{h}}$. Simultaneously, xylose is subjected to more severe degradation process, which is indicated by the increasing degradation rate $\mathrm{k}_{\mathrm{d}}$, which is confirmed by the increasing concentrations of the degradation products furfural and HMF with reaction time and with temperature. However, the model predicts much higher concentrations of xylooligomers than the experiment data, which could result from the measurements or the model itself. New equipment and experiment procedures need to be implemented to obtain more accurate measurements (as mentioned in the discussion above), and the model needs to be modified to include the direct degradation of xylobiose and xylotriose to degradation products, and differences in hydrolysis rate depending on the chain length. 


\section{Chapter 10: Future work}

All the future work proposed in former sections of this dissertation is summarized in this chapter.

\subsection{Pennycress LCA (Chapter 2)}

- Multi-year and large-scale field cultivation of pennycress in rotation with corn and soybeans is needed to confirm the iLUC assumptions.

- Field measurements of soil carbon stocks prior and after pennycress cultivation is needed to estimate dLUC (if any occurs).

- Pennycress residues need to be examined to measure the above and belowground $\mathrm{N}$ content.

- $\quad \mathrm{N}$ fertilizer credit from pennycress crop residues should be examined and included in future LCA analyses.

- Energy use of the presscake via direct combustion or fast pyrolysis can be studied to understand the environmental impact of its use for bio-power.

\section{2. dLUC of forest-based biofuel and bioenergy (Chapter 8)}

- A yield curve for aspen from field data at multiple sites needs to be compiled to predict the carbon dynamics of Michigan aspen-birch forests.

- Include all the available tree species in Michigan, namely white-red-jack pine, maple-beech-birch, spruce-fir, elm-ash-cottonwood, and oak-hickory.

- Simulate harvest by various owner groups (federal, state, industrial and nonindustrial private) as they have different harvest agendas.

- Simulate the carbon stock changes of short rotation forestry (poplar and willow) planted on abandoned agricultural land. 


\subsection{Depolymerization model (Chapter 9)}

- A Dionex HPLC equipped with CarboPac PA100 anion exchange column can measure xylooligomers up to DP 30.

- The depolymerization needs to be modified to include direct degradation of xylobiose and xylotriose.

- Effects of oligomer sugars (glucooligosaccharides, other pentose oligomers) and lignin should be taken into consideration when develop the kinetic model of hemicellulose hydrolysis.

- The model needs to be modified to include differences in hydrolysis rate depending on the chain length.

- Hydrolysis of each xylooligomer such as xylotriose and xylotetrose needed to be carried out to study the kinetic behavior of hemicellulose hydrolysis. 


\section{References}

1. U.S. Energy Information Administration. Annual Energy Review 2011.

Washington, DC: U.S. Energy Information Administration; 2012. Report nr DOE/EIA-0384(2011). 370 p.

2. Urbanchuk JM. An Economic Analysis of Legislation for a Renewable Fuels Requirement for Highway Motor Fuels. AUS Consultants; 2001.

3. Kim S, Dale BE. Life cycle assessment of various cropping systems utilized for producing biofuels: Bioethanol and biodiesel. Biomass \& Bioenergy 2005;29(6):426-439.

4. U.S Environmental Protection Agency. Regulation of Fuels and Fuel Additives: Changes to Renewable Fuel Standard Program; Final Rule. In: Agency USEP, editor. Volume EPA-HQ-OAR-2005-01612010. p 14669-15320.

5. U.S. Department of Energy. U.S. Billion-Ton Update: Biomass Supply for a Bioenergy and Bioproducts Industry. Oak Ridge, TN.: Oak Ridge National Laboratory; 2011. 227 p.

6. European parliament and of the council of the EU. DIRECTIVE 2008/101/EC of the European Parliament and of the Council of 19 November 2008 amending Directive 2003/87/EC so as to include aviation activities in the scheme for greenhouse gas emission allowance trading within the Community. In: European parliament and of the council of the EU, editor. Volume DIRECTIVE 2008/101/EC: Official Journal of the European Union; 2009.

7. ASTM certifies aviation biofuels from plant oils, animal fat [Internet]. 2011 [updated 4 July 2011, cited 12.21.2011]. Available from: http://www.flightglobal.com/news/articles/astm-certifies-aviation-biofuelsfrom-plant-oils-animal-359086/

8. Gokavi SS, Malleshi NG, Guo MR. Chemical composition of garden cress (Lepidium sativum) seeds and its fractions and use of bran as a functional ingredient. Plant Foods for Human Nutrition 2004;59(3):105-111.

9. Moser BR, Winkler-Moser JK, Shah SN, Vaughn SF. Composition and physical properties of arugula, shepherd's purse, and upland cress oils. European Journal of Lipid Science and Technology 2010;112(7):734-740.

10. Carr P. Potential of fanweed and other weeds as novel industrial oilseed crops. In: Janick J, Simon JE, editors. New Crops. New York: John Wiley \& Sons Inc; 1993. p 384-388.

11. Isbell T, Chermak S. Thlaspi arvense (Pennycress) germination, development and yield potential. Advancement of Industrial Crops Annual Meeting. Fort Collins, CO2010.

12. Phippen W, Phippen M. Evaluation of field pennycress (Thlaspi arvense L.) populations. Advancement of Industrial Crops Annual Meeting. Fort Collins, CO2010.

13. Boateng AA, Mullen CA, Goldberg NM. Producing Stable Pyrolysis Liquids from the Oil-Seed Presscakes of Mustard Family Plants: Pennycress (Thlaspi arvense L.) and Camelina (Camelina sativa). Energy \& Fuels 2010;24:6624-6632. 
14. Moser BR, Knothe G, Vaughn SF, Isbell TA. Production and Evaluation of Biodiesel from Field Pennycress (Thlaspi arvense L.) Oil. Energy \& Fuels 2009;23(8):4149-4155.

15. Daxenbichler ME, Spencer GF, Carlson DG, Rose GB, Brinker AM, Powell RG. Glucosinolate Composition of Seeds from 297 Species of Wild Plants. Phytochemistry 1991;30(8):2623-2638.

16. Vaughn SF, Palmquist DE, Duval SM, Berhow MA. Herbicidal activity of glucosinolate-containing seedmeals. Weed Science 2006;54(4):743-748.

17. Fahey JW, Zalcmann AT, Talalay P. The chemical diversity and distribution of glucosinolates and isothiocyanates among plants. Phytochemistry 2001;56(1):551.

18. Majak W, Mcdiarmid RE, Benn MH, Willms WD. Autolysis of Thlaspi-Arvense in Bovine Rumen Fluid. Phytochemistry 1991;30(1):127-129.

19. Shires A, Bell JM, Keith MO, Mcgregor DI. Rapeseed Dockage - Effects of Feeding Raw and Processed Wild Mustard and Stinkweed Seed on Growth and Feed-Utilization of Mice. Canadian Journal of Animal Science 1982;62(1):275285.

20. Ullrich I, Jahn-Deesbach W. Proteingehalt und proteinzusammensetzung verschiedener unkrautarten. Angew Bot 1984(58):255-266.

21. Moyer JR, Hironaka R. Digestible Energy and Protein-Content of Some Annual Weeds, Alfalfa, Bromegrass, and Tame Oats. Canadian Journal of Plant Science 1993;73(4):1305-1308.

22. Ampong-Nyarko K. Pennycress Product Development \& Preliminary Business Case. Peace Region Economic Development Alliance; 2010.

23. Moser BR, Vaughn SF. Evaluation of alkyl esters from Camelina sativa oil as biodiesel and as blend components in ultra low-sulfur diesel fuel. Bioresource Technology 2010;101(2):646-653.

24. Berchmans HJ, Hirata S. Biodiesel production from crude Jatropha curcas L. seed oil with a high content of free fatty acids. Bioresource Technology 2008;99(6):1716-1721.

25. Evangelista RL, Isbell TA, Cermak SC. Extraction of pennycress (Thlaspi arvense L.) seed oil by full pressing. Industrial Crops and Products 2012;37(1):76-81.

26. Creating A Pennycress Bioenergy Business [Internet]. 2011 [updated cited 01.17]. Available from: http://www.reeis.usda.gov/web/crisprojectpages/226419.html

27. Kezerle JA. Assessing the Value of a New, Dedicated Energy Crop: A TechnoEconomic Assessment of Pennycress Utilization. ALION Science and Technology; 2011.

28. USDA Plant Hardiness Zone Map [Internet]. United States Department of Agriculture. 2012 [updated cited Sep 15]. Available

from: http://planthardiness.ars.usda.gov/PHZMWeb/

29. Phippen WB, Phippen ME. Soybean Seed Yield and Quality as a Response to Field Pennycress Residue. Crop Science 2012;52(6):2767-2773. 
30. UOP/Eni Ecofining ${ }^{\text {TM }}$ Process for Green Diesel Production [Internet]. 2011 [updated cited 12/11]. Available from: http://www.uop.com/hydroprocessingecofining/

31. Kalnes T, Marker T, Shonnard DR. Green diesel: A second generation biofuel. International Journal of Chemical Reactor Engineering 2007;5.

32. Holmgren J, Gosling C, Marker T, P K, Faraci G, Perego C. Green Diesel Production from Vegetable Oil. AICHE Houston TX2007.

33. Kalnes TN, McCall MM, Shonnard DR. Renewable Diesel and Jet-Fuel Production from Fats and Oils. In: Crocker M, editor. Thermochemical conversion of biomass to liquid fuels and chemicals. Cambridge: RSC Publishing; 2010. p xxi, 532 p.

34. Kinder JD, Rahmes T. Evaluation of Bio-Derived Synthetic Paraffinic Kerosenes. Seattle: The Boeing Company; 2009 June 2009.

35. Energy provides alternative fuel for Thunderbirds performance [Internet]. DLA Defense Logistics Agency 2011 [updated 05/27/2011, cited 12/11]. Available from: http://www.dla.mil/DLA_Media_Center/Pages/newsarticle1061.aspx

36. ASTM. D7566-11a Standard Specification for Aviation Turbine Fuel Containing Synthesized Hydrocarbons. Volume ASTM D7566-11a ASTM International 2011. p 22.

37. Low Carbon Vehicle Partnership. Annex A2: Test Procedure for Measuring Fuel Economy and Emissions of Low Carbon Emission Buses Powered by Charge Sustaining Hybrid Powertrains. . Volume Annex A22011. p 29.

38. Stratton RW. Life cycle assessment of greenhouse gas emissions and non$\mathrm{CO} \backslash 2082$ combustion effects from alternative jet fuels [S m]: Massachusetts Institute of Technology; 2010. 144 p. p.

39. Huo H, Wang M, Bloyd C, Putsche V. Life-Cycle Assessment of Energy Use and Greenhouse Gas Emissions of Soybean-Derived Biodiesel and Renewable Fuels. Environmental Science \& Technology 2009;43(3):750-756.

40. Agusdinata DB, Zhao F, Ileleji K, DeLaurentis D. Life Cycle Assessment of Potential Biojet Fuel Production in the United States. Environmental Science \& Technology 2011;45(21):9133-9143.

41. PRé. SimaPro 7.2 2011.

42. ecoinvent Centre. Ecoinvent V2 database. St-Gallen Switzerland2011.

43. U.S. Energy Information Administration. Impacts of a 10-Percent Renewable Portfolio Standard. EIA service report SR/OIAF/2002-03. Washington, DC:

Energy Information Administration, Office of Integrated Analysis and Forecasting, U. S. Dept. of Energy; 2002.

44. Frischknecht R, Jungbluth N, Althaus H-J, Bauer C, Doka G, Dones R, Hischier R, Hellweg S, Humbert S, Köllner T and others. Implementation of Life Cycle Impact Assessment Methods. ecoinvent report No. 3, v2.0. Dübendorf: Swiss Centre for Life Cycle Inventories; 2007. Report nr ecoinvent report No. 3, v2.0. $151 \mathrm{p}$.

45. Gerdes K, Skone TJ. Development of Baseline Data and Analysis of Life Cycle Greenhouse Gas Emissions of Petroleum-Based Fuels. National Energy 
Technology Laboratory; 2009 November 26, 2008. Report nr DOE/NETL2009/1346. 310 p.

46. De Klein C, Novoam R, Ogle S, Smith KA, Rochette P, Wirth TC, McConkey BG, Mosier A, Rypdal K, Walsh M and others. N2O emissions from managed soils, and $\mathrm{CO} 2$ emissions from lime and urea application. Volume Volume 4, IPCC guidelines for national greenhouse gas inventories Volume 4, Agriculture, Forestry, and Other Land Use: Intergovernmental Panel for Climate Change (IPCC); 2006.

47. U.S. Environmental Protection Agency. Year 2009 State Resource Mix. eGRID2012 Version 1.0 Year 2009 Summary Tables: The Emissions \& Generation Resource Integrated Database (eGRID); 2012. p 13.

48. Spath PL, Mann MK. Life Cycle Assessment of Hydrogen Production via Ntural Gas Steam Reforming. Golden, Colo.: National Renewable Energy Laboratory; 2001.

49. Internal Revenue Service (IRS). Approvaed Fuel Terminals @12/31/2011. 2011.

50. ISO. Environmental management-Life cycle assessment-Goal and scope definition and inventory analysis. ISO 14041:1998(E). Volume ISO 14041:1998(E): International Organization for Standardization; 1998.

51. U.S Environmental Protection Agency. Regulatory Impact Analysis: Renewable Fuel Standard Program Chapter 6, Life cycle Impacts on Fossil Energy and Greenhouse Gases. (EPA) EPA, editor2007.

52. Pradhan A, Shrestha DS, McAloon A, Yee W, Haas M, Duffield JA, H. S. Energy Life-Cycle Assessment of Soybean Biodiesel. Washington DC: USDA; 2009. Report nr 845.

53. Sheehan J, Camobreco V, Duffield J, Graboski M, Shapouri H. Life cycle inventory of biodiesel and petroleum diesel for use in an urban bus : final report, May 1998. Golden, Colo.: National Renewable Energy Laboratory; 1998. p xxiv, $286 \mathrm{p}$.

54. European parliament and of the council of the EU. DIRECTIVE 2009/28/EC OF THE EUROPEAN PARLIAMENT AND OF THE COUNCIL of 23 April 2009 on the promotion of the use of energy from renewable sources and amending and subsequently repealing Directives 2001/77/EC and 2003/30/EC. In: European parliament and of the council of the European Union, editor. Volume Directive 2009/28/EC Official Journal of the European Union; 2009.

55. Wang M. GREET1_2011 transportation fuel-cycle model. GREET1_20112011.

56. Gasoline/Naphtha/MTBE (US Gulf) [Internet]. 2011 [updated cited 08/12]. Available from: http://www.icispricing.com/il shared/Samples/SubPage248.asp

57. California Environmental Protection Agency Air Resources Board. Proposed Regulation to Implement the Low Carbon Fuel Standard. In: California Environmental Protection Agency Air Resources Board, editor: California Air Resources Board. 2009.

58. The Nature of Gums and Phosphatides [Internet]. 2011 [updated 02.20.2011, cited 02.02]. Available from: http://lipidlibrary.aocs.org/processing/degumintro/index.htm 
59. Lin L, Rhee KC, Koseoglu SS. Bench-scale membrane degumming of crude vegetable oil: Process optimization. Journal of Membrane Science 1997;134(1):101-108.

60. Malça J, Freire F. A comparative assessment of rapeseed oil and biodiesel (RME) to replace petroleum diesel use in transportation. Bioenergy-I: From Concept to Commercial Processes. Tomar, Portugal. 2006.

61. Biodiesel Performance, Costs, and Use [Internet]. Energy Information Administration. 2004 [updated 06/08/2004, cited 12/11]. Available from: http://www.eia.gov/oiaf/analysispaper/biodiesel/

62. USDA. Jatropha curcas L. National Germplasm Resources Laboratory. Germplasm Resources Information Network (GRIN); 2007.

63. Ndong R, Montrejaud-Vignoles M, Saint Girons O, Gabrielle B, Pirot R, Domergue M, Sablayrolles C. Life cycle assessment of biofuels from Jatropha curcas in West Africa: a field study. Global Change Biology Bioenergy 2009;1(3):197-210.

64. Bailis RE, Bake JE. Greenhouse Gas Emissions and Land Use Change from Jatropha Curcas-Based Jet Fuel in Brazil. Environmental Science \& Technology 2010;44(22):8684-8691.

65. Agarwal D, Agarwal AK. Performance and emissions characteristics of Jatropha oil (preheated and blends) in a direct injection compression ignition engine. Applied Thermal Engineering 2007;27(13):2314-2323.

66. Achten WMJ, Verchot L, Franken YJ, Mathijs E, Singh VP, Aerts R, Muys B. Jatropha bio-diesel production and use. Biomass \& Bioenergy 2008;32(12):10631084.

67. Becker K, Francis G. Bio-diesel from Jatropha plantations on degraded land. Stuttgrart: University of Hohenheim; 2002.

68. van der Putten E, Franken YJ, Nielsen F, de Jongh J, Rijsenbeek W, Beerens P, van Eijck J, Galema T, Groeneveld G, Ansø N and others. Jatropha Handbook: From Cultivation to Applications. In: de Jongh J, editor: FACT Foundation; 2009.

69. Achten WMJ, Mathijs E, Verchot L, Singh VP, Aerts R, Muys B. Jatropha biodiesel fueling sustainability? Biofuels Bioproducts \& Biorefining-Biofpr 2007;1(4):283-291.

70. Achten WMJ. Sustainablity evaluation of biodiesel from Jatropha curcas L. - A life cycle oriented study. Leuven, Belgium: Katholieke Universiteit Leuven; 2010.

71. Weyerhaeuser H, Tennigkeit T, Yufang S, Kahrl F. Biofuels in China: An Analysis of the Opportunities and Challenges of Jatropha Curcas in Southwest China. World Agroforestry Centre; 2007. Report nr ICRAF Working Paper Number $53.27 \mathrm{p}$.

72. Grimm C, Maes J. Arthropod fauna associated with Jatropha curcas L. in Nicaragua: a synopsis of species, their biology and pest status. In: Gübitz G, Mittelbach M, Trabi M, editors1997; Managua p31-39.

73. Whitaker M, Heath GA, National Renewable Energy Laboratory (U.S.). Life cycle assessment of the use of Jatropha biodiesel in Indian locomotives. Technical 
report NREL/TP-6A2-44428. Rev. Mar. 2009. ed. Golden, Colo.: National Renewable Energy Laboratory; 2009.

74. Gubitz GM, Mittelbach M, Trabi M. Exploitation of the tropical oil seed plant Jatropha curcas L. Bioresource Technology 1999;67(1):73-82.

75. EIA. International Energy Statistics U.S Energy Information Adminstration; 2012.

76. Macintosh A, Wallace L. International aviation emissions to 2025: Can emissions be stabilised without restricting demand? Energy Policy 2009;37(1):264-273.

77. Skone TJ, Gerdes K. Development of Baseline Data and Analysis of Life Cycle Greenhouse Gas Emissions of Petroleum-Based Fuels. National Energy Technology Laboratory; 2008 November 26, 2008. Report nr DOE/NETL2009/1346. 310 p.

78. U.S. Federal Aviation Administration. FAA Aerospace Forecast, Fiscal Years 2011-2031. Federal Aviation Administration; 2011. 106 p.

79. Bisignani G. Annual Report 2011 International Air Transport Association. International Air Transport Association; 2011 June 2011. 56 p.

80. Penner JE, Lister D, Griggs DJ, Dokken DJ, McFarland M. Aviation and the Global Atmosphere: A Special Report of the Intergovernmental Panel on Climate Change. Change IPoC, editor: Cambridge University Press; 1999.

81. Bisignani G. A global approach to reducing aviation emissions, First stop: carbonneutral growth from 2020. The International Air Transport Association; 2009. 8 p.

82. Simas RC, Catharino RR, Cunha IBS, Cabral EC, Barrera-Arellano D, Eberlin MN, Alberici RM. Instantaneous characterization of vegetable oils via TAG and FFA profiles by easy ambient sonic-spray ionization mass spectrometry. Analyst 2010;135(4):738-744.

83. Kalnes T, Shonnard D, Koers K. Life Cycle Analysis of Bio-renewable Jet Fuel An Assessment of Inputs, Study Assumptions and Feedstock Type. 2008 Pacific Rim Summit on Industrial Biotechnology and Bioenergy. Vancouver, BC, Canada2008. p 21.

84. Spath PL, Mann MK, National Renewable Energy Laboratory (U.S.). Life Cycle Assessment of Hydrogen Production via Natural Gas Steam Reforming. Golden, Co: National Renewable Energy Laboratory; 2001.

85. Stratton RW, Wong HM, Hileman JI. Life cycle greenhouse gas emissions from alternative jet fuels. Cambridge, MA: Massachusetts Institute of Technology; 2010. Report nr PARTNER-COE 2010-001. 153 p. p.

86. Wang M. GREET1_2012 transportation fuel-cycle model. GREET1_20122012.

87. (S\&T)2 Consultants Inc. GHGenius 4.01: Natural Resources Canada 2004.

88. U.S. Environmental Protection Agency. Regulation of Fuels and Fuel Additives: Identification of Additional Qualifying Renewable Fuel Pathways Under the Renewable Fuel Standard Program. In: (EPA) EPA, editor. Volume EPA-HQOAR-2011-05422011.

89. Cherubini F, Bird ND, Cowie A, Jungmeier G, Schlamadinger B, Woess-Gallasch S. Energy- and greenhouse gas-based LCA of biofuel and bioenergy systems: Key 
issues, ranges and recommendations. Resources Conservation and Recycling 2009;53(8):434-447.

90. von Blottnitz H, Curran MA. A review of assessments conducted on bio-ethanol as a transportation fuel from a net energy, greenhouse gas, and environmental life cycle perspective. Journal of Cleaner Production 2007;15(7):607-619.

91. Ecoinvent. Ecoinvent V3. St. Gallen: ecoinvent Centre; 2011.

92. The GREET model [Internet]. Argonne National Laboratory. 2010 [updated Sep 3 2010, cited Sep 17th]. Available from: http://greet.es.anl.gov/

93. Bauen A, Vuille F, Watson P, Vad K. The RSB GHG accounting scheme: Feasibility of a metamethodology and way forward. Lausanne, Switzerland: Roundtable on Sustainable Biofuels 2009 Oct 8th. 91 p.

94. Searchinger T, Heimlich R, Houghton RA, Dong FX, Elobeid A, Fabiosa J, Tokgoz S, Hayes D, Yu TH. Use of US croplands for biofuels increases greenhouse gases through emissions from land-use change. Science 2008;319(5867):1238-1240.

95. Fargione J, Hill J, Tilman D, Polasky S, Hawthorne P. Land clearing and the biofuel carbon debt. Science 2008;319(5867):1235-1238.

96. Kim H, Kim S, Dale BE. Biofuels, Land Use Change, and Greenhouse Gas Emissions: Some Unexplored Variables. Environmental Science \& Technology 2009;43(3):961-967.

97. Bailis RE, Baka JE. Greenhouse Gas Emissions and Land Use Change from Jatropha Curcas-Based Jet Fuel in Brazil. Environmental Science \& Technology 2010;44(22):8684-8691.

98. Huo H, Wang M, Bloyd C, Putsche V. Life-Cycle Assessment of Energy and Greenhouse Gas Effects of Soybean-Derived Biodiesel and Renewable Fuels. Argonne National Laboratory; 2008 March 12, 2008. Report nr ANL/ESD/08-2. $101 \mathrm{p}$.

99. Kurki A, Hill A, Morris M, Lowe A. Biodiesel: The Sustainability Dimensions. ATTRA (National Sustainable Agriculture Information Service); 2010.

100. Budin JT, Breene WM, Putnam DH. Some Compositional Properties of Camelina (Camelina-Sativa L Crantz) Seeds and Oils. Journal of the American Oil Chemists Society 1995;72(3):309-315.

101. Putnam DH, Budin JT, Field LA, Breene WM. Camelina: a promising low input oilseed. In: Janick J, Simon J, editors. New Crops. New York: John Wiley \& Sons; 1993. p 314-322.

102. Shonnard DR, Williams L, Kalnes TN. Camelina-Derived Jet Fuel and Diesel: Sustainable Advanced Biofuels. Environmental Progress \& Sustainable Energy 2010;29(3):382-392.

103. U.S. Environmental Protection Agency. Renewable fuel standard program (RFS2) regulatory impact analysis. Ann Arbor, MI: Assessment and Standards Division, Office of Transportation and Air Quality, U.S. Environmental Protection Agency; 2010 . 
104. Schmidt JH. Life assessment of rapeseed oil and palm oil. Ph.D. thesis, Part 3:

Life cycle inventory of rapeseed oil and palm oil: Aalborg University; 2007. 276 p. p.

105. Rashid U, Anwar F. Production of biodiesel through optimized alkaline-catalyzed transesterification of rapeseed oil. Fuel 2008;87(3):265-273.

106. Bell JM. Nutrients and Toxicants in Rapeseed Meal - a Review. Journal of Animal Science 1984;58(4):996-1010.

107. U.S. Environmental Protection Agency. Notice of Supplemental Determination for Renewable Fuels Produced Under the Final RFS2 Program From Canola Oil. In: (EPA) EPA, editor. Volume EPA-HQ-OAR-2010-01332010. p 5.

108. California Environmental Protection Agency Air Resources Board. Detailed California-modified GREET Pathway for Conversion of North American Canola to Biodiesel (Fatty Acid Methyl Esters-FAME). In: California Environmental Protection Agency Air Resources Board, editor: California Environmental Protection Agency Air Resources Board,; 2010. p 67.

109. Karaosmanoglu F, Tetik E, Gurboy B, Sanli I. Characterization of the straw stalk of the rapeseed plant as a biomass energy source. Energy Sources 1999;21(9):801-810.

110. Electric Power and Renewable Energy in California [Internet]. Energy Efficiency \& Renewable Energy[updated June 25, 2008 cited Oct 12]. Available from: http://apps1.eere.energy.gov/states/electricity.cfm/state=CA

111. Lam MK, Lee KT, Mohamed AR. Life cycle assessment for the production of biodiesel: A case study in Malaysia for palm oil versus jatropha oil. Biofuels Bioproducts \& Biorefining-Biofpr 2009;3(6):601-612.

112. Lam MK, Tan KT, Lee KT, Mohamed AR. Malaysian palm oil: Surviving the food versus fuel dispute for a sustainable future. Renewable \& Sustainable Energy Reviews 2009;13(6-7):1456-1464.

113. U.S. Environmental Protection Agency. Notice of Data Availability Concerning Renewable Fuels Produced from Palm Oil under the RFS Program. Environmental Protection Agency (EPA); 2011 12/14/2011. Report nr EPA-HQOAR-2011-0542.

114. Vaughn SF, Isbell TA, Weisleder D, Berhow MA. Biofumigant compounds released by field pennycress (Thlaspi arvense) seedmeal. Journal of Chemical Ecology 2005;31(1):167-177.

115. Moser BR, Shah SN, Winkler-Moser JK, Vaughn SF, Evangelista RL. Composition and physical properties of cress (Lepidium sativum L.) and field pennycress (Thlaspi arvense L.) oils. Industrial Crops and Products 2009;30(2):199-205.

116. Phippen WB, John B, Phippen ME. Planting date, herbicide, and soybean rotation studies with field pennycress (Thlaspi arvense L.). 2010 September 19-22; Fort Collins, CO.

117. Fan J, Shonnard DR, Kalnes TN, Johnsen PB, Rao S. A life cycle assessment of pennycress (Thlaspi arvense L.) -derived jet fuel and diesel. Biomass and 
Bioenergy. Available online 26 February 2013

http://dx.doi.org/10.1016/j.biombioe.2012.12.040.

118. Chisti Y. Biodiesel from microalgae. Biotechnology Advances 2007;25(3):294306.

119. Scott SA, Davey MP, Dennis JS, Horst I, Howe CJ, Lea-Smith DJ, Smith AG. Biodiesel from algae: challenges and prospects. Current Opinion in Biotechnology 2010;21(3):277-286.

120. ANL, NREL, PNNL. Renewable Diesel from Algal Lipids: An Integrated Baseline for Cost, Emissions, and Resource Potential from a Harmonized Model. Argonne, IL: Argonne National Laboratory; Golden, CO: National Renewable Energy Laboratory; Richland, WA: Pacific Northwest National Laboratory.; 2012 June 2012. Report nr ANL/ESD/12-4 NREL/TP-5100-55431 PNNL-21437. 85 p.

121. Frank ED, Han J, Palou-Rivera I, Elgowainy A, Wang MQ. Life-Cycle Analysis of Algal Lipid Fuels with the GREET model. Argonne National Laboratory; 2011. Report nr ANL/ESD/11-5. $99 \mathrm{p}$.

122. Auvermann B, Kalbasi A, Ahmed A. Rendering. Carcass disposal: A comprehensive review. Manhattan, KS National Agricultural Biosecurity Center, Kansas State University; 2004. p 82.

123. California Environmental Protection Agency Air Resources Board. Detailed California-Modified GREET Pathway for Renewable Diesel Produced in California from Tallow (U. S. Sourced). In: California Environmental Protection Agency Air Resources Board, editor: California Environmental Protection Agency Air Resources Board,; 2009. p 30.

124. Mueller S, Copenhaver K. An Analysis of Modern Corn Ethanol Technologies. Chicago: University of Illinois at Chicago; 2009 Feb 16, 2009. 33 p.

125. Chowdhury H, Ingram W. California-Modified GREET Pathway for the Production of Biodiesel from Corn Oil at Dry Mill Ethanol Plants. California Air Resources Board,; 2011 Nov 3, 2011. 42 p.

126. US Environmental Protection Agency. Robust Summary of Information on Heavy Fuel Oils. US Environmental Protection Agency; 2004 June 15. Report nr 20115368B. 114 p.

127. Adjusted Distillate Fuel Oil and Kerosene Sales by End Use [Internet]. US Energy Information Adminstration. 2012 [updated 11/30, cited 12/10]. Available from: http://www.eia.gov/dnav/pet/pet_cons_821usea dcu_nus_a.htm

128. Hekkert MP, Hendriks FHJF, Faaij APC, Neelis ML. Natural gas as an alternative to crude oil in automotive fuel chains well-to-wheel analysis and transition strategy development. Energy Policy 2005;33(5):579-594.

129. U.S. Environmental Protection Agency. Inventory of U.S. greenhouse gas emissions and sinks: 1990 - 2010. Washington, DC: U.S. Environmental Protection Agency; 2012 APRIL 15. Report nr EPA 430-R-12-001.

130. U.S. Environmental Protection Agency. Chapter 1: External Combustion Sources 1.3 Fuel Oil Combustion. Compilation of Air Pollutant Emission Factors 5ed. Volume I. Washington DC: U.S. Environmental Protection Agency; 1995. 
131. Czernik S, Bridgwater AV. Overview of applications of biomass fast pyrolysis oil. Energy \& Fuels 2004;18(2):590-598.

132. ASTM International. ASTM D7544 Standard Specification for Pyrolysis Liquid Biofuel. Volume ASTM D7544-12: ASTM International; 2012.

133. Chiaramonti D, Oasmaa A, Solantausta Y. Power generation using fast pyrolysis liquids from biomass. Renewable \& Sustainable Energy Reviews 2007;11(6):1056-1086.

134. Fan JQ, Kalnes TN, Alward M, Klinger J, Sadehvandi A, Shonnard DR. Life cycle assessment of electricity generation using fast pyrolysis bio-oil. Renewable Energy 2011;36(2):632-641.

135. Bridgwater AV, Meier D, Radlein D. An overview of fast pyrolysis of biomass. Organic Geochemistry 1999;30(12):1479-1493.

136. Bridgwater AV. Production of high grade fuels and chemicals from catalytic pyrolysis of biomass. Catalysis Today 1996;29(1-4):285-295.

137. Venderbosch RH, Ardiyanti AR, Wildschut J, Oasmaa A, Heeresb HJ. Stabilization of biomass-derived pyrolysis oils. Journal of Chemical Technology and Biotechnology 2010;85(5):674-686.

138. Zhang Q, Chang J, Wang TJ, Xu Y. Review of biomass pyrolysis oil properties and upgrading research. Energy Conversion and Management 2007;48(1):87-92.

139. Kalnes T. GHG Impact of Using Fast Pyrolysis Oil for Electricity and Biofuel Generation. CO2 Summit: Technology \& Opportunity. Vail, Colorado2010. p 24.

140. Goedkoop M, Spriensma R. The Eco-indicator 99: A damage oriented method for life cycle impact assessment. Amersfoort, Netherlands: PRe Consultants; 2001 June 22nd. $144 \mathrm{p}$.

141. Mihalek MJ. Life Cycle Assessments (LCAs) of PyGasoline and PyDiesel From Different Regional Feedstocks: Corn Stover, Switchgrass, Sugar Cane Bagasse, Waste Wood, Forest Residues, Algae, and Albizia: Michigan Technological University; 2012. 167 p.

142. Bowman CT. Chemistry of Gaseous Pollutant Formation and Destruction. In: Bartok W, Sarofim AF, editors. Fossil Fuel Combustion: A Source Book. New York: John Wiley \& Sons, Inc; 1991. p 529-652.

143. Van De Kamp W, Smart J. Evaluation of the Combustion Characteristic of Pyrolytic Oil Derived from Biomass. In: Grassi G, Moncada P, Zibetta H, editors1991; Florence, Italy. p 317-319.

144. Gust S. Combustion Experiences of Flash Pyrolysis Fuel in Intermediate Size Boilers. In: Bridgwater AV, D.G.B. Boocock, editors. Developments in Thermochemical Biomass Conversion. New York: Springer; 1996. p 481-488.

145. Gust S. Combustion of Pyrolysis Liquids. In: Kalschmitt M, Bridgwater AV, editors. Biomass Gasification and Pyrolysis, State of the Art and Future Prospects: CPL Press; 1997. p 498-503.

146. Huffman DR, Vogiatzis AJ, Bridgwater AV. The Characterization of Fast Pyrolysis Bio-Oils In: Bridgwater AV, editor. Advances in Thermochemical Conversion of Biomass. Glasgow: Blackie Academic \& Professional; 1994. p 1095-1102. 
147. Wissmiller D. Pyrolysis oil combustion characteristics and exhaust emissions in a swirl-stabilized flame. Ames, Iowa: Iowa State University; 2009. 218 p.

148. Oasmaa A, Kyto M, Sipila K. Pyrolysis Oil Combustion Tests in an Industrial Boiler. In: Bridgwater AV, editor. Progress in Thermochemical Biomass Conversion. Malden, MA: Blackwell Science Ltd; 2001. p 1468-1481.

149. Baxter L, Jenkins B, Winter F. Baseline NOx Emissions during Combustion of Wood-Derived Pyrolysis Oils. Sandia National Laboratories; 1994. Report nr SAND94-8780 UC-1409. 16 p.

150. (S\&T)2 Consultants Inc. The Addition of Pyrolysis Oil Pathways to GHGenius. Delta, BC Canada2011 March 31. 50 p.

151. Spelter H, McKeever D, Toth D. Profile 2009: Softwood Sawmills in the United States and Canada. Madison, WI: U.S. Department of Agriculture, Forest Service, Forest Products Laboratory; 2009. Report nr FPL-RP-659. 55 p.

152. National Agricultural Statistics Service. Crop Production 2012 Summary. United States Department of Agriculture; 2013. Report nr ISSN: 1057-7823. 98 p.

153. Morey RV, Kaliyan N, Tiffany DG, Schmidt DR. A Corn Stover Supply Logistics System. Applied Engineering in Agriculture 2010;26(3):455-461.

154. Brazil [Internet]. Washington DC: U.S. Department of Energy. 2012 [updated Feb 28, 2012, cited Feb 20th]. Available from: http://www.eia.gov/countries/cab.cfm?fips=BR

155. Energy Information Administration. Annual Energy Outlook 2009 With Projections to 2030. Washington, DC: Energy Information Administration; 2009. Report nr DOE/EIA-0383(2009). 230 p.

156. U.S. Energy Information Administration. Electric Power Annual 2009. Washington, DC: U.S. Energy Information Administration; 2011 Jan 4. Report nr DOE/EIA-0348(2009). 108 p.

157. Potter-Witter K. Timber Producer Certification in Michigan: A Report to The Mackinac Center for Public Policy. The Mackinac Center for Public Policy; 1995.

158. Froese R. Biomass for Biofuels in the Michigan Upper Peninsula. Houghton, MI: Michigan Technological University; 2007.

159. Wallberg O, Linde M, Jonsson AS. Extraction of lignin and hemicelluloses from kraft black liquor. Desalination 2006;199(1-3):413-414.

160. Van Heiningen A. Converting a kraft pulp mill into an integrated forest biorefinery. Pulp \& Paper-Canada 2006;107(6):38-43.

161. Galbe M, Zacchi G. A review of the production of ethanol from softwood. Applied Microbiology and Biotechnology 2002;59(6):618-628.

162. Bruce Lippke, Richard Gustafson RV, Timothy Volk, Elaine Oneil, Leonard Johnson, Maureen Puettmann, Steele6 P. Sustainable Biofuel Contributions to Carbon Mitigation and Energy Independence. Forests 2011;2(4):861-874.

163. USDA Forest Service. Forest Inventory \& Analysis. 12.12.2011 ed: USDA Forest Service; 2011.

164. Campbell JE, Lobell DB, Genova RC, Field CB. The global potential of bioenergy on abandoned agriculture lands. Environmental Science \& Technology 2008;42(15):5791-5794. 
165. Allen DT, Shonnard DR. Green Engineering: Enrironmentally Conscious Design of Chemical Processes. New Jersy: Prentice Hall; 2002.

166. Frischknecht R, Jungbluth N, Althaus H-J, Bauer C, Doka G, Dones R, Hischier R, Hellweg S, Humbert S, Kollner T and others. Implementation of life cycle impact assessment methods. Dübendorf, Switzerland: Swiss Centre for Life Cycle Inventories; 2007. Report nr ecoinvent report No.3, v2.0. $151 \mathrm{p}$.

167. Heller MC, Keoleian GA, Mann MK, Volk TA. Life cycle energy and environmental benefits of generating electricity from willow biomass. Renewable Energy 2004;29(7):1023-1042.

168. Gasol CM, Gabarrell X, Anton A, Rigola M, Carrasco J, Ciria P, Rieradevall J. LCA of poplar bioenergy system compared with Brassica carinata energy crop and natural gas in regional scenario. Biomass \& Bioenergy 2009;33(1):119-129.

169. Wright MM, Brown RC, Boateng AA. Distributed processing of biomass to biooil for subsequent production of Fischer-Tropsch liquids. Biofuels Bioproducts \& Biorefining-Biofpr 2008;2(3):229-238.

170. Mann MK, Spath PL. A life cycle assessment of biomass cofiring in a coal fired power plant. Clean Products and Processes 2001;3(2):81-91.

171. Jaramillo P, Matthews HS, Griffin WM. A life cycle comparison of coal and natural gas for electricity generation and the production of transportation fuels [Thesis (PH D)]. Pittsburgh, PA: Carnegie Mellon University, Carnegie Mellon University, 2007.; 2007. xii, 117 p. p.

172. Khan A. GHGenius. 4.01. 2011.

173. Wagenaar B, Gansekoele E, Florijn J, Venderbosch R, Penninks F, Stellingwerf A. Bio-oil as natural gas substitute in a $350 \mathrm{MW}$ power station. Second world conference on biomass for energy, industry and climate protection. Rome, Italy2004.

174. Spath PL, Mann MK. Biomass Power and Conventional Fossil Systems with and without CO2 Sequestration - Comparing the Energy Balance, Greenhouse Gas Emissions and Economics. National Renewable Energy Laboratory; 2004. Report nr NREL/TP-510-32575.

175. Ness SR, Dunham GE, Weber GF, Ludlow DK. Scr Catalyst-Coated Fabric Filters for Simultaneous Nox and High-Temperature Particulate Control. Environmental Progress 1995;14(1):69-74.

176. Storing biomass [Internet]. Biomass Energy Centre[updated cited 2010 Feb 8]. Available from: http://www.biomassenergycentre.org.uk/portal/page?_pageid $=75,17306 \&$ dad=portal\& schema $=$ PORTAL

177. Calabria R, Chiariello F, Massoli P. Combustion fundamentals of pyrolysis oil based fuels. Experimental Thermal and Fluid Science 2007;31(5):413-420.

178. Elliott DC, Schiefelbein GF. Liquid-Hydrocarbon Fuels from Biomass. Abstracts of Papers of the American Chemical Society 1989;198:55-Fuel.

179. Graça I, Lopes JM, Cerqueira HS, Ribeiro MF. Bio-oils Upgrading for Second Generation Biofuels. Industrial \& Engineering Chemistry Research 2012;52(1):275-287. 
180. Han J, Elgowainy A, Palou-Rivera I, Dunn J.B, M.Q W. Wells-to-Wheels Analysis of Fast Pyrolysis Pathway with GREET. Argonne, IL: Argonne National Laboratory; 2011. Report nr ANL/ESD/11-8. 76 p.

181. Al-Sabawi M, Chen JW, Ng S. Fluid Catalytic Cracking of Biomass-Derived Oils and Their Blends with Petroleum Feedstocks: A Review. Energy \& Fuels 2012;26(9):5355-5372.

182. Brown RC, Holmgren J. Fast Pyrolysis and Bio-Oil Upgrading. Richland, WA2007.

183. Elliott DC. Historical developments in hydroprocessing bio-oils. Energy \& Fuels 2007;21(3):1792-1815.

184. Bridgwater AV. Review of fast pyrolysis of biomass and product upgrading. Biomass \& Bioenergy 2012;38:68-94.

185. Bridgwater AV. Catalysis in Thermal Biomass Conversion. Applied Catalysis aGeneral 1994;116(1-2):5-47.

186. Mortensen PM, Grunwaldt JD, Jensen PA, Knudsen KG, Jensen AD. A review of catalytic upgrading of bio-oil to engine fuels. Applied Catalysis a-General 2011;407(1-2):1-19.

187. Wright MM, Satrio JA, Brown RC, Daugaard DE, Hsu DD. Techno-economic analysis of biomass fast pyrolysis to transportation fuels. Golden, Colorado: National Renewable Energy Laboratory; 2010 November 2010. Report nr NREL/TP-6A20-46586. 73 p.

188. Jones SB, Holladay JE, Valkenburg C, Stevens DJ, Walton CW , Kinchin C, Elliott DC , S C. Production of Gasoline and Diesel from Biomass via Fast Pyrolysis, Hydrotreating and Hydrocracking: A Design Case. Pacific Northwest National Laboratory; 2009. Report nr PNNL-18284. 76 p.

189. ASTM. ASTM D1655 - 12 Standard Specification for Aviation Turbine Fuels. Volume ASTM D1655: ASTM International 2007. p 16.

190. Elgowainy A, Han J, M.Wang, N.Carter, Stratton R, J.Hileman. Life-cycle Analysis of Alternative Aviation Fuels in GREET. Argonne National Laboratory; 2012. Report nr ANL/ESD/12-8. 76 p.

191. Hsu DD. Life Cycle Assessment of Gasoline and Diesel Produced via Fast Pyrolysis and Hydroprocessing Golden, Colorado: National Renewable Energy Laboratory; 2011. Report nr NREL/TP-6A20-49341. 15 p.

192. Han J, Elgowainy A, Dunn JB, Wang MQ. Life cycle analysis of fuel production from fast pyrolysis of biomass. Bioresource Technology 2013(133):421-428.

193. USDA Forest Service. Forest Inventory Data Online. Arlington, VA: Forest Inventory and Analysis National Program; 2013.

194. Leefers LA, Vasievich JM. Timber Resources and Factors Affecting Timber Availability and Sustainability for Kinross, Michigan. East Lansing, MI: Michigan State University; 2011. Report nr Kinross Project 2 Report, Version 3.0. $61 \mathrm{p}$.

195. Pedersen L. Michigan State Forest Timber Harvest Trends: A Review of Recent Harvest Levels and Factors Influencing Future Levels. Department of Natural Resources - State of Michigan; 2005. 75 p. 
196. Michigan Department of Natural Resources and Environment. Michigan Woody Biomass Harvesting Guidance. Lansing, MI: Michigan Department of Natural Resources and Environment; 2010. 18 p.

197. Tessa Systems LLC. Forest-based Woody Biomass Assessment for MIchigan's Upper Peninsula Final Report. East Lansing, MI: Michigan Economic Development Corporation; 2010. 113 p.

198. IPCC. Volume 4: Agriculture, Forestry and Other Land Use. In: Eggleston HS, Buendia L, Miwa K, Ngara T, Tanabe K, editors. 2006 IPCC Guidelines for National Greenhouse Gas Inventories. Prepared by the National Greenhouse Gas Inventories Programme. IGES, Japan: IPCC; 2006.

199. Asante P, Armstrong GW, Adamowicz WL. Carbon sequestration and the optimal forest harvest decision: A dynamic programming approach considering biomass and dead organic matter. Journal of Forest Economics 2011;17(1):3-17.

200. Kurz WA, Dymond CC, White TM, Stinson G, Shaw CH, Rampley GJ, Smyth C, Simpson BN, Neilson ET, Tyofymow JA and others. CBM-CFS3: A model of carbon-dynamics in forestry and land-use change implementing IPCC standards. Ecological Modelling 2009;220(4):480-504.

201. The Intergovernmental Panel on Climate Change (IPCC). Good Practice Guidance for Land Use, Land-Use Change and Forestry. In: Penman J, Gytarsky M, Hiraishi T, Krug T, Kruger D, Pipatti R, Buendia L, Miwa K, Ngara T, Tanabe $\mathrm{K}$ and others, editors. Hayama, Kanagawa, Japan: Institute for Global Environmental Strategies (IGES); 2003.

202. Boudewyn P, Song X, Magnussen S, Gillis MD. Model-based, volume-tobiomass conversion for forested and vegetated land in Canada. Victoria, British Columbia: Natural Resources Canada; 2007. Report nr Information Report • BC$\mathrm{X}-411.124 \mathrm{p}$.

203. Li Z, Kurz WA, Apps MJ, Beukema SJ. Belowground biomass dynamics in the Carbon Budget Model of the Canadian Forest Sector: recent improvements and implications for the estimation of NPP and NEP. Canadian Journal of Forest Research-Revue Canadienne De Recherche Forestiere 2003;33(1):126-136.

204. Ter-Mikaelian MT, McKechnie J, Colombo SJ, Chen JX, MacLean HL. The carbon neutrality assumption for forest bioenergy: A case study for northwestern Ontario. Forestry Chronicle 2011;87(5):644-652.

205. Mckechnie J, Colombo S, Chen JX, Mabee W, Maclean HL. Forest Bioenergy or Forest Carbon? Assessing Trade-Offs in Greenhouse Gas Mitigation with WoodBased Fuels. Environmental Science \& Technology 2011;45(2):789-795.

206. Mitchell SR, Harmon ME, O'Connell KEB. Carbon debt and carbon sequestration parity in forest bioenergy production. Global Change Biology Bioenergy 2012;4(6):818-827.

207. Manomet Center for Conservation Sciences. Biomass Sustainability and Carbon Policy Study: Report to the Commonwealth of Massachusetts Department of Energy Resources. Brunswick, Maine2010. Report nr NCI-2010-03. 182 p. 
208. Forest Management. In: Sargent MS, Carter KS, editors. Managing Michigan Wildlife: A Landowners Guide. East Lansing, MI: Michigan United Conservation Clubs; 1999. p 297.

209. Piva RJ, Weatherspoon AK. Michigan Timber Industry: An Assessment of Timber Product Output and Use 2006. Newtown Square, PA: United States Department of Agriculture: Forest Service; 2010. 71 p.

210. Clearcuts Provide Multiple Benefits to Forests and Wildlife [Internet]. Department of Natural Resources. 2009 [updated May 21, 2009, cited Feb 8th]. Available from: http://www.michigan.gov/dnr/0,4570,7-153-

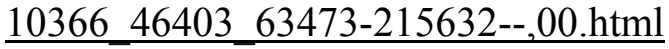

211. Mills JR, Zhou X. Projecting National Forest Inventories for the 2000 RPA Timber Assessment. Portland, OR: Department of Agriculture, Forest Service, Pacific Northwest Research Station; 2003. Report nr PNW-GTR-568. 58 p.

212. Ek AR, Brodie JD. A Preliminary Analysis of Short-rotation Aspen Management. Canadian Journal of Forest Research 1975;5(2):245-258.

213. Canada's terrestrial ecozones [Internet]. Natural Resources Canada. 2013 [updated 2013-03-21, cited March 15]. Available from: http://cfs.nrcan.gc.ca/pages/125

214. Zhang YM, Mckechnie J, Cormier D, Lyng R, Mabee W, Ogino A, Maclean HL. Life Cycle Emissions and Cost of Producing Electricity from Coal, Natural Gas, and Wood Pellets in Ontario, Canada. Environmental Science \& Technology 2010;44(1):538-544.

215. Dale BE, Henk LL, Shiang M. Fermentation of lignocellulosic materials treated by ammonia freeze-explosion. Dev. Ind. Microbiol 1984;26:223-233.

216. Wright JD. Ethanol from Biomass by Enzymatic-Hydrolysis. Chemical Engineering Progress 1988;84(8):62-74.

217. Duff SJB, Murray WD. Bioconversion of forest products industry waste cellulosics to fuel ethanol: A review. Bioresource Technology 1996;55(1):1-33.

218. Sun Y, Cheng JY. Hydrolysis of lignocellulosic materials for ethanol production: a review. Bioresource Technology 2002;83(1):1-11.

219. Jensen J, Morinelly J, Aglan A, Mix A, Shonnard DR. Kinetic characterization of biomass dilute sulfuric acid hydrolysis: Mixtures of hardwoods, softwood, and switchgrass. Aiche Journal 2008;54(6):1637-1645.

220. Wyman CE. Biomass ethanol: Technical progress, opportunities, and commercial challenges. Annual Review of Energy and the Environment 1999;24:189-226.

221. Fengel D, Wegener G. Wood : chemistry, ultrastructure, reactions. Berlin ; New York: W. de Gruyter; 1984. xiii, 613 p. p.

222. Alonso DM, Wettstein SG, Dumesic JA. Bimetallic catalysts for upgrading of biomass to fuels and chemicals. Chemical Society Reviews 2012;41(24):80758098.

223. Hendriks ATWM, Zeeman G. Pretreatments to enhance the digestibility of lignocellulosic biomass. Bioresource Technology 2009;100(1):10-18.

224. Zakzeski J, Bruijnincx PCA, Jongerius AL, Weckhuysen BM. The Catalytic Valorization of Lignin for the Production of Renewable Chemicals. Chemical Reviews 2010;110(6):3552-3599. 
225. Li X, Converse AO, Wyman CE. Characterization of molecular weight distribution of oligomers from autocatalyzed batch hydrolysis of xylan. Applied Biochemistry and Biotechnology 2003;105:515-522.

226. Kumar P, Barrett DM, Delwiche MJ, Stroeve P. Methods for Pretreatment of Lignocellulosic Biomass for Efficient Hydrolysis and Biofuel Production. Industrial \& Engineering Chemistry Research 2009;48(8):3713-3729.

227. Mosier N, Wyman C, Dale B, Elander R, Lee YY, Holtzapple M, Ladisch M. Features of promising technologies for pretreatment of lignocellulosic biomass. Bioresource Technology 2005;96(6):673-686.

228. Hsu T. Pretreatment of Biomass. In: Wyman CE, editor. Handbook on Bioethanol, Production and Utilization. Washington, DC: Taylor \& Francis; 1996. p 179-212.

229. Jacobsen SE, Wyman CE. Cellulose and hemicellulose hydrolysis models for application to current and novel pretreatment processes. Applied Biochemistry and Biotechnology 2000;84-6:81-96.

230. Esteghlalian A, Hashimoto AG, Fenske JJ, Penner MH. Modeling and optimization of the dilute-sulfuric-acid pretreatment of corn stover, poplar and switchgrass. Bioresource Technology 1997;59(2-3):129-136.

231. Wyman CE, Dale BE, Elander RT, Holtzapple M, Ladisch MR, Lee YY. Coordinated development of leading biomass pretreatment technologies. Bioresource Technology 2005;96(18):1959-1966.

232. Saeman J. Kinetics of wood saccharification: hydrolysis of cellulose and decomposition of sugars in dilute acid at high temperatures. Ind Eng Chern 1945;37(1):43-52.

233. Allen SG, Kam LC, Zemann AJ, Antal MJ. Fractionation of sugar cane with hot, compressed, liquid water. Industrial \& Engineering Chemistry Research 1996;35(8):2709-2715.

234. Torget R, Hatzis C, Hayward TK, Hsu TA, Philippidis GP. Optimization of reverse-flow, two-temperature, dilute-acid pretreatment to enhance biomass conversion to ethanol. Applied Biochemistry and Biotechnology 1996;57-8:85101.

235. Bobleter O. Hydrothermal Degradation of Polymers Derived from Plants. Progress in Polymer Science 1994;19(5):797-841.

236. Qing Q, Yang B, Wyman CE. Xylooligomers are strong inhibitors of cellulose hydrolysis by enzymes. Bioresource Technology 2010;101(24):9624-9630.

237. Chen RF, Lee YY, Torget R. Kinetic and modeling investigation on two-stage reverse-flow reactor as applied to dilute-acid pretreatment of agricultural residues. Applied Biochemistry and Biotechnology 1996;57-8:133-146.

238. Morinelly JE, Jensen JR, Browne M, Co TB, Shonnard DR. Kinetic Characterization of Xylose Monomer and Oligomer Concentrations during Dilute Acid Pretreatment of Lignocellulosic Biomass from Forests and Switchgrass. Industrial \& Engineering Chemistry Research 2009;48(22):9877-9884. 
239. Lloyd T, Wyman CE. Application of a depolymerization model for predicting thermochemical hydrolysis of hemicellulose. Applied Biochemistry and Biotechnology 2003;105:53-67.

240. Yang B, Wyman CE. Characterization of the degree of polymerization of xylooligomers produced by flowthrough hydrolysis of pure xylan and corn stover with water. Bioresource Technology 2008;99(13):5756-5762.

241. Kumar R, Wyman CE. The impact of dilute sulfuric acid on the selectivity of xylooligomer depolymerization to monomers. Carbohydrate Research 2008;343(2):290-300.

242. Yat SC, Berger A, Shonnard DR. Kinetic characterization for dilute sulfuric acid hydrolysis of timber varieties and switchgrass. Bioresource Technology 2008;99(9):3855-3863.

243. Sluiter A, Hames B, Ruiz R, Scarlata C, Sluiter J, Templeton D. Determination of sugars, byproducts, and degradation products in liquid fraction process samples. Golden, CO: National Renewable Energy Laboratory; 2008. Report nr NREL/TP510-42623. $14 \mathrm{p}$.

244. U.S. Environmental Protection Agency. Summary of Modeling Input Assumptions for Canola Oil Biodiesel for the Notice of Supplemental Determination for Renewable Fuels Produced Under the Final RFS2 Program. Environmental Protection Agency (EPA); 2010 July 10, 2010. Report nr EPAHQ-OAR-2010-0133. $10 \mathrm{p}$.

245. Bernesson S, Nilsson D, Hansson PA. A limited LCA comparing large- and small-scale production of rape methyl ester (RME) under Swedish conditions. Biomass \& Bioenergy 2004;26(6):545-559. 


\section{A. Appendix A: Supporting Information for Chapter 3}

\section{A.1. HRJ from soybean}

The soybean farming inputs used in this review are summarized in Table A.1. The GREET 2012 shows the lowest fertilizer inputs, while the energy inputs from three sources are relatively similar. In addition to the $\mathrm{N}$ fertilizer, both Stratton and GREET include the $\mathrm{N}$ from above and below ground biomass (200.7 $\mathrm{g} \mathrm{N} / \mathrm{bu})$ when calculating total $\mathrm{N}_{2} \mathrm{O}$ emission. The combined direct and indirect conversion rate for nitrogen from synthetic fertilizers is $1.325 \%$ and nitrogen from crop residues $1.225 \%$ according to the IPCC Tier methodology. GHGenius assumes higher $\mathrm{N}$ left in crop residues $(38.2 \mathrm{~g} \mathrm{~N} / \mathrm{kg}$ soybean), which is calculated from the following formula:

$(1-0.15) * 0.0169 * 2.8 * 0.95=0.0382 \mathrm{~g} \mathrm{~N} / \mathrm{g}$ soybean harvested

in which 0.15 is the moisture content, 0.0169 is the $\mathrm{N}$ content in crop residues, 2.8 is the weight ratio of crop residues and harvested soybean, 0.95 is the fraction of crop residues left on field.

Table A.1: Fertilizers and energy inputs of soybean farming

\begin{tabular}{|c|c|c|c|}
\hline & Stratton et al ${ }^{85 *}$ & GREET $2012^{86}$ & GHGenius ${ }^{87}$ \\
\hline $\mathrm{N}(\mathrm{g} / \mathrm{bu})$ & 49 & 30.9 & 48.7 \\
\hline $\mathrm{P}_{2} \mathrm{O}_{5}(\mathrm{~g} / \mathrm{bu})$ & 155 & 113.4 & 144.8 \\
\hline $\mathrm{K}_{2} \mathrm{O}(\mathrm{g} / \mathrm{bu})$ & 278 & 210 & 231.1 \\
\hline Herbicide (g/bu) & 14 & 15 & \\
\hline Pesticide (g/bu) & & 0.4 & 13.6 \\
\hline $\operatorname{Diesel}(\mathrm{mL} / \mathrm{bu})$ & 403.2 & 311.7 & 315.2 \\
\hline Gasoline $(\mathrm{mL} / \mathrm{bu})$ & 110.1 & 96.1 & 99.4 \\
\hline Natural gas (L/bu) & 33.24 & 34.83 & 30.2 \\
\hline $\mathrm{LPG}(\mathrm{mL} / \mathrm{bu})$ & 33.9 & 56.1 & 33.8 \\
\hline Electricity $(\mathrm{kWh} / \mathrm{bu})$ & 0.17 & 0.14 & 0.16 \\
\hline
\end{tabular}

* The inputs of baseline scenario is presented, which assumes soybean yield of $110 \mathrm{bu} / \mathrm{ha}$ 
Both Stratton and GREET 2012 assume solvent extraction of soybean oil while GHGenius assumes mechanical crushing. The energy inputs of the oil extraction are summarized in Table A.2. Stratton assumes the highest energy requirement, mainly due to the natural gas use for the process heat.

Table A.2: Inputs of soybean oil extraction

\begin{tabular}{|l|l|l|l|}
\hline & Stratton et al & GREET 2012 & $\begin{array}{l}\text { GHGenius } \\
\text { (year 2012) }\end{array}$ \\
\hline Seeds (kg/kg oil) & 5.7 & 5.4 & 5.21 \\
\hline Natural gas (L/kg oil) & 326 & 131.3 & 166.1 \\
\hline Steam (MJ/kg oil) & & & \\
\hline Coal (MJ/kg oil) & & 2.37 & \\
\hline Electricity (kWh/kg oil) & 0.36 & 0.289 & 0.284 \\
\hline Hexane (ml/kg oil) & 14.4 & 4.7 & \\
\hline Total energy (MJ/kg oil) & 13.64 & 10.4 & 7.92 \\
\hline
\end{tabular}

Table A.3 summarizes the co-products of soybean HRJ and their credits, including soybean meal and fuel products from HRJ production. In the market allocation method used by Stratton and our simulation in GREET, Stratton allocates less burdens to soybean oil, mainly because of the low oil content assumed by Stratton. However, Stratton includes more co-products in the HRJ production process, thus fewer emissions are allocated to the main product HRJ, which reflects on the lower emission results shown in Table 3.2. GHGenius uses displacement method for the co-products produced along the soybean HRJ life cycle. Each co-product is assigned a GHG credit and subtracted from the emission of the main product. The soybean meal shows a GHG credit of $415 \mathrm{~g} \mathrm{CO}_{2}$ eq $/ \mathrm{kg}$ meal, which translates to $-45.1 \mathrm{~g} \mathrm{CO}_{2} / \mathrm{MJ}$ oil and $-70.1 \mathrm{~g} \mathrm{CO}_{2} / \mathrm{MJ}$ HRJ. The coproducts of HRJ production are LPG and gasoline, which have GHG credit of 80.35 and $96.23 \mathrm{~g} \mathrm{CO}_{2}$ eq/MJ, respectively. When displacement method was applied in GREET $2012,1 \mathrm{~kg}$ of soybean meal displaces $1.2 \mathrm{~kg}$ soybean, which has GHG burden of $180.8 \mathrm{~g}$ 
$\mathrm{CO}_{2} \mathrm{eq} / \mathrm{kg}$ soybean. Therefore, GHGenius shows much higher soybean meal credit, which reflects on the lower oil extraction emission shown in Table 3.2.

Table A.3: Product and co-products of soybean $\mathrm{HRJ}^{\mathrm{a}}$

\begin{tabular}{|c|c|c|c|}
\hline & Stratton et al ${ }^{85}$ & GREET $2012^{86}$ & GHGenius $^{87}$ \\
\hline Soybean oil & $\begin{array}{l}1 \mathrm{~kg} * 1.05 \$ / \mathrm{kg} \\
(44.7 \%)\end{array}$ & $\begin{array}{l}1 \mathrm{~kg} * 0.846 \$ / \mathrm{kg} \\
(46.8 \%)\end{array}$ & $1 \mathrm{~kg}$ \\
\hline Soybean meal & $\begin{array}{l}4.48 \mathrm{~kg} * 0.29 \$ / \mathrm{kg} \\
(55.3 \%)\end{array}$ & $\begin{array}{l}3.7 \mathrm{~kg}^{\mathrm{b}} * 0.26 \$ / \mathrm{kg} \\
(53.2 \%)\end{array}$ & $4.21 \mathrm{~kg}$ \\
\hline HRJ (MJ/kg HRJ) & $44.07(65.2 \%)$ & $44.09(80.8 \%)$ & 44.1 \\
\hline $\begin{array}{l}\text { Naphtha }(\mathrm{MJ} / \mathrm{kg} \\
\text { HRJ) }\end{array}$ & $19.94(29.5 \%)$ & $4.32(7.9 \%)$ & \\
\hline $\begin{array}{l}\text { Propane }(\mathrm{MJ} / \mathrm{kg} \\
\mathrm{HRJ})\end{array}$ & $3.53(5.2 \%)$ & $6.12(11.2 \%)$ & \\
\hline LPG (MJ/kg HRJ) & & & 13.92 \\
\hline $\begin{array}{l}\text { Gasoline }(\mathrm{MJ} / \mathrm{kg} \\
\text { HRJ) }\end{array}$ & & & 5.10 \\
\hline
\end{tabular}

a:The Stratton and GREET use market value allocation for soybean oil and meal, and energy allocation for HRJ and its co-products, numbers in parentheses are the allocation factors. b: bone dry

Stratton yields lower fuel production emissions compared to GREET 2012, because: 1 . Small allocation factor as discussed above; 2 . Lower energy inputs, mainly natural gas used in the process (Table 3.1). GHGenius yields lower life cycle emission results than GREET 2012 when displacement method was applied, because of the larger GHG credits from the co-products, which include both soybean meal and fuel co-products.

\section{A.2. HRJ from camelina}

The camelina farming inputs and seed yields used in this review are summarized in Table A.4. The Forward 3000 scenario reported by Shonnard et al is used in this study, which 
represents projected yield gains from crop improvement research. GREET 2012 obtained the farming inputs from the Farmer 2008 scenario studied by Shonnard et al, which uses increased $\mathrm{N}$ application rate to boost yield. GHGenius assumes camelina planted in Canada, which shows higher fertilizer application rates and diesel use.

Table A.4: Chemicals and energy inputs of camelina farming

\begin{tabular}{|l|l|l|l|l|l|}
\hline & Shonnard $^{102}$ & $\begin{array}{l}\text { Agusdinata } \\
40\end{array}$ & EPA $^{88}$ & GREET $^{86}$ & GHGenius $^{87}$ \\
\hline Yield (kg/ha) & 3368 & 1681 & 1850 & $1123^{*}$ & 1020 \\
\hline $\begin{array}{l}\text { Urea, as N (g/kg } \\
\text { seed) }\end{array}$ & 24.9 & 18.3 & 24.2 & 37 & 55 \\
\hline $\begin{array}{l}\text { Thomas meal, as } \\
\mathrm{P}_{2} \mathrm{O}_{5}(\mathrm{~g} / \mathrm{kg} \text { seed })\end{array}$ & 5 & 7.3 & 9.1 & 15 & 15.31 \\
\hline $\begin{array}{l}\text { Potassium } \\
\text { chloride, as } \mathrm{K}_{2} \mathrm{O} \\
\text { (g/kg seed) }\end{array}$ & 3.3 & 0 & 6.06 & 10 & 4.08 \\
\hline $\begin{array}{l}\text { Herbicide (g/kg } \\
\text { seed) }\end{array}$ & 0 & 0.015 & 0.018 & 0.028 & 0.031 \\
\hline $\begin{array}{l}\text { Diesel (L/kg } \\
\text { seed) }\end{array}$ & 0.009 & 1.67 & 0 & \\
\hline
\end{tabular}

* The camelina yields of GREET are assumed the same as the Farmer 2008 scenario reported by Shonnard et al, as GREET shows the same fertilizer and energy inputs.

Table A.5 summarizes camelina oil extraction inputs. GHGenius assumes mechanical crushing, which uses more energy while achieve higher yield. Shonnard used energy allocation method to credit the camelina meal of oil extraction, based on the LHV of meal and the crude oil. The allocation factor of oil was calculated as 0.445 . The GREET model 
assumes $1.78 \mathrm{~kg}$ meal $/ \mathrm{kg}$ oil is produced as co-product, allocation factor of camelina oil is 0.61 based on the energy content. This allocation factor results in higher emissions allocated to the camelina oil (compared to Shonnard and SimaPro), which translates to higher farming emission. In the displacement scenario, GREET assumes camelina meal displaces the same amount of soybean, which has a GHG profile of $181.4 \mathrm{~g} \mathrm{CO}_{2} \mathrm{eq} / \mathrm{kg}$ soybean. GHGenius assumes the camelina oil extraction rate is $2.43 \mathrm{~kg}$ seed/L oil, while the meal has GHG emissions of $312 \mathrm{~g} \mathrm{CO}_{2} \mathrm{eq} / \mathrm{kg}$ meal. Therefore, GHGenius shows higher GHG credit of camelina meal than GREET 2012, which results in lower oil extraction emission (Table 3.3).

Table A.5: Inputs and co-product of camelina oil extraction (and refining)

\begin{tabular}{|c|c|c|c|c|}
\hline & Shonnard et al ${ }^{102}$ & $\mathrm{EPA}^{88}$ & GREET $^{86}$ & GHGenius $^{87}$ \\
\hline \multicolumn{5}{|l|}{ Inputs } \\
\hline Natural gas (MJ/kg oil) & 1.523 & 1.814 & 1.725 & 2.561 \\
\hline \multirow[t]{2}{*}{ Electricity (Wh/kg oil) } & & & & \\
\hline & 30.30 & 30.36 & 32.94 & 130.42 \\
\hline \multirow[t]{2}{*}{ Hexane (mL/kg oil) } & & & & \\
\hline & 3.47 & & 3.97 & \\
\hline Diesel (mL/kg oil) & 18.52 & & & \\
\hline \multicolumn{5}{|l|}{ Co-product } \\
\hline \multirow{2}{*}{ Meal (kg/kg oil) } & & & & \\
\hline & 1.78 & 1.85 & 1.78 & 1.51 \\
\hline
\end{tabular}

GREET 2012 also yields much higher fuel production emission compared to Shonnard and SimaPro. Shonnard study assumes much lower natural gas use (similar to Stratton inputs shown in Table 3.1) than GREET. In addition, co-products yields are also higher which means less emission burdens are allocated to the HRJ. EPA also includes more coproducts of HRJ production. $\mathrm{H}_{2}$ requirement assumed by EPA is lower than GREET as well. When comparing GREET (SE) to GHGenius, GHGenius shows much higher co- 
products credits, which make the fuel production emission lower even GHGenius assumes higher energy requirement.

\section{A.3. HRJ from jatropha}

The jatropha farming inputs are summarized in Table A.6. The fertilizers and energy requirement from these sources are comparatively similar, with the exception of GHGenius, which are much lower. However, GHGenius includes $\mathrm{N}$ from jatropha crop residues, which are converted to $\mathrm{N}_{2} \mathrm{O}$. The $\mathrm{N}$ content is calculated by the following formula: $(1-0.1) * 0.035 * 1=0.0315 \mathrm{~g} \mathrm{~N} / \mathrm{g}$ crop harvested, in which 0.1 is the moisture content, 0.035 is the $\mathrm{N}$ content in crop residues, and 1 is the ratio of crop residues and harvested jatropha crop. The emission factors of fertilizers are also relatively high compare to GREET 2012.

Table A.6: Chemical and energy inputs of jatropha cultivation

\begin{tabular}{|c|c|c|c|c|c|c|}
\hline & \multicolumn{3}{|c|}{ Stratton $^{85}$} & \multirow{2}{*}{$\begin{array}{l}\text { Bailis } \\
\text { and } \\
\text { Baka }^{97}\end{array}$} & \multirow{2}{*}{$\begin{array}{l}\text { GREET } \\
2012^{86}\end{array}$} & \multirow[t]{2}{*}{ GHGenius $^{87}$} \\
\hline & Low & Baseline & High & & & \\
\hline Yield (t/ha- yr) & 5 & 2.5 & 1 & 4 & & 2.38 \\
\hline $\mathrm{N}$ (g/kg seed) & 31.8 & 34 & 35.3 & 21 & 34 & 8.5 \\
\hline $\mathrm{P}_{2} \mathrm{O}_{5}(\mathrm{~g} / \mathrm{kg}$ seed $)$ & 12.6 & 13 & 13.4 & 8.5 & 13 & 3.32 \\
\hline $\mathrm{K}_{2} \mathrm{O}(\mathrm{g} / \mathrm{kg}$ seed $)$ & 31.3 & 37.4 & 37.4 & 23.5 & 37.4 & 14.8 \\
\hline $\begin{array}{l}\text { Diesel (L/kg } \\
\text { seed) }\end{array}$ & 0.034 & 0.039 & 0.041 & & 0.039 & 0.036 \\
\hline $\begin{array}{l}\text { Electricity } \\
\text { (kWh/kg seed) }\end{array}$ & & & & & & 0.02 \\
\hline $\begin{array}{l}\text { Natural gas } \\
\text { (MJ/kg seed) }\end{array}$ & & & & & & \\
\hline
\end{tabular}




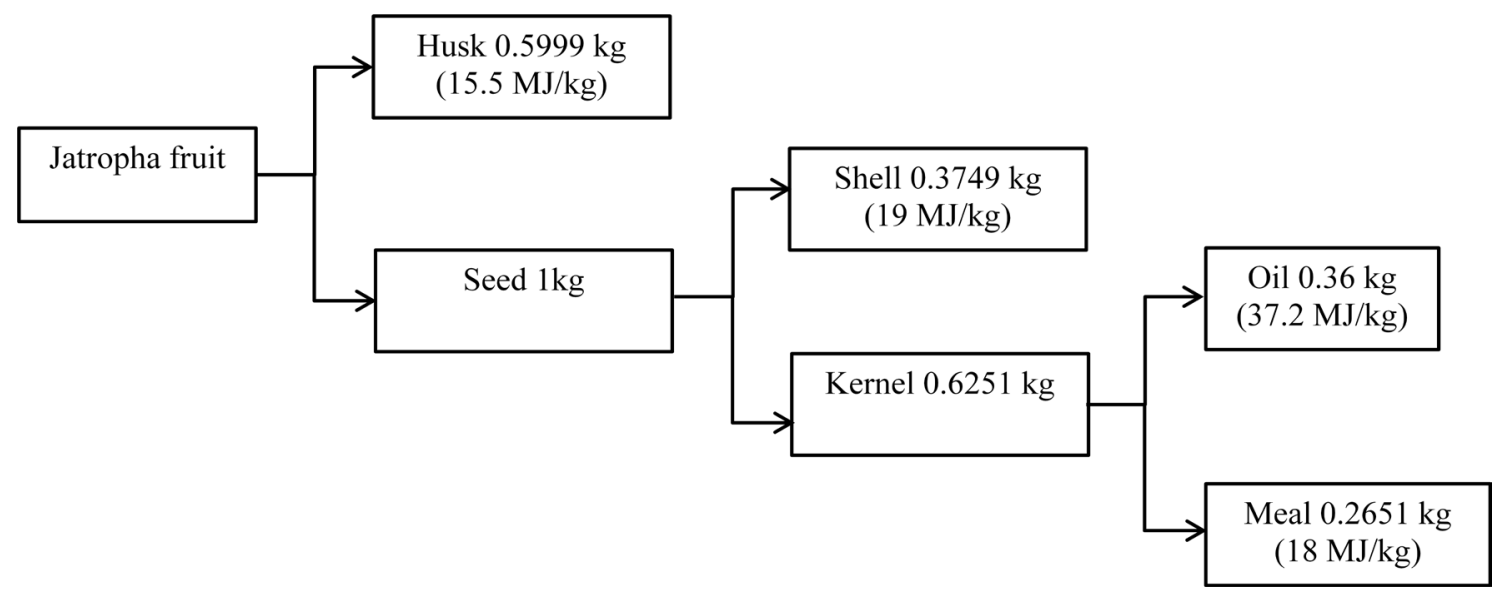

Figure A.1: Flow diagram of GREET jatropha oil extraction (per kg seed)

GREET model assumes the co-products (seed meal, husks, shells) are combusted for power generation. The quantity and LHV of each co-product are illustrated in Figure A.1. $99 \%$ of them are combusted in biomass boiler with efficiency of $20.8 \%$ and the remainder $1 \%$ is combusted in integrated gasification combined cycle ( IGCC) with efficiency of $40 \%$. Total electricity credit from the co-products is $3.37 \mathrm{kWh} / \mathrm{kg}$ oil, the emission factor of electricity is $677.53 \mathrm{~g} \mathrm{CO}_{2} \mathrm{eq} / \mathrm{kWh}$. The Stratton report assumes power generation for the co-products as well, $99 \%$ of biomass is burned in boiler with efficiency of $32.1 \%$ and the the remainder $1 \%$ is burned in IGCC with efficiency of $43 \%$, transmission loss of $8 \%$ is included. Energy allocation method is used for the electricity generated, therefore, the credit of electricity is much lower than what GREET yields. Bailis and Baka assumes mechanical pressing process with heat. 3 scenarios are considered for the seedcake and husks: 1. Waste; 2. Displace domestic urea and SSP, and imported potash (based on nutrient content); 3. Displace fuel oil (based on energy content). If the biomass is discarded as waste, there is no co-product credits generated, thus the oil extraction impact is the highest among 3 scenarios. In the second scenario, $\mathrm{N}$, $\mathrm{P}$ and $\mathrm{K}$ content in the seedcake and husk are used to calculate the amount of fertilizers the co-products can displace. The cake and husk contains the equivalent of $21.8 \mathrm{~kg} \mathrm{~N}$, $24.6 \mathrm{~kg} \mathrm{P}_{2} \mathrm{O}_{5}$, and $8.51 \mathrm{~kg} \mathrm{~K}_{2} \mathrm{O}$. In the third scenario, the energy content of seedcake and 
husk exceeds the process heat requirement, which is assumed to produce briquettes to displace heating oil ( $69 \mathrm{~kg}$ oil/GJ HRJ).

Table A.7: Process inputs of jatropha oil extraction (and refining) per kg of oil

\begin{tabular}{|c|c|c|c|c|c|c|}
\hline & \multicolumn{3}{|c|}{ Stratton et $\mathrm{al}^{85}$} & \multirow{2}{*}{$\begin{array}{l}\text { Bailis et } \\
\text { al }^{97}\end{array}$} & \multirow[t]{2}{*}{ GREET $^{86}$} & \multirow[t]{2}{*}{ GHGenius ${ }^{* 87}$} \\
\hline & Low & Baseline & High & & & \\
\hline \multicolumn{7}{|l|}{ Inputs } \\
\hline Seeds (kg) & 2.70 & 2.86 & 2.94 & & 2.78 & 3.19 \\
\hline $\begin{array}{l}\text { Natural gas } \\
\text { (L) }\end{array}$ & 50.33 & 49.29 & 50.77 & & 49.27 & 66.13 \\
\hline $\begin{array}{l}\text { Electricity } \\
(\mathrm{kWh})\end{array}$ & 0.168 & 0.195 & 0.201 & 0.38 & 0 & 0.175 \\
\hline Hexane $(\mathrm{g})$ & 4.02 & 3.93 & 4.05 & & 3.95 & \\
\hline $\mathrm{NaOH}(\mathrm{kg})$ & & & & 0.012 & & \\
\hline Fuel oil (kg) & & & & 0.015 & & \\
\hline Water $(\mathrm{kg})$ & & & & 0.24 & & \\
\hline \multicolumn{7}{|l|}{ Co-products } \\
\hline Husk (kg) & 1.3 & 1.71 & 1.76 & 1.4 & 1.67 & \\
\hline Shell (kg) & 0.89 & 1.06 & 1.09 & & 1.04 & \\
\hline Meal (kg) & 0.81 & 0.8 & 0.85 & 1.39 & 0.74 & \\
\hline Gums (kg) & & & & 0.137 & & \\
\hline
\end{tabular}

* GHGenius doesn't give credit to the jatropha husk/meal due to its toxicity.

Stratton assumes jatropha oil extraction and hydroprocessing occur at the same location, thus no oil transport is required. Bailis and Bark calculated the weighted average road distances from jatropha growers to oil expeller $(1439 \mathrm{~km})$. The oil is then transported to Brazil's principle seaport at Santos, and then shipped $15000 \mathrm{~km}$ to UOP facility on West Coast of US. The authors also assume that the jatropha SPK will follow a similar distribution path as conventional kerosene-based jet fuel. A emission factor of $0.9 \mathrm{~kg} \mathrm{CO}_{2}$ 
eq/kg fuel was used. In Shonnard's study, the jatropha capsules are trucked 95 km (190 $\mathrm{km}$ round trip) to the oil extraction plant at Uman, and then $320 \mathrm{~km}$ (640 km round trip) to Cancún where the oils are converted to green jet fuel using the UOP LLC process.

\section{A.4. HRJ from rapeseed (canola)}

The fertilizers and energy inputs of rapeseed (canola) farming are summarized in Table A.8. This feedstock requires much higher fertilizers use compared to other oil plants. In addition, Stratton and GREET includes $\mathrm{N}$ from rapeseed residues, which converts to $\mathrm{N}_{2} \mathrm{O}$ via direct and indirect emissions. 
Table A.8: Chemical and energy inputs of rapeseed cultivation (per t seed)

\begin{tabular}{|c|c|c|c|c|c|c|c|}
\hline & \multicolumn{3}{|c|}{ Stratton et $a l^{84}$} & \multirow{2}{*}{$\begin{array}{l}\text { GREET } \\
2012^{85}\end{array}$} & \multicolumn{2}{|l|}{$\mathrm{EPA}^{239}$} & \multirow[b]{2}{*}{ CARB $^{107}$} \\
\hline & Low & Baseline & High & & $\begin{array}{l}\text { (US } \\
\text { canola) }\end{array}$ & \begin{tabular}{|l} 
Canada \\
canola)
\end{tabular} & \\
\hline $\begin{array}{l}\text { Yield (t/ha- } \\
\text { yr) }\end{array}$ & 2.79 & 3.35 & 1.885 & & 1.885 & 2.025 & \\
\hline $\mathrm{N}^{\mathrm{a}}(\mathrm{kg})$ & 50.18 & 48.96 & 46.27 & 48.96 & 46.4 & 37 & $50.12^{b}$ \\
\hline $\mathrm{P}_{2} \mathrm{O}_{5}(\mathrm{~kg})$ & 12.19 & 14.03 & 14.4 & 14.03 & 14.1 & 9.86 & 13.36 \\
\hline $\mathrm{K}_{2} \mathrm{O}(\mathrm{kg})$ & 12.54 & 12.84 & 21.08 & 12.69 & 13.7 & 7.4 & 10.02 \\
\hline $\begin{array}{l}\text { Herbicide } \\
(\mathrm{kg})\end{array}$ & 0.65 & 0.69 & 0.72 & 0.69 & 0.33 & 0.17 & 0.23 \\
\hline $\begin{array}{l}\text { Insecticide } \\
(\mathrm{kg})\end{array}$ & & & & & & 0.023 & 0.06 \\
\hline Diesel (L) & 18.59 & 19.26 & 28.25 & 26.99 & 24.71 & 16.6 & 20.3 \\
\hline Gasoline (L) & & & & & 2.98 & & \\
\hline $\begin{array}{l}\text { Electricity } \\
(\mathrm{kWh})\end{array}$ & & & & & & 14.6 & 18.3 \\
\hline
\end{tabular}

a: $7125 \mathrm{~g} \mathrm{~N} / \mathrm{kg}$ rapeseed is reapplied to soil in the form of straw, in addition to the synthetic fertilizer ${ }^{85}$.

b: 70.7\% Ammonia, 21.1\% Urea, 8.2\% Ammonium Nitrate

Solvent extraction is used in all the studies in this review. Hexane and energy use of oil extraction are summarized in Table A.9, which are relatively higher than jatropha oil. Stratton used market allocation method to credit the rapeseed meal. When the same method is used in GREET 2012, rapeseed oil and meal have market value of 1.05 and $0.26 \$ / \mathrm{kg}$ respectively, the allocation factor of rapeseed oil is 0.764 . When energy 
allocation method is applied in GREET, the LHVs of rapeseed oil and meal are 37.2 and 13.35 MJ/kg, the allocation factor of rapeseed oil is 0.686 . However, EPA assumes higher LHV of rapeseed meal $(20.06 \mathrm{MJ} / \mathrm{kg})$, more emissions are allocated to the coproduct, thus EPA inputs generate lower oil extraction impacts. CARB used mass allocation for the canola oil/meal pathway, 57\% of canola farming impacts were allocated to canola meal while the remainder $(43 \%)$ to the oil.

Table A.9: Chemical and energy inputs of rapeseed oil extraction

\begin{tabular}{|c|c|c|c|c|c|c|}
\hline \multirow[t]{2}{*}{ per $\mathrm{kg}$ oil } & \multicolumn{3}{|c|}{ Stratton et al ${ }^{85}$} & \multirow{2}{*}{$\begin{array}{l}\text { GREET } \\
2012^{86}\end{array}$} & \multirow[t]{2}{*}{ EPA $^{244}$} & \multirow[t]{2}{*}{ CARB $^{108}$} \\
\hline & Low & Baseline & High & & & \\
\hline Seeds (kg) & 2.22 & 2.27 & 2.44 & 2.27 & 2.5 & 2.34 \\
\hline Natural gas (L) & 64.76 & 66.23 & 71.08 & 66.28 & 63.89 & 63.87 \\
\hline Electricity (kWh) & 0.111 & 0.114 & 0.122 & 0.114 & 0.114 & 0.115 \\
\hline Hexane $(\mathrm{g})$ & 4.893 & 5.005 & 5.371 & 4.989 & $1.5-2.9$ & 2.18 \\
\hline \multicolumn{7}{|l|}{ Co-product } \\
\hline Meal (kg) & 1.22 & 1.27 & 1.44 & $\begin{array}{l}1.27(13.35 \\
\mathrm{MJ} / \mathrm{kg})\end{array}$ & $\begin{array}{l}1.5(20.06 \\
\left.\mathrm{MJ} / \mathrm{kg}^{*}\right)\end{array}$ & 1.34 \\
\hline
\end{tabular}

* The LHV of canola meal was obtained from Bernessen $2004^{245}$ and used in the SimaPro

The transport of the rapeseed (to oil extraction) and oil (to fuel production) are summarized in Table A.10. Although the distances vary in these sources, transport stage has very small contribution to the total GHG results. 
Table A.10: Transport mode and distance of rapeseed and oil (in km)*

\begin{tabular}{|c|c|c|c|c|c|c|}
\hline \multicolumn{3}{|c|}{ Stratton et al ${ }^{85}$} & \multicolumn{3}{|c|}{ GREET $^{86}$} & \multirow{2}{*}{\begin{tabular}{|l} 
CARB \\
108 \\
16.1 \\
(truck)
\end{tabular}} \\
\hline $\begin{array}{l}\text { Seed } \\
\text { transport }\end{array}$ & $\begin{array}{l}\text { Farm to } \\
\text { oil } \\
\text { extraction } \\
\text { facility }\end{array}$ & 115 (truck) & \multirow[t]{2}{*}{$\begin{array}{l}\text { Seed } \\
\text { transport }\end{array}$} & $\begin{array}{l}\text { Farm to } \\
\text { stack }\end{array}$ & 16.1 (truck) & \\
\hline \multirow[t]{3}{*}{$\begin{array}{l}\text { Oil } \\
\text { transport }\end{array}$} & $\begin{array}{l}\text { Oil } \\
\text { facility to } \\
\text { EU ports }\end{array}$ & 150 (truck) & & $\begin{array}{l}\text { Stack to } \\
\text { oil mills }\end{array}$ & 64.4 (truck) & $\begin{array}{l}64.4 \\
\text { (truck) }\end{array}$ \\
\hline & $\begin{array}{l}\text { EU ports } \\
\text { to US } \\
\text { ports }\end{array}$ & $\begin{array}{l}6000 \\
\text { (tanker) }\end{array}$ & \multirow[t]{2}{*}{$\begin{array}{l}\text { Oil } \\
\text { transport }\end{array}$} & \multirow[t]{2}{*}{$\begin{array}{l}\text { Oil mills } \\
\text { to fuel } \\
\text { facility }\end{array}$} & \multirow{2}{*}{$\begin{array}{l}128.7 / 1126.3 \\
\text { (truck } \\
67 \% / \text { rail } \\
33 \% \text { ) }\end{array}$} & \multirow[t]{2}{*}{$\begin{array}{l}1930.8 \\
\text { (rail) }\end{array}$} \\
\hline & $\begin{array}{l}\text { US ports } \\
\text { to fuel } \\
\text { facility }\end{array}$ & $\begin{array}{l}257.5 / 1287 \\
\text { (truck } \\
50 \% / \text { rail } \\
50 \% \text { ) }\end{array}$ & & & & \\
\hline
\end{tabular}

* The EPA doesn't list the rapeseed transport, the distances are assumed to be the same as those in the CARB report, with the exception that oil is transported $570 \mathrm{mi}$ by rail ${ }^{53}$ to the hydroprocessing facility in the US scenario.

\section{A.5. HRJ from palm oil}

The farming inputs of oil palm are summarized in Table A.11. The fruit yields reported in these sources are similar, but the fertilizers inputs vary. EPA assumes the lowest $\mathrm{N}$ fertilizer use, thus it generates low cultivation emissions. GHGenius generates the highest cultivation emission because of the large fertilizer use, especially the $\mathrm{N}$ fertilizer. 
Table A.11: Chemicals and energy inputs of palm fruit farming and harvest

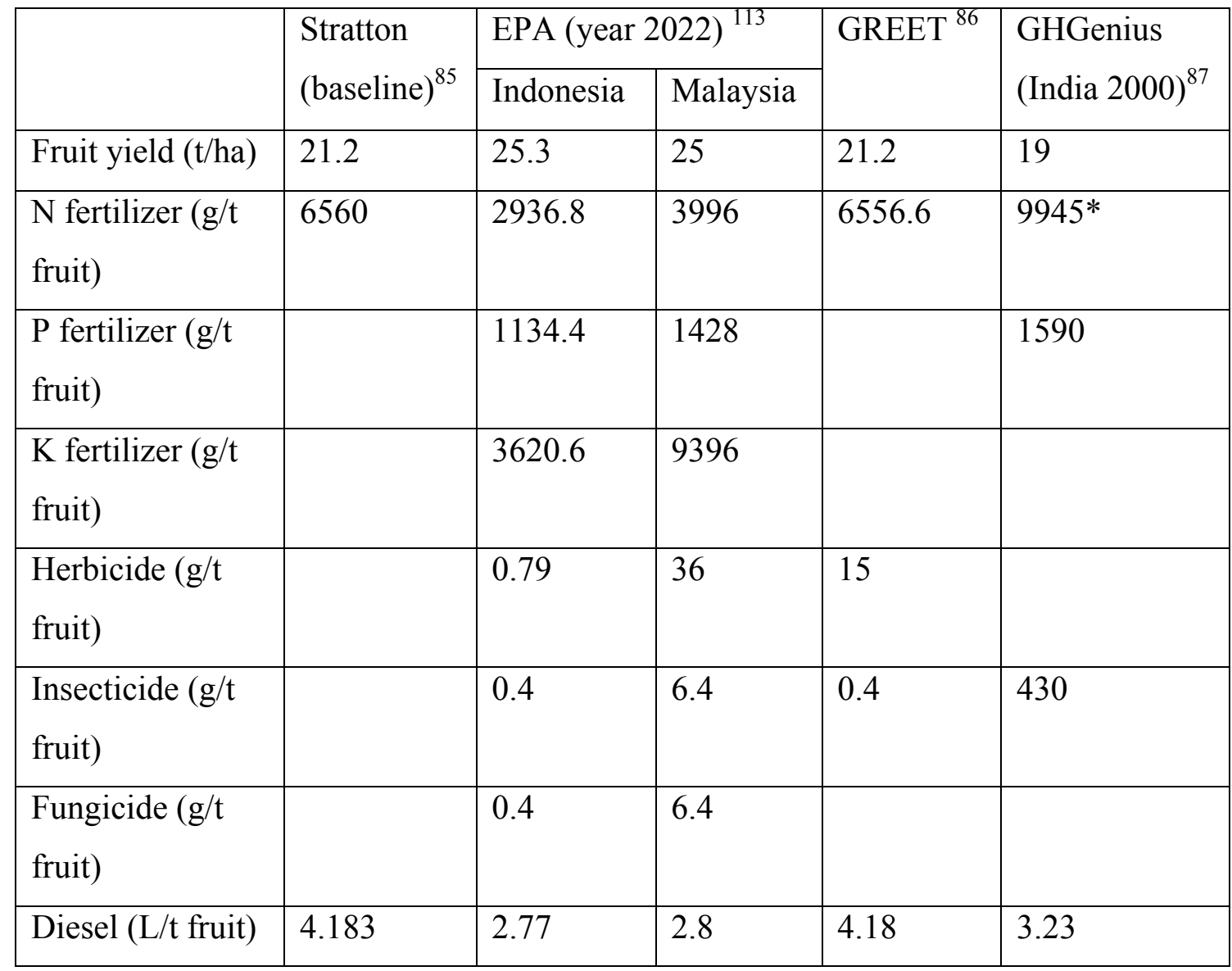

$* \mathrm{~N}$ in crop residues add another $8366 \mathrm{~g} \mathrm{~N} / \mathrm{t}$ fruit, which also contributes to total $\mathrm{N}_{2} \mathrm{O}$ emission

Stratton and GREET assume the oil produced includes palm oil extracted from FFB and kernel oil from palm kernel, while EPA only accounts for palm oil from FFB, and palm kernel is used as animal feed. Therefore, EPA has a higher FFB to oil ratio, but also higher co-product yield ( $0.27 \mathrm{~kg}$ kernel $/ \mathrm{kg}$ oil vs. $0.11 \mathrm{~kg}$ kernel expeller $/ \mathrm{kg}$ oil $)$. The GREET assumes $0.11 \mathrm{~kg}$ kernel expeller per kg crude oil is produced as co-product, which displaces $0.132 \mathrm{~kg}$ soybean with GHG burden of $180.76 \mathrm{~g} \mathrm{CO} 2 \mathrm{eq} / \mathrm{kg}$. The GHGenius assumes that $0.14 \mathrm{~kg}$ of palm meal is produced per liter crude oil, which displaces soybean meal (415 g CO2 eq/ $\mathrm{kg}$ ) on a ratio of 0.35 (1 kg palm meal displaces $0.35 \mathrm{~kg}$ soybean meal). 
The EPA assumes POME yield of $3 \mathrm{t} / \mathrm{t}$ oil, and $18.2 \mathrm{~m}^{3}$ of methane is generated per tonne of POME. $3 \%$ of palm oil mills capture methane with $90 \%$ capture efficiency. Of all the mills capture methane, $27 \%$ flare the gas onsite with destruction efficiency of $90 \%, 7 \%$ of them use methane to generate electricity with efficiency of $34 \%$. The GHGenius assumes crop residues $(0.225 \mathrm{~kg} / \mathrm{L}$ oil $)$ are burned onsite for heat and power, which has emission factor of $2407 \mathrm{~g} \mathrm{CO}_{2}$ eq/GJ biomass. Emissions from POME treatment are also included in the oil extraction stage, which includes $900 \mathrm{~g} \mathrm{CH}_{4} / \mathrm{GJ}$ oil and $60 \mathrm{~g} \mathrm{PM} / \mathrm{GJ}$ oil. Because CH4 is a potent greenhouse gas, it accounts for almost all the GHG emission (98.75\%) during oil extraction.

Table A.12: Inputs of palm oil extraction (per kg crude oil)

\begin{tabular}{|l|l|l|l|l|}
\hline per kg crude oil & $\begin{array}{l}\text { Stratton et al } \\
(\text { baseline) }\end{array}$ & EPA $^{113}$ & GREET $^{86}$ & GHGenius $^{\text {b 87 }}$ \\
\hline Fruit $(\mathrm{kg})$ & 4.5 & 5 & 4.49 & 4.34 \\
\hline Electricity (kWh) & 0.019 & $0^{\mathrm{a}}$ & 0.0194 & \\
\hline Diesel (L) & 0.011 & 0.0045 & 0.011 & \\
\hline
\end{tabular}

a: electricity generated on-site from combustion of palm kernel shell and fiber

b: crop residues $(0.225 \mathrm{~kg} / \mathrm{L}$ oil $)$ burned on-site for heat and power

The transport of palm fruit and oil are summarized in Table A.13. Transoceanic long distance shipping is included in all sources, but the transport has insignificant impact to the life cycle of HRJ emissions. 


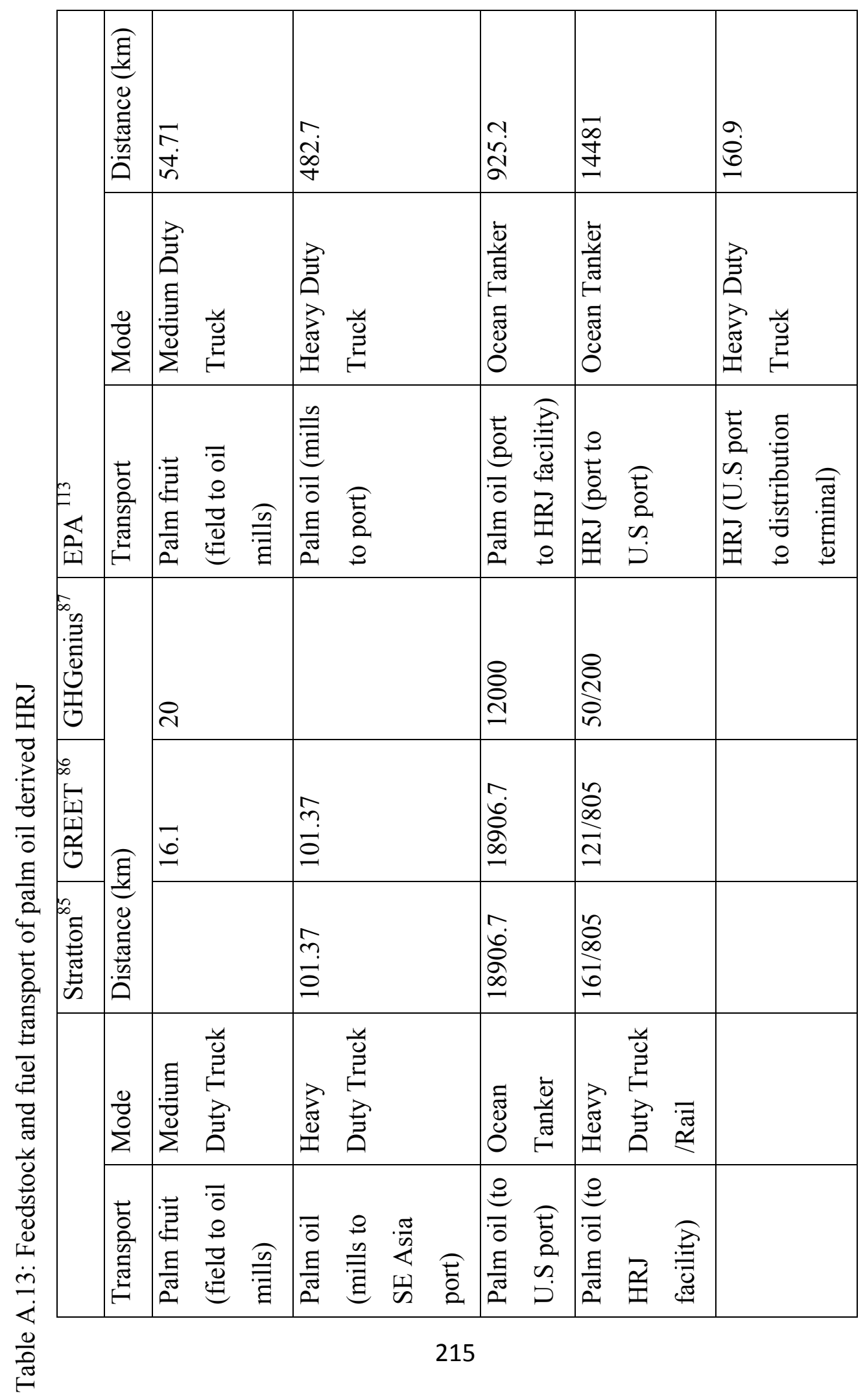




\section{A.6. HRJ from algae}

Inputs for algae cultivation and dewatering are shown below in Table A.14. Although each study assumes similar oil content, algae yields can vary widely according to geography and season, and these variations are incorporated in the most recent GREET assessment of algae cultivation. Estimates of electricity use are roughly double in the GREET assessment, compared to Stratton 2010. Table A.15 displays key input data for algal oil extraction and refining to HRJ. Many differences are apparent in the assumptions made in these life cycle stages, especially concerning the internal vs. external use of lipid-extracted algae (LEA) for heat and power. Internal use of LEA offsets a great deal of natural gas, but also results in fugitive methane emissions which contribute to the overall GHG emissions profile.

Table A.14: Inputs for algae cultivation and dewatering

\begin{tabular}{|l|l|l|}
\hline Item & GREET & Stratton et $\mathrm{al}^{85}$ \\
\hline Algae yield $\left(\mathrm{g} / \mathrm{m}^{2}-\mathrm{d}\right)$ & $13.2 *$ & 25 \\
\hline Lipid fraction & $25 \%$ & $25 \%$ \\
\hline Net $\mathrm{N}$ demand $(\mathrm{mg} / \mathrm{g}$ algae) & 19.5 & 13.25 \\
\hline Net $\mathrm{P}$ demand $(\mathrm{mg} / \mathrm{g}$ algae) & 4.1 & 1.3 \\
\hline Net $\mathrm{CO}_{2}$ demand $(\mathrm{kg} / \mathrm{kg}$ algae) & 2.46 & 2.18 \\
\hline Electricity for $\mathrm{CO}_{2}$ delivery $\left(\mathrm{KJ} / \mathrm{kg} \mathrm{CO}_{2}\right)$ & 151.93 & 82.61 \\
\hline $\begin{array}{l}\text { Electricity for algae growth and } 1 \mathrm{st} \\
\text { dewatering (KJ/kg Algae) }\end{array}$ & 1215.4 & 608.98 \\
\hline $\begin{array}{l}\text { Electricity for Remaining Dewatering } \\
\text { centrifuge (KJ/kg Algae) }\end{array}$ & 629.87 & 422 \\
\hline Site-based assessment of algal productivity incorporated in Davis et al
\end{tabular}


Table A.15: Inputs for algae oil extraction and refining to HRJ

\begin{tabular}{|l|l|l|}
\hline & GREET $^{86}$ & Stratton et al $^{85}$ \\
\hline Algae input (kg algae / kg oil) & 4.68 & Not mentioned \\
\hline Energy for Extraction (KJ/kg oil) & $15.26^{\mathrm{a}}$ & $4.66^{\mathrm{b}}$ \\
\hline LEA sent to biomass (kg biomass / kg oil) & 3.73 & 3 \\
\hline $\begin{array}{l}\text { Energy Consumed in Recovery Step } \\
\text { (MJ/kg dry lipid-extracted biomass) }\end{array}$ & 1.098 & none $^{\mathrm{c}}$ \\
\hline Methane in Biogas yield (kg/dry-kg residue) & 0.213 & \\
\hline Recovered $\mathrm{CO}_{2}$ (kg/dry-kg residue) & 0.288 & No recycle mentioned \\
\hline AD Residue Yield, kg/dry-kg residue & 0.499 & $\begin{array}{l}\text { No mention - treated } \\
\text { as waste }\end{array}$ \\
\hline Methane loss from prod./ processing & $2 \%$ & None mentioned \\
\hline Oil use: $\mathrm{kg}$. oil/kg. renewable jet fuel & 1.39 & 1.72 \\
\hline Propane fuel mix (kg/kg) & 0.142 & 0.081 \\
\hline Naphtha (kg/kg) & 0.097 & 0.446 \\
\hline $\begin{array}{l}\text { Yield of HRJ from vegetable oil } \\
\text { (kg/kg vegetable oil) }\end{array}$ & 0.889 & 0.587 \\
\hline Natural gas (MJ/kg HRJ) & 7.87 & 0.43 \\
\hline Electricity (MJ/kg HRJ) & 0.22 & 0.33 \\
\hline Hydrogen (MJ/kg HRJ) & 6.54 & 6.91 \\
\hline
\end{tabular}

a: $23.1 \%$ electricity, $76.9 \%$ heat

b: $8.5 \%$ due to electricity, $91.5 \%$ heat

c: Heat and electricity from biogas combustion used to satisfy needs of anaerobic digestion and post-centrifuge thermal drying to $90 \%$ solids

\section{A.7. HRJ from tallow}

The tallow rendering inputs are summarized in Table A.16. GHGenius includes much higher energy requirement. However, it assumes the bone meal produced in the rendering process displace soybean as animal feed, offering a GHG credit of $27272 \mathrm{~g} \mathrm{CO}_{2} \mathrm{eq} / \mathrm{GJ}$ tallow. 
Table A.16: Tallow rendering process from CARB and GHGenius

\begin{tabular}{|l|l|l|}
\hline per L of crude tallow & CARB $^{123}$ & GHGenius $^{87}$ \\
\hline Inputs & & \\
\hline Natural gas (L) & 185.6 & 442.3 \\
\hline Electricity $(\mathrm{kWh})$ & 0.25 & 0.68 \\
\hline Co-product & & \\
\hline Bone meal* $(\mathrm{kg})$ & & -2.28 \\
\hline
\end{tabular}

* The CARB considers the bone meal as waste because animal based waste products are likely to be banned by the FDA. GHGenius assumes that the bone-meal are used as animal feed, offering a GHG credit of $27272 \mathrm{~g} \mathrm{CO}_{2}$ eq/GJ tallow by displacing soybean meals (412 $\mathrm{g} \mathrm{CO}_{2} \mathrm{eq} / \mathrm{kg}$ meal)

\section{A.8. HRJ from fuel grade corn oil}

With the oil extraction system reported in the Mueller study ${ }^{124}$, the thermal energy requirements of the ethanol production remain the same while the VOC emissions are reduced. Electricity is needed to power the centrifuges for oil extraction. The oil extraction rate is assumed to be 3.5 vol\% $(0.035$ gal oil/gal EtOH $)$. The CARB ${ }^{125}$ studies the GreenShift process, which extracts corn oil from the stillage portion of DGS. The process includes two system: thin stillage is heated by steam and centrifuged in the first system (Corn Oil Extraction 1), in which almost 30\% of available oil is extracted; the second system (Corn Oil Extraction 2) extracts another 30\% of oil bound in the whole stillage. 6.5 gallons of corn oil is assumed to be extracted per 100 gallons of ethanol produced. The Corn Oil Extraction 1 system can significantly reduce the thermal energy requirement in the DGS drying process, due to improved heat transfer efficiency, increased drying efficiency, and improved DGS flow characteristics following corn oil removal. The steam credit is also accounted for by the CARB study. The removal of corn oil results in a reduction of DDGS yield, which translates into a reduction in $\mathrm{CO}_{2}$ credit from DDGS. This $\mathrm{CO}_{2}$ credit reduction ( $1.08 \mathrm{~g} \mathrm{CO}_{2} \mathrm{eq} / \mathrm{MJ}$ ethanol) is converted to a $\mathrm{g}$ $\mathrm{CO}_{2}$ eq per kg corn oil basis, which finally translates into a $\mathrm{g} \mathrm{CO}_{2}$ eq per MJ HRJ basis. The crude corn oil refining inputs are assumed to be the same as camelina oil ${ }^{102}$ (Table A.18). 
Table A.17: Energy inputs of corn oil extraction

\begin{tabular}{|l|l|l|}
\hline & CARB $^{125}$ & Mueller $^{124}$ \\
\hline Yield (L oil/L ethanol) & 0.065 & 0.035 \\
\hline Electricity (kWh/L oil) & 0.405 & 0.53 \\
\hline Natural gas (L/L oil) & 33.96 & \\
\hline Natural gas credit (L/L oil) & -433.2 & \\
\hline
\end{tabular}

Table A.18:Material and energy inputs of corn oil refining (per kg refined oil)

\begin{tabular}{|l|l|}
\hline Crude corn oil $(\mathrm{kg})$ & 1.0417 \\
\hline Electricity $(\mathrm{kWh})$ & 0.0063 \\
\hline Steam $(\mathrm{kg})$ & 0.106 \\
\hline
\end{tabular}




\section{B. Appendix B: Supporting information for Chapter 8}

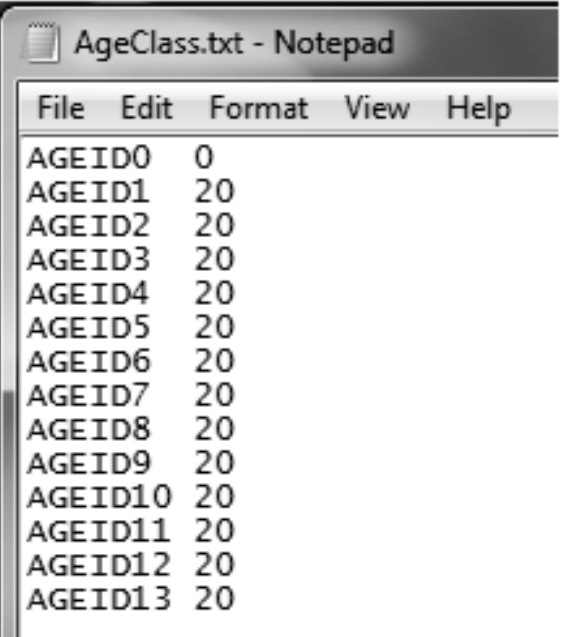

Figure B.1: Age class import file of the BAU and INT scenarios

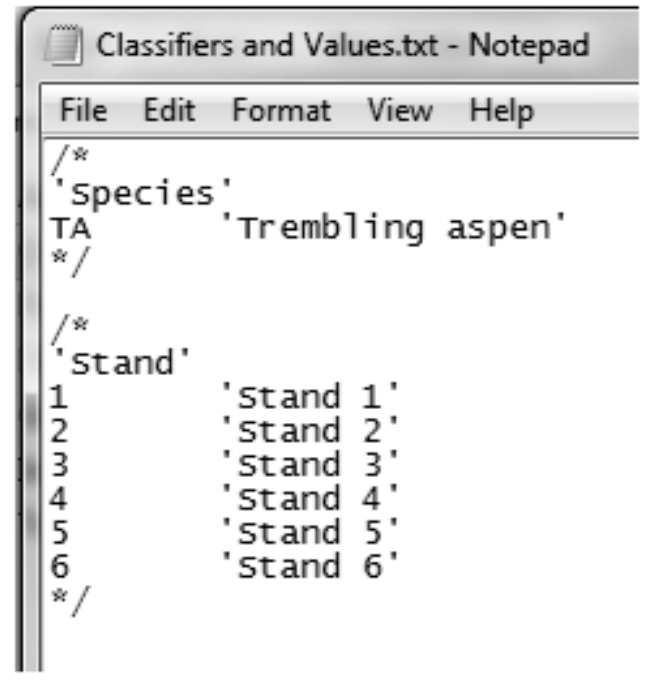

Figure B.2: Classifier file of the BAU scenario 


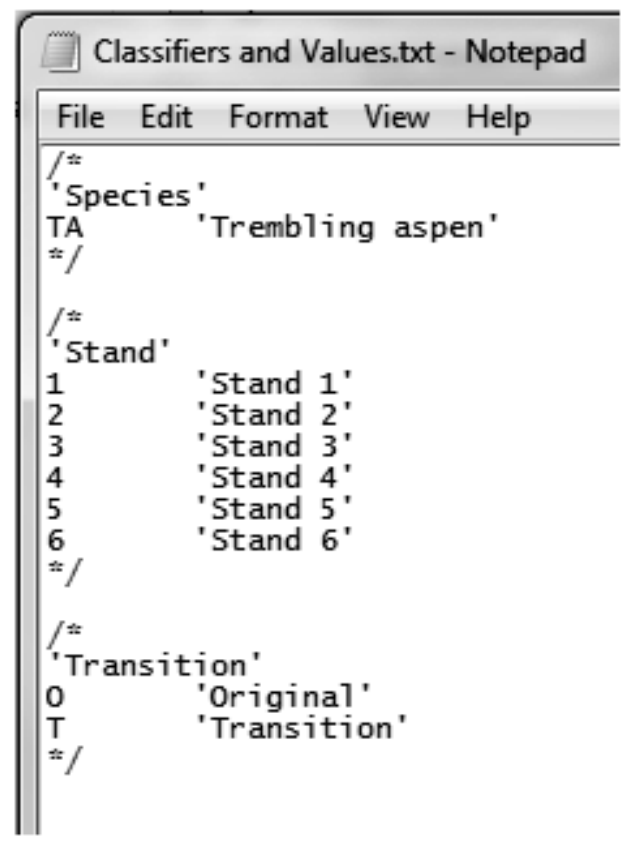

Figure B.3: Classifier file of the INT scenario

\begin{tabular}{l} 
DistType.txt - Notepad \\
\hline File Edit Format View Help \\
\hline DISTID1 'Natura1 for est fire', \\
DISTID2 'Clearcut Harvesting'
\end{tabular}

Figure B.4: Disturbance type import file of the BAU and INT scenarios

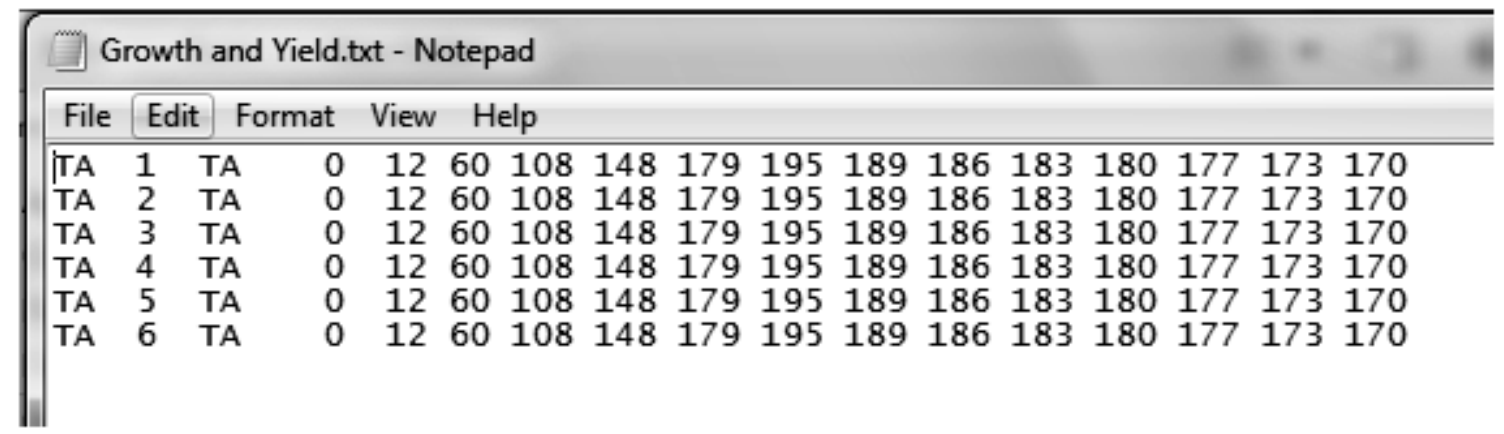

Figure B.5: Yield import file of the BAU scenario 
Growth and Yield.txt - Notepad

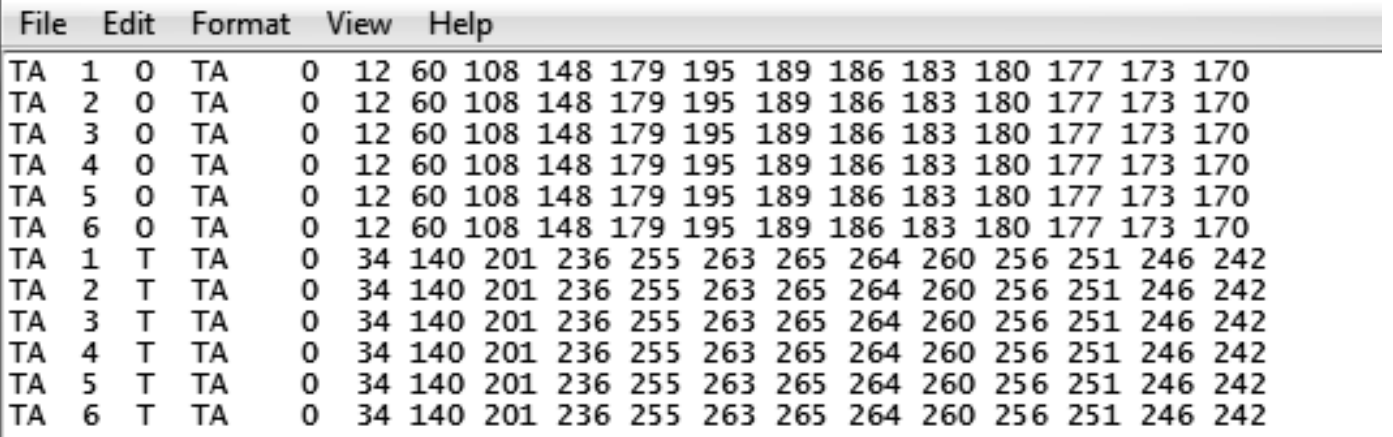

Figure B.6: Yield import file of the INT scenario

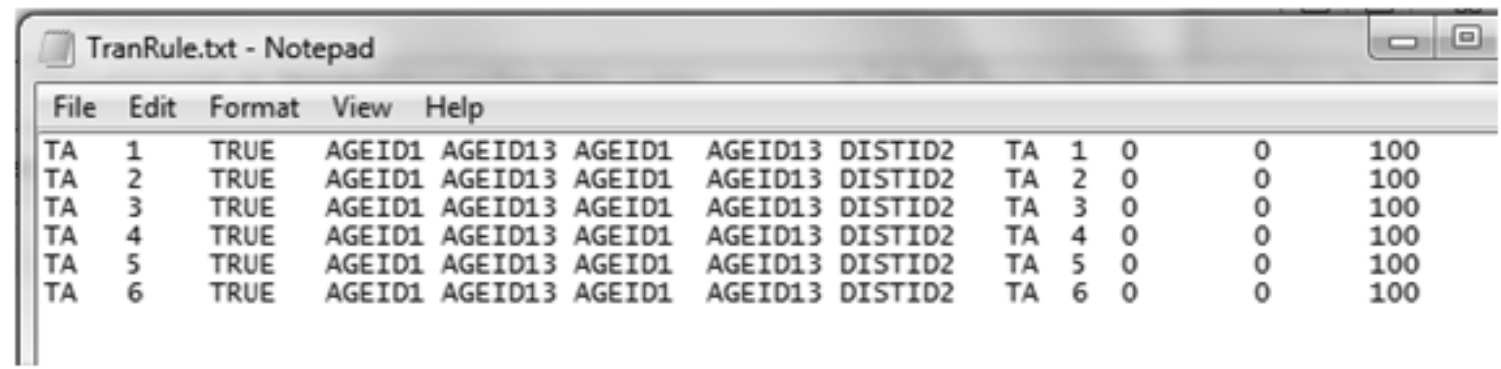

Figure B.7: Transition rule file of the BAU scenario

\begin{tabular}{|c|c|c|c|c|c|c|c|c|c|c|c|c|c|c|}
\hline \multicolumn{4}{|c|}{ (7) TranRule.txt - Notepad } & \multicolumn{2}{|c|}{ 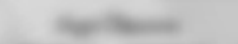 } & \multicolumn{2}{|c|}{$\sin 20=0$} & 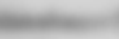 & e & & $\tan =$ & $-6=2$ & 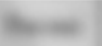 & \\
\hline File & Edit & & mat View & N Help & & & & & & & & & & \\
\hline $\begin{array}{l}11 \\
\text { TA } \\
\text { TA } \\
\text { TA } \\
\text { TA } \\
\text { TA } \\
\text { TA } \\
\text { TA } \\
\text { TA } \\
\text { TA } \\
\text { TA } \\
\text { TA } \\
\text { TA }\end{array}$ & $\begin{array}{l}2 \\
1 \\
2 \\
3 \\
4 \\
5 \\
6 \\
1 \\
2 \\
3 \\
4 \\
5 \\
6\end{array}$ & $\begin{array}{l}3 \\
0 \\
0 \\
0 \\
0 \\
0 \\
0 \\
T \\
T \\
T \\
T \\
T \\
T \\
T\end{array}$ & $\begin{array}{l}\text { UsingID } \\
\text { TRUE } \\
\text { TRUE } \\
\text { TRUE } \\
\text { TRUE } \\
\text { TRUE } \\
\text { TRUE } \\
\text { TRUE } \\
\text { TRUE } \\
\text { TRUE } \\
\text { TRUE } \\
\text { TRUE } \\
\text { TRUE }\end{array}$ & $\begin{array}{l}\text { SWStart } \\
\text { AGEID1 } \\
\text { AGEID1 } \\
\text { AGEID1 } \\
\text { AGEID1 } \\
\text { AGEID1 } \\
\text { AGEID1 } \\
\text { AGEID1 } \\
\text { AGEID1 } \\
\text { AGEID1 } \\
\text { AGEID1 } \\
\text { AGEID1 } \\
\text { AGEID1 }\end{array}$ & $\begin{array}{l}\text { SWEnd } \\
\text { AGEID13 } \\
\text { AGEID13 } \\
\text { AGEID13 } \\
\text { AGEID13 } \\
\text { AGEID13 } \\
\text { AGEID13 } \\
\text { AGEID13 } \\
\text { AGEID13 } \\
\text { AGEID13 } \\
\text { AGEID13 } \\
\text { AGEID13 } \\
\text { AGEID13 }\end{array}$ & $\begin{array}{l}\text { HaStart } \\
\text { AGEID1 } \\
\text { AGEID1 } \\
\text { AGEID1 } \\
\text { AGEID1 } \\
\text { AGEID1 } \\
\text { AGEID1 } \\
\text { AGEID1 } \\
\text { AGEID1 } \\
\text { AGEID1 } \\
\text { AGEID1 } \\
\text { AGEID1 } \\
\text { AGEID1 }\end{array}$ & $\begin{array}{l}\text { HiNEnd } \\
\text { AGEID13 } \\
\text { AGEID13 } \\
\text { AGEID13 } \\
\text { AGEID13 } \\
\text { AGEID13 } \\
\text { AGEID13 } \\
\text { AGEID13 } \\
\text { AGEID13 } \\
\text { AGEID13 } \\
\text { AGEID13 } \\
\text { AGEID13 } \\
\text { AGEID13 }\end{array}$ & $\begin{array}{l}\text { DistID } \\
\text { DISTID2 } \\
\text { DISTID2 } \\
\text { DISTID2 } \\
\text { DISTID2 } \\
\text { DISTID2 } \\
\text { DISTID2 } \\
\text { DISTID2 } \\
\text { DISTID2 } \\
\text { DISTID2 } \\
\text { DISTID2 } \\
\text { DISTID2 } \\
\text { DISTID2 }\end{array}$ & $\begin{array}{l}1 \\
\text { TA } \\
\text { TA } \\
\text { TA } \\
\text { TA } \\
\text { TA } \\
\text { TA } \\
\text { TA } \\
\text { TA } \\
\text { TA } \\
\text { TA } \\
\text { TA } \\
\text { TA }\end{array}$ & $\begin{array}{l}2 \\
1 \\
2 \\
3 \\
4 \\
5 \\
6 \\
1 \\
2 \\
3 \\
4 \\
5 \\
6\end{array}$ & $\begin{array}{l}3 \\
T \\
T \\
T \\
T \\
T \\
T \\
T \\
T \\
T \\
T \\
T \\
T \\
T\end{array}$ & $\begin{array}{l}\text { Delay } \\
0 \\
0 \\
0 \\
0 \\
0 \\
0 \\
0 \\
0 \\
0 \\
0 \\
0 \\
0\end{array}$ & $\begin{array}{l}\text { ReAge } \\
0 \\
0 \\
0 \\
0 \\
0 \\
0 \\
0 \\
0 \\
0 \\
0 \\
0 \\
0\end{array}$ & $\begin{array}{l}\text { Pertent } \\
100 \\
100 \\
100 \\
100 \\
100 \\
100 \\
100 \\
100 \\
100 \\
100 \\
100 \\
100\end{array}$ \\
\hline
\end{tabular}

Figure B.8: Transition rule file of the INT scenario 


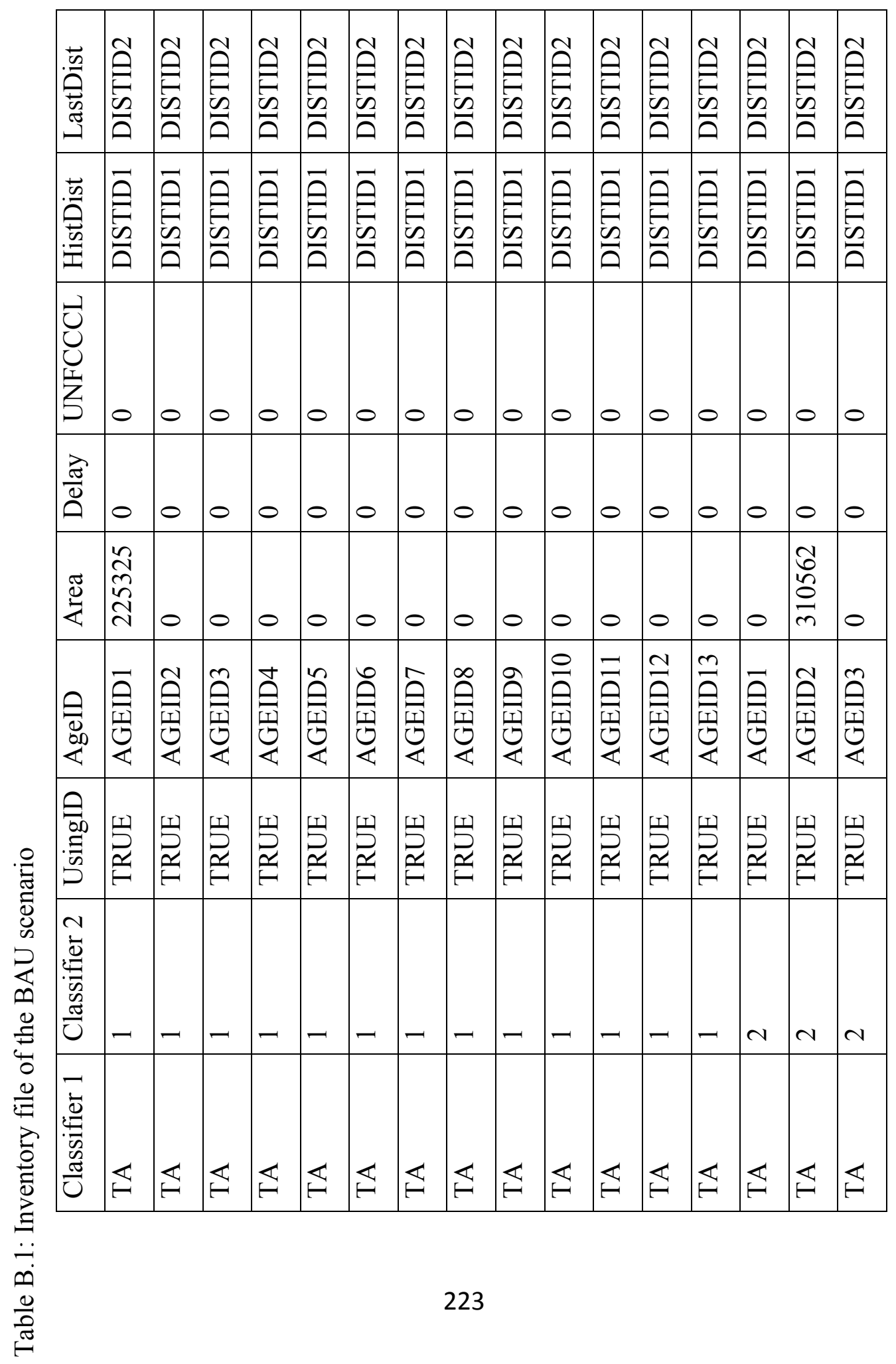




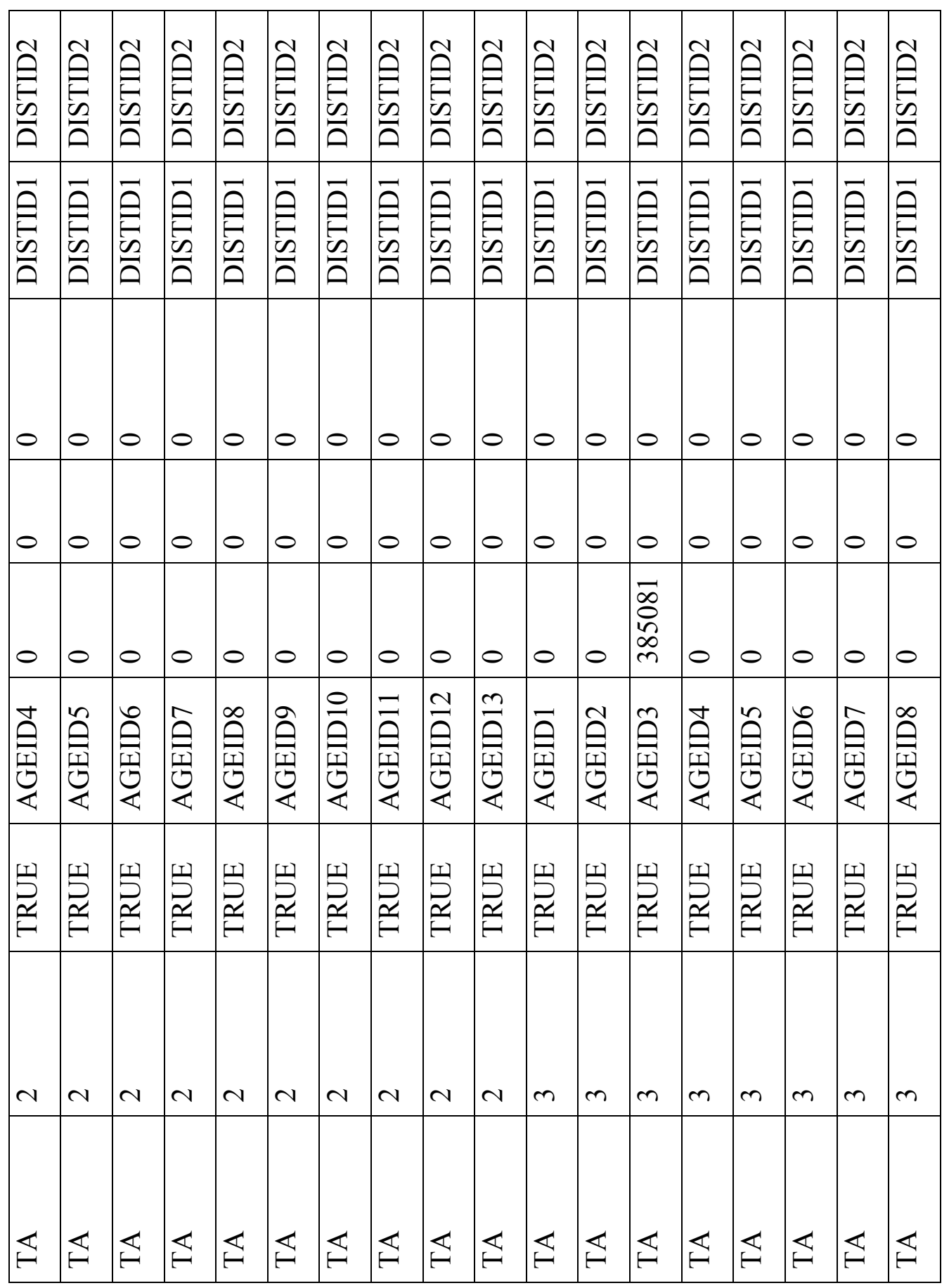




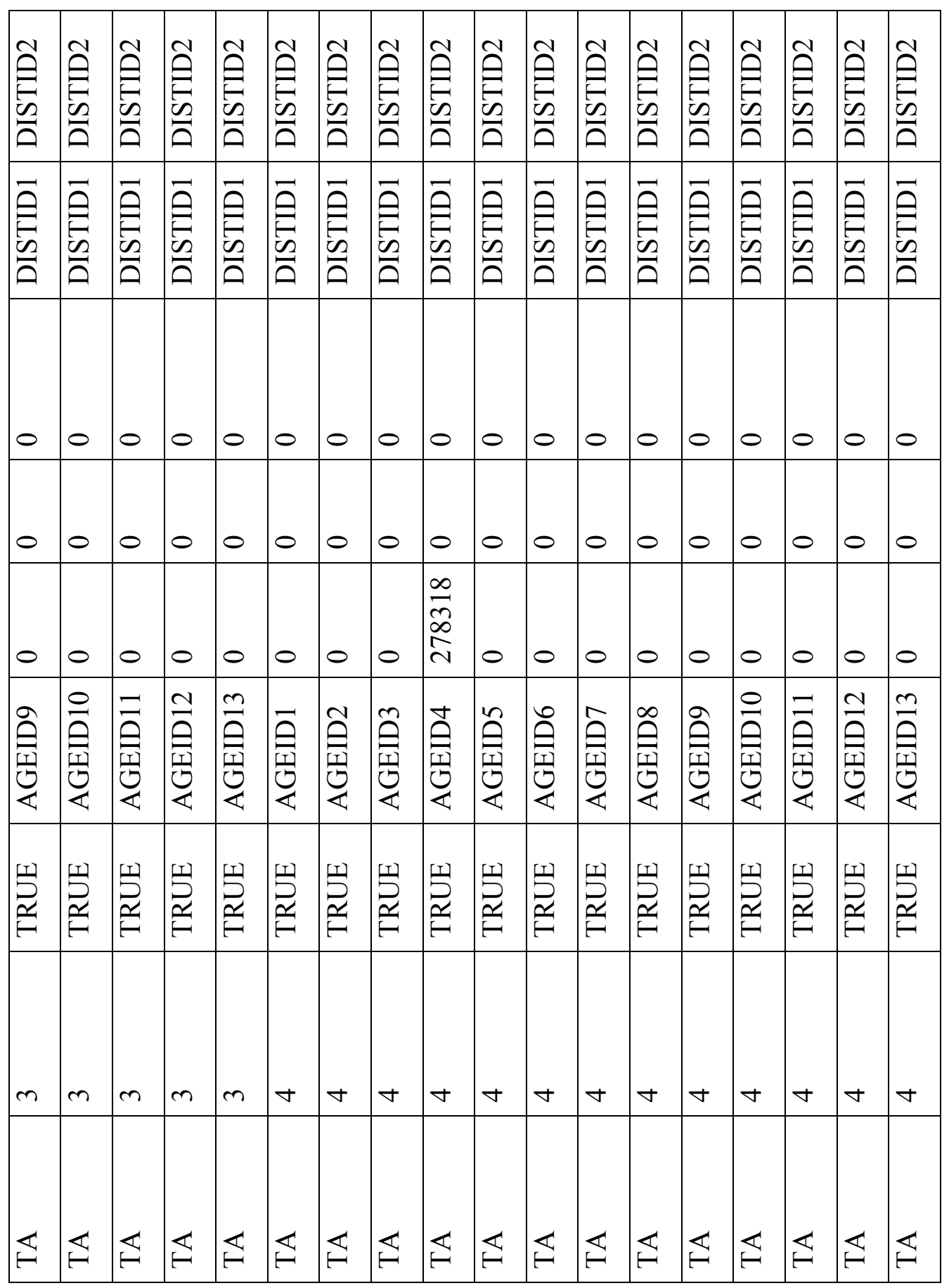




\begin{tabular}{|c|c|c|c|c|c|c|c|c|c|c|c|c|c|c|c|c|c|c|}
\hline \multicolumn{2}{|r|}{$\begin{array}{l}\vec{E} \\
\text { 兄 } \\
\vec{\theta}\end{array}$} & 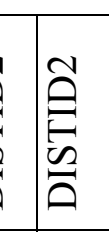 & 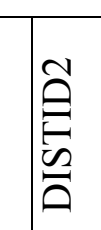 & 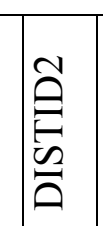 & \multicolumn{2}{|c|}{ 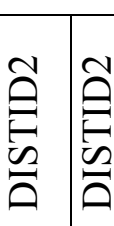 } & \multicolumn{2}{|c|}{ 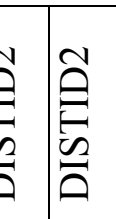 } & 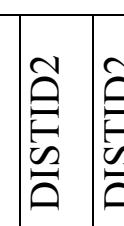 & \multicolumn{2}{|c|}{ 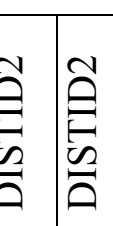 } & \multicolumn{2}{|c|}{ 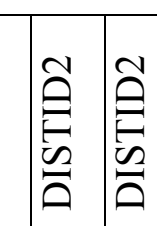 } & & 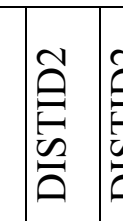 & & $\begin{array}{ll}a \\
\hat{a} \\
\hat{a}\end{array}$ \\
\hline 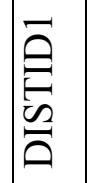 & & $\mid \begin{array}{l}\overrightarrow{\tilde{n}} \\
\vec{n}\end{array}$ & $\begin{array}{l}\overrightarrow{\hat{O}} \\
\hat{n} \\
\bar{n}\end{array}$ & 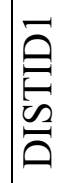 & $\widehat{t}$ & & & & & 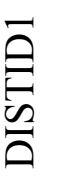 & & $\begin{array}{l}\overline{\hat{O}} \\
\underline{n_{n}} \\
\vec{\Xi}\end{array}$ & $\begin{array}{l}\overline{\hat{O}} \\
\underline{n^{2}} \\
\overline{0}\end{array}$ & & \begin{tabular}{|l}
$\overrightarrow{\hat{\theta}}$ \\
$\underline{\underline{n}}$ \\
$\overrightarrow{0}$
\end{tabular} & & & 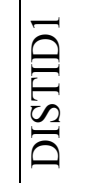 \\
\hline 0 & 0 & 0 & 0 & 0 & 0 & 0 & c & $b c$ & b & 0 & 0 & 0 & 0 & 0 & 0 & & 0 & 0 \\
\hline$p$ & 0 & 0 & 0 & 0 & o & 0 & $c$ & oc & o & 0 & 0 & 0 & 0 & 0 & 0 & 0. & 0 & 0 \\
\hline & 0 & 0 & 0 & $\stackrel{1}{\infty}$ & 0 & 0 & c & & o & 0 & 0 & 0 & 0 & 0 & 0 & 0 & 0 & 0 \\
\hline 鸽 & 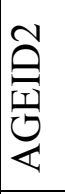 & 筧 & 握 & 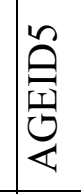 & 罗 & 息 & 递 & 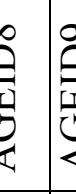 & & 窟 & 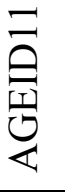 & 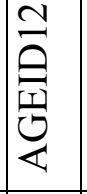 & 粫 & $\overrightarrow{\hat{U}_{0}}$ & 倉 & & 苚 & 突 \\
\hline$\stackrel{5}{\simeq 2}$ & 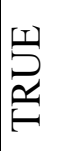 & $\frac{1}{2}$ & 焉 & $\underset{2}{2}$ & 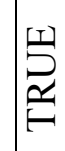 & 焉 & 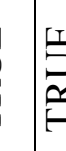 & 㲅 & 跣 & 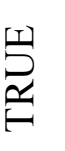 & 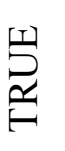 & 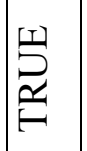 & 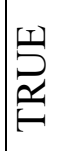 & 兆 & 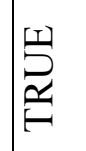 & & & 焉 \\
\hline 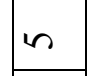 & n & in & in & in & in & in & v & r & $n$. & in & in & in & in & 6 & 6 & 6 & 6 & 6 \\
\hline & & & & & & & & & & & & & & & 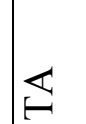 & $\varangle$ & 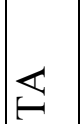 & $\leq$ \\
\hline
\end{tabular}




\begin{tabular}{|c|c|c|c|c|c|c|c|}
\hline & 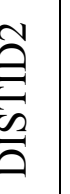 & & 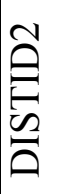 & $\underline{\underline{E}}$ & 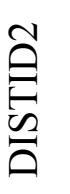 & & 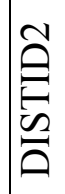 \\
\hline & & & 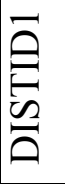 & $\begin{array}{l}\overrightarrow{\hat{\theta}} \\
\overrightarrow{0} \\
\overrightarrow{0}\end{array}$ & 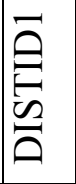 & $\overline{\mathrm{C}}$ & \begin{tabular}{|l}
$\overrightarrow{\hat{\theta}}$ \\
$\underline{\hat{\Omega}}$ \\
$\overrightarrow{0}$
\end{tabular} \\
\hline 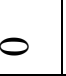 & 0 & 0 & 0 & 0 & 0 & 0 & 0 \\
\hline & 0 & 0 & 0 & 0 & 0 & 0 & 0 \\
\hline & 0 & 0 & 0 & 0 & 0 & 0 & 0 \\
\hline 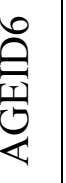 & 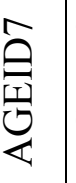 & 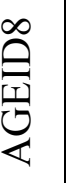 & 割 & 穿 & 窟 & 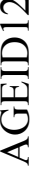 & 皇 \\
\hline & 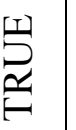 & 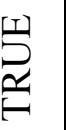 & 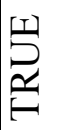 & $\underset{2}{2}$ & & $\begin{array}{l}\text { I⿱ } \\
\stackrel{2}{\approx}\end{array}$ & 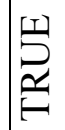 \\
\hline 0 & 6 & 6 & 6 & 0 & 6 & 0 & 6 \\
\hline & & F & $F$ & & 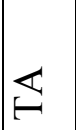 & & 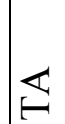 \\
\hline
\end{tabular}




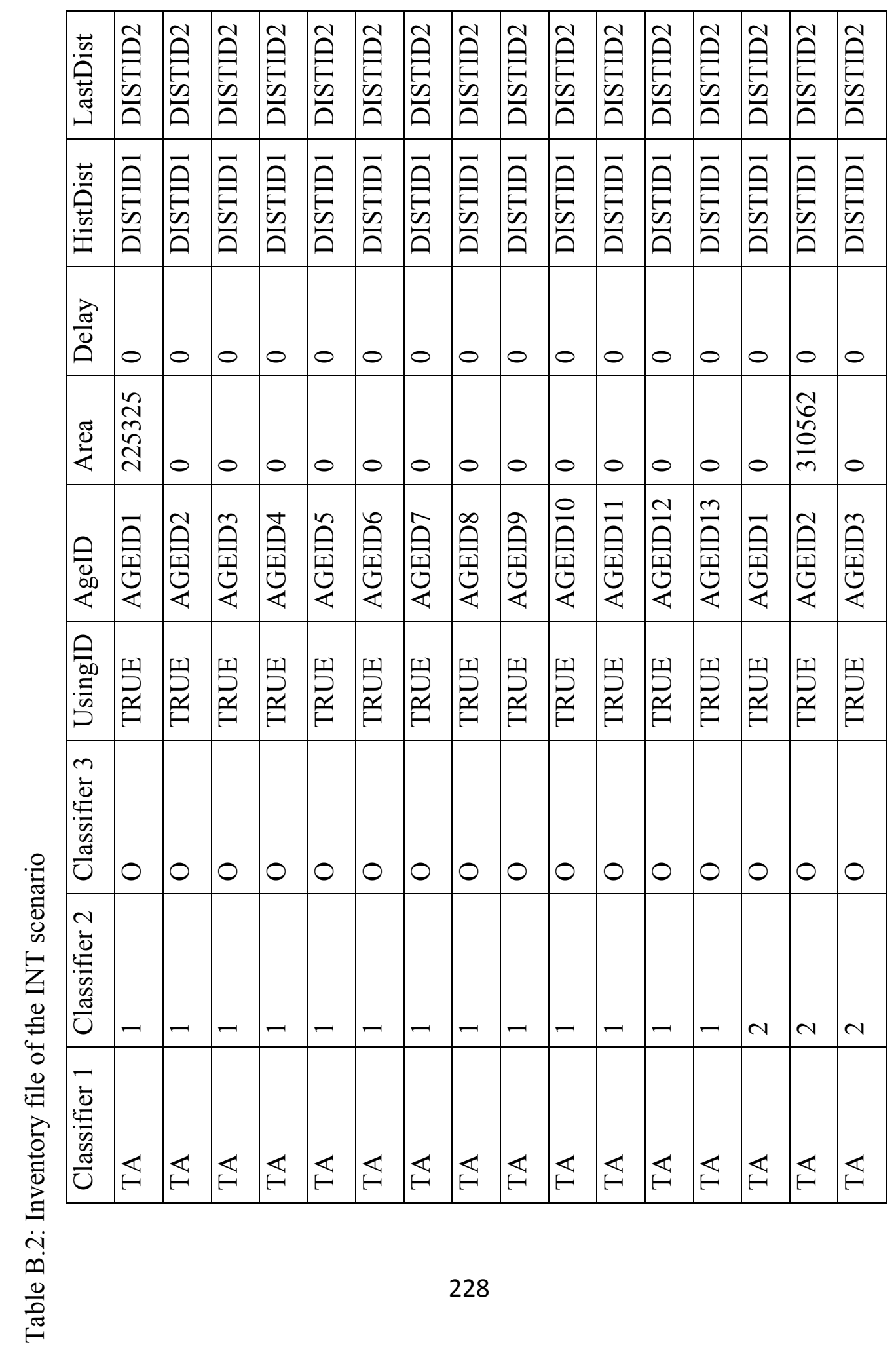




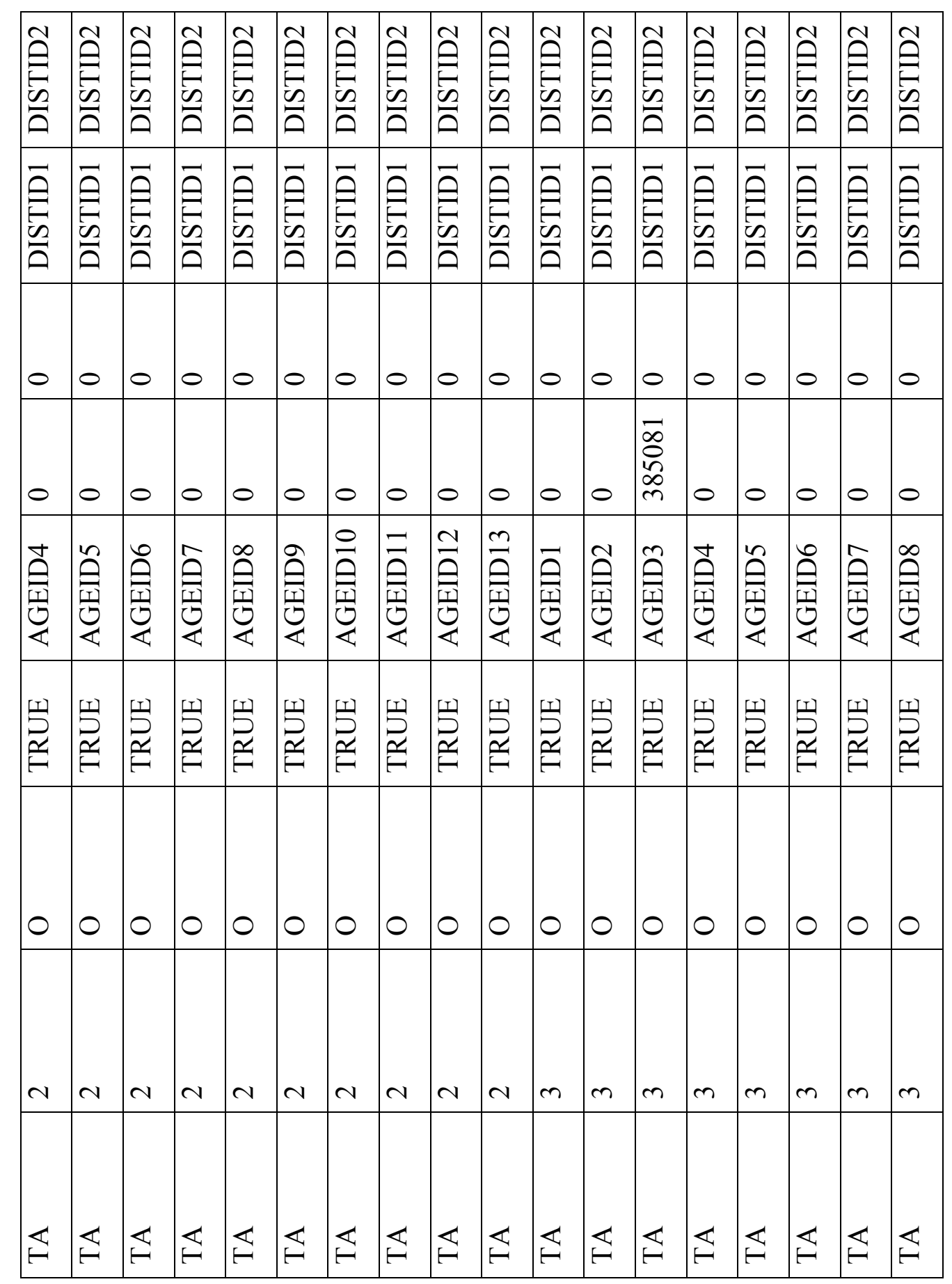




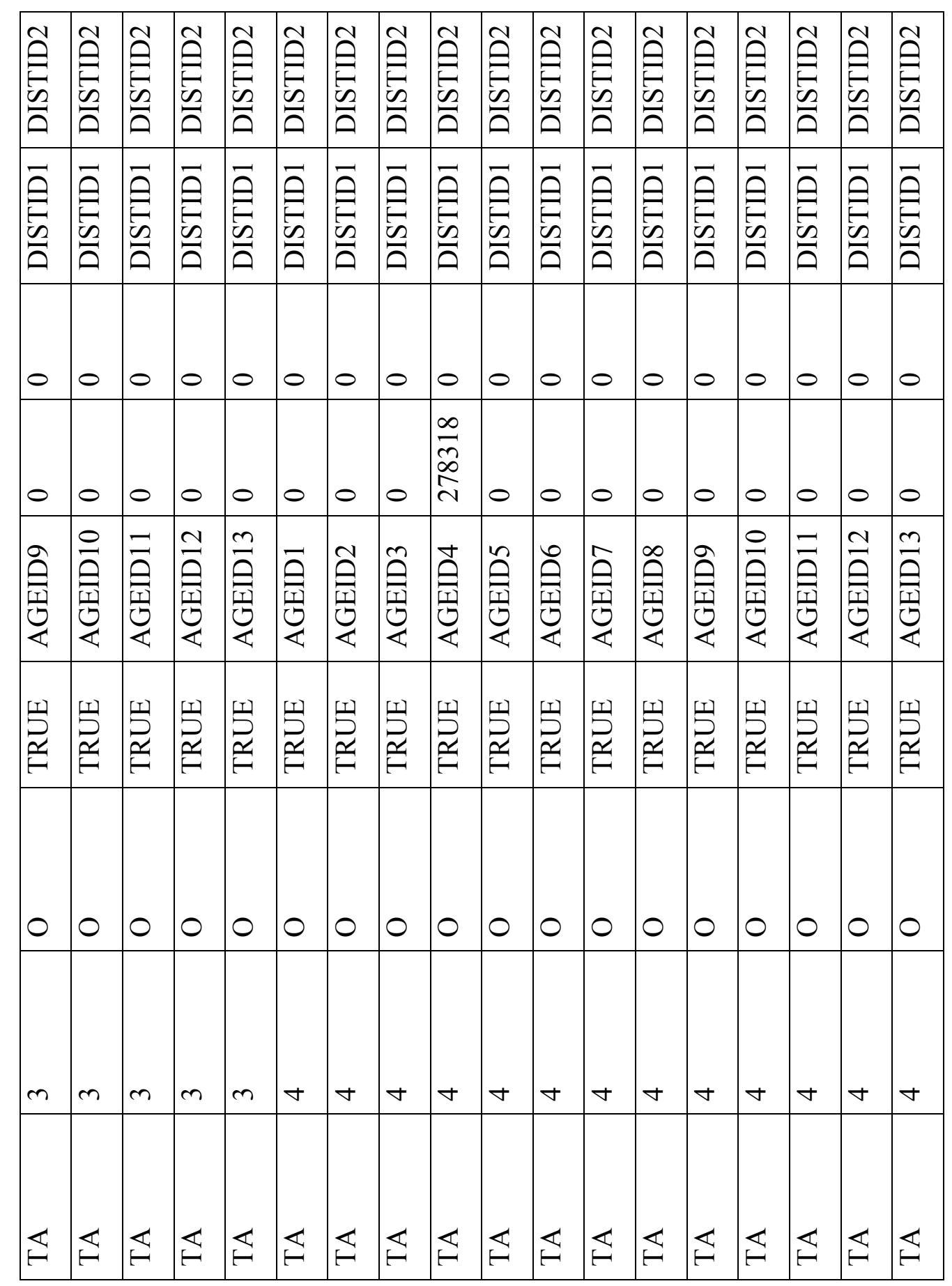




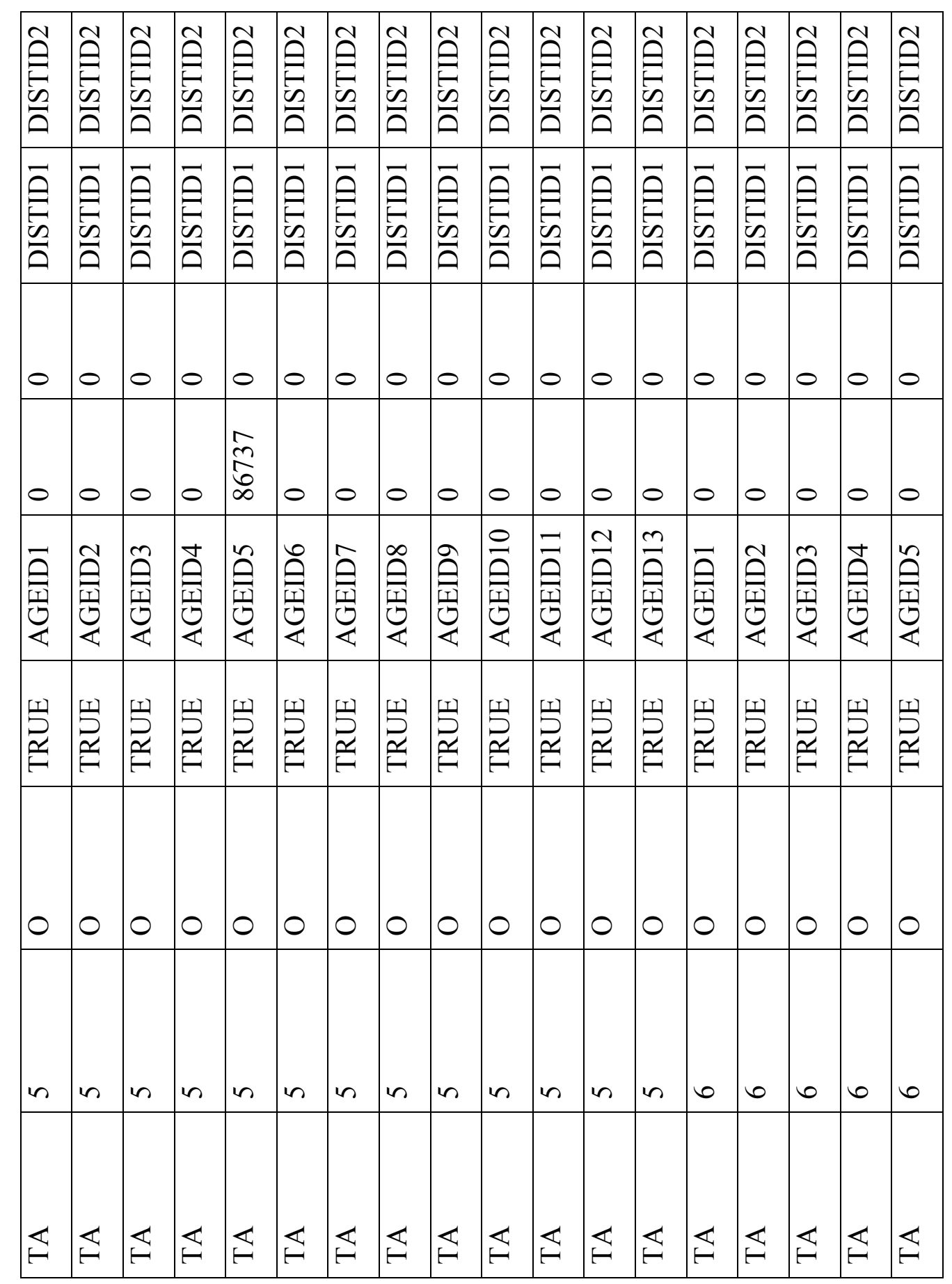




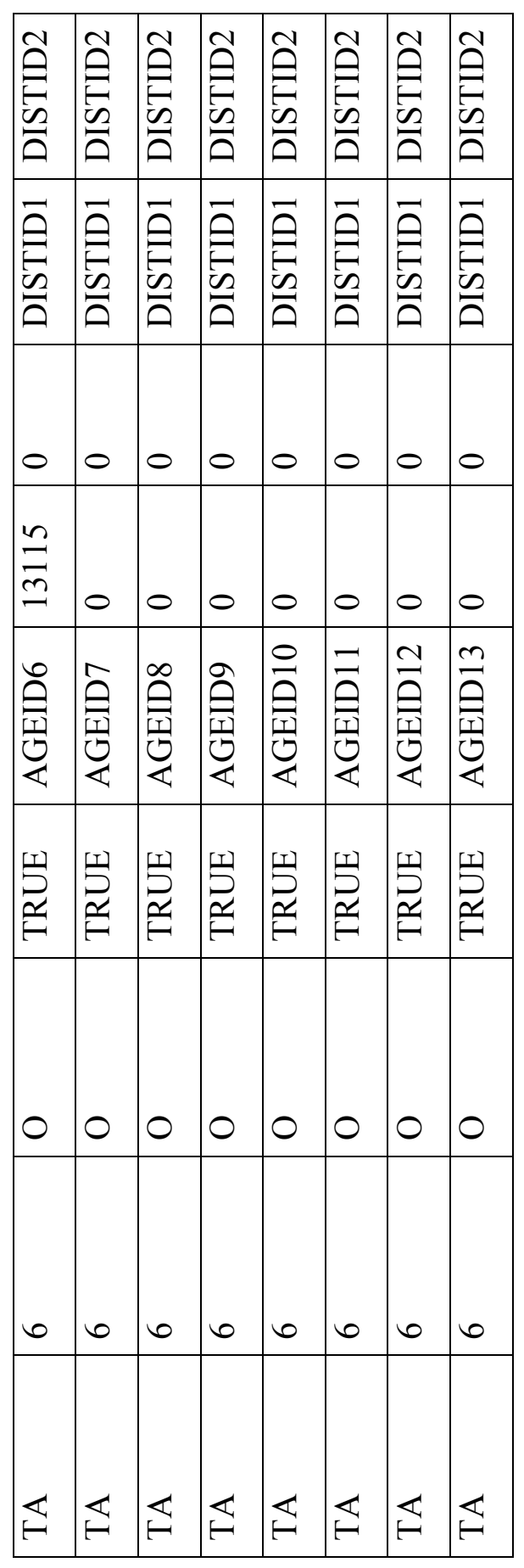




\section{Appendix C: Supporting information for chapter 9}

\section{C.1. Procedures of solving differential equations of $\mathbf{N}$}

\section{C.1.1. Procedures of solving N1 when $n=2$}

$$
\begin{gathered}
\frac{d N_{1}}{d t}=2 k_{h} N_{2}-k_{d} N_{1}=2 k_{h} \exp \left(-k_{h}\right) t-k_{d} N_{1} \\
\frac{d N_{1}}{d t}+k_{d} N_{1}=2 k_{h} \exp \left(-k_{h}\right) t \\
N_{1}=e^{-\int k_{d} d t} \times\left(\int e^{\int k_{d} d t} \times 2 k_{h} \exp \left(-k_{h}\right) t d t\right) \\
N_{1}=e^{-k_{d} t} \times\left(\int e^{k_{d} t} \times 2 k_{h} \exp \left(-k_{h}\right) t d t\right) \\
N_{1}=e^{-k_{d} t} \times 2 k_{h}\left(\int e^{\left(k_{d}-k_{h}\right) t} d t\right) \\
N_{1}=\frac{2 k_{h}}{k_{d}-k_{h}} e^{-k_{d} t}\left(e^{\left(k_{d}-k_{h}\right) t}+C\right) \\
N_{1}^{0}=\frac{2 k_{h}}{k_{d}-k_{h}}(1+C)=0 \\
C=-1 \\
N_{1}=\frac{2 k_{h}}{k_{d}-k_{h}}\left(e^{-k_{h} t}-e^{-k_{d} t}\right) \\
N_{1}=\frac{2 k_{h}}{k_{d}-k_{h}} e^{-k_{d} t}\left(e^{\left(k_{d}-k_{h}\right) t}-1\right) \\
C
\end{gathered}
$$

\section{C.1.2. Procedures of solving N1 when $n=3$}

$$
\begin{gathered}
N_{3}=\exp \left(-2 k_{h} t\right) \\
N_{2}=2\left(\exp \left(-2 k_{h} t\right)-\exp \left(-2 k_{h} t\right)\right) \\
\frac{d N_{1}}{d t}=2 k_{h}\left(N_{2}+N_{3}\right)-k_{d} N_{1}=2 k_{h}\left(2 \exp \left(-k_{h}\right) t-\exp \left(-2 k_{h} t\right)\right)-k_{d} N_{1}
\end{gathered}
$$




$$
\begin{gathered}
\frac{d N_{1}}{d t}+k_{d} N_{1}=2 k_{h}\left(2 \exp \left(-k_{h} t\right)-\exp \left(-2 k_{h} t\right)\right) \\
N_{1}=e^{-k_{d} t} \times\left(\int e^{k_{d} t} \times 2 k_{h}\left(2 \exp \left(-k_{h}\right) t-\exp \left(-2 k_{h} t\right) d t\right)\right. \\
N_{1}=e^{-k_{d} t} \times 2 k_{h}\left(\int 2 e^{\left(k_{d}-k_{h}\right) t}-\mathrm{e}^{\left(k_{d}-2 k_{h}\right) t} d t\right. \\
N_{1}=2 k_{h} e^{-k_{d} t}\left(\frac{2}{k_{d}-k_{h}} e^{\left(k_{d}-k_{h}\right) t}-\frac{1}{k_{d}-2 k_{h}} \mathrm{e}^{\left(k_{d}-2 k_{h}\right) t}+\mathrm{C}\right) \\
N_{1}^{0}=2 k_{h}\left(\frac{2}{k_{d}-k_{h}}-\frac{1}{k_{d}-2 k_{h}}+C\right)=0 \\
N_{1}=2 k_{h} e^{-k_{d} t}\left(\frac{2}{k_{d}-k_{h}} e^{\left(k_{d}-k_{h}\right) t}-\frac{1}{k_{d}-2 k_{h}}-\frac{2}{k_{d}-k_{h}} \mathrm{e}^{\left(k_{d}-2 k_{h}\right) t}+\frac{1}{k_{d}-2 k_{h}}-\frac{2}{k_{d}-k_{h}}\right) \\
N_{1}=\frac{4 k_{h}}{k_{d}-k_{h}} e^{-k_{h} t}-\frac{2 k_{h}}{k_{d}-2 k_{h}} e^{-2 k_{h} t}+\frac{2 k_{h}}{k_{d}-2 k_{h}} e^{-k_{d} t}-\frac{4 k_{h}}{k_{d}-2 k_{h}} e^{-k_{d} t} \\
N_{1}=\frac{4 k_{h}}{k_{d}-k_{h}}\left(e^{-k_{h} t}-e^{-k_{d} t}\right)-\frac{2 k_{h}}{k_{d}-2 k_{h}}\left(e^{-2 k_{h} t}-e^{-k_{d} t}\right)
\end{gathered}
$$

\section{C.1.3. Procedures of solving $N 1$ when $n=4$}

$$
\begin{gathered}
N_{4}=e^{-3 k_{h} t} \\
N_{3}=2\left(e^{-2 k_{h} t}-e^{-3 k_{h} t}\right) \\
\left.N_{2}=3 e^{-k_{h} t}-4 e^{-2 k_{h} t}+e^{-3 k_{h} t}\right) \\
\frac{d N_{1}}{d t}=2 k_{h}\left(N_{2}+N_{3}+N_{4}\right)-k_{d} N_{1}=2 k_{h}\left(3 e^{-k_{h} t}-2 e^{-2 k_{h} t}\right)-k_{d} N_{1} \\
N_{1}=e^{-k_{d} t}\left(\int e^{k_{d} t} \times 2 k_{h} \times\left(3 e^{-k_{h} t}-2 e^{-2 k_{h} t}\right) d t\right. \\
N_{1}=2 k_{h} \times e^{-k_{d} t} \times \int\left(3 e^{k_{d}-k_{h} t}-2 e^{k_{d}-2 k_{h} t}\right) d t
\end{gathered}
$$




$$
\begin{gathered}
N_{1}=2 k_{h} \times e^{-k_{d} t} \times\left(\frac{3}{k_{d}-k_{h}} e^{k_{d}-k_{h} t}-\frac{2}{k_{d}-2 k_{h}} e^{k_{d}-2 k_{h} t}+\frac{2}{k_{d}-2 k_{h}}-\frac{3}{k_{d}-k_{h}}\right) \\
N_{1}=\frac{6 k_{h}}{k_{d}-k_{h}}\left(e^{-k_{h} t}-e^{-k_{d} t}\right)-\frac{4 k_{h}}{k_{d}-2 k_{h}}\left(e^{-2 k_{h} t}-e^{-k_{d} t}\right)
\end{gathered}
$$

\section{C.2. Depolymerization model with different hydrolysis reaction rates}

In order to investigate if hydrolysis reaction rates depend on the chain length, the xylooligomers in the system were simplified as $\mathrm{N}_{1}, \mathrm{~N}_{2}$ and $\mathrm{N}_{3}$. The kinetics of the xylooligomers are as follows:

$$
\begin{gathered}
\frac{d N_{3}}{d t}=-2 k_{3} N_{3} \\
\frac{d N_{2}}{d t}=2 k_{3} N_{3}-k_{2} N_{2} \\
\frac{d N_{1}}{d t}=2 k_{3} N_{3}+2 k_{2} N_{2}-k_{d} N_{1} \\
\frac{d D}{d t}=k_{d} N_{1}
\end{gathered}
$$

To solve these three equations with initial conditions of $\mathrm{N}_{3}(0)=1$ and $\mathrm{N}_{2}(0)=\mathrm{N}_{1}(0)=0$ (see Figure C. 4 and C.5 for derivation), the kinetics behavior of $\mathrm{N}_{1}, \mathrm{~N}_{2}$ and $\mathrm{N}_{3}$ are as follows:

$$
\begin{gathered}
N_{3}=\exp \left(-2 k_{3} t\right) \\
\frac{d N_{2}}{d t}=2 k_{3} N_{3}-k_{2} N_{2}=2 k_{3} e^{-2 k_{3} t}-k_{2} N_{2} \\
\frac{d N_{2}}{d t}+k_{2} N_{2}=2 k_{3} e^{-2 k_{3} t} \\
N_{2}=e^{-k_{2} t} \times\left(\int\left(e^{k_{2} t} \times 2 k_{3} e^{-2 k_{3} t}\right) d t\right) \\
=2 k_{3} \times e^{-k_{2} t} \times\left(\int\left(e^{\left(k_{2}-2 k_{3}\right) t}\right) d t\right) \\
=2 k_{3} \times e^{-k_{2} t} \times\left(\frac{1}{k_{2}-2 k_{3}} e^{\left(k_{2}-2 k_{3}\right) t}+C\right)
\end{gathered}
$$




$$
\begin{aligned}
& N_{2}(0)=\frac{2 k_{3}}{k_{2}-2 k_{3}}+C=0 \quad C=\frac{-2 k_{3}}{k_{2}-2 k_{3}} \\
& N_{2}=\frac{2 k_{3}}{k_{2}-2 k_{3}}\left(e^{-2 k_{3} t}-e^{-k_{2} t}\right) \\
& N_{1}=\frac{6 k_{2} k_{3}-4 k_{3}^{2}}{\left(k_{2}-2 k_{3}\right) *\left(k_{d}-2 k_{3}\right)}\left(\exp \left(-2 k_{3} t\right)-\exp \left(-k_{d} t\right)\right) \\
& -\frac{4 k_{2} k_{3}}{\left(k_{2}-2 k_{3}\right) *\left(k_{d}-k_{2}\right)}\left(\exp \left(-k_{2} t\right)-\exp \left(-k_{d} t\right)\right) \\
& D=\frac{3 k_{2} k_{d}-2 k_{3} k_{d}}{-\left(k_{2}-2 k_{3}\right) *\left(k_{d}-2 k_{3}\right)} \exp \left(-2 k_{3} t\right) \\
& +\frac{6 k_{2} k_{3}-4 k_{3}^{2}}{\left(k_{2}-2 k_{3}\right) *\left(k_{d}-2 k_{3}\right)} \exp \left(-k_{d} t\right) \\
& +\frac{4 k_{3} k_{d}}{\left(k_{2}-2 k_{3}\right) *\left(k_{d}-k_{2}\right)}\left(\exp \left(-k_{2} t\right)\right. \\
& -\frac{4 k_{2} k_{3}}{\left(k_{2}-2 k_{3}\right) *\left(k_{d}-k_{2}\right)} \exp \left(-k_{d} t\right)+\frac{3 k_{2} k_{d}-2 k_{3} k_{d}}{\left(k_{2}-2 k_{3}\right) *\left(k_{d}-2 k_{3}\right)} \\
& -\frac{6 k_{2} k_{3}-4 k_{3}^{2}}{\left(k_{2}-2 k_{3}\right) *\left(k_{d}-2 k_{3}\right)}-\frac{4 k_{3} k_{d}}{\left(k_{2}-2 k_{3}\right) *\left(k_{d}-k_{2}\right)} \\
& +\frac{4 k_{2} k_{3}}{\left(k_{2}-2 k_{3}\right) *\left(k_{d}-k_{2}\right)}
\end{aligned}
$$

When xylotriose is hydrolyzed, the concentractions of xylotriose, xylobiose, xylose, and degradation products should follow the trend illustrated in Figure C.6. Experiments need to be conducted to obtain the concentrations of furfural, xylose, xylobiose, and xylotriose for the hydrolysis rate $\mathrm{k}_{1}, \mathrm{k}_{2}, \mathrm{k}_{3}$, and degradation rate $\mathrm{k}_{\mathrm{d}}$. 


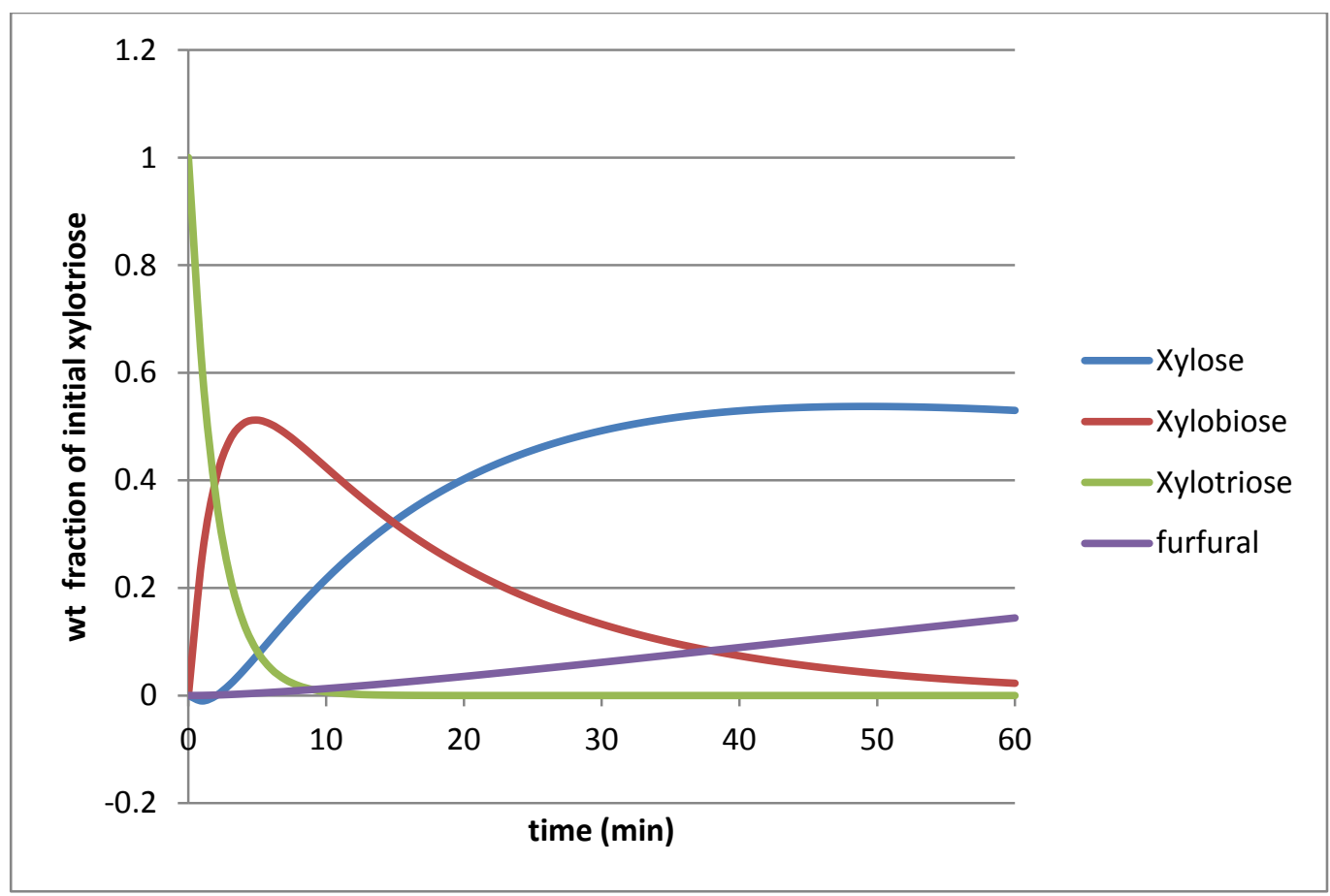

Figure C.1: Xylotriose hydrolysis profiles predicted by the depolymerization model

\section{C.3. Depolymerization model with updated kinetic reactions}

Assuming the kinetic expressions of xylooligomers are as follows:
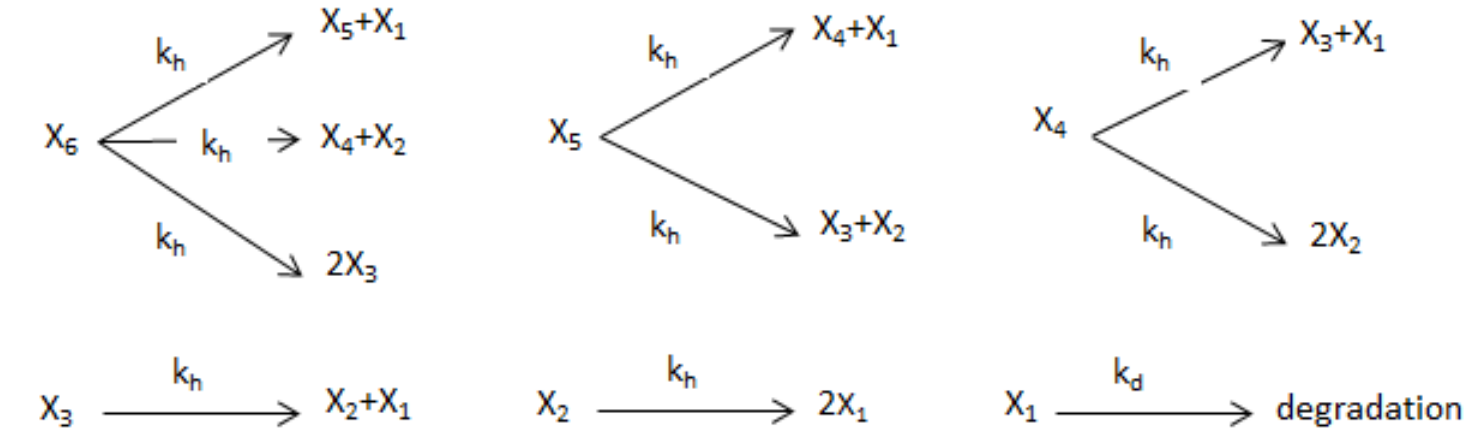

The corresponding rate laws are as follows:

When $\mathrm{n}$ and $\mathrm{i}$ are even:

$$
\frac{d N_{n}}{d t}=-k_{h} \frac{n}{2} N_{n}
$$




$$
\begin{gathered}
\frac{d N_{i}}{d t}=\left(k_{h} \sum_{i+1}^{n} N_{j}\right)+2 k_{h} N_{2 i}-k_{h} \frac{i}{2} N_{i}(\text { if } i \geq 4) \\
\frac{d N_{i}}{d t}=\left(k_{h} \sum_{i+1}^{n} N_{j}\right)+2 k_{h} N_{2 i}-k_{h} N_{i}(\text { if } i=2) \\
\frac{d N_{1}}{d t}=\left(k_{h} \sum_{3}^{n} N_{j}\right)+2 k_{h} N_{2}-k_{d} N_{1} \\
\frac{d D}{d t}=k_{d} N_{1}
\end{gathered}
$$

When $\mathrm{n}$ and $\mathrm{i}$ are odd:

$$
\begin{gathered}
\frac{d N_{n}}{d t}=-k_{h} \frac{n-1}{2} N_{n} \\
\frac{d N_{i}}{d t}=\left(k_{h} \sum_{i+1}^{n} N_{j}\right)+2 k_{h} N_{2 i}-k_{h} \frac{i-1}{2} N_{i}(\text { if } i \geq 5) \\
\frac{d N_{i}}{d t}=\left(k_{h} \sum_{i+1}^{n} N_{j}\right)+2 k_{h} N_{2 i}-k_{h} N_{i}(\text { if } i=1 \text { or } 3) \\
\frac{d N_{1}}{d t}=\left(k_{h} \sum_{3}^{n} N_{j}\right)+2 k_{h} N_{2}-k_{d} N_{1} \\
\frac{d D}{d t}=k_{d} N_{1}
\end{gathered}
$$

Assuming xylotetrose is hydrolyzed by dilute acid, the kinetic rates of xylotetrose, xylotriose, xylobiose and xylose are as follows:

$$
\begin{gathered}
N_{4}=\exp \left(-2 k_{h} t\right) \\
N_{3}=-\exp \left(-2 k_{h} t\right)+\exp \left(-k_{h} t\right) \\
N_{2}=-\exp \left(-2 k_{h} t\right)+\left(1+k_{h} t\right) \exp \left(-k_{h} t\right) \\
N_{1}=\frac{-2 k_{h}}{k_{d}-2 k_{h}} \exp \left(-2 k_{h} t\right)+\frac{3 k_{h}}{k_{d}-k_{h}} \exp \left(-k_{h} t\right)+\frac{2 k_{h}^{2}\left[\left(k_{d}-k_{h}\right) t-1\right]}{\left(k_{d}-k_{h}\right)^{2}} \exp \left(-k_{h} t\right) \\
+\frac{2 k_{h}}{k_{d}-2 k_{h}} \exp \left(-k_{d} t\right)-\frac{3 k_{h}}{k_{d}-k_{h}} \exp \left(-k_{d} t\right)+\frac{2 k_{h}^{2}}{\left(k_{d}-k_{h}\right)^{2}} \exp \left(-k_{d} t\right)
\end{gathered}
$$


The xylotetrose hydrolysis is illustrated in Figure C.7. Experiments need to be conducted to obtain the concentrations of xylose, xylibiose, xylotriose and xylotetrose for the hydrolysis rate $\mathrm{k}_{\mathrm{h}}$ and degradation rate $\mathrm{k}_{\mathrm{d}}$.

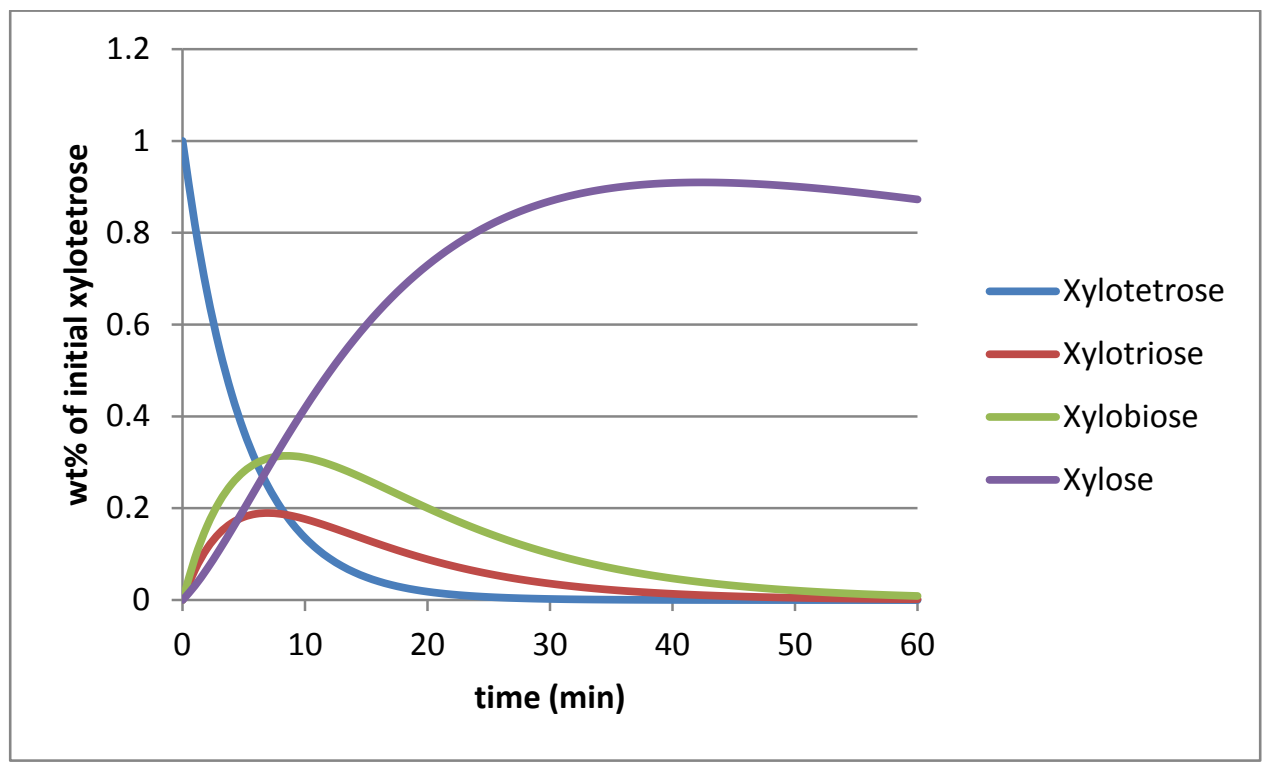

Figure C.2: Xylotetrose hydrolysis predicted by the depolymerization model

\section{C.4. Reaction kinetics of xylooligomers developed by Kumar and Wyman}

Kumar and Wyman ${ }^{241}$ assumed first-order reaction kinetics for xylose degradation and xylooligomers hydrolysis. Their study shows that the hydrolysis rate increased with DP. In addition, direct degradation of xylobiose and xylotriose occurs along with the hydrolysis, especially in the absence of acid, but is negligible for higher DP oligomers. The reaction kinetics can be summarized as follows: 

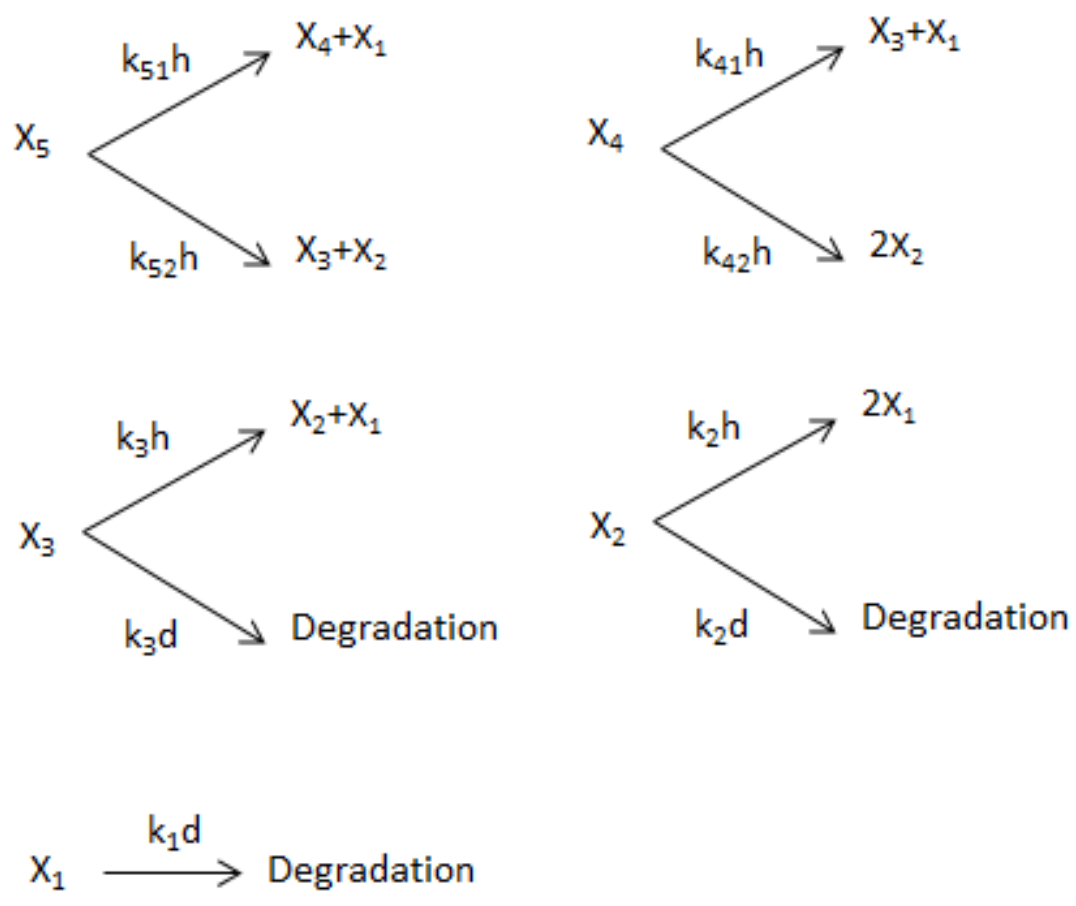

The authors estimated the reaction rates by using the least-square method for the data at different $\mathrm{pH}$ values. The reaction rates at $\mathrm{pH} 1.45$ are tabulated in Table C.1.

Table C.1: Depolymerization reaction rates at $\mathrm{pH} 1.45^{241}$

\begin{tabular}{|l|l|l|l|l|l|l|l|l|}
\hline $\mathrm{k}_{51} \mathrm{~h}$ & $\mathrm{k}_{52} \mathrm{~h}$ & $\mathrm{k}_{41} \mathrm{~h}$ & $\mathrm{k}_{42} \mathrm{~h}$ & $\mathrm{k}_{3} \mathrm{~h}$ & $\mathrm{k}_{3} \mathrm{~d}$ & $\mathrm{k}_{2} \mathrm{~h}$ & $\mathrm{k}_{2} \mathrm{~d}$ & $\mathrm{k}_{1} \mathrm{~d}$ \\
\hline 1.914 & 1.9246 & 1.78 & 4.35 & 1.362 & 0.00001 & 1.5 & 0.12 & 0.0048 \\
\hline
\end{tabular}




\section{Appendix D: Copyright clearance}

Authors publishing in Elsevier journals have wide rights to use their works for teaching and scholarly purposes without needing to seek permission.

Table of Authors' Rights

\begin{tabular}{|c|c|c|c|}
\hline & $\begin{array}{l}\text { Preprint version (with a few } \\
\text { exceptions- see below }{ }^{*} \text { ) }\end{array}$ & $\begin{array}{l}\text { Accepted Author } \\
\text { Manuscript }\end{array}$ & $\begin{array}{l}\text { Published Journal } \\
\text { Articles }\end{array}$ \\
\hline $\begin{array}{l}\text { Use for classroom teaching by } \\
\text { author or author's institution } \\
\text { and presentation at a meeting } \\
\text { or conference and distributing } \\
\text { copies to attendees }\end{array}$ & Yes & $\begin{array}{l}\text { Yes with full } \\
\text { adknowledgement of fingl } \\
\text { article }\end{array}$ & $\begin{array}{l}\text { Yes with full } \\
\text { adknowledgement of } \\
\text { final article }\end{array}$ \\
\hline $\begin{array}{l}\text { Use for internal training by } \\
\text { author's company }\end{array}$ & Yes & $\begin{array}{l}\text { Yes with full } \\
\text { adknowledgement of fingl } \\
\text { article }\end{array}$ & $\begin{array}{l}\text { Yes with full } \\
\text { adknowledgement of } \\
\text { final artide }\end{array}$ \\
\hline $\begin{array}{l}\text { Distribution to colleagues for } \\
\text { their research use }\end{array}$ & Yes & Yes & Yes \\
\hline $\begin{array}{l}\text { Use in a subsequent } \\
\text { compilation of the author's } \\
\text { works }\end{array}$ & Yes & $\begin{array}{l}\text { Yes with full } \\
\text { adknowledgement of fingl } \\
\text { article }\end{array}$ & $\begin{array}{l}\text { Yes with full } \\
\text { adknowledgement of } \\
\text { final article }\end{array}$ \\
\hline $\begin{array}{l}\text { Inclusion in a thesis or } \\
\text { dissertation }\end{array}$ & Yes & $\begin{array}{l}\text { Yes with full } \\
\text { adknowledgement of final } \\
\text { article }\end{array}$ & $\begin{array}{l}\text { Yes with full } \\
\text { adknowledgement of } \\
\text { final artide }\end{array}$ \\
\hline $\begin{array}{l}\text { Reuse of portions or extracts } \\
\text { from the article in other works }\end{array}$ & Yes & $\begin{array}{l}\text { Yes with full } \\
\text { adknowledgement of fingl } \\
\text { article }\end{array}$ & $\begin{array}{l}\text { Yes with full } \\
\text { adknowledgement of } \\
\text { final article }\end{array}$ \\
\hline $\begin{array}{l}\text { Preparation of derivative } \\
\text { works (other than for } \\
\text { commercial purposes) }\end{array}$ & Yes & $\begin{array}{l}\text { Yes with full } \\
\text { adknowledgement of fingl } \\
\text { article }\end{array}$ & $\begin{array}{l}\text { Yes with full } \\
\text { adknowledgement of } \\
\text { fingl article }\end{array}$ \\
\hline Preprint servers & Yes & $\begin{array}{l}\text { Yes with the specific } \\
\text { written permission of } \\
\text { Elsevier }\end{array}$ & No \\
\hline $\begin{array}{l}\text { Voluntary posting on open } \\
\text { web sites operated by author } \\
\text { or author's institution for } \\
\text { scholarly purposes }\end{array}$ & $\begin{array}{l}\text { Yes (author may later add an } \\
\text { appropriate bibliographic } \\
\text { citation, indicating } \\
\text { subsequent publication by } \\
\text { Elsevier and journal title) }\end{array}$ & $\begin{array}{l}\text { Yes, with appropriate } \\
\text { bibliographic citation and } \\
\text { a link to the article once } \\
\text { published }\end{array}$ & $\begin{array}{l}\text { Only with the specific } \\
\text { written permission of } \\
\text { Elsevier }\end{array}$ \\
\hline $\begin{array}{l}\text { Mandated deposit or deposit } \\
\text { in or posting to subject- } \\
\text { oriented or centralized } \\
\text { repositories }\end{array}$ & $\begin{array}{l}\text { Yes under specific } \\
\text { agreement between Elsevier } \\
\text { and the repository }\end{array}$ & $\begin{array}{l}\text { Yes under specific } \\
\text { agreement between } \\
\text { Elsevier and the } \\
\text { repository }\end{array}$ & $\begin{array}{l}\text { Yes under specific } \\
\text { agreement between } \\
\text { Elsevier and the } \\
\text { repository }\end{array}$ \\
\hline $\begin{array}{l}\text { Use or posting for commercial } \\
\text { gain or to substitute for } \\
\text { services provided directly by } \\
\text { journal }\end{array}$ & $\begin{array}{l}\text { Only with the specific written } \\
\text { permission of Elsevier }\end{array}$ & $\begin{array}{l}\text { Only with the specific } \\
\text { written permission of } \\
\text { Elsevier }\end{array}$ & $\begin{array}{l}\text { Only with the specific } \\
\text { written permission of } \\
\text { Elsevier }\end{array}$ \\
\hline
\end{tabular}

Figure D.1: Copyright clearance from Elsevier for Chapter 2 and 6 (http://www.elsevier.com/authors/author-rights-and-responsibilities) 


\section{Freedom of Information Act}

The Freedom of Information ACt (FOIA), which can be found in Title 5 of the United States Code, section 552, was enacted in 1966 and provides that any person has the right to request access to federal agency records or information. All agencies of the United States government are required to disclose records upon receiving a written request for them, except for those records that are protected from disclosure by the nine exemptions and three exclusions of the FOIA. This right of access is enforceable in court. The federal FOIA does not, however, provide access to records held by state or local government agencies, or by private businesses or individuals. All states have their own statutes governing public access to state and local records; state agencies should be consulted for further information about them.

USDA maintains a FOIA home page which can be accessed at:

- Freedom of Information Act

\section{USDA's Significant Guidance Documents}

On January 18, 2007, the President issued Executive Order 13422, "Amendment to Executive Order 12866 for Regulatory Planning and Review." On that same day, the Office of Management and Budget (OMB) issued a final Bulletin entitled, "Agency Good Guidance Practices." The primary focus of the Executive Order and Bulletin is to increase the quality and transparency of agency guidance practices and the significant documents produced through them.

- USDA's Significant Guidance Documents

\section{Digital Rights and Copyright}

Most information presented on the USDA Web site is considered public domain information. Public domain information may be freely distributed or copied, but use of appropriate byline/photo/image credits is requested. Attribution may be cited as follows: "U. S. Department of Agriculture."

Some materials on the USDA Web site are protected by copyright, trademark, or patent, and/or are provided for personal use only. Such materials are used by USDA with permission, and USDA has made every attempt to identify and clearly label them. You may need to obtain permission from the copyright, trademark, or patent holder to acquire, use, reproduce, or distribute these materials.

Figure D.2: Copyright clearance from USDA (for Figure 2.1)

http://www.usda.gov/wps/portal/usda/usdahome?navtype=FT\&navid=POLICY_LINK

\section{Honeywell}

\section{Honeywell Copyright Notice}

Honeywell International Inc. authorizes you to copy documents published by Honeywell International Inc. on the World Wide Web for personal or non-commercial use only, provided any copy of these documents that you make shall retain all copynight and other proprietary notices contained herein. Except as expressly provided, nothing contained in this paragraph shall be construed as conferring any license or right under any Honeywell International Inc. copyright. No materials available on the Honeywell International Inc. Web site may be stored, transmitted by any means (including but not limited to electronic, mechanical, scanning, photocopying or recording) without prior written permission of Honeywell international inc.

Figure D.3: Copyright clearance from UOP Honeywell (for Figure 2.3) 
Thomas White<white.ijeser@gmail.com>

to me -

Dear Dr Fan,

We have no objection in using the paper in your thesis. Please feel free to do it.

Thomas White

Sent from my iPad

Figure D.4: Permission by the IJESER editor Thomas White to use the paper in this dissertation (Chapter 4)

Kalnes, Tom $\mathbf{N}$

ㄹe May 21 (1 day ago)

to me, David -

Hi Jiqing,

Figure 4.1 was first created for a presentation that I made back in 2008. This presentation was made available on the conference website, so it was in the public domain prior to being published in the book chapter. A copy of the presentation is attached (see slide 6 of 21).

Figure 5.1 was also part of at least one presentation that was made available on a conference web site. A copy of a 2010 presentation is attached (see slide 11/24).

From UOP's perspective, both of these presentations are in the public domain.

I suggest changing the references to match these presentations.

Tom

Figure D.5: Permission by Tom Kalnes to use Figure 4.1 and 5.1 in this dissertation

\title{
Ownership and Usage of Content Provided on This Site
}

\begin{abstract}
Materials on this website were produced and/or compiled by Natural Resources Canada for the purpose of providing Canadians with access to information about the programs and services offered by the Government of Canada. You may use and reproduce the materials as follows:
\end{abstract}

\section{Non-Commercial Reproduction}

Unless otherwise specified you may reproduce the materials in whole or in part for noncommercial purposes, and in any format, without charge or further permission, provided you do the following:

- Exercise due diligence in ensuring the accuracy of the materials reproduced;

- Indicate both the complete title of the materials reproduced, as well as the author (where available); and

- Indicate that the reproduction is a copy of the version available at [URL where original document is available].

Figure D.6: Copyright clearance from Natural Resources Canada for Figure 8.4 (http://www.nrcan.gc.ca/important-notices) 